\title{
Development of a micro-dilution tunnel system for in-use, on- board heavy-duty vehicle particulate matter emissions measurement
}

\author{
Emily Deanna Cirillo \\ West Virginia University
}

Follow this and additional works at: https://researchrepository.wvu.edu/etd

\section{Recommended Citation}

Cirillo, Emily Deanna, "Development of a micro-dilution tunnel system for in-use, on-board heavy-duty vehicle particulate matter emissions measurement" (2001). Graduate Theses, Dissertations, and Problem Reports. 1155.

https://researchrepository.wvu.edu/etd/1155

This Thesis is protected by copyright and/or related rights. It has been brought to you by the The Research Repository @ WVU with permission from the rights-holder(s). You are free to use this Thesis in any way that is permitted by the copyright and related rights legislation that applies to your use. For other uses you must obtain permission from the rights-holder(s) directly, unless additional rights are indicated by a Creative Commons license in the record and/ or on the work itself. This Thesis has been accepted for inclusion in WVU Graduate Theses, Dissertations, and Problem Reports collection by an authorized administrator of The Research Repository @ WVU. For more information, please contact researchrepository@mail.wvu.edu. 


\title{
Development of a Micro-Dilution Tunnel System for In-Use, On-Board Heavy Duty Vehicle Particulate Matter Emissions Measurement
}

THESIS

By

Emily D. Cirillo

\author{
Submitted to \\ The College of Engineering and Mineral Resources \\ at \\ West Virginia University \\ in partial fulfillment of the requirements \\ for the degree of \\ Master of Science \\ in \\ Mechanical Engineering \\ Mridul Gautam, Ph.D., chair \\ Gary Morris, Ph.D. \\ Gregory J. Thompson, Ph.D. \\ Department of Mechanical and Aerospace Engineering \\ Morgantown, West Virginia \\ 2001
}

Keywords: Particulate Matter, Mini-Dilution 


\title{
Development of a Micro-Dilution Tunnel System for In-Use, On-Board Heavy Duty Vehicle Particulate Matter Emissions Measurement
}

\author{
Emily D. Cirillo
}

\begin{abstract}
A novel portable particulate matter measuring system was designed, developed and qualified. The heavy-duty engine Federal Test Procedure (FTP) requires the use of a full-flow tunnel to measure particulate emissions from diesel fueled engines. However, a full-flow tunnel based constant volume sampler (CVS) system is not only expensive to build and maintain, it also requires a large work space. The portable micro-dilution system that could be used for measuring on-board, in-use emissions from heavy-duty vehicles would cost significantly less. The micro-dilution tunnel operates on the same principle as a full-flow dilution tunnel. The added advantage of the proposed design is that unlike a full-flow tunnel, dilution ratios can be controlled very accurately. The micro-dilution tunnel system was designed to maintain a dilution ratio of at least four to one. Dilution ratios were determined by measuring the mass flow rates of the dilution air and dilute exhaust, and the difference of the two was equal to the raw exhaust mass flow rate. The design incorporates a novel (3.175 $\mathrm{mm}$ in diameter, and $0.254 \mathrm{~m}$ long) concentric stainless dilution tunnel, which was a porous stack sampler manufactured by Mott Corporation. The unique feature of the system is its use of a single pump for not only drawing the diluted exhaust out of the micro-dilution tunnel, but also supplying filtered and dry dilution air to the tunnel. The system was used to collect PM emissions data from two different engines, namely, Navistar T444E and Detroit Diesel Series 60. The engines were tested over several steady state and transient tests. The micro-dilution system was compared to West Virginia University's (WVU) Engine and Emissions Research Laboratory (EERL) full flow tunnel system.

As expected, the particulate matter data correlated better with steady state than with transient tests. The particulate matter mass emission rates were within $14 \%$ for the steady state tests and within $17 \%$ for majority of the transient tests of the full-flow laboratory's PM mass emissions data. However, one transient test resulted in a 33\% difference between the micro-dilution tunnel and the full-flow dilution tunnel. The test results indicate that modifications are necessary to the micro-dilution system before it is to be used for on-road PM emission measurements.
\end{abstract}




\section{ACKNOWLEDGEMENTS}

As my sixth year at West Virginia University comes to an end, I must say that all goods things must come to an end. There are several people who have played an important role during my graduate studies at WVU and I would like to try to thank each and every one of them.

I must first thank Dr. Mridul Gautam for giving me the opportunity to attend graduate school. Thank you for being my advisor and friend. Your support has encouraged me to keep going and never give up. I also wish to thank my other committee members, Dr. Gary Morris and Dr. Greg Thompson for their continued support and influence throughout my graduate education.

I would like to thank the most important people in my life, my family. My Mom has been a huge influence throughout my life and deserves more recognition than I can acknowledge. She has also supported me with her endless love and for that I would like to thank her from the bottom of my heart. I would also like to thank my sisters, Nicole and Davina, for constantly telling me how proud they were of me and to continue on. The special person in my life that is also very important and is like family to me is my boyfriend Andy. Thank you for taking me out to dinner all of the time, helping me with my research, and supporting me in every which way possible over these past several years. I am looking forward to all the time that we will spend together in the future.

I also would like to thank all of the MAE secretaries. In particular, Jean Kopasko, Marilyn Host, Fern Wood, Debbie Willis, Vicky Grim, Sharon Lemley, and Carole Methaney. Jean and Marilyn thank you for all the loving support that you gave me these past six years at WVU. You both are like family to me. 
There are several people at the EERL that I would like to thank for giving the Jersey girl a chance. In particular, Tom Spencer, Wayne Hildebrand, Andy Pertl, Richard Atkinson and Dan Carder for taking the time out to answer all of my questions. I also would to thank Jason Snyder, Brad Bane, and Eric Corrigan for their assistance along the way with running tests and for teaching me how to run them. I wish everybody the best in everything you do. 


\section{TABLE OF CONTENTS}

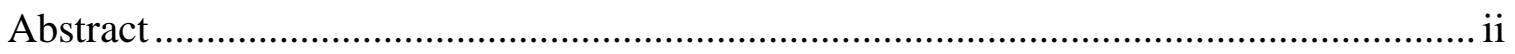

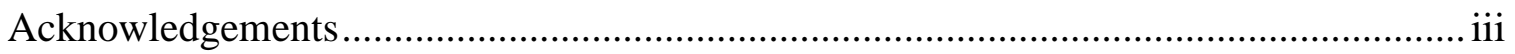

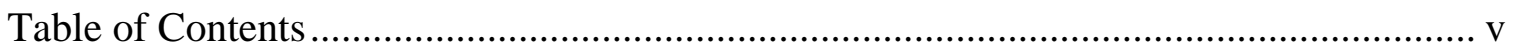

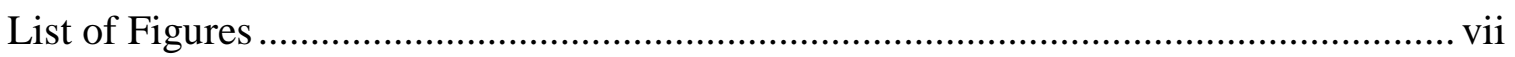

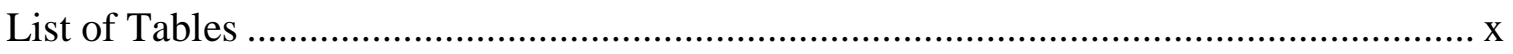

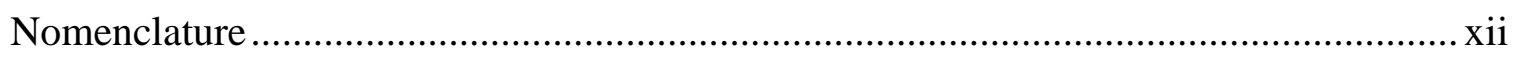

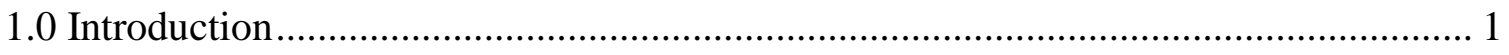

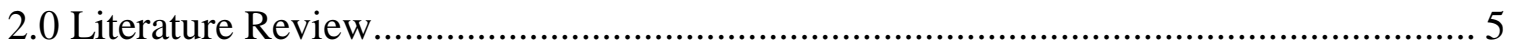

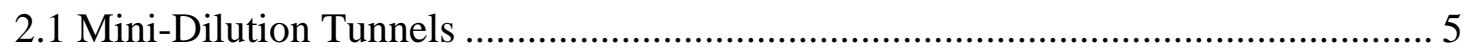

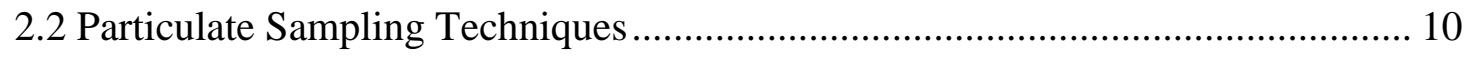

2.3 Variability in Particulate Sampling .............................................................. 13

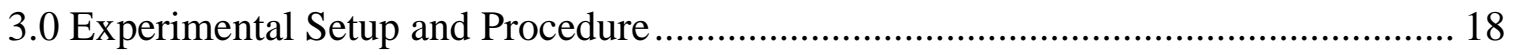

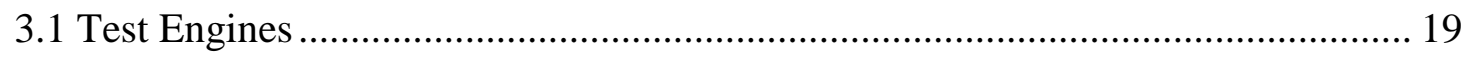

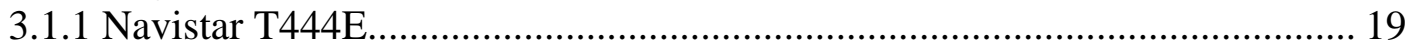

3.1.2 Detroit Diesel 60 Series....................................................................... 20

3.2 Engine Dynamometer.................................................................................. 22

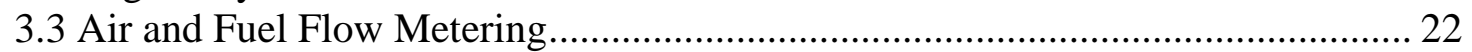

3.4 Full-Flow Dilution Tunnel System .................................................................. 23

3.4.1 Full-Flow Dilution Tunnel …………………..................................... 24

3.4.2 Secondary Dilution Tunnel ..................................................................... 25

3.4.3 Critical Flow Venturi............................................................................ 25

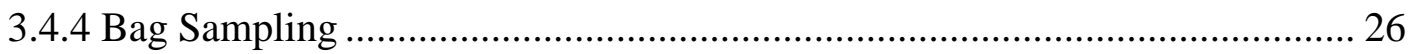

3.4.5 Particulate Matter Measurement .............................................................. 26

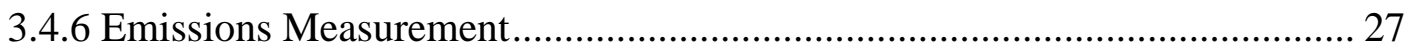

3.4.7 Instrumentation Control and Data Acquisition ........................................... 28

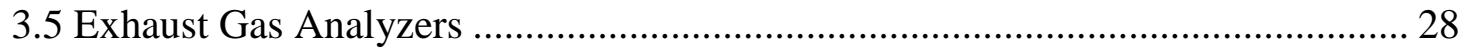

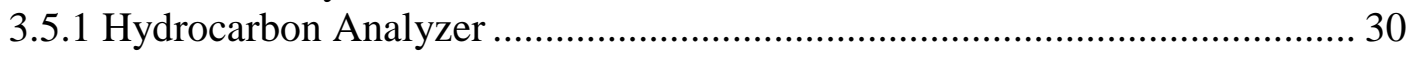

3.5.2 Oxides of Nitrogen Analyzer ...................................................................... 30

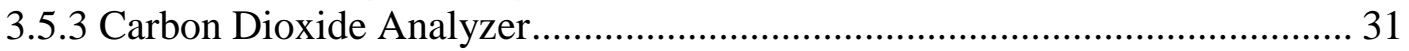

3.5.4 Carbon Monoxide Analyzer ..................................................................... 32

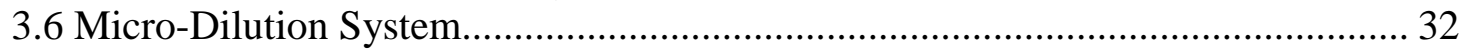

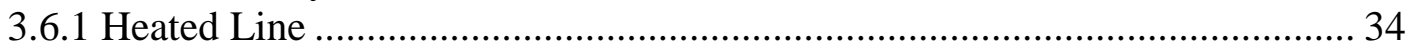

3.6.2 Micro-Dilution Tunnel ............................................................................ 34

3.6.3 Mass Flow Controllers ............................................................................... 36

3.6.3.1 Sierra 840 Series Mass Flow Controllers ……………………………... 37

3.6.3.2 Fathom GR Series Mass Flow Controller ............................................. 40

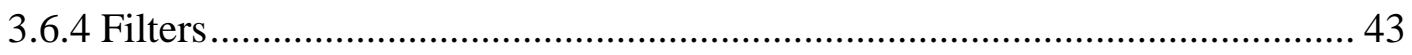

3.6.4.1 Particulate Matter Filter...................................................................... 43

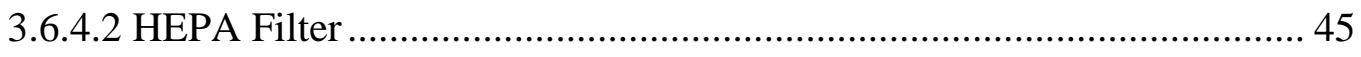

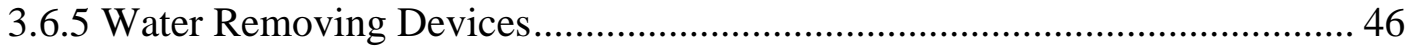




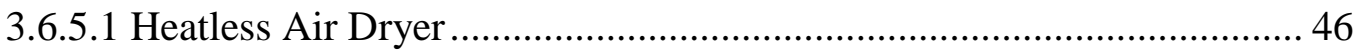

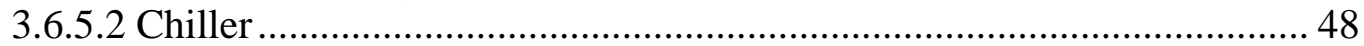

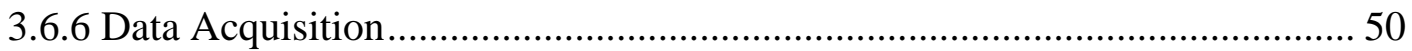

3.6.6.1 National Instruments Data Acquisition Card 1200 Series...................... 50

3.6.6.2 National Instruments Data Acquisition Card A1-16E-4......................... 51

3.6.7 Pumps ……………………………………................................... 52

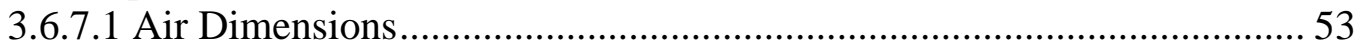

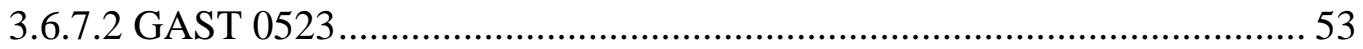

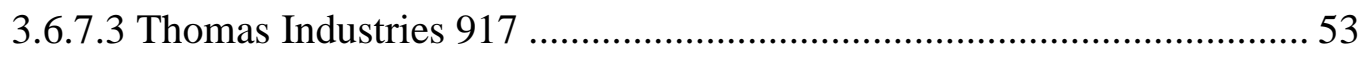

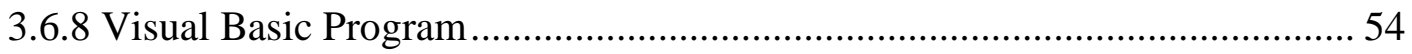

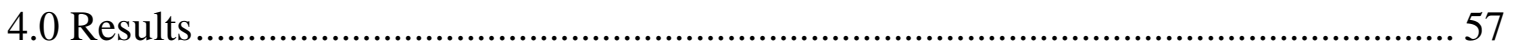

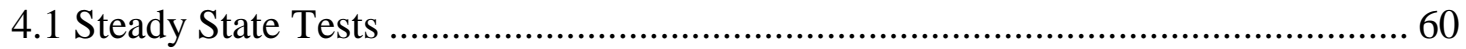

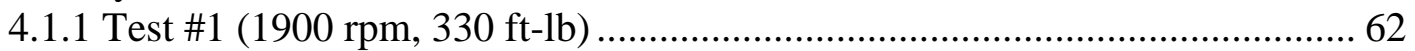

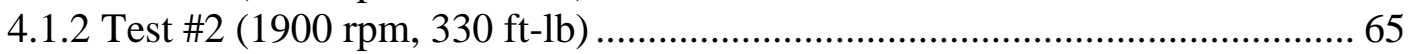

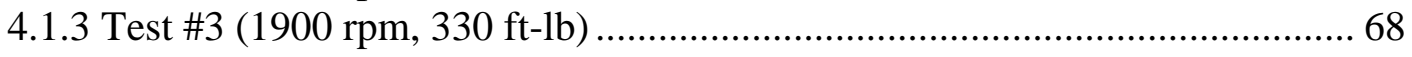

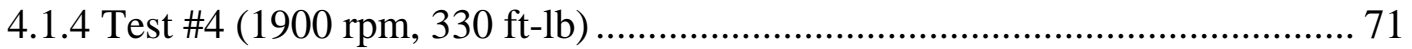

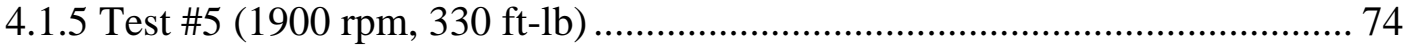

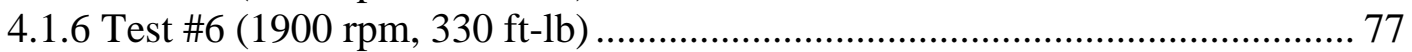

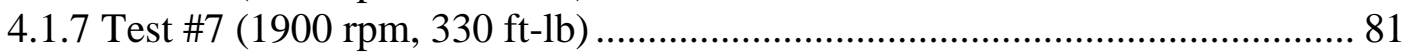

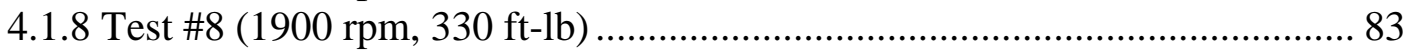

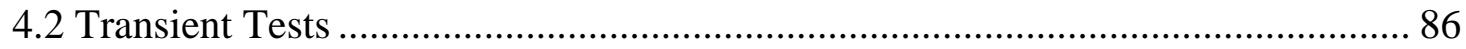

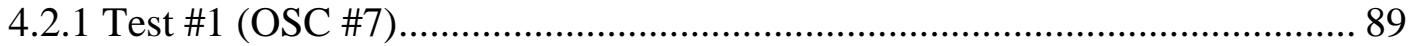

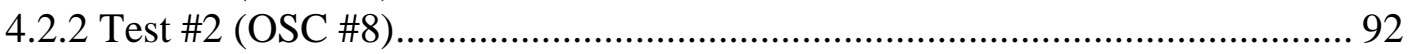

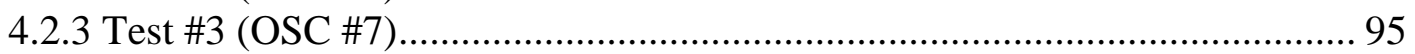

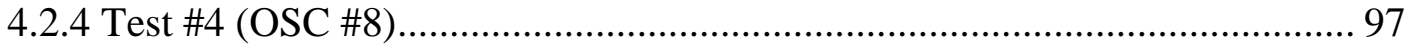

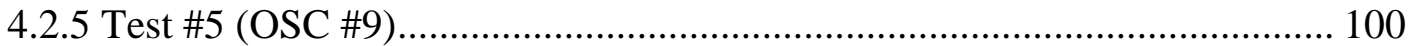

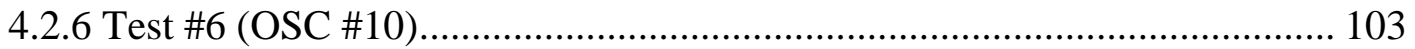

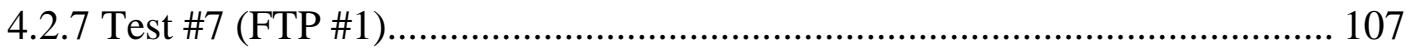

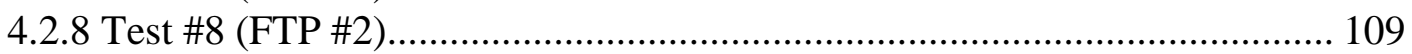

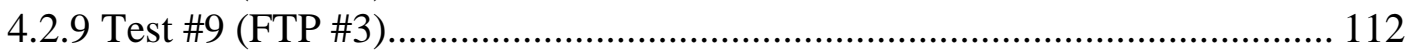

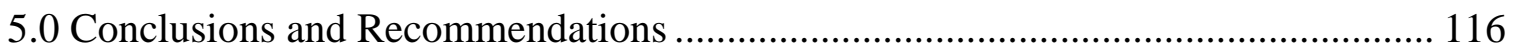

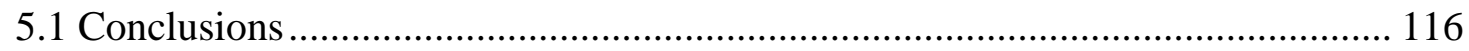

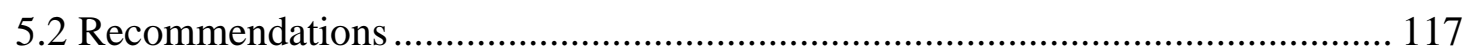

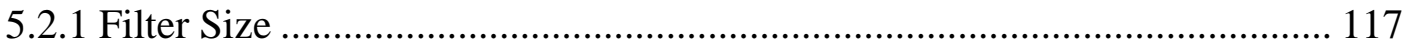

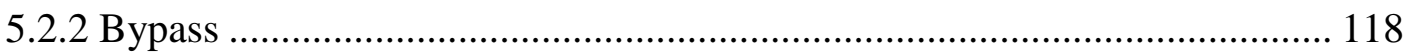

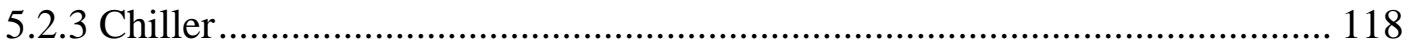

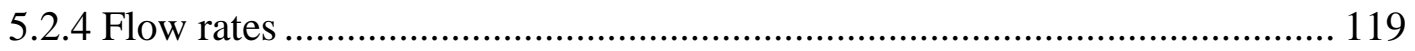

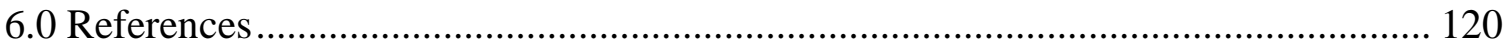

APPENDIX A. Filter Weights .............................................................................. 125

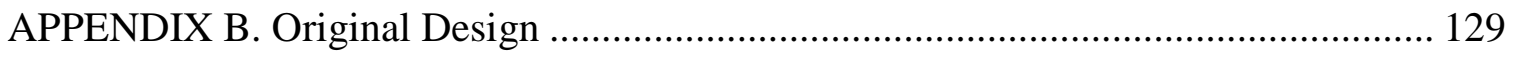

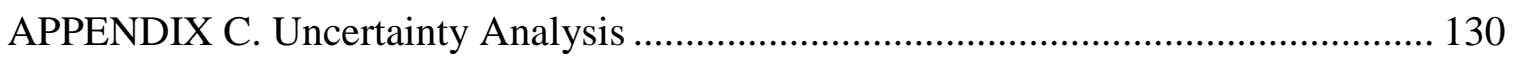

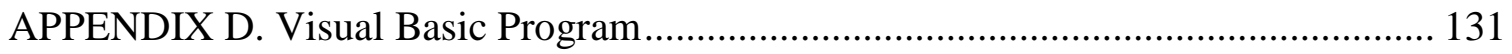




\section{LIST OF FIGURES}

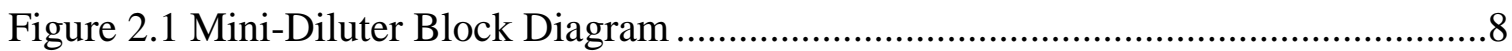

Figure 3.1 Schematic of Experimental Layout ……………........................................18

Figure 3.2 Navistar T444E coupled to GE Dynamometer at the EERL ……………........20

Figure 3.3 Navistar T444E Map …………………………………………………....2

Figure 3.4 Detroit Diesel Series 60 coupled to GE Dynomometer at the EERL ...............21

Figure 3.5 Detroit Diesel 60 Series Map …………….............................................22

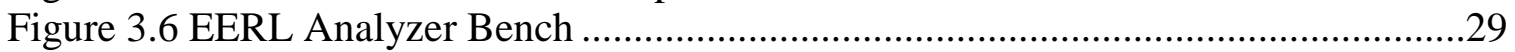

Figure 3.7 Block Diagram of Micro-Dilution System Using One Pump ...........................33

Figure 3.8 Micro-Dilution Tunnel (Model 7610) ……………………………....................35

Figure 3.9 Internal View of Dilution Tube …………….................................................

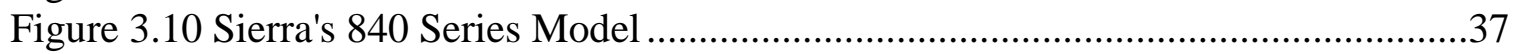

Figure 3.11 Calibration Chart for Sierra's 840 Sidetrak Model ..........................................39

Figure 3.12 Calibration Chart for Sierra's 840 Series Model ...........................................40

Figure 3.13 Fathom's GR Series Model ......................................................................41

Figure 3.14 Calibration Chart for Fathom's GR Series Model ………………….............42

Figure 3.15 Gelman Science Model 2220..................................................................4

Figure 3.16 Gelman Sciences HEPA Capsule ...............................................................46

Figure 3.17 Permapure Heatless Air Dryer...................................................................4

Figure 3.18 Universal Sample Chiller .......................................................................48

Figure 3.19 Thomas Industries 917 Series Model ..........................................................54

Figure 3.20 Main Form in Visual Basic.......................................................................55

Figure 4.1 Comparison of Total Particulate Matter for Steady State Tests .......................60

Figure 4.2 Comparison of $\mathrm{CO}_{2}$ Emissions Data for Steady State Tests ...........................61

Figure 4.3 Comparison of NOx Emissions Data for Steady State Tests ...........................61

Figure 4.4 Temperatures During Steady State Test \#1 .....................................................63

Figure 4.5 Mass Flow Rates During Steady State Test \#1 ................................................64

Figure 4.6 Comparison of Raw Exhaust and Bleed Flow Rates During Steady

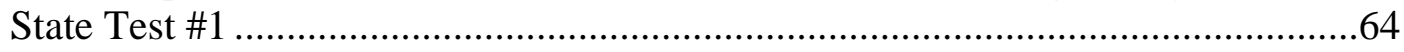

Figure 4.7 Differential Pressures During Steady State Test \#1 .......................................65

Figure 4.8 Temperatures During Steady State Test \#2 …………………………............66

Figure 4.9 Mass Flow Rates During Steady State Test \#2 ………………………..........67

Figure 4.10 Comparison of Raw Exhaust and Bleed Flow Rates During Steady

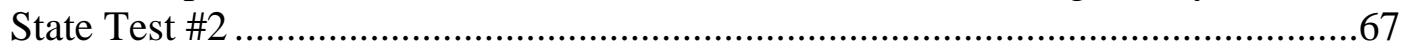

Figure 4.11 Differential Pressures During Steady State Test \#2 …………………..........68

Figure 4.12 Temperatures During Steady State Test \#3 ………………………...............69

Figure 4.13 Mass Flow Rates During Steady State Test \#3 ..............................................70

Figure 4.14 Comparison of Raw Exhaust and Bleed Flow Rates During Steady

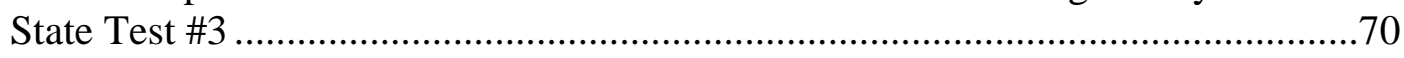

Figure 4.15 Differential Pressures During Steady State Test \#3 ......................................71

Figure 4.16 Temperatures During Steady State Test \#4 ………………………...............72

Figure 4.17 Mass Flow Rates During Steady State Test \#4 ............................................73

Figure 4.18 Comparison of Raw Exhaust and Bleed Flow Rates During Steady

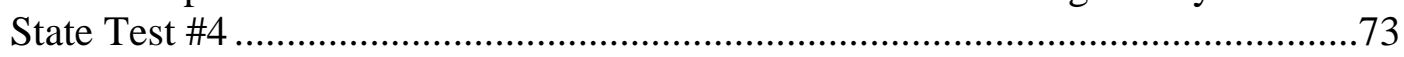


Figure 4.19 Differential Pressure During Steady State Test \#4 .....................................74

Figure 4.20 Temperatures During Steady State Test \#5 ................................................75

Figure 4.21 Mass Flow Rates During Steady State Test \#5 .........................................76

Figure 4.22 Comparison of Raw Exhaust and Bleed Flow Rates During Steady

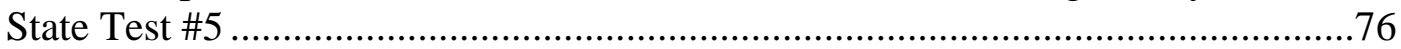

Figure 4.23 Differential Pressure During Steady State Test \#5 .......................................77

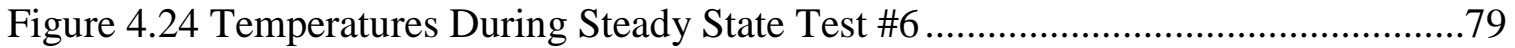

Figure 4.25 Mass Flow Rates During Steady State Test \#6 ..........................................79

Figure 4.26 Entering Flow Rate During Steady State Test \#6 ........................................80

Figure 4.27 Differential Pressure During Steady State Test \#6 ......................................80

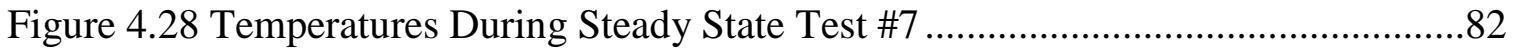

Figure 4.29 Mass Flow Rates During Steady State Test \#7 .......................................82

Figure 4.30 Comparison of Raw Exhaust and Bleed Flow Rates During Steady

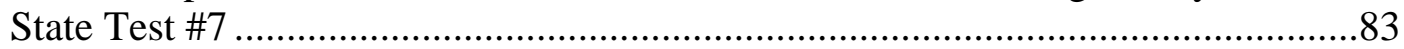

Figure 4.31 Temperatures During Steady State Test \#8 …...................................... 84

Figure 4.32 Mass Flow Rates During Steady State Test \#8 .........................................85

Figure 4.33 Comparison of Raw Exhaust and Bleed Flow Rates During Steady

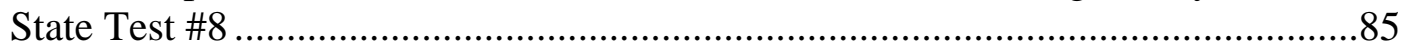

Figure 4.34 Comparison of Oscillating Transient Tests with the Navistar T444E

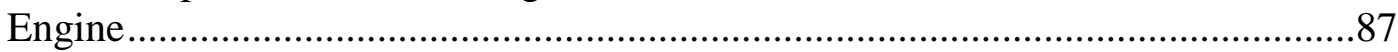

Figure 4.35 Comparison of $\mathrm{CO}_{2}$ Emissions Data for Transient Tests ............................88

Figure 4.36 Comparison of $\mathrm{NO}_{\mathrm{x}}$ Emissions Data for Transient Tests ............................88

Figure 4.37 Oscillating Transient Test \#7 Cycle .........................................................89

Figure 4.38 Temperatures During Transient Test \#1 ................................................ 90

Figure 4.39 Mass Flow Rates During Transient Test \#1 ..............................................91

Figure 4.40 Comparison of Raw Exhaust and Bleed Flow Rates During Transient

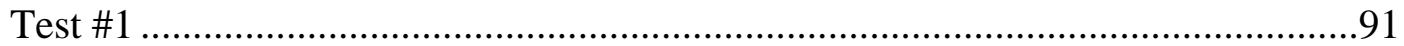

Figure 4.41 Oscillating Transient Test \#8 Cycle ..........................................................93

Figure 4.42 Temperatures During Transient Test \#2 ...................................................93

Figure 4.43 Mass Flow Rates During Transient Test \#2 .............................................94

Figure 4.44 Comparison of Raw Exhaust and Bleed Flow Rates During Transient

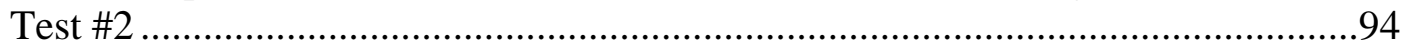

Figure 4.45 Temperatures During Transient Test \#3 ..................................................96

Figure 4.46 Mass Flow Rates During Transient Test \#3 ..............................................96

Figure 4.47 Comparison of Raw Exhaust and Bleed Flow Rates During Transient

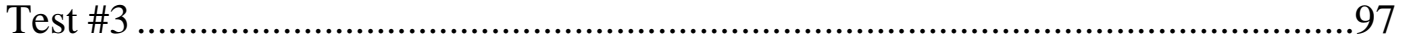

Figure 4.48 Temperatures During Transient Test \#4 .................................................98

Figure 4.49 Mass Flow Rates During Transient Test \#4 ..............................................99

Figure 4.50 Comparison of Raw Exhaust and Bleed Flow Rates During Transient

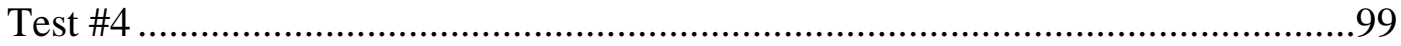

Figure 4.51 Oscillating Transient Test \#9 Cycle ...........................................................101

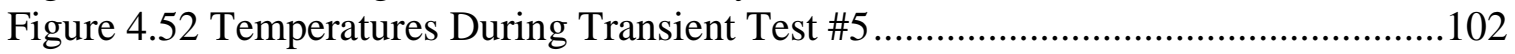

Figure 4.53 Mass Flow Rates During Transient Test \#5 ............................................ 102

Figure 4.54 Comparison of Raw Exhaust and Bleed Flow Rates During Transient

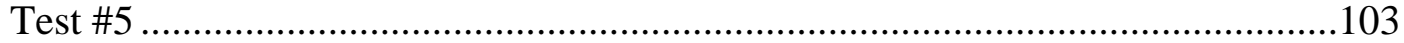

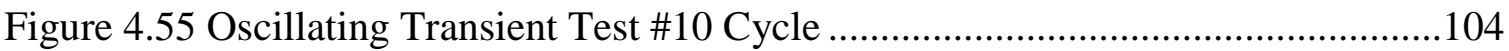




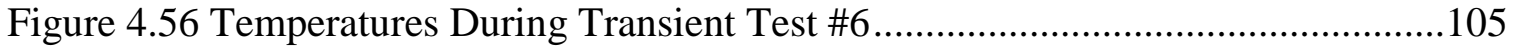

Figure 4.57 Mass Flow Rates for Transient Test \#6 ....................................................105

Figure 4.58 Comparison of Raw Exhaust and Bleed Flow Rates for Transient Test

\#6 106

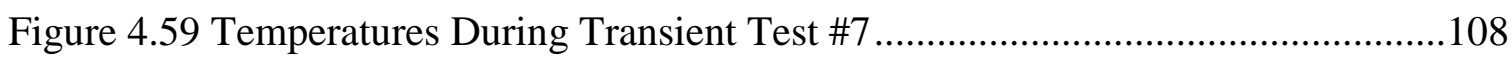

Figure 4.60 Mass Flow Rates During Transient Test \#7 ............................................. 108

Figure 4.61 Comparison of Raw Exhaust and Bleed Flow Rates During Transient

Test \#7 109

Figure 4.62 Temperatures During Transient Test \#8 ..................................................111

Figure 4.63 Mass Flow Rates During Transient Test \#8 ............................................111

Figure 4.64 Comparison of Raw Exhaust and Bleed Flow Rates During Transient

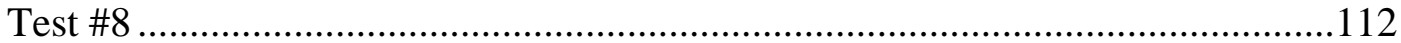

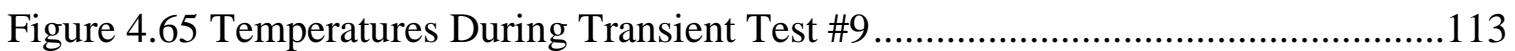

Figure 4.66 Mass Flow Rates During Transient Test \#9 ..............................................114

Figure 4.67 Comparison of Raw Exhaust and Bleed Flow Rates During Transient

Test \#9

Figure B.1 Micro-Dilution System with Two Pumps 


\section{LIST OF TABLES}

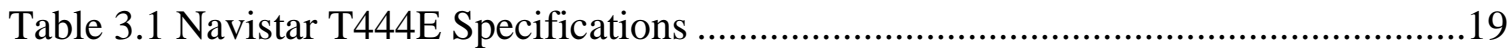

Table 3.2 Detroit Diesel 60 Series Specifications .....................................................21

Table 3.3 Filter Face Velocities $(70-\mathrm{mm})$...................................................................27

Table 3.4 Calculated Orifice Size For Sierra's 840 Series Models ...................................37

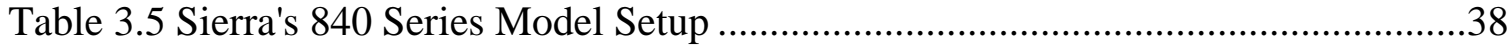

Table 3.6 Calibration Data for Sierra's 840 Series Model ................................................39

Table 3.7 Calibration Data for Sierra's 840 Sidetrak Series Model ..................................40

Table 3.8 Calculated Orifice Size for Fathom's GR Series Model ...................................41

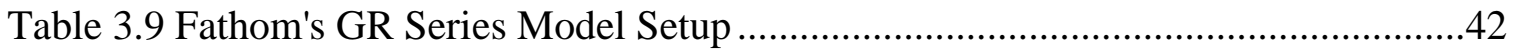

Table 3.10 Calibration Data for Fathom's GR Series Model .......................................42

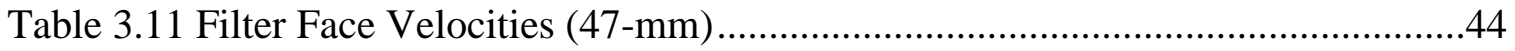

Table 3.12 Filter Face Velocities (HEPA) .......................................................................46

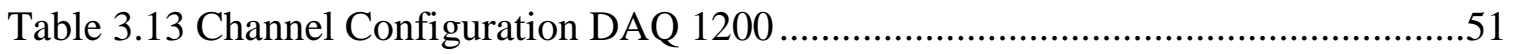

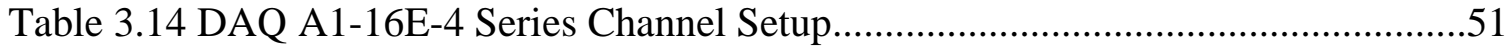

Table 3.15 Temperature Limits in Selected Locaitons .................................................56

Table 4.1 Comparison of Full-Flow Dilution and Micro-Dilution Tunnels for

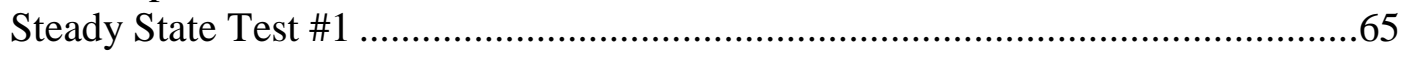

Table 4.2 Comparison of Full-Flow Dilution and Micro-Dilution Tunnels for

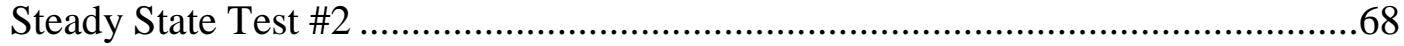

Table 4.3 Comparison of Full-Flow Dilution and Micro-Dilution Tunnels for Steady State Test \#3 ....................................................................................... 71

Table 4.4 Comparison of Full-Flow Dilution and Micro-Dilution Tunnels for

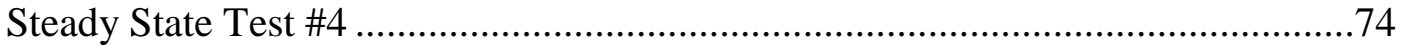

Table 4.5 Comparison of Full-Flow Dilution and Micro-Dilution Tunnels for

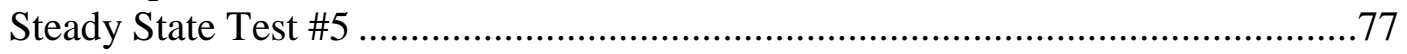

Table 4.6 Comparison of Full-Flow Dilution and Micro-Dilution Tunnels for

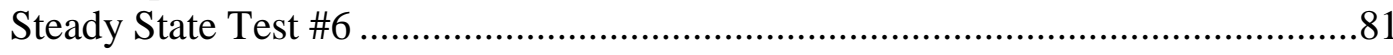

Table 4.7 Comparison of Full-Flow Dilution and Micro-Dilution Tunnels for Steady State Test \#7

Table 4.8 Comparison of Full-Flow Dilution and Micro-Dilution Tunnels for

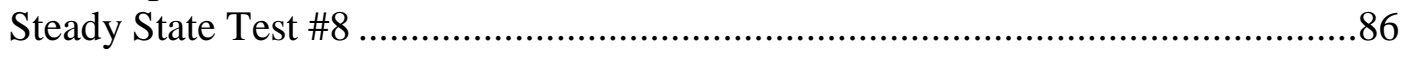

Table 4.9 Comparison of Full-Flow Dilution and Micro-Dilution Tunnels for

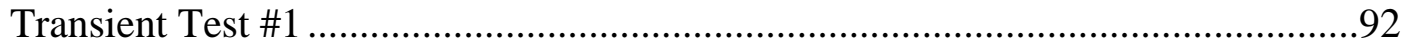

Table 4.10 Comparison of Full-Flow Dilution and Micro-Dilution Tunnels for Transient Test \#2

Table 4.11 Comparison of Full-Flow Dilution and Micro-Dilution Tunnels for Transient Test \#3

Table 4.12 Comparison of Full-Flow Dilution and Micro-Dilution Tunnels for Transient Test \#4

Table 4.13 Comparison of Full Flow and Micro-Dilution Tunnels for Transient Test \#5

Table 4.14 Comparison of Full-Flow Dilution and Micro-Dilution Tunnels for Transient Test \#6 106 
Table 4.15 Comparison of Full-Flow Dilution Dilution and Micro-Dilution

Tunnels for Transient Test \#7

Table 4.16 Comparison of Full-Flow Dilution Dilution and Micro-Dilution

Tunnels for Transient Test \#8

Table 4.17 Comparison of Full-Flow Dilution Dilution and Micro-Dilution

Tunnels for Transient Test \#9

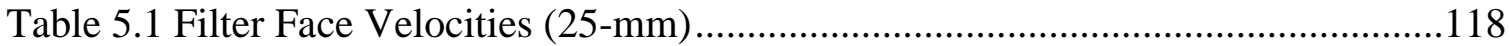

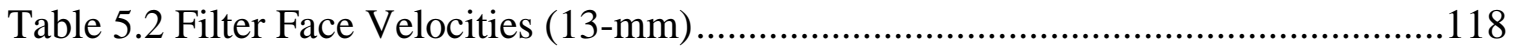

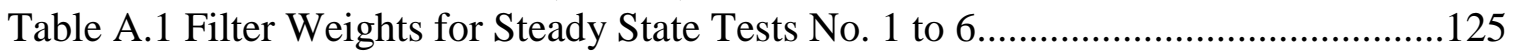

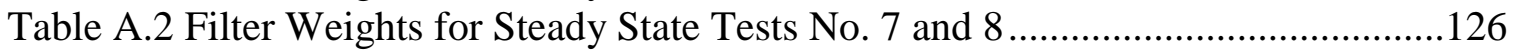

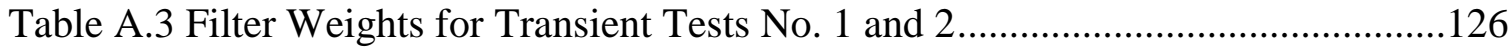

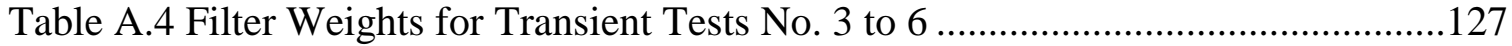

Table A.5 Filter Weights for Transient Tests No. 7 ..................................................128

Table A.6 Filter Weights for Transient Tests No. 8 and 9........................................128 


\section{NOMENCLATURE}

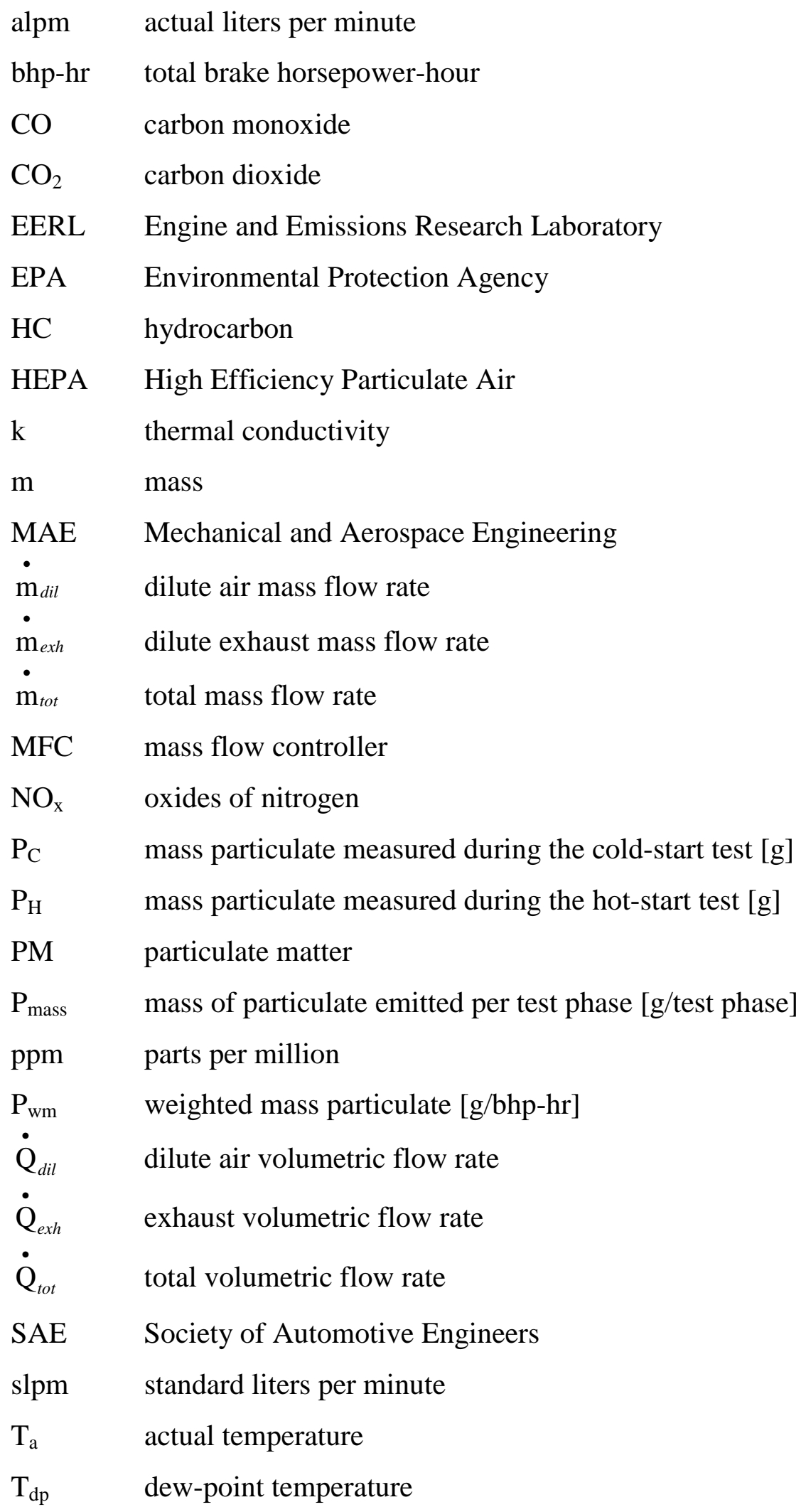




$\begin{array}{ll}\mathrm{T}_{\mathrm{s}} & \text { standard temperature } \\ \text { TEOM } & \text { Tapered Element Oscillating Microbalance } \\ \mathbf{V} & \text { velocity } \\ \mathrm{V}_{\text {mix }} & \text { total dilute exhaust volume corrected to standard conditions }\left[\mathrm{ft}^{3}\left(\mathrm{~m}^{3}\right)\right] \\ \mathrm{V}_{\mathrm{o}} & \text { volume of gas pumped by the positive displacement pump }\left[\mathrm{ft}^{3}\left(\mathrm{~m}^{3}\right)\right] \\ \mathrm{V}_{\text {sf }} & \text { total volume of sample removed from the primary dilution tunnel }\left[\mathrm{ft}^{3}\left(\mathrm{~m}^{3}\right)\right] \\ \text { WVU } & \text { West Virginia University }\end{array}$

\section{Greek Letters}

$\phi \quad$ relative humidity

$\omega \quad$ absolute or specific humidity

\section{Subscripts}

$\begin{array}{ll}\text { a } & \text { air } \\ \text { abs } & \text { absolute } \\ \text { act } & \text { actual } \\ \text { atm } & \text { atmospheric } \\ \text { avg } & \text { average } \\ \text { C } & \text { cold-start test } \\ \text { H } & \text { hot-start test } \\ \text { mass } & \text { mass } \\ \text { mix } & \text { mixture } \\ \text { wm } & \text { weighted } \\ \text { sys } & \text { system }\end{array}$




\subsection{Introduction}

Diesel fueled internal combustion engines are one of the leading producers of exhaust gas emissions in the world today. These emissions include oxides of nitrogen, particulate matter, hydrocarbons, carbon dioxide, carbon monoxide, and sulfur dioxide. Particulate matter has become the focus of increased attention due to the potential health effects. In laboratory animals, some soluble organic compounds have been determined as a potential carcinogens, or cancer causing agents (Baumgard, 1986). Studies performed by the National Institute for Occupational Safety and Health (NIOSH) indicate an association between diesel particulate exposure and the development of lung cancer or other cancers in animals (IARC, 1989). This increased health concern has prompted the need for increased research into the area of diesel particulate matter, its causes, and its control.

Testing particulate matter from heavy-duty diesel engines is essential to reduce air pollution from these vehicles. West Virginia University's (WVU) Engine and Emissions Research Laboratory (EERL) is equipped to test heavy-duty diesel engines and measure both gaseous emissions and measure particulate matter emissions using a constant volume sampling (CVS) full flow dilution tunnel. The laboratory was built according to the specifications outlined in CFR 40, Part 86, Subpart N, and has been in full operation since 1993. At this testing facility, engines are operated through transient and steady state test cycles to test amongst other things particulate emissions from diesel engines (Gautam et al., 1996).

On-road emissions measurement systems give a better representation of how vehicles are driven on the highway. WVU Mobile Emissions Measurement System 
(MEMS) can test specific diesel exhaust emissions on-board (Gautam et al., 1999). A portable on-board micro-dilution tunnel system can test particulate matter to give an accurate measurement of these particles.

To help reduce the harmful pollutants expelled from diesel fueled engines, the Environmental Protection Agency (EPA) developed the Federal Test Procedure (FTP) as indicated in the CFR 40, Part 86, Subpart N. The FTP specifies that the engine is to be mounted on a dynamometer and operated over a transient cycle with varying speed and load conditions. The entire exhaust stream from the engine is then injected into a fullflow dilution tunnel where it is mixed and diluted with ambient air. The CVS, which is located downstream, draws the diluted exhaust through the tunnel. Samples of diluted exhaust are drawn to measure bake-specific gaseous and particulate matter emissions.

Measurement of diesel exhaust emissions using an engine dynamometer and a total-exhaust CVS requires a large work space. Although full-flow dilution tunnels are widely used to test particulates, a partial exhaust dilution tunnel would considerably save space, time and money. Partial exhaust dilution tunnels may vary from a "micro-dilution tunnel" to a "mini-tunnel" such as the AVL system, BG-1 and the JAT tunnel (Smith (1993), Sierra Instruments (1995)). The micro-dilution tunnel operates on the sample principle as the full-flow tunnel, but uses only a small portion of the exhaust that is emitted by the engine. The size requirements for a dilution tunnel are significantly reduced when a small portion of the exhaust is sampled. In turn, the size of the equipment, quantity of air and power requirements needed by a micro-dilution tunnel based CVS system are drastically reduced compared to a full-flow dilution system. 
The objectives of this research were to design and construct a portable microdilution particulate sampling system and compare it to a full-flow dilution tunnel for particulate matter emission testing of heavy-duty diesel engines and vehicles. First, a system was designed and theoretically analyzed. Second, the system was constructed and tested on a diesel engine that was exercised over steady state cycles only. The majority of the problems were discovered at this stage, and they were corrected. It should be noted that the PM samples were collected on a filter with the micro-dilution mass emissions of PM was determined gravimetrically. Once all the known problems were fixed, the system was prepared for transient cycles. The results were then compared directly to the full-flow dilution tunnel. Finally, the system prototype was prepared for on road testing. This system will be interfaced with MEMS using a signal from an exhaust flow meter for control. The system will draw a proportional sample from the exhaust stack to test actual on-road driving conditions as opposed to simulated driving conditions performed in laboratories. Particulate matter samples from the mini-dilution tunnel were collected on Pallflex T60A20, 47-mm filters, while the full-flow dilution tunnel particulate samples were collected on Pallflex T60A20 70-mm filters.

This research is separated into five main chapters. The remaining chapters explain in detail all of the research involved. Researching of mini-tunnels, particulate sampling techniques and the variability in particulate sampling are presented in Chapter 2. Chapter 3 explains in detail the experimental setup and procedures used in this research for the EERL and the micro-dilution tunnel system. Chapter 4 displays the results and conclusions of the numerous steady state and transient tests performed with the Navistar T444E and the Detroit Diesel 60 series. Some recommendations to the 
micro-dilution system are presented in Chapter 5. The Appendices contain additional information not included in the other chapters. Appendix A shows the filter weights of the micro-dilution system and the full-flow tunnel system for each test. Appendix B shows the initial design of the micro-dilution system. Appendix $\mathrm{C}$ shows the Visual Basic code used to monitor and control the micro-dilution systems components. 


\subsection{Literature Review}

The US EPA CFR 40, Part 86, Subpart N requires that a total-exhaust dilution tunnel be used to measure diesel exhaust emissions. The prime reason for using a dilution tunnel is to dilute the concentrations of pollutants in the exhaust and the temperature prior to sampling for gaseous and PM measurements. The dilution tunnel attempts to simulate atmospheric dilution of ample exhaust. In addition to lowering the dew point of the exhaust, dilution also promotes the condensation and adsorption of heavier hydrocarbons on the available PM. This supposedly allows the PM to mature via the gas-to-particle transformation and post-nucleation processes, such as coagulation. However, minidilution tunnel diesel particulate sampling research and application has greatly increased over the years, particularly in steady state testing of engines.

The selected works cited in this chapter include the topics on mini-dilution tunnels, sampling techniques and the variability in sampling techniques.

\subsection{Mini-Dilution Tunnels}

The purpose of a dilution tunnel is to draw a raw exhaust into the dilution tunnel and dilute it with a large quantity of ambient air. This process simulates the conditions under which vehicles release exhaust into the atmosphere. The full flow dilution tunnel is the accepted method by the US EPA to measure heavy duty diesel emissions. In this system, the exhaust is diluted by ambient air in the main dilution tunnel. A sample is drawn from at least ten diameters downstream.

A mini-dilution tunnel is quite similar to a full-flow dilution tunnel except that a smaller sample is drawn and the system as a whole is much smaller. The mini-dilution tunnel does correlate with full-flow tunnels using steady-state emission tests. The four 
basic types of mini-dilution tunnels that are discussed are iso-kinetic method, twinventuri type, ejector method and the multi-tube type method.

Hirakouchi et al. (1990) measured unregulated exhaust emissions from heavyduty diesel engines with a multi-tube type mini-dilution tunnel, developed by the Mitsubishi Motors Corporation, and a full-flow dilution tunnel. Both tunnels were used to measure emissions rates of $\mathrm{PM}, \mathrm{CO}, \mathrm{CO}_{2}, \mathrm{NO}_{\mathrm{x}}$, and $\mathrm{HC}$. Three engines were tested with compression ratios ranging from 16:1 to $22: 1$ using different fuel types. The unregulated exhaust emission measurements of heavy-duty diesel engines agreed well between the multi-tube type mini-dilution tunnel and the full-flow type dilution tunnel. The mini-tunnel is compact and is $1 / 3$ of the cost of a full-flow tunnel. This multi-tube type mini-tunnel is a useful and valid exhaust emission measuring instrument under steady state and transient testing conditions from any size engine.

Graze (1993) designed a total sampling system to perform all dilution and filtering functions at the exhaust stack. The dilution tunnel was constructed using a small (12" long, 1" diameter) outer shell pressure vessel around a sintered, 0.375" ID stainless steel tube with a nominal 2 micron pore size mounted concentrically within the vessel. The dilution air was provided via pressurized shop air that was filtered, HC scrubbed and dried prior to entering the dilution system. Distribution of the dilution air and sample sides of the system was handled using critical flow orifices. Singer dry gas meters were used to measure dilution air and total dilute sample flow and to infer the extracted stack sample volume. To meet the concerns of subtracting two large numbers, a calibration loop was developed. Two separate "micro-dilution" units were correlated against two 
full dilution tunnels on two different engine bore size families using the ISO 8178 correlation study. Their dilution ratios were approximately 4:1 and 27:1, respectively.

The system was redesigned using Sierra Instruments Series 840, then later Sierra's 860 in place of the dry gas meters. The filter holder was also redesigned to provide the capability of unified encapsulation of two $90-\mathrm{mm}$ diameter filter membranes in a leak free easily accessed housing. However, the dilution tunnel itself did not change significantly, since it reduced deposits on the tunnel walls. The mini-dilution unit proved to be a true fractional sampler, insensitive to engine size, requiring only a simple stack probe change to provide accurate, representative diesel stack sampling on any size diesel engine.

Stotler and Human (1995) studied an ISO 8178 correlation between raw and dilute exhaust emission sampling systems. The test engine used was a 1988 Cummins LTA-10 rated $\mathrm{kW}(300 \mathrm{hp})$ at $2100 \mathrm{rpm}$. The correlation study was broken up into three test phases. The first test phase consisted of gaseous and particulate emissions being measured simultaneously from both the raw exhaust and full dilute sampling systems. Only particulate matter was sampled simultaneously by the MDT and full dilute systems for the second test phase. The third and final phase examined the effect of water vapor on the $\mathrm{NO}_{\mathrm{x}}$ analysis system. To address the concerns of PM loss in the transfer tube due to thermophoretic, inertial and various other forms of deposition, different lengths of the transfer tube were used. The two measurement systems were within $2.5 \%$ of each other when the 6" transfer tube was used and $1.0 \%$ with the 15 ' transfer tube. Theories as to why the length of the transfer tube has little effect on PM measurement is due to the transfer tube being heated to a constant $250^{\circ} \mathrm{C}\left(480^{\circ} \mathrm{F}\right)$, running conditioning cycles 
before taking actual particulate sample, and minimizing bends and contractions of the transfer tube. The correlation between the raw and full dilution sampling systems for $\mathrm{HC}, \mathrm{NO}_{\mathrm{x}}$, and $\mathrm{CO}$ were within $7.0 \%, 3.0 \%$, and $1.0 \%$, respectively. Similarly, the correlation between the mini-dilution tunnel (MDT) and full dilution particulate sampling systems was within $2.5 \%$.

Silvis et al. (1999) used a critical flow venturi (CFV) type mini-dilution sampling system to measure vehicle exhaust emissions. A water vapor adjustment technique was also used to compensate for exhaust gas composition changes on cold start emissions tests. The CFV Type mini-diluter is shown in Figure 2.1. Its features include small CFVs, a differential pressure regulator, heated lines, and a mass flow controller. The small CFVs establish a stable dilution ratio while the differential pressure regulator maintains equal pressure at the inlets of the two orifices. The heated lines are used to bring the wet raw exhaust to the dilution component. The venturis and pressure regulator are kept in an oven to prevent any condensation of the sample before it is diluted. Finally, the mass flow controller with a $300 \mathrm{~ms}$ response delay were used to proportion the flow to the sample bags.

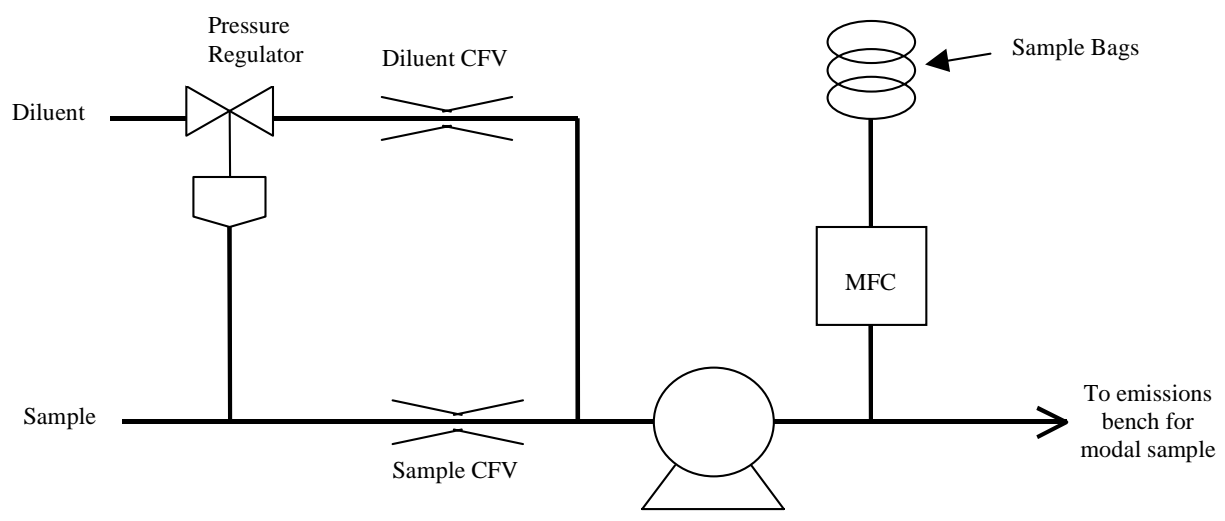

Figure 2.1 Mini-Diluter Block Diagram 
The mini-diluter presented two advantages over a full flow system. These are the higher, more easily measured concentrations resulting from less dilution and the absence of background contaminants, eliminating a need for a separate, error prone collection and analysis of the background contaminant levels. Since the humidity is quite low during cold start tests, a water vapor sensor and correction factor were added to eliminate any inaccuracies caused by water vapor. The Mini-diluter and a Flow Technology DVE (Direct Vehicle Exhaust) measurement system were connected in series with a conventional CVS system so that results from both systems could be obtained from the same emissions test. The results from the Mini-diluter correlated well to the Constant Volume Sampler. However, the vehicle themselves were not repeatable enough to allow conclusions from the test to test variations.

Review of the dilution factor (DF) calculation procedure specified in the FTP indicates that it is a simplification of a more rigorous calculation needed to most accurately determine the true DF. Although the calculated DF is properly used to correct for contamination of the dilution air, the DF calculation procedure specified in the FTP is valid only when the dilution air in uncontaminated. In addition, the DF calculation procedure contained in the FTP is based on the assumption of stoichiometric combustion. Finally the DF calculation assumes that emissions are being measured without the removal of any water from the sample. This is a good assumption under some conditions, but some emissions analysis systems cause water to condense out from the sample under certain test conditions.

The dilution tunnel has been developed to model the process of exhaust diluted in the atmosphere. A mini-dilution tunnel has been developed to minimize the size 
requirements of a full flow dilution tunnel. Some of the authors whose work has been based on dilute diesel exhaust emissions using mini-dilution tunnels include Asaumi et al. (1989), Harrington et al. (1981), MacDonald et al. (1980), O’Neal et al. (1983), Nussear (1992), Potter et al. (1988), Suzuki et al. (1985), Takeda et al. (1991), and Yamane et al. (1988).

\subsection{Particulate Sampling Techniques}

In order to compare full-flow tunnel emissions with mini-dilution tunnel emissions, particulate emissions must be accurately measured. Some particulate sampling techniques include sampling sonde technique (SST), proportional sampling (PS) and constant volume sampling (CVS). All of these particulate sampling techniques and their results are discussed below.

Silvis and Chase (1999) examine the systematic errors inherent in the CVS (Constant Volume Sampling) technique specified in federal regulations, estimates their sizes, and proposes a method using proportional ambient sampling whereby they can be avoided. The CVS system has served as a robust method for determining the mass of gaseous emissions for more than 25 years. In the EPA (Environmental Protection Agency) light-duty mandated tests, the vehicle is driven on a chassis dynamometer, which provides the proper load to simulate driving on the road, and a specified velocity versus time schedule is followed. The CVS method dilutes the vehicle exhaust with ambient air and maintains the total flow rate of diluted exhaust constant. The water content in the moist exhaust remains in vapor form and is not lost during the sampling process. Samples of the diluted exhaust and ambient air are collected in special inert bags. In the CFR (Code of Federal Regulations), permits corrections to be made for 
contaminants present in the dilution air. Silvis and Chase state that what was once a second-order correction for ambient contaminants has become a sensitive small difference between two large numbers.

To avoid contaminants in the ambient air while diluting, a large catalytic converter chemically reacts the residual hydrocarbons in the ambient air to carbon dioxide and water. Another alternative method would be to use a mini-diluter. This device draws an exhaust sample at a very low flow rate and dilutes it with a small quantity of air at a constant ratio. High purity air containing very little hydrocarbons can be used because of the low flow rates. However, the sample must be collected at a synchronized flow rate that is proportional to the exhaust flow rate. This would mean that the mini-diluter approach would also require the use of additional instrumentation to accurately measure the instantaneous exhaust flow rate.

González-Oropeza and López (1994) analyzed a sampling sonde technique (SST) that is not accepted by the main regulatory agencies. The tests were performed with a Renault engine type MIDR 0620 45, produced in France. The engine was coupled to a Heenan \& Froude hydraulic dynamometer and a Tecner $^{\mathrm{TM}}$ nozzle TG-50 was used to measure the airflow. NDIR (non-dispersive infrared), FID (Flame ionization detection) and CHLD (chemical luminescence detection) measured the gas constituents. The SST allows the suction and dilution of a small fraction of the exhaust gases. The mixing starts right at the sampling zone in order to avoid transport to a dilution tunnel or mini-tunnel. The dilution gas is taken from a compressed air tank, which is located downstream of the sampling nozzle. The dilution rate is dependent upon the characteristics of the engine 
being used. Injection timing, engine speed (rpm) and load conditions can affect the reduction of particulate matter generation (PMG).

Even though a significant number of tests were not performed, the results obtained by the SST techniques were in good agreement with other techniques. At low load, the soluble organic fraction (SOF) content increased with timing delays, whereas at higher loads the insoluble organic fraction (IOF) is more important. Greater levels of PMG were detected at higher loads and lower speeds. At low loads, larger levels of SOF were detected, even when the total mass of particulate was smaller than at larger loads. The SOF/IOF relation continuously decreased up to the full load condition.

Abe et al. (1989) investigated particulate matter emission characteristics over steady state and transient operating cycles. Photoacoustic spectroscopy method (PAS) was found to be effective for continuous measurement of particulate concentrations in a dilution tunnel. However, the engine low load zone was not effective because the SOF emission was not sufficient. The light extinction opacity meter (OPM) is not convenient to measure particulate matter because the opacity, engine air flow, fuel flow, exhaust gas temperature, plus others are required. The OPM is a high speed response type which can be installed to vehicle exhaust systems and can be used even during actual driving. The tapered element oscillating microbalance (TEOM) is another particulate measuring device that is high speed in accuracy, but has produced problems with its response and detection sensitivity in determining emission behavior during continuous measurements.

There are several techniques to measure particulate matter. Some additional works and there topics proceed. Vuk et al. (1976) used an Anderson Inertial Impactor for gravimetric or electron microscopy. Khatri et al. (1978) used an Electric Aerosol 
Analyzer to measure particle size distribution. Lipkea et al. (1978) reviewed techniques for the measurement and characterization of the chemical and physical nature of particulate matter. Additional works include Dementhon and Martin (1997), Gautam et al. (1994), Gautam et al. (1996) and Genova et al. (1996).

\subsection{Variability in Particulate Sampling}

The previous section discussed different methods of particulate sampling. It is very important that results from any particulate sampling technique used be accurate and consistent. Any possible factors that could effect the final measurement and analysis of the species should be identified to reduce any variability. The following section is some research that has been done in this area.

Kittelson and Johnson (1991) studied the intra- and inter-laboratory variability in particulate measurements using the Heavy-Duty Transient Test (40 CFR Part 86 Subpart N). During the mid to late 1980's, a series of Round Robin tests of emissions from heavyduty diesel engines were conducted under the direction of the Engine Manufacturers Association Calibration Task Force and the Coordinating Research Council Smoke and Particulate Panel. They found that the major contributor to the indeterminate errors associated with particulate measurements was the flow sample uncertainty through the secondary dilution tunnel. A sensitivity analysis was performed by modifying some components of the system, which included the secondary dilution ratio, primary flow and filter face velocity. The study showed that the particulate measurements from these Round Robin tests showed unacceptably high levels of variability for the intra- and interlab variability. 
Hall et al. (1998) proposed that particulate matter from gasoline engines as well as diesel engines might make a significant contribution to total particulate emissions. Four diesel and three gasoline vehicles were tested, using a limited fuel matrix and varied driving conditions. The testing protocol covered steady state driving conditions as well as testing over the future European legislative drive cycle. Particulate emissions were measured in terms of their mass collected on filter paper. This experimental study used a chassis dynamometer and particulate information was obtained for steady-state and legislated European cycle conditions. Gaseous emissions measurements were obtained from 3 bags for gasoline and from 2 bags for diesel. Measurements of the regulated emissions $\mathrm{CO}$, NOx and $\mathrm{HC}$ were made on diluted exhaust gas via a dilution tunnel/CVS system, using the customary methods based on IR (Infra-Red), chemiluminescence and FID (Flame Ionization Detector), respectively. Regulated particulate emission measurements were made over all MVEG (Motor Vehicle Emission Group) gasoline and diesel cycles and some gravimetric data was generated from the steady state conditions. The probes for the particulate sizing analyzers were positioned in the dilution tunnel at the same point as the probe for the regulated filter sample.

Gasoline particulate emissions were lower than those for diesel, but at high speed the number emitted were similar. More than $85 \%$ of all particulate mass were smaller than $1 \mu \mathrm{m}$. Also, particulate emissions measured from LD diesel vehicles were much higher than from LD gasoline vehicles. In mass terms, the factor was $40-85$ based on information from both steady-speed and MVEG driving cycle tests, while in number terms, it was around 200 for MVEG cycles, more than 2000 at $50 \mathrm{~km} / \mathrm{h}$, but down to around 3 at $120 \mathrm{~km} / \mathrm{h}$. Particulate emissions were lower under fully warmed-up 
conditions than for cold engines. The largest difference in particulate number emissions was apparent in gasoline versus diesel technology. No significant fuel effects were identified on the particulate number emissions.

Austin and Caretto (1998) analyze the constant volume sampling (CVS) technique as described by the Federal Test Procedure (FTP). They explain that the FTP procedure is too simplified for such a rigorous calculation. The dilution factor (DF) is only valid when the dilution air is uncontaminated and it is based on stoichiometric combustion. The DF calculation assumes that emissions are being measured without the removal of any water from the sample. This is a good assumption for the way most analytical systems are designed; however, some emissions analysis systems condense water from the sample under certain test conditions. The currently used DF calculation technique as specified by the FTP, can introduce errors in the mass emissions calculation, but the magnitude of the potential errors is small relative to the current emission standards. When used to calculate raw exhaust concentrations from dilute sample, the DF calculation procedure specified in the FTP can result in errors that are relatively larger.

Using a more rigorous derivation of the DF, the accuracy of raw exhaust concentrations calculated from dilute sample is significantly improved. The improved DF calculation procedure would also improve the accuracy of mass emission measurements. The procedure dilution factor equation presented is recommended for an accurate computation that can consider both the effects of background pollutants and nonstoichiometric combustion.

$$
D F=\frac{100-K_{1} C O_{2-b a c k}-K_{2} C O_{b a c k}-H C_{b a c k}}{K_{1}\left(C O_{2-d i l}-C O_{c-b a c k}\right)+K_{2}\left(C O_{d i l}-C O_{b a c k}\right)+H C_{d i l}-H C_{b a c k}}
$$


where $K_{1}$ and $K_{2}$ are constants for fuels that depend on whether it is dry or wet. This equation can be applied to both wet and dry analyses by appropriate choice of the fueldependent constants in the formula.

Laymac et. al. (1991) designed an aftertreatment device to meet the 1994 NOx and Total Particulate Matter (TPM) standards of $5.0 \mathrm{~g} / \mathrm{bhp}-\mathrm{hr}$ and $0.10 \mathrm{~g} / \mathrm{bhp}-\mathrm{hr}$, respectively. The diesel exhaust sampling system collected emissions using a ceramic wall-flow particulate trap during periods of controlled electric regeneration with the exhaust emissions bypassing the trap. This system provided data regarding the physical, chemical and biological character of regeneration emissions relative to baseline and trap emissions.

A 1988 Cummins L-10 300 horsepower heavy-duty diesel engine was the engine used in this study. The exhaust system was designed so the emissions could be sampled from all three operating conditions: baseline, trap and regeneration. The large dilution tunnel (DT) was used to mix exhaust with ambient air prior to measurement and sample collection. Butterfly valves were used to control the flow of exhaust into the large DT and the dilution air was controlled from the engine cell air thermostat. TPM was collected on a $508 \times 508 \mathrm{~mm}$ Teflon-coated, glass woven filter. The Electrical Aerosol Particle Size Analyzer (EAA) measured dilute exhaust particulate size distributions and concentrations based on its electrical equivalent mobility diameter. This was only effective for particle sizes ranging from $0.01 \mu \mathrm{m}$ to $1.0 \mu \mathrm{m}$. A separate regeneration DT and sampling system was designed to eliminate erroneous errors due to possible particle re-entrainment from previous baseline and trap samples or particles becoming deposited on the walls of the large DT. 
The primary difference between this system and the baseline and trap system was that all of the regeneration mass emitted from the trap enters the regeneration tunnel, while during periods of non-regeneration only a small fraction of the total exhaust enters the large DT. Total particulate matter mass emission rates from the trap were found to be two to three orders of magnitude lower than those measure at baseline or trap conditions, while peak particulate concentrations were similar to baseline and trap emission rates.

Gautam et al. (1998) investigated the uncertainty associated with in-use particulate matter measurements using a Transportable Heavy Duty Vehicle Emissions Testing Laboratory. The measurements were dependent upon the bias and random errors inherent in the measuring equipment. A sensitivity analysis revealed that the largest contributor to the uncertainty in the particulate measurements was the dilute exhaust mass flow rate. The uncertainty in the particulate matter emissions measurement was found to be less than $2 \%$. Through the sensitivity analysis, the errors associated with the pressure transducer and the critical flow venturi constant also contributed significantly to the overall uncertainty.

Some additional authors that investigated variability in particulate sampling include, but are not limited to, Abdul-Khalek (1998), Black and Doberstein (1980), Black and High (1979), Duleep (1980), Johnson (2000), Lies (1983), MacDonald et al. (1984), and Rickeard et al. (1996). 


\subsection{Experimental Setup and Procedure}

To attain the goals of this research program, the experimental setup had to be designed such that the micro-dilution tunnel could be compared to a full exhaust dilution tunnel. The micro-dilution system was placed 18 inches from its sampling port, which was located 12 inches from the engine. To the left of the micro-dilution system was a desktop computer that controlled and monitored the data acquisition system. A schematic of the experimental layout is shown in Figure 3.1.

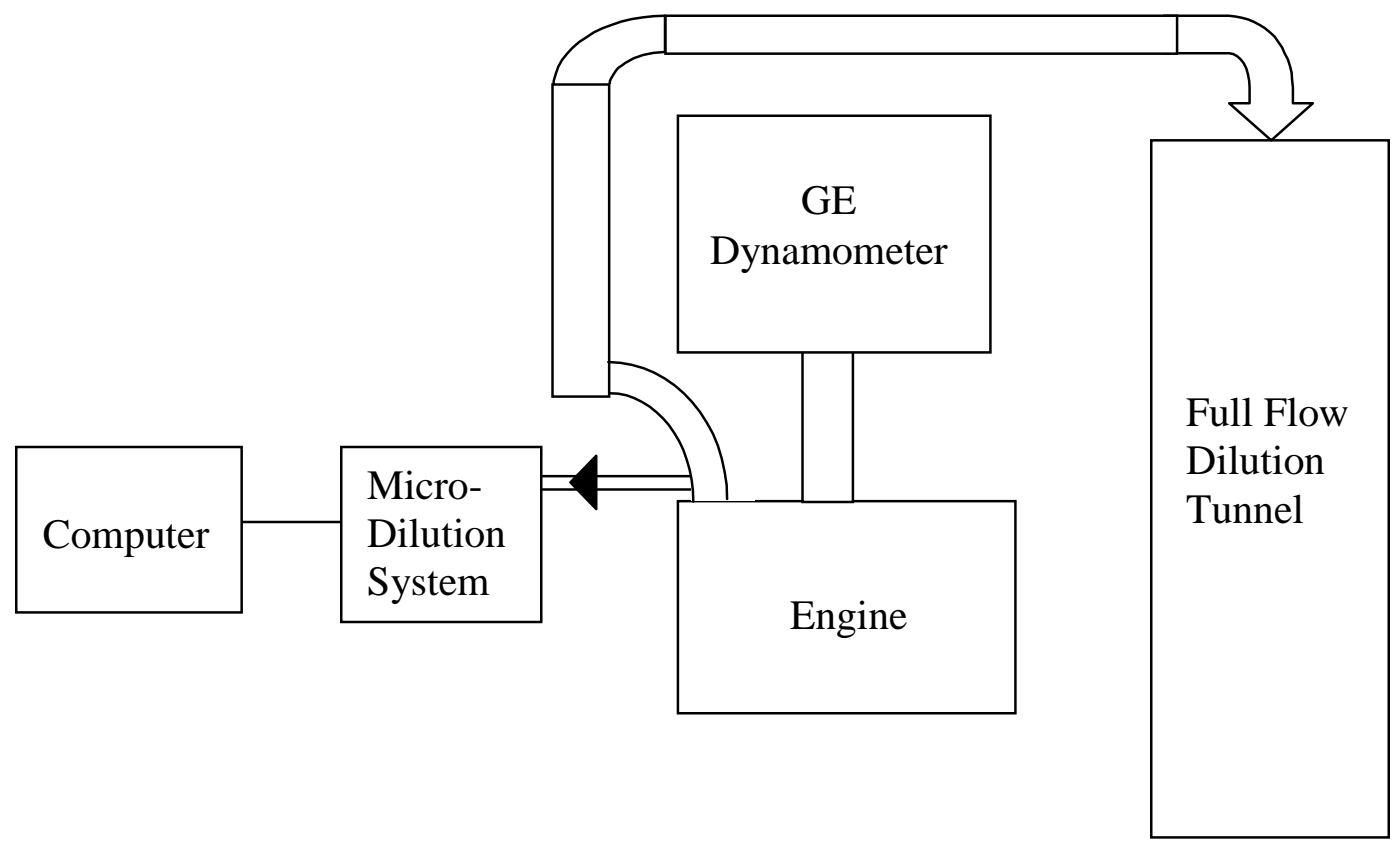

Figure 3.1 Schematic of Experimental Layout

All engine dynamometer testing for this research was conducted at West Virginia University's Engine and Emissions Research Laboratory (EERL). The engine testing equipment and emissions sampling and measurement systems in the EERL were designed in accordance to the specifications outlined in the Code of Federal Regulations Title 40, Part 86, Subpart N. This chapter describes the equipment and instruments that were used for qualification testing of the micro-dilution tunnel (Gautam et al., 1994). 


\subsection{Test Engines}

A Navistar T444E diesel engine was used for most of the testing that was performed in this study. A Detroit Diesel 60 series was also used in this study. A description each of the engines is given in the next sub-sections.

\subsubsection{Navistar T444E}

The Navistar T444E is a turbocharged, direct-injection, 90-degree eight-cylinder engine. The engine was tested using a direct current (DC) engine dynamometer. Specifications of this engine are given in Table 3.1. The Navistar T444E engine is used in trucks and school buses manufactured by the International Truck and Engine Corporation. The engine coupled to the dynamometer is shown in Figure 3.2. The Navistar T444E engine was mapped in the EERL and the actual torque and horsepower maps are presented in Figure 3.3.

\section{Table 3.1 Navistar T444E Specifications}

\begin{tabular}{|c|c|}
\hline Engine Manufacturer & International Truck and Engine Corporation \\
\hline Engine Model & T444E \\
\hline Displacement & $444 \mathrm{in}^{3}(7.3 \mathrm{l})$ \\
\hline Power Rating & $210 \mathrm{hp}(156.6 \mathrm{~kW}) @ 2300 \mathrm{rpm}$ \\
\hline Torque Rating & $520 \mathrm{ft}-1 \mathrm{~b}(705 \mathrm{~N}-\mathrm{m})$ @ $1500 \mathrm{rpm}$ \\
\hline Bore x Stroke & $4.11 \mathrm{in} \times$ 4.18 in $(10.4 \mathrm{~cm} \mathrm{x} 10.6 \mathrm{~cm})$ \\
\hline Configuration & 90 -degree 8 cylinder \\
\hline Injection & Direct \\
\hline Compression Ratio & $17.5: 1$ \\
\hline Dry Weight & $930 \mathrm{lb}(421.8 \mathrm{~kg})$ \\
\hline
\end{tabular}




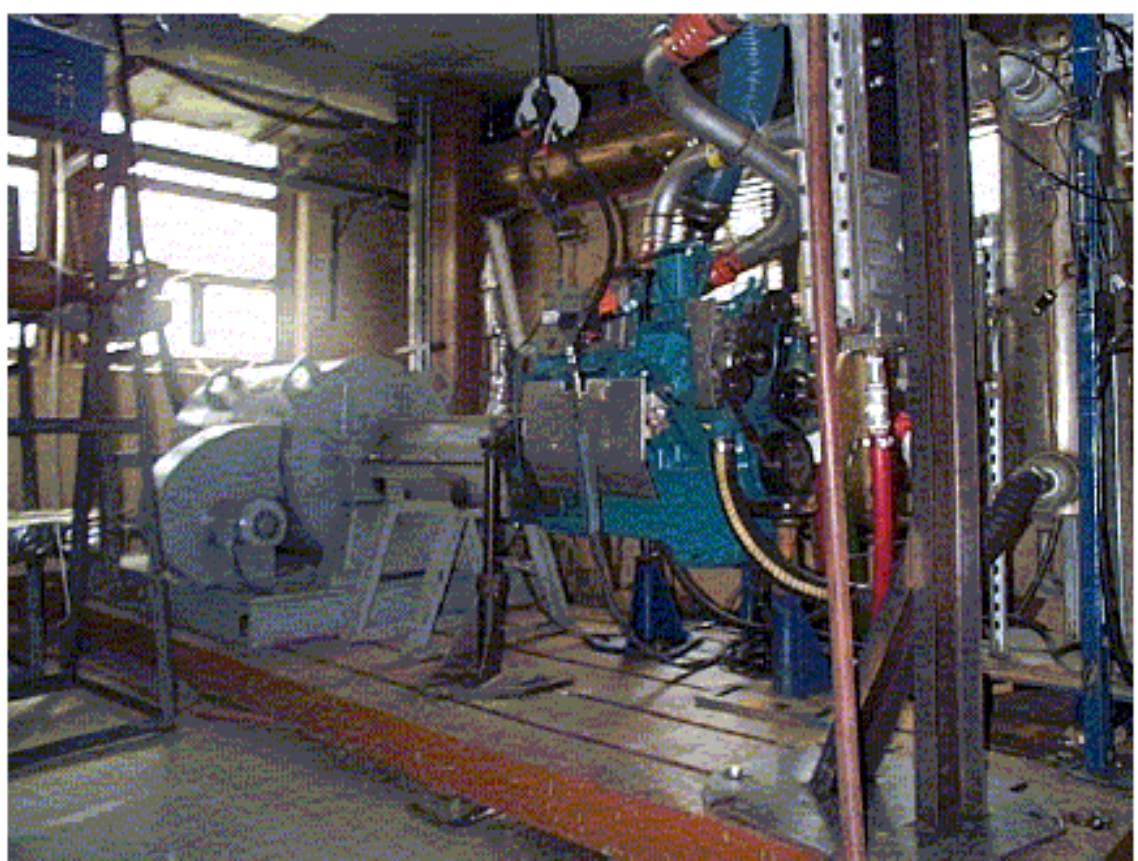

Figure 3.2 Navistar T444E coupled to GE Dynamometer at the EERL

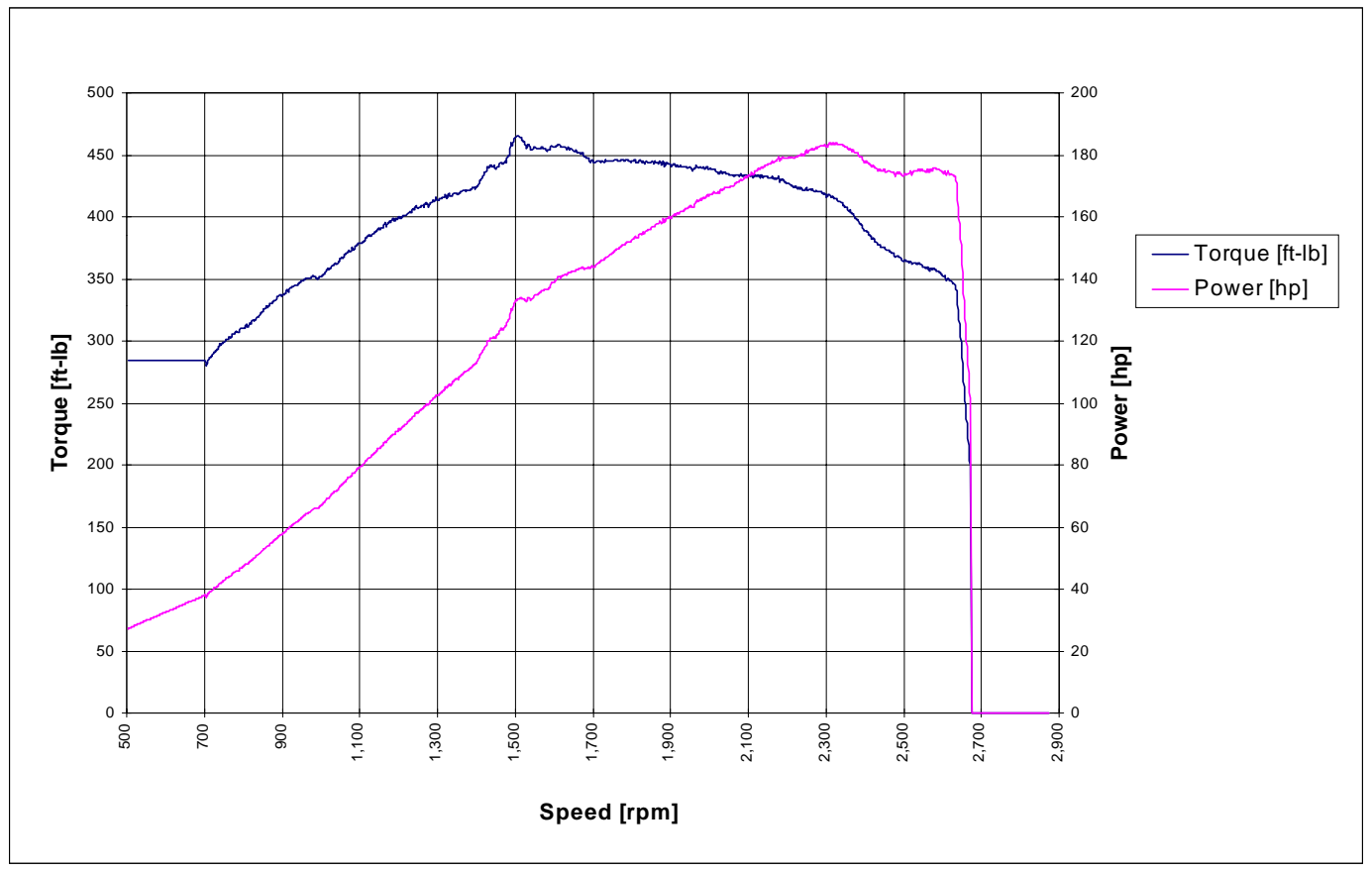

Figure 3.3 Navistar T444E Map

\subsubsection{Detroit Diesel 60 Series}

The Detroit Diesel 60 Series is a turbocharged, six-cylinder engine. The engine was tested using a direct current (DC) engine dynamometer. Specifications of this engine 
are given in Table 3.2. The engine coupled to the dynamometer is shown in Figure 3.4. The Navistar T444E engine was mapped in the EERL and the actual torque and power maps are presented in Figure 3.5.

Table 3.2 Detroit Diesel 60 Series Specifications

\begin{tabular}{|c|c|}
\hline Engine Manufacturer & Detroit Diesel \\
\hline Engine Model & 60 Series \\
\hline Displacement & $775 \mathrm{in}^{3}(12.7 \mathrm{l})$ \\
\hline Power Rating & $500 \mathrm{hp}(373 \mathrm{~kW}) @ 2100 \mathrm{rpm}$ \\
\hline Torque Rating & $1735 \mathrm{ft}-1 \mathrm{~b}(2352 \mathrm{~N}-\mathrm{m}) @ 1450 \mathrm{rpm}$ \\
\hline Bore x Stroke & $5.12 \mathrm{in} \times 6.3 \mathrm{in}(13 \mathrm{~cm} \times 16 \mathrm{~cm})$ \\
\hline Configuration & 6 cylinder \\
\hline Compression Ratio & $16.5: 1$ \\
\hline
\end{tabular}

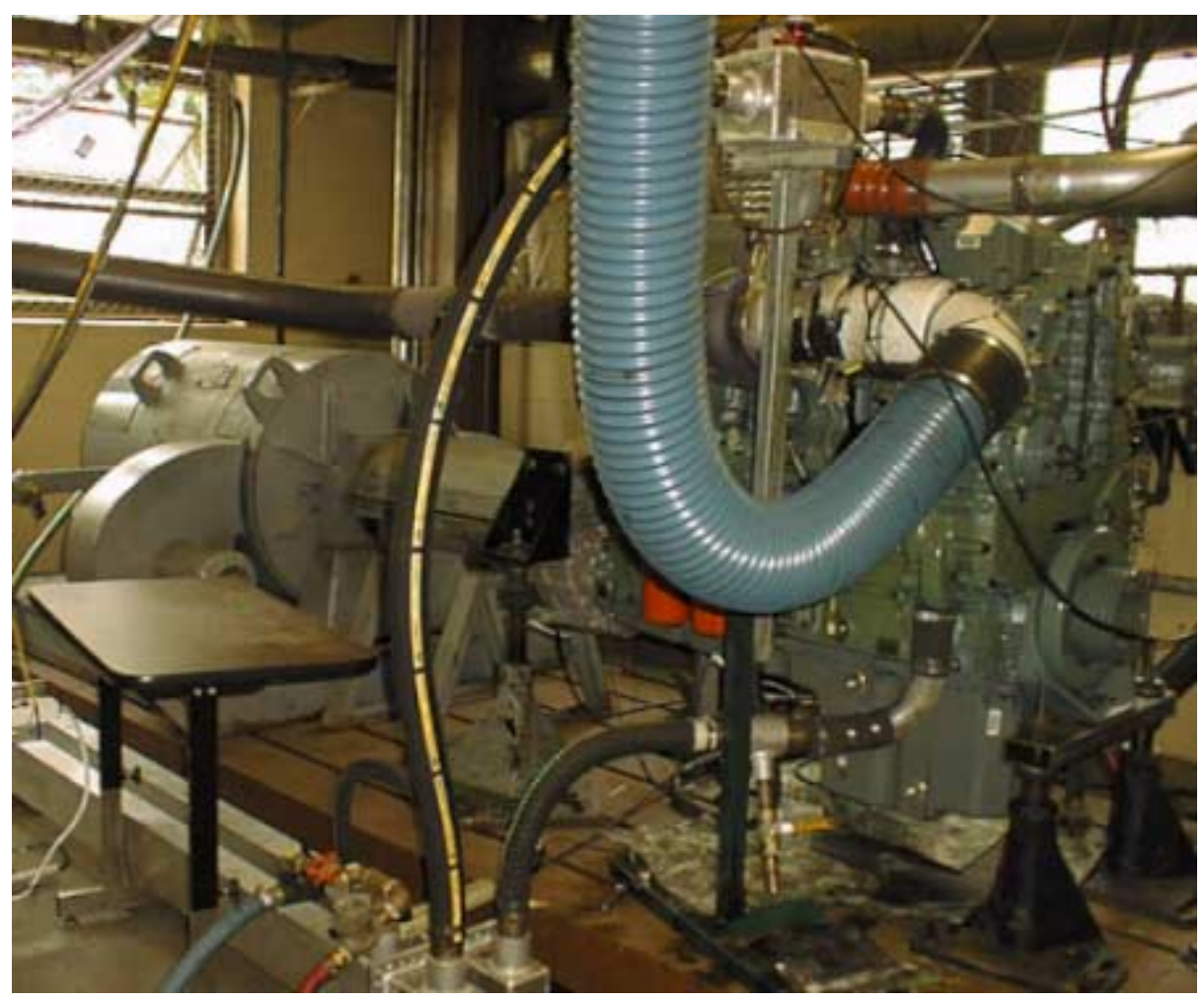

Figure 3.4 Detroit Diesel Series 60 coupled to GE Dynomometer at the EERL 


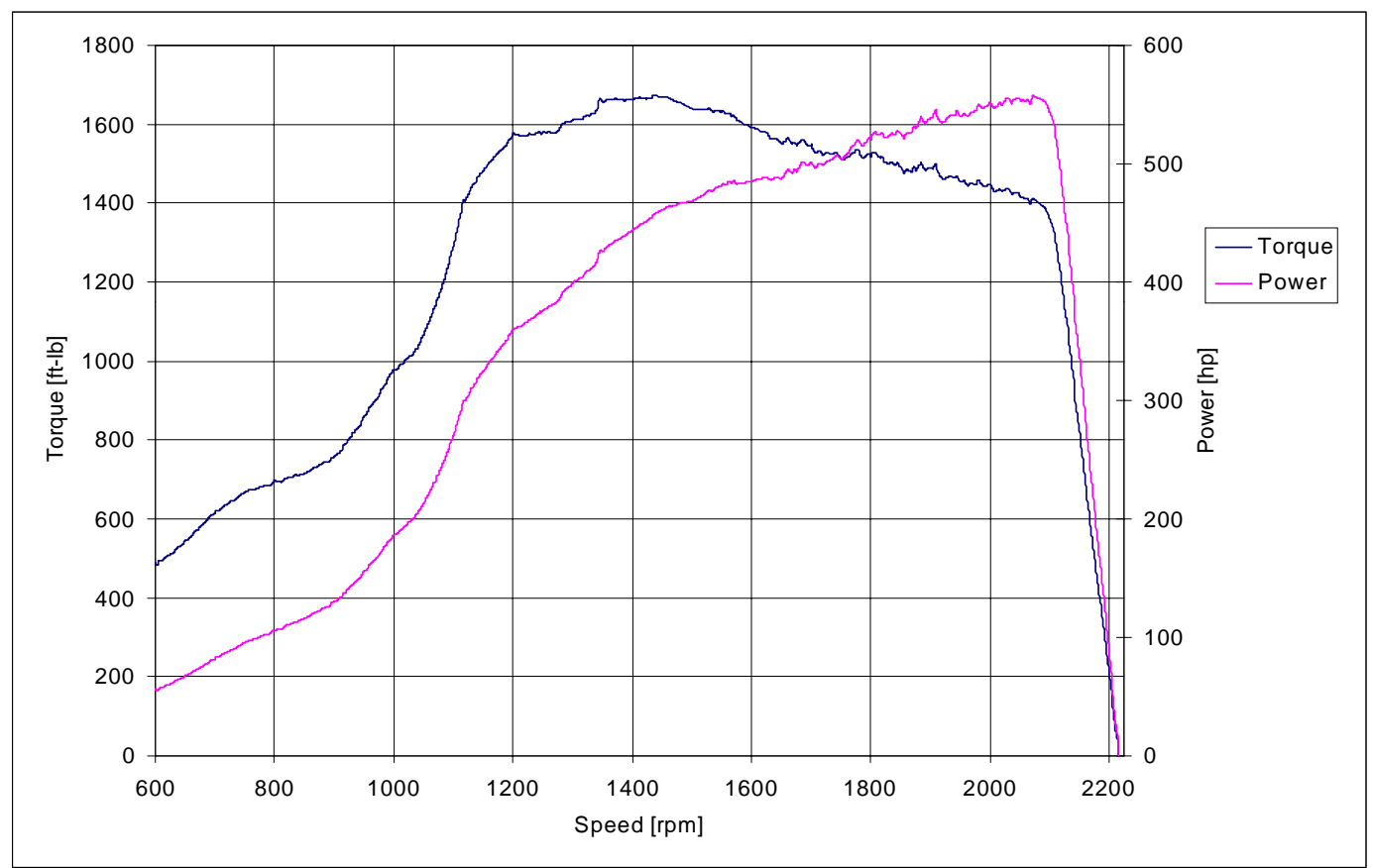

Figure 3.5 Detroit Diesel 60 Series Map

\subsection{Engine Dynamometer}

An engine dynamometer applies a load to the engine during emissions testing to simulate the load applied to the engine when it is operating in the vehicle. The engine dynamometer at the WVU EERL used for this testing was a General Electric (GE) DYC 243 air cooled, direct current (DC) dynamometer. This dynamometer is capable of absorbing up to $550 \mathrm{hp}$ and providing $500 \mathrm{hp}$ when motoring the engine. Torque is measured using a load cell, attached to an arm of known length, that measures force. Engine speed is determined via a digital encoder inside of the dynamometer. A driveshaft and a bonded-rubber coupling link the dynamometer directly to the flywheel of the engine.

\subsection{Air and Fuel Flow Metering}

In order to calculate the engine exhaust flow it was necessary to obtain accurate fuel and air flow measurements. The EERL uses a Max Machinery, Inc. Max Model 710 
fuel conditioning system to meter fuel and a Meriam Instruments laminar flow element (LFE) Model 50MC2-6 to measure intake air. This section will describe both of these metering devices.

The fuel metering system is comprised of a filter, vapor eliminator, level controller, flow meter, heat exchanger, two pumps, two regulators, pressure relief valves, several pressure gauges and a thermocouple. A transfer pump draws fuel from the tank and supplies it to the vapor eliminator and flow meter at a steady pressure controlled by a 20 psi pressure regulator. A K-type thermocouple measures the temperature of the fuel for mass flow calculations. Excess fuel that is not sent to the flow meters is routed through a heat exchanger to provide cooling for engine return fuel and then is sent back to the fuel tank. Fuel from the flow meter is combined with cooled return fuel from the engine in the level controller where a second pump can be activated to provide adequate supply pressure for fuel injection systems. This system interfaces with the data acquisition computer of the lab to obtain accurate fuel measurements.

To obtain the intake air flow rate, a Meriam Instruments LFE was used. The differential pressure across the element, absolute pressure and temperature of the air at the inlet, were measured and related to the flow. The inlet pressure was adjusted with a butterfly valve placed upstream of the LFE. A remote butterfly valve was placed in the

exhaust piping close to the engine to adjust exhaust backpressure to the engine manufacturer's specifications.

\subsection{Full-Flow Dilution Tunnel System}

The Environmental Protection Agency (EPA) Federal Test Procedures (FTP) transient test requires the use of full-flow dilution tunnel to measure heavy-duty diesel 
exhaust emissions (CFR 40, 1997). The micro-dilution tunnel system was compared to the EERL full-flow dilution tunnel based heavy-duty engine test facility. The main components of the EERL full-flow dilution tunnel system are the full-flow dilution tunnel, secondary dilution tunnel, critical flow venturi (CFV), bag sampling systems, gaseous sampling system, and particulate sampling system. The following is a detailed description of the components installed in the WVU's EERL.

\subsubsection{Full-Flow Dilution Tunnel}

The purpose of a dilution tunnel is to dilute an engine's raw exhaust gas with ambient air not only to simulate the effect of exhaust emissions under real world conditions, but also to aid in the emissions sampling process. As the exhaust leaves the engine's manifold or tailpipe it is immediately diluted with a nearly infinite quantity of ambient air. The temperature of the exhaust gas is also reduced to nearly that of the dilution air. It is necessary to simulate these real world conditions using a dilution tunnel to determine how diluted exhaust affects the health of humans. Diluting the raw exhaust with air also lowers the dew point temperature, which in turn prevents water condensation. Water removal is very important in emissions testing, as it can interfere in the output readings of some of analyzers, such as NDIR, and result in the loss of certain exhaust constituents, such as $\mathrm{NO}_{2}$ and certain components that constitute particulate matter (PM).

The stainless steel dilution tunnel at the EERL is $15 \mathrm{ft}(4.57 \mathrm{~m})$ in length from the point of exhaust injection into the dilution tunnel to the sampling zone, with a diameter of 18 inches $(0.46 \mathrm{~m})$. The exhaust is directed to the center of the dilution tunnel which is pulled through the tunnel by a $75 \mathrm{hp}(55.93 \mathrm{~kW})$ blower. There are four critical flow 
venturis available to provide constant volume sampling ranging from 400 to $3400 \mathrm{scfm}$ $\left(11.33 \mathrm{~m}^{3} / \mathrm{min}\right.$ to $\left.96.28 \mathrm{~m}^{3} / \mathrm{min}\right)$. A 10 in $(0.25 \mathrm{~m})$ mixing orifice is installed at the location where exhaust is introduced into the tunnel. A 0.75 in $(1.9 \mathrm{~mm})$ probe draws a sample into the secondary tunnel for particulate sampling. This configuration complies with the requirements set forth in CFR 40, Part 86, Subpart N.

\subsubsection{Secondary Dilution Tunnel}

The secondary dilution tunnel is used to further dilute the diluted exhaust from the main tunnel, if necessary. A pump draws the sample through the secondary tunnel and across a set of filters for particulate analysis. The secondary dilution tunnel is constructed of 304 stainless steel with a sample residence time greater than 0.25 seconds which meets the criteria specified in the CFR 40, Part 86, subpart N.

\subsubsection{Critical Flow Venturi}

The EERL uses critical flow venturis to maintain a constant total flow rate. This laboratory contains four venturis, three of which are designed for a flow rate of 1000 scfm and the other for $400 \mathrm{scfm}$. The minimum flow rate for diluted exhaust is 1000 scfm and the maximum flow rate is $2400 \mathrm{scfm}$. The higher flow rates of 3000 and 3400 scfm cannot be achieved due to blower limitations. The mass flow through the venturi can be calculated using Equation 3.1.

$$
\dot{Q}=K_{v} \frac{P}{\sqrt{T}}
$$

where $\mathrm{Q}$ is the mass flow rate in scfm, $\mathrm{K}_{\mathrm{v}}$ is the calibration coefficient, $\mathrm{P}$ is the absolute pressure at the inlet of the venturi in $\mathrm{kPa}$ and $\mathrm{T}$ is the absolute temperature of the gas a the inlet of the venturi in $\mathrm{K}$. The temperature is measured with a 3-wire resistance temperature detector (RTD) and the pressure is measured with a Viatran absolute 
pressure transducer. A differential pressure gauge is used to ensure that the venturi is operating under sonic conditions.

\subsubsection{Bag Sampling}

There are individual dilute exhaust sample bags for each of the four phases of the FTP Test D. The dilute exhaust is sampled into Tedlar bags to obtain modal and integrated concentrations of gaseous emissions for the entire test. A background bag is used to measure the integrated value of exhaust constituents in the dilution air entering the main tunnel. Background bag samples are collected in $80 \mathrm{~L}$ Tedlar bags at EERL. The bags are analyzed using the same emissions analyzers described in Section 3.5, and then evacuated. Background measurements are subtracted from the exhaust measurements to account for exhaust constituents present in the ambient dilution air.

\subsubsection{Particulate Matter Measu rement}

Fluorocarbon coated glass fiber filters, T60A20 70-mm filters made by Pall Gelman Sciences were used to collect PM during the testing. Two filters were placed in series at the bottom of the secondary tunnel attached to the primary dilution tunnel. This secondary dilution tunnel is used to control the temperature of the sample at the filter face by further diluting the exhaust sample. The CFR 40 requires that the temperature at the filter face may not exceed $125^{\circ} \mathrm{F}$. Dilution air was used when necessary in the secondary tunnel to decrease the temperature of the gas sample flowing through the filter during steady-state test cycles. Secondary dilution was generally not needed during transient test cycles. The filter face velocities of $70-\mathrm{mm}$ filters with an effective filtration area of $28.27 \mathrm{~cm}^{2}$ are presented in Table 3.3 . 
Table 3.3 Filter Face Velocities (70-mm)

\begin{tabular}{|c|c|c|}
\hline $\begin{array}{c}\text { Flow Rate } \\
{[\mathrm{scfm}]}\end{array}$ & $\begin{array}{c}\text { Flow Rate } \\
{\left[\mathrm{m}^{3} / \mathrm{min}\right]}\end{array}$ & $\begin{array}{c}\text { Filter Face Velocity } \\
{[\mathrm{cm} / \mathrm{s}]}\end{array}$ \\
\hline 3 & 0.085 & 50.08 \\
\hline 3.25 & 0.092 & 54.26 \\
\hline 3.5 & 0.099 & 58.43 \\
\hline 3.75 & 0.106 & 62.60 \\
\hline 4 & 0.113 & 66.78 \\
\hline 4.25 & 0.120 & 70.95 \\
\hline 4.5 & 0.127 & 75.12 \\
\hline 4.75 & 0.135 & 79.30 \\
\hline 5 & 0.142 & 83.47 \\
\hline
\end{tabular}

The PM filters were conditioned in a Thermotron SM-80 chamber at $45 \%( \pm 8 \%)$ humidity and $22^{\circ} \mathrm{C}\left( \pm 3^{\circ} \mathrm{C}\right)$ for at least four hours before each test. Once conditioned, the filter's weight was determined with a Cahn C-32 microbalance $( \pm 1 \mu \mathrm{g})$ and the filters were placed in filter holders for testing. After the emissions test, the filters were placed back into the conditioning chamber and reconditioned for at least eight hours prior to measuring the post test weight. A background filter, a PM filter that collects PM only from the tunnel without the engine running. This was taken at the end of each testing day. The background filter weight was subtracted from the test filter weights to yield PM produced by the engine during the cycle.

\subsubsection{Emissions Measurement}

Research grade gaseous emissions analyzers for $\mathrm{HC}, \mathrm{CO}, \mathrm{NO}_{\mathrm{x}}$, and $\mathrm{CO}_{2}$ were used in conjunction with a full-scale dilution tunnel, which was described previously. Analyzers were calibrated at the beginning of each set of tests, test series, as well as zeroed and spanned daily. "Zeroing" analyzers entails passing a known gas that contains no chemical species that the instruments detects through the analyzers and setting the output of the analyzer to zero. Analyzers were spanned in the same way except that the 
instrument detects the span gas, which represents the maximum concentration that the analyzer can detect for the current calibration, and the output is set to $100 \%$.

\subsubsection{Instrumentation Control and Data Acquisition}

Correlation of the EERL full-flow tunnel to the micro-dilution tunnel required measurement of a variety of different parameters so that comparisons could be made between the two systems. These parameters include engine fuel and air consumption rates, dilution ratios, and filter face temperature. For steady state testing, these parameters remained relatively constant and the total values of some parameters such as the fuel flow rates would be acquired and averaged across the entire test while other values such as filter face temperature could be periodically sampled and data logged. During transient tests, the parameters would constantly change as the engine speed and torque set points varied.

The laboratory data collected in this experiment was obtained using the software and data acquisition hardware of the EERL. The data was collected using a signal conditioning backplane with Analog Devices 3B system modules and RTI-815 analog-todigital converter data acquisition boards housed inside of the computer. The data was recorded in ADC code and it was later reduced using in-house software to convert it into engineering units.

\subsection{Exhaust Gas Analyzers}

The gaseous sampling system at the WVU EERL consisted of heated sampling probes, heated sampling lines, heated pumps, heated filters, a water-removing device and gas analyzers. Three stainless steel sampling probes are placed in the dilution tunnel to sample a portion of the diluted exhaust. $\mathrm{HC}, \mathrm{NO}_{\mathrm{x}}$, and $\mathrm{CO} / \mathrm{CO}_{2}$ each have their own 
probe. Heated lines transfer the sample to the analyzers via heated pumps. Line temperatures are held constant by temperature controllers at $375^{\circ} \mathrm{F}$ and $235^{\circ} \mathrm{F}$ for $\mathrm{HC}$ and $\mathrm{CO} / \mathrm{CO}_{2}$, respectively and heated heat pumps were also held constant by temperature controllers. The $\mathrm{CO} / \mathrm{CO}_{2}$ sample is pumped through a Hankinson compressed air-dryer to further remove moisture from the sample.

The emissions analyzer bench at the WVU EERL contains analyzers manufactured by Rosemount Analytical, Inc. and the bench is shown in Figure 3.6. It is capable of measuring $\mathrm{HC}, \mathrm{CO}, \mathrm{CO}_{2}, \mathrm{NO}_{\mathrm{x}}, \mathrm{SO}_{\mathrm{x}}$, and $\mathrm{O}_{2}$. A Rosemount $\mathrm{NO}_{\mathrm{x}}$ efficiency tester Model 958 was used to test the $\mathrm{NO}_{\mathrm{x}}$ analyzer converter efficiency. The sections that follow will briefly describe the specifications and operation of each of the analyzers. The reference manuals supplied by the manufacturer give a more detailed description of the operation and instrument theory.

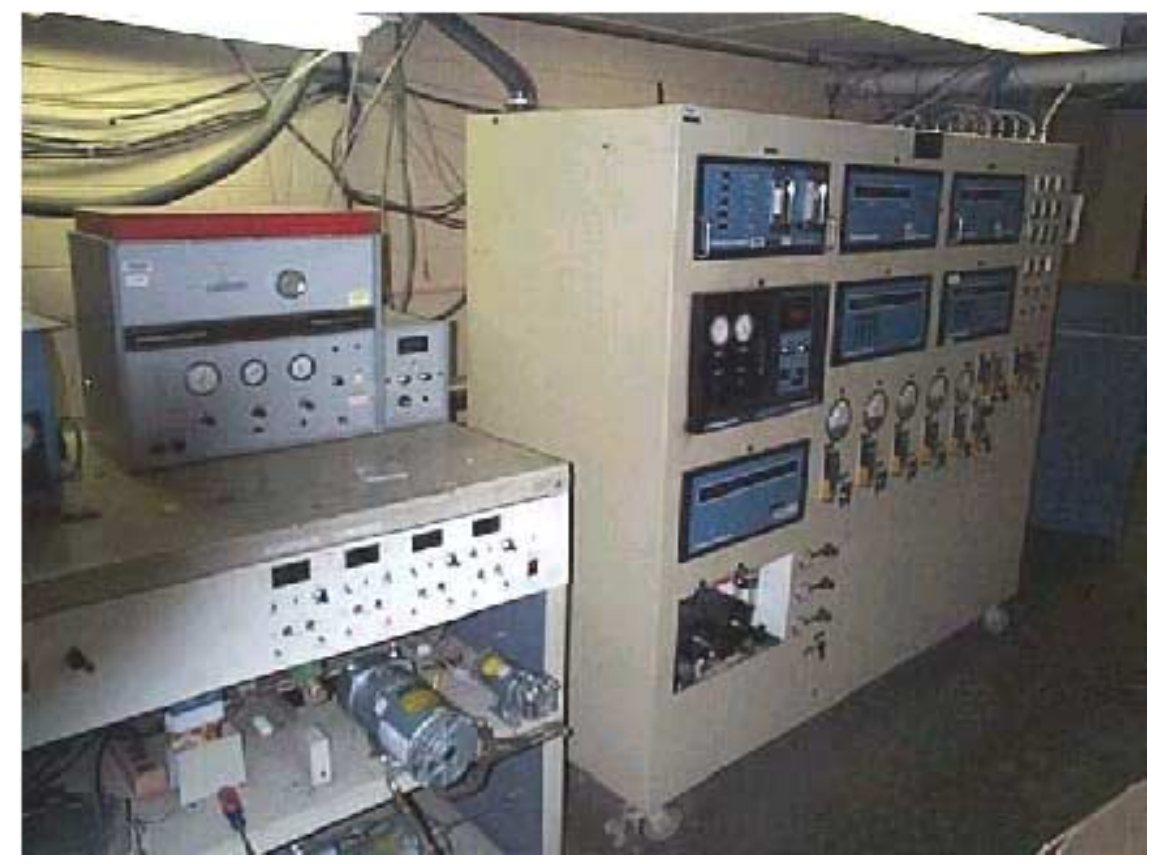

Figure 3.6 EERL Analyzer Bench 


\subsubsection{Hydrocarbon Analyzer}

A Rosemount Model 402 Heated Flame Ionization Detector measures the hydrocarbon (HC) concentration of the engine exhaust. A flame ionization detector operates on the principle of using polarized electrodes to collect positive ions. A regulated flow of the sample gas is introduced to the instrument. The sample then passes through a flame maintained by hydrogen/diluent fuel. As the sample passes through the flame, the hydrocarbons in it go through an ionization process in which electrons and positive ions are produced. Electrons go to the anode and the positive ions go to the cathode. The equations below show the ionization process.

$$
\begin{gathered}
\mathrm{CH}+\mathrm{O} \rightarrow \mathrm{CHO}^{+}+e^{-} \\
\stackrel{\mathrm{CHO}^{+}}{+}+\mathrm{H}_{2} \mathrm{O} \rightarrow \mathrm{H}_{3} \mathrm{O}^{+}+\mathrm{CO} \\
\mathrm{H}_{3} \mathrm{O}^{+}+e^{+} \rightarrow \mathrm{H}_{2} \mathrm{O}+\mathrm{H}
\end{gathered}
$$

A small ionization current, which is proportional to the concentration of carbon atoms in the sample, passed between the two electrodes. This current is measured by electronic circuitry to determine the $\mathrm{HC}$ concentration in the sample. The Model 402 measures concentrations up to $250,000 \mathrm{ppm}$. A multiplier switch is located on the front of the analyzer to obtain measurement with the best solution (Rosemount, 1991).

\subsubsection{Oxides of Nitrogen Analyzer}

A Rosemount Model 955 heated chemiluminescent analyzer is used to measure the concentration of any oxides of nitrogen $\left(\mathrm{NO}_{\mathrm{x}}\right)$ in the diluted exhaust. This analyzer is capable of measuring $\mathrm{NO}$ or total $\mathrm{NO}_{\mathrm{x}}$, by either bypassing or utilizing its internal converter. Chemiluminescence results when light is a product in a chemical reaction. 
The Model 955 measures nitric oxide concentrations by determining the chemiluminescent radiation over a small region of the total emission through the use of a bandpass filter and photomultiplier. Ozone $\left(\mathrm{O}_{3}\right)$ is generated by the ultraviolet irradiation of oxygen in a quartz tube. Excess $\mathrm{O}_{3}$ is present to ensure complete reaction and to minimize quenching effects. The sample pressure and flow rate must be carefully monitored, as the photomultiplier is proportional to the number of $\mathrm{NO}$ molecules in the sample, rather than the concentration of NO in the sample. The equations below show this process.

$$
\begin{aligned}
& \mathrm{NO}_{2}+\text { catalyst } \rightarrow \mathrm{NO}+\mathrm{O} \\
& \mathrm{NO}+\mathrm{O}_{3} \rightarrow \mathrm{NO}_{2}+\mathrm{O}_{2}+h v
\end{aligned}
$$

A problem with chemiluminescent detection is that is does not detect nitrogen dioxide $\left(\mathrm{NO}_{2}\right)$, as it does not undergo the same reaction with $\mathrm{O}_{3}$ as NO. A second problem with the analyzer is that a chemiluminescent detection scheme does not report high concentrations accurately during highly transient engine events. The Model 955 analyzer can measure $\mathrm{NO}_{\mathrm{x}}$ concentrations in full-scale ranges of 10, 25, 100, 250, 1000, 2500, and 10000 ppm (Rosemount, 1992).

\subsubsection{Carbon Dioxide Analyzer}

A Rosemount Model 868 NDIR analyzer is used to measure the amount of carbon dioxide $\left(\mathrm{CO}_{2}\right)$ present in the sample. This NDIR detector is a spectrophotometer, which uses a filter to measure light absorption over a small range of wavelengths. Different gases absorb different bands of infrared light, with some of those gases overlapping small regions. The detection mechanism consists of a light source, a filter, two cells, and a detector. The gas sample enters the sample cell, where infrared light is passed through it 
and infrared light is passed through the reference cell, which contains nitrogen or some other gas that does not absorb light at the wavelength used in the analyzer. The gas under observation will absorb some of the light in the sample cell, reducing the amount of energy in the light. A detector measures the energy difference between the light exiting the reference cell and the light exiting the sample cell. The ratio of the detector cells can then be related to the gas concentrations in the sample cell. This analyzer is capable of measuring $\mathrm{CO}_{2}$ in ranges of $0-5 \%$ and $0-20 \%$ (Rosemount, 1991).

\subsubsection{Carbon Monoxide Analyzer}

A Rosemount Model 880A NDIR analyzer is used to determine carbon monoxide (CO) concentrations. This analyzer is a newer model of 868 discussed in the previous section. The analyzer bench has two $\mathrm{CO}$ analyzers, one for high $\mathrm{CO}$ concentrations and one for low concentrations. The high $\mathrm{CO}$ analyzer has ranges of $0-2 \%$ and $0-10 \%$, while the low CO analyzer has ranges of 0 - 1000 ppm and 0 - 5000 ppm.

\subsection{Micro-Dilution System}

The main objective of this research effort was to design, develop, and test a micro-dilution tunnel. Primary design constraints were:

1. Compact and portable system

2. Dilution ratios that meet ISO 8178 requirements

3. Sample flow rates that will permit up to two hours of sampling. Sampling durations of two hours would cover most on-board on-road in-use emissions investigations.

The micro-dilution tunnel system consisted of five main components: dilution tunnel, mass flow controllers, data acquisition, filters, and a pump. The system was 
designed to maintain a constant dilution ratio of 4 to 1 based on flow rates. This system can be used in steady state or transient cycles.

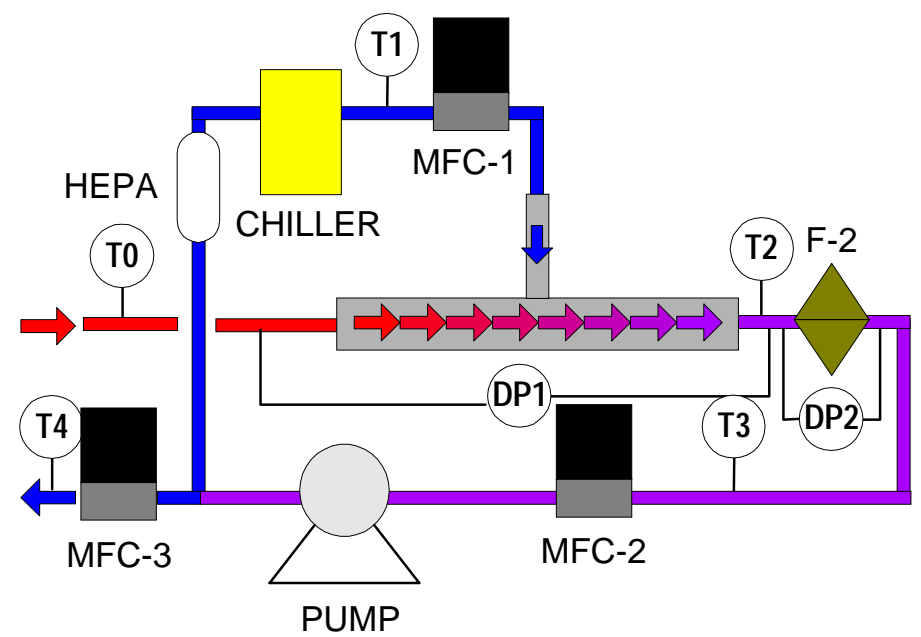

\section{Figure 3.7 Block Diagram of Micro-Dilution System Using One Pump}

Figure 3.7 shows the process of the micro-dilution system using recirculated dilution air. This system operates by drawing raw exhaust from the engine's exhaust stack into the micro-dilution system through a heated line maintained at $160^{\circ} \mathrm{F}$. The raw exhaust sample is diluted with dry, filtered air and metered with a mass flow controller. The diluted exhaust is drawn across a filter and particulate matter is collected for gravimetric analysis. A mass flow controller located downstream of the PM sample filter meters the diluted exhaust flow rate. After the diluted exhaust passes through the PM filter, any remaining particles are captured in the High Efficiency Particulate Air (HEPA) filter. The filtered exhaust is then recirculated into the system and is then used as dilution air. Then, the flow passes through a chiller that removes any moisture and long chain hydrocarbons in the recirculated air. The cleaned air now enters the mass flow controller and dilutes the raw exhaust. The third MFC is used to bleed air out of the system. This last MFC proves that the subtraction of the two large numbers (MFC2 - MFC1) is 
approximately equal to the air that is bled out. The following sections will describe each of the components of the micro-dilution system in detail.

\subsubsection{Heated Line}

A heated line was used to reduce any cooling effects of diesel exhaust because condensation of vapor phase organics and semivolitale components can affect hydrocarbon and particulate mass emission measurements. Also, particle migration towards a tube wall can occur due to thermophoresis. Goren (1977), Walker et al. (1979), Epstein et al. (1985), and Kittleson and Johnson (1991) all have investigated thermophoresis and the thermophoretic deposition of particles as it pertains to particulate losses and reentrainment in diesel engine emissions testing. Thermophoresis occurs when micron and sub-micron particles are transported from the exhaust flow to the transfer tube wall due to the temperature gradient which exists as a result of the cooling of the transfer tube. Once the particles contact the wall, they do not have enough kinetic energy to return to the exhaust flow, thereby becoming attached to the wall, and then later becoming randomly reentrained into the exhaust flow.

\subsubsection{Micro-Dilution Tunnel}

An exhaust dilution tunnel system is designed to dilute the exhaust from an engine with filter and dry air. The dilute exhaust is then sampled to determine the mass emission rates of the pollutants. The dilution tunnel, used in this study, consists of a porous length of 6 in $(15.24 \mathrm{~cm})$ with a 0.5 micron grade and overall length of 10 in (25.4 $\mathrm{cm})$. The tunnel used in this study is a gas sampler that was designed to remove particles from the sample stream. The porous tube sampler, Model 7610, is commercially available from Mott Corporation. This sampler will be referred to as the dilution tunnel 
in this report. There are two entrances to the 316 stainless steel dilution tunnel, one used for the raw exhaust and the other for the dilution air. The raw exhaust sample entered the tunnel axially. The clean air entrance has an outer diameter of 0.25 in $(6.35 \mathrm{~mm})$ with an inner diameter of 0.125 in $(3.175 \mathrm{~mm})$. The raw exhaust entrance has a 0.5 in $(12.7 \mathrm{~mm})$ outer diameter with an inner diameter of 0.25 in $(6.35 \mathrm{~mm})$. In order for the flow to be fully developed, the tunnel must be at least ten diameters in length. The minimal length in order to achieve fully developed flow would be 2.5 inches, which is exceeded greatly by the tunnel's length of 10 inches. Figure 3.9 shows an internal view of the dilution tube. Figure 3.8 shows the dilution tunnel developed by Mott Corporation.

Model 7610 features a cross-flow design which keeps most particles in the gas stream. As a result, the tunnel can operate without clogging for great lengths of time, even when used with highly contaminated gas streams. It can also be used in high pressure applications with differential pressures well in excess of $1000 \mathrm{psig}$.

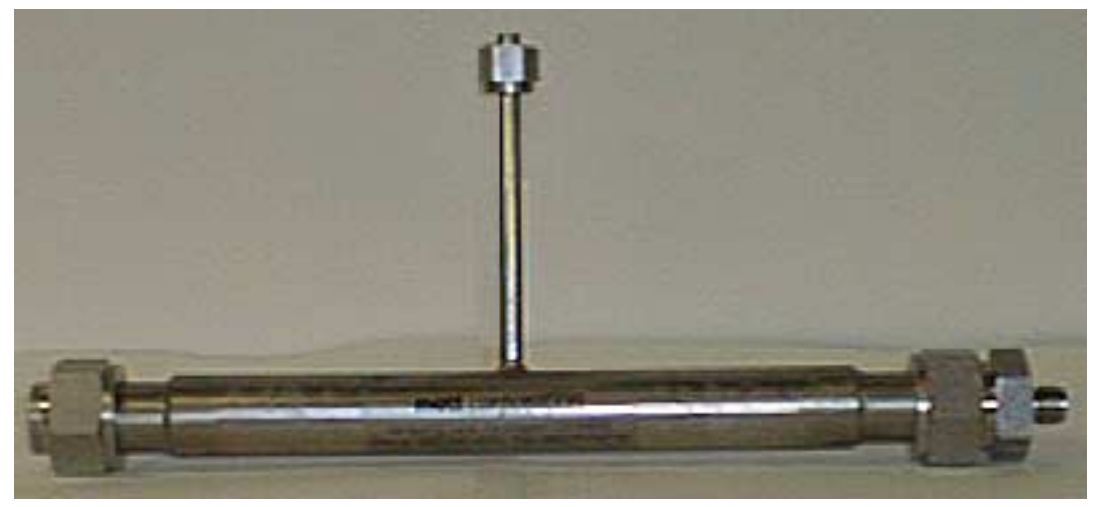

Figure 3.8 Micro-Dilution Tunnel (Model 7610) 


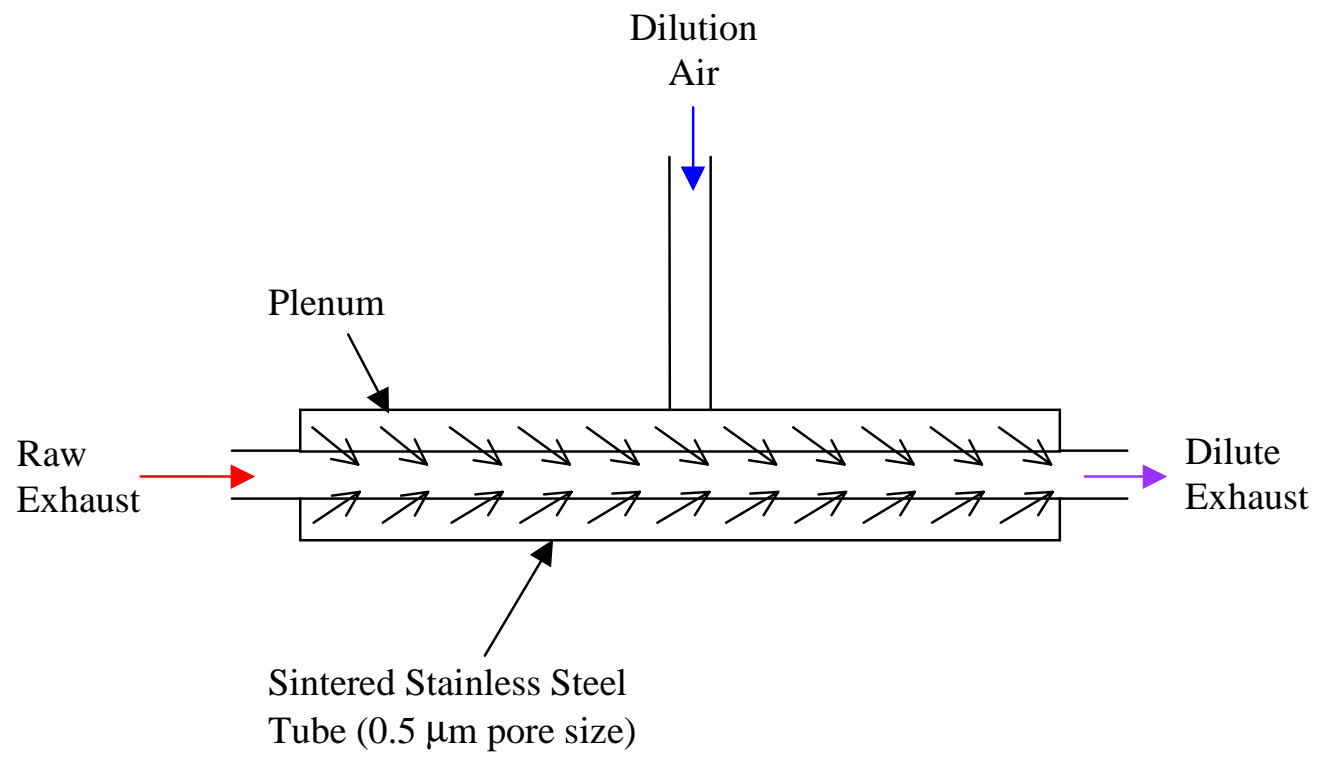

\section{Figure 3.9 Internal View of Dilution Tube}

After the raw exhaust enters the dilution tunnel, it is then diluted with the clean air entering from the port that is located on the body, thus producing diluted exhaust. The dilution air radially enters the centrally located porous tube. The pressure drop across the porous tube ensures a uniform distribution of air into the tunnel. The Reynolds number for the mass flow rate entering the dilution tube equated to 10,200 , which indicated turbulent flow.

\subsubsection{Mass Flow Controllers}

In the micro-dilution setup, three mass flow controllers (MFCs) were employed. The Sierra 840 was used to control the dilution air, the Sierra 840 Sidetrak was used to control the diluted exhaust and the Fathom Technologies GR Series was used to control the flow rate of air that was bled off from the system. Each MFC had at least ten diameters of tube length before and at least five diameters after the MFC to ensure uniform flows and thus, minimize errors in flow rate control. 


\subsubsection{Sierra 840 Series Mass Flow Controllers}

The Sierra 840's were calibrated, by Rule Products, for $0-15 \mathrm{lpm}$, and 0 - $5 \mathrm{lpm}$ to $0-10 \mathrm{lpm}$ each for air. Their orifices of $0.04 \mathrm{in}(1.016 \mathrm{~mm})$ diameter, and their pressure range of $0-250$ psi remained unchanged. The 316 stainless steel and NIST traceable Sierra 840 Series were controlled by an electromagnetic valve. Table 3.4 shows the calculation of their orifices after being calibrated.

Table 3.4 Calculated Orifice Size For Sierra's 840 Series Models

\begin{tabular}{|c|c|c|c|c|c|c|}
\hline \multicolumn{3}{|l|}{ CONSTANTS } & & & & \\
\hline Density = & 1.23 & {$\left[\mathrm{~kg} / \mathrm{m}^{3}\right]$} & & & & \\
\hline $\mathrm{Pi}=$ & 3.141593 & & & & & \\
\hline Radius $=$ & $3.81 \mathrm{E}-03$ & {$[\mathrm{~m}]$} & & & & \\
\hline Upstream Area $=$ & 4.56E-05 & {$\left[\mathrm{m}^{2}\right]$} & & & & \\
\hline \multicolumn{7}{|l|}{ VARIABLES } \\
\hline $\begin{array}{c}\text { Volumetric } \\
\text { Flowrate } \\
\text { [slpm] }\end{array}$ & $\begin{array}{c}\text { Volumetric } \\
\text { Flowrate } \\
{\left[\mathrm{m}^{3} / \mathrm{s}\right]}\end{array}$ & $\begin{array}{c}\text { Differential } \\
\text { Pressure } \\
\text { [psi] }\end{array}$ & $\begin{array}{c}\text { Differential } \\
\text { Pressure } \\
{[\mathrm{Pa}]} \\
\end{array}$ & $\begin{array}{c}\text { Downstream } \\
\text { Area } \\
{\left[\mathrm{m}^{\angle}\right]} \\
\end{array}$ & $\begin{array}{c}\text { Orifice } \\
\text { Radius } \\
{[\mathrm{m}]}\end{array}$ & $\begin{array}{c}\text { Orifice } \\
\text { Radius } \\
\text { [in] }\end{array}$ \\
\hline 5.7 & $9.50 \mathrm{E}-05$ & 1.02 & 7032.65 & $8.88 \mathrm{E}-07$ & $5.32 \mathrm{E}-04$ & 0.02 \\
\hline 6.1 & $1.02 \mathrm{E}-04$ & 0.82 & 5653.7 & $1.06 \mathrm{E}-06$ & $5.81 \mathrm{E}-04$ & 0.02 \\
\hline Notes: & & & Iny & carro & & \\
\hline
\end{tabular}

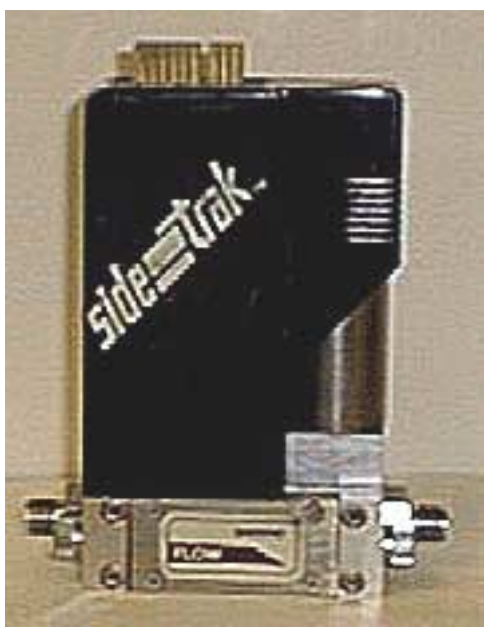

Figure 3.10 Sierra's 840 Series Model 


\section{Table 3.5 Sierra's 840 Series Model Setup}

\begin{tabular}{|r|c|c|c|}
\hline & 1 & A & SET \\
\hline GRD & 2 & B & \\
\hline ANALOG INPUT & 3 & C & \\
\hline 15 V DC & 4 & D & \\
\hline & 5 & E & \\
\hline & 6 & F & -15 V DC \\
\hline & 7 & G & \\
\hline GRD & 8 & H & \\
\hline & 9 & I & \\
\hline & 10 & J & \\
\hline
\end{tabular}

Figure 3.10 is a picture of the Sierra 840 Series and Table 3.5 shows the necessary pin connections to operate this mass flow controller. The operating principle of the Sierra SideTrak is based on heat transfer and the first law of thermodynamics. The process gas enters the Sidetrak flow body and divides into two flow paths, one through the sensor tube, the other through the bypass. Here a pressure drop is created forcing a small fraction of the total flow through the sensor tube that is then monitored. Sierra's patented straight sensor tube is mounted on the side of the bypass flow path. Two resistance temperature detector (RTD) coils around the sensor tube direct a constant amount of heat into the gas stream. The gas mass flow carries heat from the upstream coil to the downstream coil. The resulting temperature difference $(\Delta \mathrm{T})$ is detected by the RTD coils. The coils are legs of a bridge circuit with an output voltage in direct proportion to the difference in the coils' resistance and the result is the temperature difference. The flow then leaves the flow monitoring section and enters the built in servo-control valve. This normally closed electromagnetic valve's magnetic field is modulated so that the ferromagnetic valve armature assumes the exact height above the valve's orifice required to maintain the valve's command flow. 
After each of the mass flow controllers was calibrated, it was checked for their accuracy. The MFCs were tested again at WVU using a DryCal flow meter and one of two filter types, Gelman Sciences (GS) High Efficiency Particulate Air (HEPA) and a 47mm GS Model 2220 with two 47-mm Fiberfilm filters. Table 3.6 and Table 3.7 both show the calibration data for the Sierra 840 MFCs. Figure 3.11 and Figure 3.12 both display the linearity of this data. The R squared value for each for the lines were 0.9988 and 0.9972 .

Table 3.6 Calibration Data for Sierra's 840 Series Model

\begin{tabular}{|c|c|c|c|c|c|c|c|c|}
\hline & \multirow{2}{*}{$\begin{array}{c}\text { Reading } \\
\text { Number }\end{array}$} & \multirow{2}{*}{$\begin{array}{c}\text { MFC } \\
\text { Set }\end{array}$} & \multirow{2}{*}{$\begin{array}{c}\text { MFC } \\
\text { Set }\end{array}$} & \multicolumn{2}{c|}{$\begin{array}{c}\text { Dry Cal Readings } \\
\text { Filter Type }\end{array}$} & \multicolumn{2}{c|}{$\begin{array}{c}\text { Corrected for STP } \\
\text { Filter Type }\end{array}$} & \multicolumn{2}{c|}{$\begin{array}{c}\text { Percent Error } \\
\text { Filter Type }\end{array}$} \\
\cline { 4 - 9 } & GS HEPA & GS w/ 2 filters & GS HEPA & GS w/ 2 filters & GS HEPA & GS w/ 2 filters \\
\hline & {$[\mathrm{V}]$} & {$[\mathrm{slpm}]$} & {$[$ alpm] } & {$[$ alpm] } & {$[$ slpm] } & {$[$ [slpm] } & {$[\%$ Error] } & {$[\%$ Error] } \\
\hline 1 & 0.50 & 1.0 & 1.50 & 1.28 & 1.35 & 1.15 & 3.50 & 1.52 \\
\hline 2 & 1.00 & 2.0 & 2.44 & 2.37 & 2.20 & 2.13 & 1.99 & 1.29 \\
\hline 3 & 1.50 & 3.0 & 3.46 & 3.43 & 3.12 & 3.08 & 1.16 & 0.84 \\
\hline 4 & 2.00 & 4.0 & 4.49 & 4.49 & 4.04 & 4.04 & 0.40 & 0.39 \\
\hline 5 & 2.50 & 5.0 & 5.54 & 5.58 & 4.99 & 5.03 & 0.11 & 0.27 \\
\hline 6 & 3.00 & 6.0 & 6.77 & 6.85 & 6.10 & 6.17 & 0.96 & 1.66 \\
\hline 7 & 3.50 & 7.0 & 8.10 & 8.15 & 7.29 & 7.34 & 2.91 & 3.40 \\
\hline 8 & 4.00 & 8.0 & 9.19 & 9.27 & 8.28 & 8.35 & 2.76 & 3.49 \\
\hline 9 & 4.25 & 8.5 & $\mathrm{~N} / \mathrm{A}$ & 9.89 & $\mathrm{~N} / \mathrm{A}$ & 8.91 & $\mathrm{~N} / \mathrm{A}$ & 4.07 \\
\hline
\end{tabular}

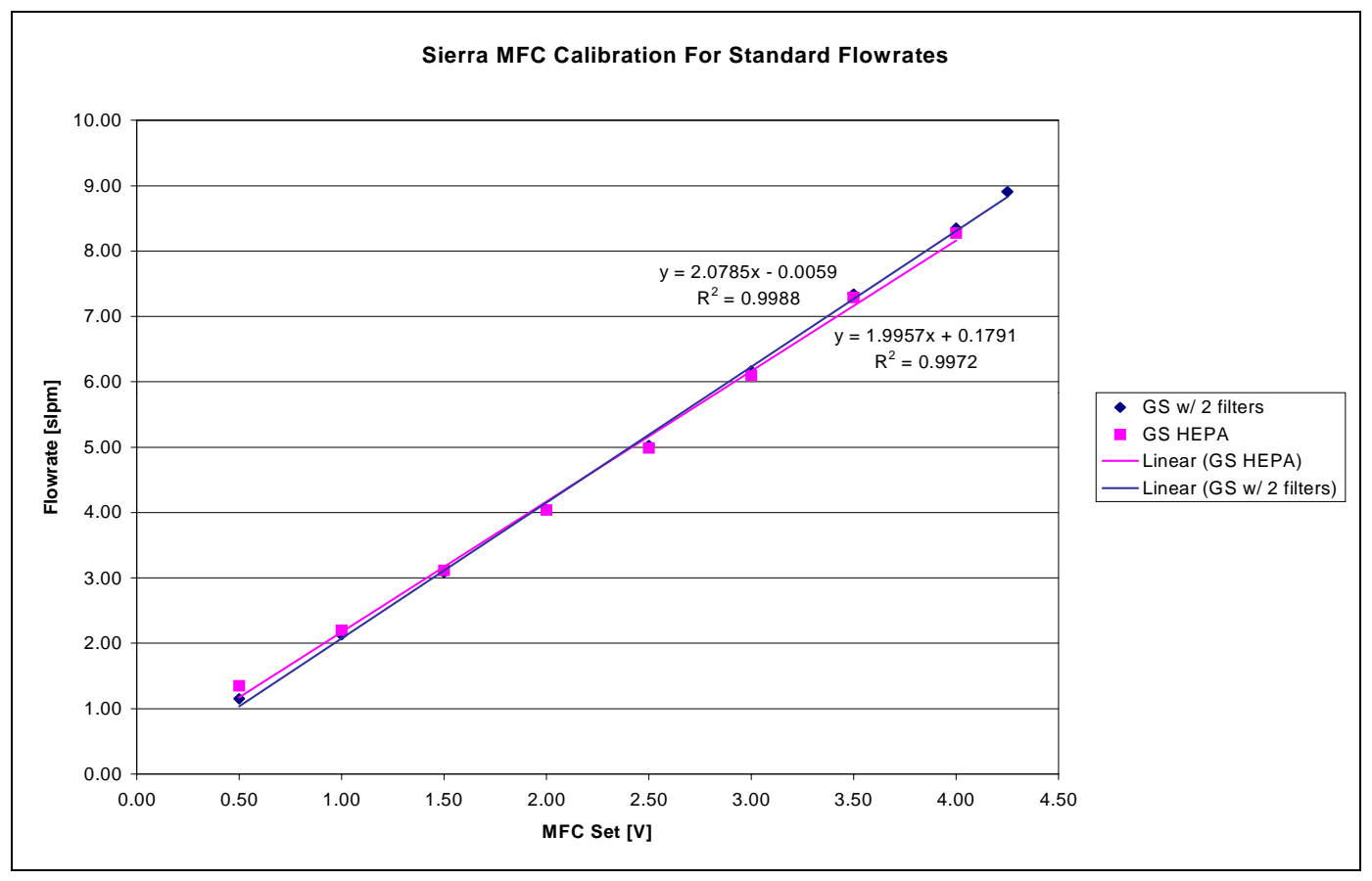

Figure 3.11 Calibration Chart for Sierra's 840 Sidetrak Model 
Table 3.7 Calibration Data for Sierra's 840 Sidetrak Series Model

\begin{tabular}{|c|c|c|c|c|c|c|c|c|}
\hline \multirow{2}{*}{$\begin{array}{l}\text { Reading } \\
\text { Number }\end{array}$} & \multirow{2}{*}{$\begin{array}{c}\text { MFC } \\
\text { Set }\end{array}$} & \multirow{2}{*}{$\begin{array}{c}\text { MFC } \\
\text { Set }\end{array}$} & \multicolumn{2}{|c|}{$\begin{array}{c}\text { Dry Cal Readings } \\
\text { Filter Type }\end{array}$} & \multicolumn{2}{|c|}{$\begin{array}{l}\text { Corrected for STP } \\
\text { Filter Type }\end{array}$} & \multicolumn{2}{|c|}{$\begin{array}{l}\text { Percent Error } \\
\text { Filter Type }\end{array}$} \\
\hline & & & GS HEPA & GS w/ 2 filters & GS HEPA & GS w/ 2 filters & GS HEPA & GS w/ 2 filters \\
\hline & {$[\mathrm{V}]$} & [slpm] & [alpm] & [alpm] & [slpm] & [slpm] & [\% Error] & [\% Error] \\
\hline 1 & 0.50 & 1.0 & 0.90 & 0.93 & 0.81 & 0.83 & 2.40 & 1.71 \\
\hline 2 & 1.00 & 2.0 & 2.05 & 2.13 & 1.84 & 1.90 & 0.87 & 0.96 \\
\hline 3 & 1.50 & 3.0 & 3.19 & 3.27 & 2.86 & 2.93 & 0.50 & 0.67 \\
\hline 4 & 2.00 & 4.0 & 4.28 & 4.38 & 3.83 & 3.92 & 0.44 & 0.77 \\
\hline 5 & 2.50 & 5.0 & 5.40 & 5.54 & 4.84 & 4.97 & 0.33 & 0.35 \\
\hline 6 & 3.00 & 6.0 & 6.63 & 6.75 & 5.94 & 6.04 & 0.11 & 0.43 \\
\hline 7 & 3.50 & 7.0 & 7.86 & 7.89 & 7.04 & 7.07 & 0.06 & 0.69 \\
\hline 8 & 4.00 & 8.0 & 8.98 & 9.00 & 8.04 & 8.06 & 0.05 & 0.61 \\
\hline 9 & 4.25 & 8.5 & 9.57 & 9.62 & 8.57 & 8.61 & 0.08 & 1.13 \\
\hline
\end{tabular}

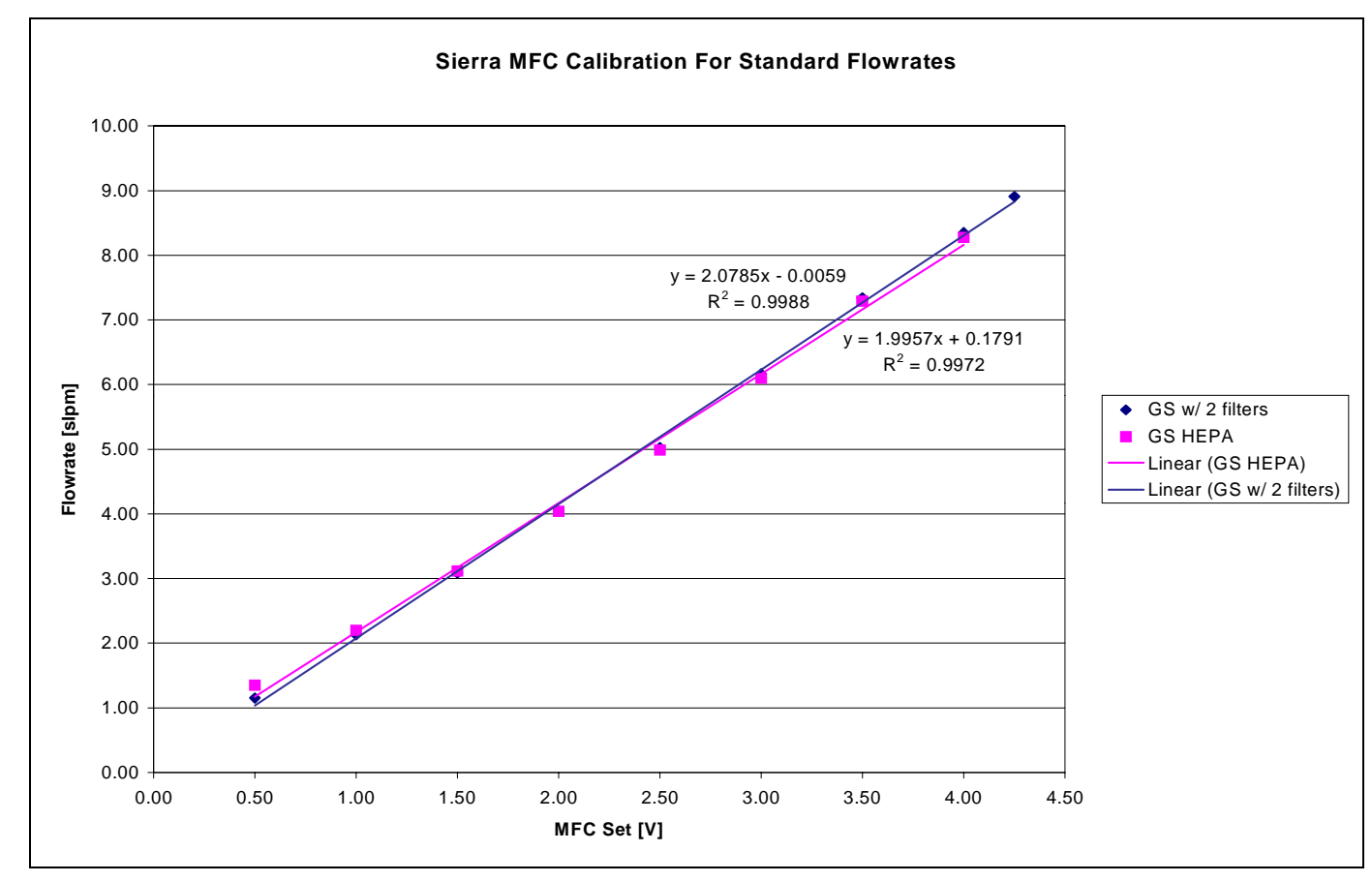

Figure 3.12 Calibration Chart for Sierra's 840 Series Model

\subsubsection{Fathom GR Series Mass Flow Controller}

The bleed-off mass flow controller was a Fathom's GR Series MFC. The GR Series mass flow controllers utilize a thermal sensor technology to measure and control mass flow directly. Gas entering the flow body is divided at a constant ratio by a laminar bypass. Gas molecules traveling through the sensor carry heat downstream creating a differential temperature between the RTDs. This difference is directly proportional to the mass flow rate. Fathom's electronics compare the gas flow rate to the command setpoint, 
then by applying the proper voltage to the coil magnetically raising or lowering the actuator above the orifice to obtain the desired flow rate. The wetted material is 316 stainless steel with an output signal of $0-5 \mathrm{~V} \mathrm{DC}$ and input power of $+12 \mathrm{~V}$ DC. They are $\pm 1 \%$ full scale accurate with a repeatability of \pm 0.15 FS.

Table 3.10 shows the calibration data for the Fathom's GR Series. The accuracy for this MFC was better calibration of Fathom GR Series compared to the Sierra 840 Series MFCs. Figure 3.14 shows the linearity of the calibration data points. Table 3.8 shows the calculation of the orifice size for this MFC

Table 3.8 Calculated Orifice Size for Fathom's GR Series Model

\begin{tabular}{|c|c|c|c|c|c|c|}
\hline \multicolumn{3}{|l|}{ CONSTANTS } & & & & \\
\hline Density $=$ & 1.23 & {$\left[\mathrm{~kg} / \mathrm{m}^{3}\right]$} & & & & \\
\hline $\mathrm{Pi}=$ & 3.1415927 & & & & & \\
\hline Radius $=$ & $3.81 \mathrm{E}-03$ & {$[\mathrm{~m}]$} & & & & \\
\hline Upstream Area = & $4.56 \mathrm{E}-05$ & {$\left[\mathrm{~m}^{2}\right]$} & & & & \\
\hline \multicolumn{7}{|l|}{ VARIABLES } \\
\hline $\begin{array}{l}\text { Volumetric } \\
\text { Flowrate } \\
\text { [slpm] }\end{array}$ & $\begin{array}{c}\text { Volumetric } \\
\text { Flowrate } \\
{\left[\mathrm{m}^{3} / \mathrm{s}\right]}\end{array}$ & $\begin{array}{c}\text { Differential } \\
\text { Pressure } \\
\text { [psi] }\end{array}$ & $\begin{array}{c}\text { Differential } \\
\text { Pressure } \\
{[\mathrm{Pa}]}\end{array}$ & $\begin{array}{c}\text { Downstream } \\
\text { Area } \\
{\left[\mathrm{m}^{2}\right]}\end{array}$ & $\begin{array}{c}\text { Orifice } \\
\text { Radius } \\
{[\mathrm{m}]}\end{array}$ & $\begin{array}{c}\text { Orifice } \\
\text { Radius } \\
\text { [in] }\end{array}$ \\
\hline 4.3 & 7.17E-05 & 2.2 & 15168 & 4.56E-07 & 3.81E-04 & 0.015 \\
\hline Notes: & $3 / 8$ & inly & ectly & and after & MFC & \\
\hline
\end{tabular}

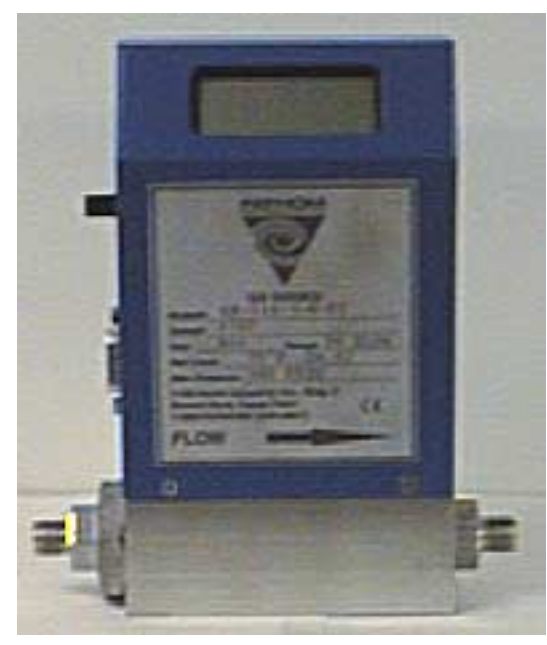

Figure 3.13 Fathom's GR Series Model 
Table 3.9 Fathom's GR Series Model Setup

\begin{tabular}{|r|c|c|l|}
\hline SET HI & 5 & 6 & LOCAL SET \\
\hline $0-5$ V DC & 4 & 7 & 15 V DC \\
\hline & 3 & 8 & \\
\hline & 2 & 9 & \\
\hline GRD & 1 & & \\
\hline
\end{tabular}

Table 3.10 Calibration Data for Fathom's GR Series Model

\begin{tabular}{|c|c|c|c|c|c|c|c|c|}
\hline \multirow{2}{*}{$\begin{array}{l}\text { Reading } \\
\text { Number }\end{array}$} & \multirow{2}{*}{$\begin{array}{c}\text { MFC } \\
\text { Set }\end{array}$} & \multirow{2}{*}{$\begin{array}{c}\text { MFC } \\
\text { Set }\end{array}$} & \multicolumn{2}{|c|}{$\begin{array}{c}\text { Dry Cal Readings } \\
\text { Filter Type }\end{array}$} & \multicolumn{2}{|c|}{$\begin{array}{l}\text { Corrected for STP } \\
\text { Filter Type }\end{array}$} & \multicolumn{2}{|c|}{$\begin{array}{c}\text { Percent Error } \\
\text { Filter Type }\end{array}$} \\
\hline & & & GS HEPA & GS w/ 2 filters & GS HEPA & GS w/ 2 filters & GS HEPA & GS w/ 2 filters \\
\hline & [V] & [slpm] & [alpm] & [alpm] & [slpm] & [slpm] & [\% Error] & [\% Error] \\
\hline 1 & 0.50 & 1.0 & 1.25 & 1.15 & 1.20 & 1.11 & 2.03 & \\
\hline 2 & 1.00 & 2.0 & 2.28 & 2.08 & 2.20 & 2.00 & 1.98 & 0.02 \\
\hline 3 & 1.50 & 3.0 & 3.24 & 3.11 & 3.13 & 3.00 & 1.25 & 0.01 \\
\hline 4 & 2.00 & 4.0 & 4.27 & 4.19 & 4.12 & 4.04 & 1.20 & 0.43 \\
\hline 5 & 2.50 & 5.0 & 5.34 & 5.22 & 5.15 & 5.03 & 1.52 & 0.34 \\
\hline 6 & 3.00 & 6.0 & 6.35 & 6.26 & 6.12 & 6.03 & 1.20 & 0.35 \\
\hline 7 & 3.50 & 7.0 & 7.34 & 7.28 & 7.08 & 7.02 & 0.77 & 0.17 \\
\hline 8 & 4.00 & 8.0 & 8.39 & 8.32 & 8.09 & 8.02 & 0.90 & 0.19 \\
\hline 9 & 4.50 & 9.0 & 9.30 & 9.27 & 8.97 & 8.93 & 0.31 & 0.66 \\
\hline 10 & 4.75 & 9.5 & 9.79 & 9.81 & 9.44 & 9.46 & 0.60 & 0.44 \\
\hline
\end{tabular}

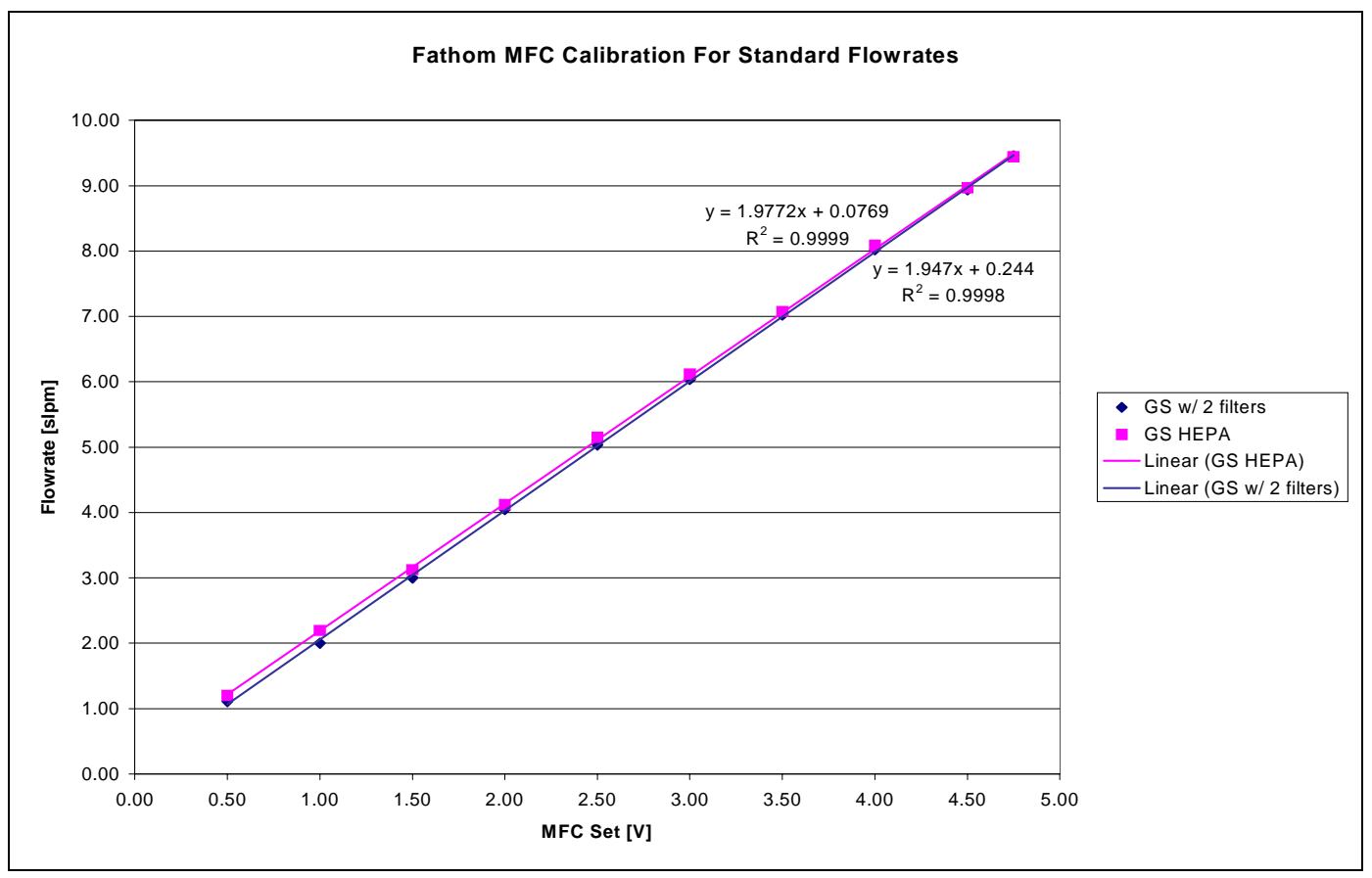

Figure 3.14 Calibration Chart for Fathom's GR Series Model 


\subsubsection{Filters}

Most dilution systems use ambient air as the dilution air. This would require the use of a second pump in the micro-dilution tunnel. The micro-dilution system used recirculated air for dilution purposes, which only required the use of a single pump. In order to use this recirculated diluted exhaust, three features were incorporated in the system to clean the air. First, the particulate matter from the diluted exhaust was collected on a 47-mm T60A20 Fiberfilm filter, which was also gravimetrically analyzed. Then, the filtered recirculating exhaust is directed through a HEPA filter, which removes any remaining particles. Finally, moisture and heavier hydrocarbons in the air are extracted using a refrigerated dryer.

The filter face velocity was calculated for each filter type and size using the effective filtration area, the filter area that was available for filtration. A larger filter area produced a faster flow rate at a given pressure differential and the larger the expected filter throughout volume prior to clogging for a given solution. The filter efficiency is a measure of the quantity of particulate retained by a filter as a function of the total number and size of the challenging particles and differential pressure. The next three sections will discuss each of these steps in detail.

\subsubsection{Particulate Matter Filter}

The particulate matter (PM) filter is conditioned and weighed before and after each test. The filter must be conditioned for at least 4 hours and no more than 80 hours before and at least 8 hours after being weighed. The Gelman Sciences 2220 is a high quality, corrosion resistant filter holder. The filter remains undisturbed for particulate analysis. This stainless steel $47-\mathrm{mm}$ has an effective filtration area of $9.6 \mathrm{~cm} 2$ with an 
overall length $5.7 \mathrm{~cm}(2.2 \mathrm{in})$ and diameter of $5.9 \mathrm{~cm}(2.3 \mathrm{in})$. The maximum operating temperature is limited by filter type or by hose barb $93^{\circ} \mathrm{C}\left(199^{\circ} \mathrm{F}\right)$ and a maximum operating pressure of $14 \mathrm{bar}$ (200 psi). Table 3.11shows the filter face velocities of the Gelman Sciences 47-mm filter holder.

Table 3.11 Filter Face Velocities (47-mm)

\begin{tabular}{|c|c|c|}
\hline $\begin{array}{c}\text { Flow Rate } \\
{[\mathrm{scfm}]}\end{array}$ & $\begin{array}{c}\text { Flow Rate } \\
{\left[\mathrm{m}^{3} / \mathrm{min}\right]}\end{array}$ & $\begin{array}{c}\text { Filter Face Velocity } \\
{[\mathrm{cm} / \mathrm{s}]}\end{array}$ \\
\hline \hline 0.1 & 0.0028 & 4.92 \\
\hline 0.15 & 0.0042 & 7.37 \\
\hline 0.2 & 0.0057 & 9.83 \\
\hline 0.25 & 0.0071 & 12.29 \\
\hline 0.3 & 0.0085 & 14.75 \\
\hline 0.35 & 0.0099 & 17.21 \\
\hline 0.4 & 0.0113 & 19.66 \\
\hline 0.45 & 0.0127 & 22.12 \\
\hline
\end{tabular}

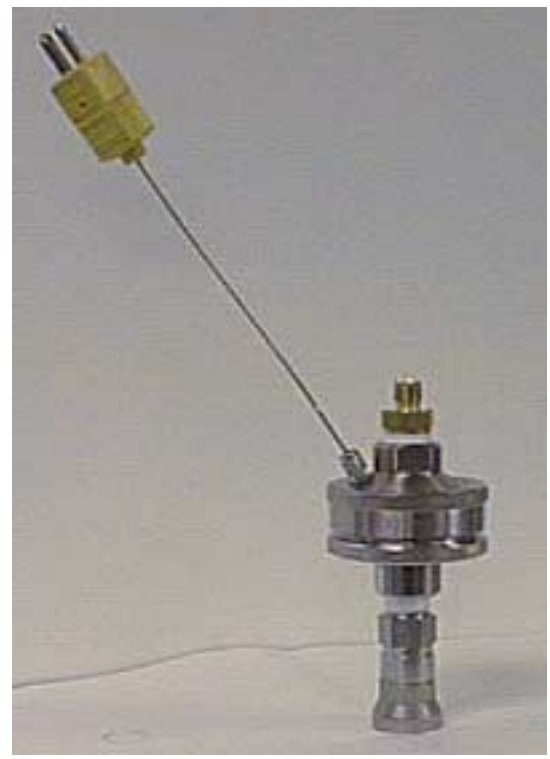

Figure 3.15 Gelman Science Model 2220

Tissuquartz $^{\mathrm{TM}}$ and Fiberfilm ${ }^{\mathrm{TM}}$ were the two types of filters that were used with the Gelman Sciences 2220 when collecting PM with the mini-dilution tunnel system. The Tissuquartz ${ }^{\mathrm{TM}}$ filters weighed about $30-35 \mathrm{mg}$ more and were more fragile than the Fiberfilm ${ }^{\mathrm{TM}}$ filters. 
Tissuquartz ${ }^{\mathrm{TM}}$ filters are pure quartz filters that are heat treated for reduction of trace organics and superior chemical purity. These filters can be used at high temperature of up $1093^{\circ} \mathrm{C}\left(2000^{\circ} \mathrm{F}\right)$ for analysis of acidic gases and stack sampling aerosols. They can withstand high flow rates of up to $731 / \mathrm{min} / \mathrm{cm}^{2}$ at 0.7 bar (10 psi) and maintain a high efficiency of $99.9 \%$. A typical filter weighs $5.8 \mathrm{mg} / \mathrm{cm}^{2}$ with a thickness of $432 \mu \mathrm{m}$ (17 mils).

Fiberfilm ${ }^{\mathrm{TM}}$ filters are well suited for a broad range of air sampling applications. Moisture variations in air or gases during air sampling will not cause chemical reactions on the filter. These filters can also be heat-treated to reduce trace organics. These filters are made of heat resistant borosilicate glass fiber coated with fluorocarbon (TFE) with a typical thickness of $203 \mu \mathrm{m}$ ( 8 mils) and filter weight of $3.4 \mathrm{mg} / \mathrm{cm}^{2}$. The maximum operating temperature is only $315.5^{\circ} \mathrm{C}\left(600^{\circ} \mathrm{F}\right)$; however, the typical air flow rate at 0.7 bar $(10 \mathrm{psi})$ is $180 \mathrm{~L} / \mathrm{min} / \mathrm{cm}^{2}$. These filters cannot handle temperatures as high as the Tissuquartz filters, but they can handle about 2.5 times the amount of flow rate. Since the flow rate and temperature for this research were low, the Fiberfilm T60A20 filters were chosen.

\subsubsection{HEPA Filter}

The High Efficiency Particulate-free Air (HEPA) filter was used to collect any particles after the gas stream exited the PM filter. The HEPA filter was located after the PM filter holder and before the dilution air MFC. This HEPA capsule has a porous membrane that delivers high air flow rates at low differential pressures. The non fibrereleasing member prevents the introduction of particles downstream. The HEPA capsule is constructed of polypropylene with a Versapor membrane filter inside. The maximum 
operating temperature and pressure is $190^{\circ} \mathrm{F}$ and 5 psi, respectively. Figure 3.16 is a three dimensional drawing of the Gelman Sciences HEPA Capsule and Table 3.12 shows the filter face velocities for this filter type and size.

Table 3.12 Filter Face Velocities (HEPA)

\begin{tabular}{|c|c|c|}
\hline $\begin{array}{c}\text { Flow Rate } \\
{[\mathrm{scfm}]}\end{array}$ & $\begin{array}{c}\text { Flow Rate } \\
{\left[\mathrm{m}^{3} / \mathrm{min}\right]}\end{array}$ & $\begin{array}{c}\text { Filter Face Velocity } \\
{[\mathrm{cm} / \mathrm{s}]}\end{array}$ \\
\hline \hline 0.1 & 0.0028 & 0.05 \\
\hline 0.15 & 0.0042 & 0.08 \\
\hline 0.2 & 0.0057 & 0.11 \\
\hline 0.25 & 0.0071 & 0.14 \\
\hline 0.3 & 0.0085 & 0.16 \\
\hline 0.35 & 0.0099 & 0.19 \\
\hline 0.4 & 0.0113 & 0.22 \\
\hline 0.45 & 0.0127 & 0.25 \\
\hline
\end{tabular}

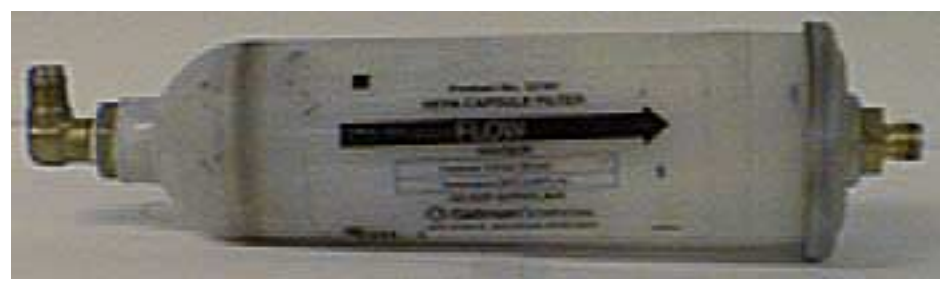

Figure 3.16 Gelman Sciences HEPA Capsule

\subsubsection{Water Removing Devices}

A water removing device is necessary in the micro-dilution system so that condensation does not occur on the particulate filter. The initial design, shown in Appendix B, used a Permapure Heatless Air Dryer (HAD) to remove any moisture. However, in the final design the HAD was changed to a chiller due to the high inlet pressure required by the HAD. The following sections discuss the operations of each of these two water removing devices.

\subsubsection{Heatless Air Dryer}

A Permapure HAD operates by supplying a compressed air line with a minimum of 60 psig and a maximum of 1000 psig that should be connected to the $1 / 2$ " wet air inlet 
port located between the solenoid valves. The purge air exhaust ports located at the center of the solenoid valve coil are left open to the atmosphere to provide venting for the wet air exhaust. The 1/2" polypropylene compression fitting is the dry air outlet port. Permapure $^{\mathrm{TM}}$ series heatless dryers are ideal for low flow air drying operations. Dryer operation is fully automatic and outlet dew points as low as $-50^{\circ} \mathrm{C}$ can be achieved. HAD consisted of two chambers filled with highly absorbent desiccant, molecular sieve 4A. One chamber dries the gas stream while the opposite chamber is regenerated. Purge air is a small portion of died air taken from the drying chamber, expanded to atmospheric pressure and passed countercurrent through the regenerating wet chamber. Wet purge air is released from an exhaust port in the vapor state so that no drain is required. Purge air volume is controlled with an orifice housed within the unit. A solid state controller governs chamber switching. The controller contains no relays, for high reliability and durability. This dryer has an inlet flow rate of up to $60 \mathrm{lpm}$ with an inlet maximum temperature of $43^{\circ} \mathrm{C}$. Figure 3.17 is a picture of the Permapure heatless air dryer.

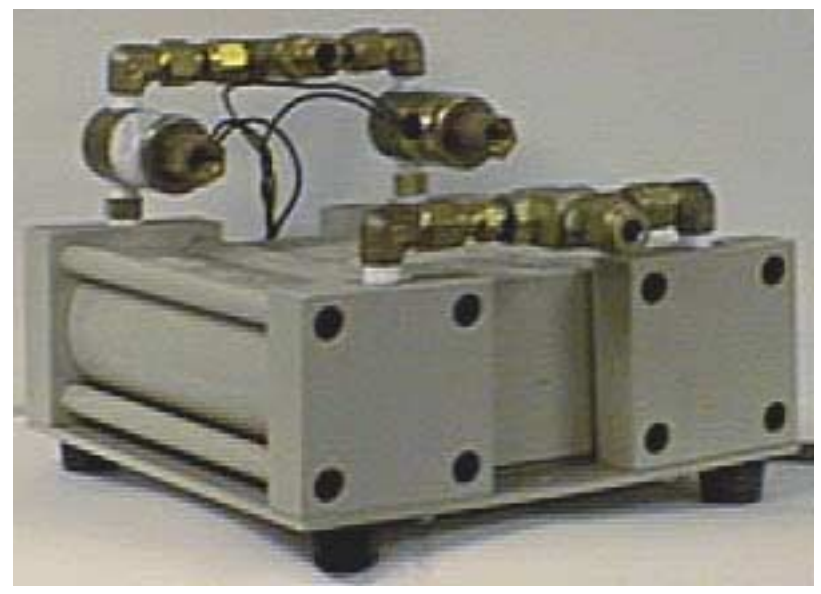

Figure 3.17 Permapure Heatless Air Dryer 


\subsubsection{Chiller}

In the final design, a chiller was selected to remove any water in the gas stream. The added advantage of installing a chiller before the dilution air MFC was to extract any moisture while decreasing the dew point temperature to minimize loss of water-soluble gas fraction. The Universal Analyzers Peltier Effect Sample Cooler Model 1080 was employed to decrease the dew point of combustion gases to a stable low dew point. The process of how the analyzer works is described next. Figure 3.18 is a picture of this chiller type.

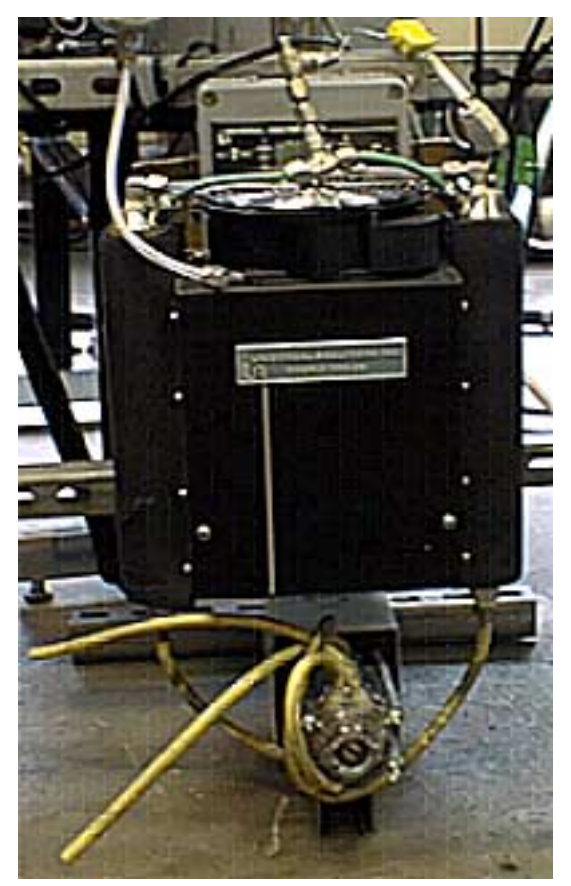

\section{Figure 3.18 Universal Sample Chiller}

The dew point of a gas sample passing through the Universal Sampler Cooler is lowered to $5{ }^{\circ} \mathrm{C}$. Condensate removal from the heat exchangers within the sample cooler is accomplished by using a continuously running peristaltic tubing pump. The Model 
1080 can condition two independent gas sample streams to remove the moisture in two parallel paths or one sample gas stream.

In the micro-dilution system, a single sample was conditioned so both sides of the chiller were used in order to handle a higher sample flow rate. These sides were connected in parallel with equal tube lengths to equalize the pressure drop at the inlets and outlets so the flow rates through each side would approximately be equal. Connecting them in parallel allowed a maximum of $15 \mathrm{lpm}$ at a low vapor concentration in the sample.

The two heat exchangers/impingers are cooled thermoelectrically and controlled with independent temperature sensors and control circuitry. The design of the heat exchangers enables this cooler to be able to condense the water from a wet gas sample with a minimal loss of the water-soluble gas fraction. The separation occurs in a classical impinger which has a highly polished cylindrical surface cooled to the desired dew point temperature. The gas sample is brought to the bottom of the cylinder through an insulated tube and allowed to rise through a narrow annular area at a relatively high Reynolds number to insure the entire sample is influenced by the cold surface. The condensate falls down the cold polished surface in the form of a sheet, as opposed to droplets or the bubbling of the gas sample through the condensate, which minimizes the surface area in contact with the gas sample.

The temperature of the cylindrical condensation surface of each of the heat exchangers is maintained through intimate contact with aluminum heat transfer blocks. The first of the heat transfer blocks in each line is cooled by direct contact with the fancooled sink. The temperature of the first of the two heat exchangers is about $18^{\circ} \mathrm{F}$ above 
the temperature of the air passing through the heat sink when under full load conditions. The second of the heat exchangers in each line is cooled by the use of thermoelectric elements to a controlled temperature of $5{ }^{\circ} \mathrm{C}$. The temperature sensors are type "K" thermocouples. The controllers are proportional controllers with a proportional band of $1^{\circ} \mathrm{C}$.

The fan-cooled heat sink is constructed from anodized pure aluminum fins which carry and transfer heat to the air, which is pulled through the heat sink with a high capacity fan. The Universal Analyzers Peltier Effect Sample Cooler Model 1080 assembly results in the cooler having superior heat exhausting capabilities under high ambient temperature conditions. (Universal, 1999)

\subsubsection{Data Acquisition}

In the design of the on-board micro-dilution system, there were two National Instruments (NI) data acquisition cards (DAQ) that were used, NIDAQ 1200 and NIDAQ A1-16E-4. The NIDAQ 1200 controlled and measured the analog inputs/outputs, digital input/outputs and differential pressures. The NIDAQ A1-16E-4 measured the differential temperatures.

\subsubsection{National Instruments Data Acquisition Card 1200 Series}

The National Instruments 1200 series data acquisition card can supply three digital input/output ports with eight lines each, eight analog inputs and two analog outputs. The two analog outputs were used to set the total and dilute air MFC's $\mathrm{V}_{\text {out }}$ signals. The analog inputs were used for each of the MFC's sense signal and to record the differential pressures. A digital to analog converter was used to control the set signal 
of the third MFC. Table 3.13 shows the channels for the components monitored or controlled by the DAQ 1200.

Table 3.13 Channel Configuration DAQ 1200

\begin{tabular}{|c|c|c|c|}
\hline \multicolumn{2}{|c|}{ Channel } & \multicolumn{2}{c|}{ Device } \\
Name & Channel & Name \\
\hline DP1_Sense & Analog Input & 2 & DAQ-1200 \\
\hline DP2_Sense & Analog Input & 1 & DAQ-1200 \\
\hline MFC1_Sense & Analog Input & 0 & DAQ-1200 \\
\hline MFC2_Sense & Analog Input & 1 & DAQ-1200 \\
\hline MFC3_Sense & Analog Input & 4 & DAQ-1200 \\
\hline MFC1_Set & Analog Output & 0 & DAQ-1200 \\
\hline MFC2_Set & Analog Output & 1 & DAQ-1200 \\
\hline MFC3_Sense2 & Analog Input & 5 & DAQ-1200 \\
\hline Pump_Switch & Digital I/O & PA Line 2 & DAQ-1200 \\
\hline SDAC_ChipSelect & Digital I/O & PA Line 5 & DAQ-1200 \\
\hline SDAC_Clock & Digital I/O & PA Line 6 & DAQ-1200 \\
\hline SDAC_Data & Digital I/O & PA Line 7 & DAQ-1200 \\
\hline SampleTrigger & Digital I/O & PB Line 0 & DAQ-1200 \\
\hline
\end{tabular}

\subsubsection{National Instruments Data Acquisition Card A1-16E-4}

National Instruments DAQ A1-16E-4 was used to measure the differential temperatures from each of the five K-type thermocouples in conjunction with NI SCB-68 board. The thermocouples were located one before the dilution air MFC, after MFC \#3, at the filter face, after the chiller, and at the entrance of the system. Measurement and Automation was used in conjunction with the Visual Basic program to configure each channel. This information is shown in Table 3.14.

Table 3.14 DAQ A1-16E-4 Series Channel Setup

\begin{tabular}{|c|c|c|c|c|}
\hline \multicolumn{2}{|c|}{ Channel } & \multicolumn{2}{c|}{ Device Channel } & Device \\
Name & Type & Positive & Negative & Name \\
\hline CJC & Analog Input & 0 & 8 & DAQ-A1-16E-4 \\
\hline RawExhaust_Temp & Analog Input & 1 & 9 & DAQ-A1-16E-4 \\
\hline MFC1_Temp & Analog Input & 2 & 10 & DAQ-A1-16E-4 \\
\hline MFC2_Temp & Analog Input & 3 & 11 & DAQ-A1-16E-4 \\
\hline PMFilter_Temp & Analog Input & 4 & 12 & DAQ-A1-16E-4 \\
\hline Chiller_Temp & Analog Input & 5 & 13 & DAQ-A1-16E-4 \\
\hline
\end{tabular}


The maximum voltage level thermocouples generate is typically a few $\mathrm{mV}$. The differential configuration was chosen, as opposed to the single ended configuration, because a differential configuration has better noise immunity. Cold junction compensation with the SCB-68 board is only accurate if the temperature sensor reading is close to the actual temperature of the screw terminals. To provide a return path for instrumentation amplifier bias currents, the floating sources had a resistor to analog input ground (AIGND).

The SCB-68 is a shielded board with 68 screw terminals for easy connection to National Instruments 68-pin products. To accommodate thermocouples, the SCB-68 connector block has a temperature sensor for cold junction compensation. The SCB-68 temperature sensor outputs $10 \mathrm{mV} /{ }^{\circ} \mathrm{C}$ and has an accuracy of $\pm 1^{\circ} \mathrm{C}$

\subsubsection{Pumps}

Since there is only one pump in the system, this pump must draw vacuum and also pump gas to a higher pressure. When the pump is turned on, the raw exhaust is drawn through the tunnel while being diluted with air that is being supplied from the other side of the pump. Since only one pump was desired, this pump would have to handle both suction and supply of airflow. Three pumps were experimented with to see if each could handle the pressure drops created by various components within the system. Once a pressure drop was applied, flow rates of all the pumps dropped significantly. Mass flow controllers also caused large pressure drops, which in turn affected the performance of the pump. 
Three pumps were selected for use within the micro-dilution system, Air Dimensions diaphragm, Gast 0523 rotary vane, and Thomas Industries 917 diaphragm. Each pump is briefly discussed in each of the following sections.

\subsubsection{Air Dimensions}

The first of the three pumps that were tried out was an Air Dimensions heated head pump. This diaphragm pump was rated at $17 \mathrm{lpm}$ with no load. A heated head pump was chosen to maintain the temperature of the gas to decrease the amount of condensate that might occur. This pump was not adequate because the mass flow controllers created large pressure drops which in turn decreased the mass flow rate that the pump could pull.

\subsubsection{GAST 0523}

The second pump that was tried was a rotary vane GAST 0523 pump. Rotary vane is pulsation-free for oilless applications with minimal vibration. The self-sealing compound carbon vanes self-adjust as they wear so the pump will perform efficiently. This pump could handle higher flow rates, but would leak air through the vanes causing an unknown quantity of extra air being added to the outlet.

\subsubsection{Thomas Industries 917}

The last pump tried was a Thomas Industries diaphragm cold head pump. This pump could handle the pressure drop created by the MFCs and the other components of the system combined. It is an oil-less operation with stainless steel valves and an aluminum valve plate. This pump only weighed $11 \mathrm{lb}(5 \mathrm{~kg})$, which is essential in maintaining a small system overall. Figure 3.19 is a picture of the Thomas Industries 917 Series Model. 


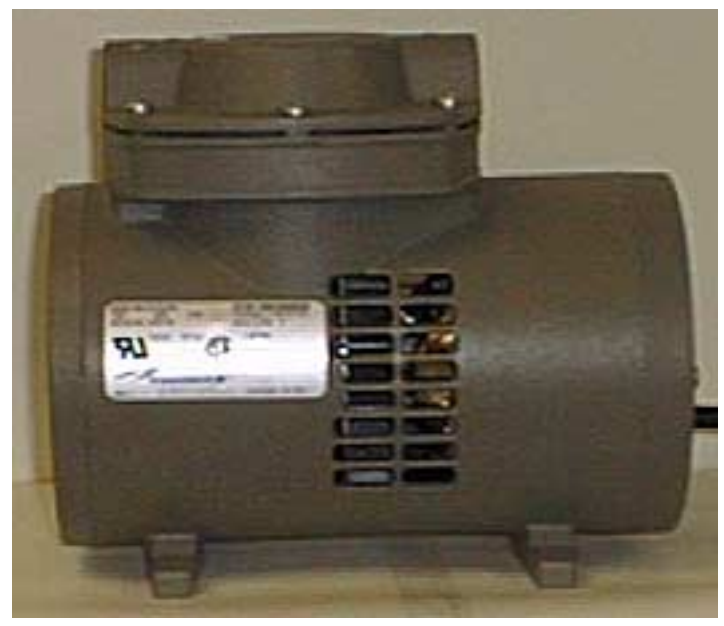

Figure 3.19 Thomas Industries 917 Series Model

\subsubsection{Visual Basic Program}

Visual Basic Professional Version 6.0 in conjunction with Component Works Version 3.0 with NIDAQ drivers Version 6.9 was used to design a Windows based program to control the micro-dilution tunnel system. Figure 3.20 shows the main form that was created in Visual Basic. The six main menus are File, Data, Control, Method, Engine Test Cycle and Sampling Type. Under File, Exit will stop all components that are running and quit the executable. The Data menu starts and stops data taking. When Start Data is selected, the program will ask for a file name and location for the data to be stored. The Method menu is to choose between a countdown method or using a bit supplied by the EERL. The countdown method will countdown the time and test for a selected amount of time. The bit is used to sample simultaneously with the full flow dilution tunnel during steady state tests in the main test cell. This program can be controlled either manually or by the computer. The Sampling Type menu has the choice between proportional sampling or control volume sampling. If proportional sampling is selected, then an external signal must be supplied to the micro-dilution system. The last menu is to select the engine test cycle of choice, either steady state or transient. 


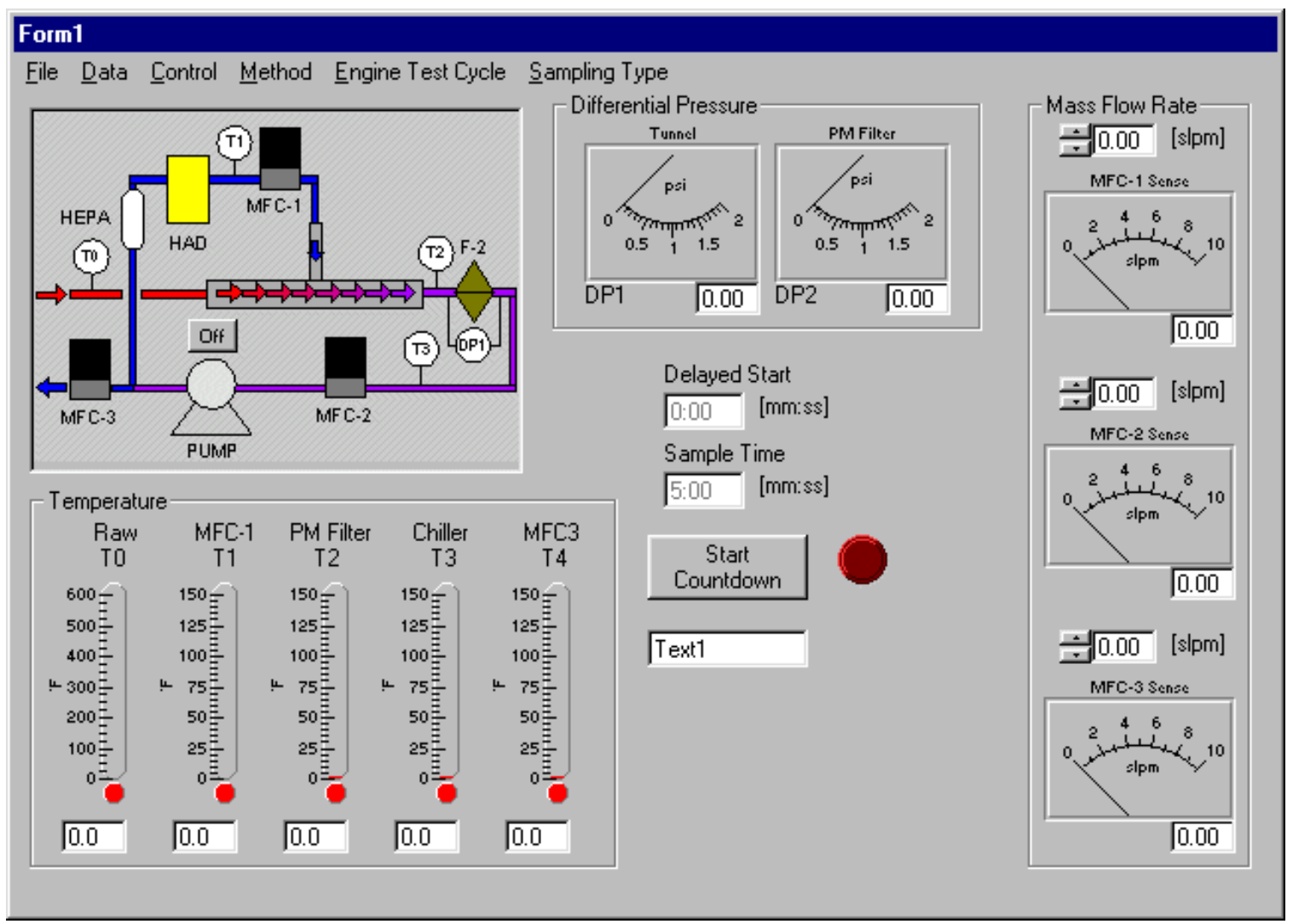

Figure 3.20 Main Form in Visual Basic

The two pressure sensors measured the differential pressure across the tunnel and PM filter. The MPX5010 could measure small differential pressures that ranged from 0 to 1.45 psi. The MPX5050 could measure a larger differential pressures that ranged from 0 to 7.3 psi. Since there was a small pressure drop recorded across the tunnel, the MPX5010 was used. On the other hand, the PM filter exceeded that limit, so the MPX5050 was used. The pressure dials display the differential pressure across the tunnel and PM filter holder, as shown in Figure 3.20.

In the upper left-hand corner of the main form, there is a block diagram of the micro-dilution system. The button above the pump can turn the pump on and off by clicking this button. 
Also on the main form, each of the five temperatures are displayed with slider bars. When the temperature exceeds the user specified limit of each location, the slider turns from green to red to alert the user of this. The limits of the five temperature locations are shown in Table 3.15.

Table 3.15 Temperature Limits in Selected Locaitons

\begin{tabular}{|c|c|c|}
\hline Number & Location & Max Temperature $\left[{ }^{\circ} \mathrm{F}\right]$ \\
\hline T0 & Raw & 400 \\
\hline T1 & MFC-1 & 100 \\
\hline T2 & PM Filter & 125 \\
\hline T3 & Chiller & 100 \\
\hline T4 & MFC-3 & 100 \\
\hline
\end{tabular}

Each mass flow controller flow rates can be set manually by either entering a set value or using the arrows to increment the value in steps of $0.2 \mathrm{slpm}$. The sense value will be displayed with the dial and text box that are both below the set box. The maximum set value that the mass flow controllers in the micro-dilution system is 10 slpm each.

To run the program for a test, the following must be completed in the correct order. First, a steady state or transient test cycle should be selected from the Engine Test Cycle menu. Next, choose a method in which the program should start, either countdown or bit. If countdown is selected, then the button Start Countdown needs to be pressed to start the countdown. Then either proportional or constant volume sampling should be selected from the Sampling Type menu. If manual control is desired, then the mass flow controllers will need to be set to their desired values. Lastly, select Start Data and choose a file name and location for the data file to be stored. This file will be stored as comma delimited file (.cvs). Once the testing has ended, select Stop Data and exit out of the program. 


\subsection{Results}

The primary objective of this study was to develop a portable micro-dilution tunnel, and conduct qualification test to highlight the systems strengths and weaknesses. While the development of the tunnel was discussed in previous chapters, the qualification study is described below.

The micro-dilution and the full flow dilution tunnel are compared in this chapter. The results from eight steady state tests and six transient tests are described. Each set of test results will show the temperatures, mass flow rates, and differential pressures recorded in the micro-dilution system. The micro-dilution system results are then computed to compare with the full-flow dilution tunnel results.

The first graph will show five temperatures that were recorded throughout the micro-dilution system. The first thermocouple was located at the entrance of the microdilution system to monitor the temperature of the raw exhaust from the engine. The second thermocouple was installed at the filter face in the PM filter holder. This is to monitor the temperature at the filter face, which should remain below $125^{\circ} \mathrm{F}$ for TPM measurements (CFR 40, Part 86, Subpart N). The third thermocouple was located upstream of the dilution air mass flow controller to protect its internal parts from high temperature excursions. The fourth and fifth thermocouples were added to the final design. The fourth thermocouple was located downstream of the chiller to monitor its performance. The fifth thermocouple was placed after MFC \#3 to monitor the temperature of the gas exiting the system. This temperature generally mirrored the temperature of the test cell. 
The second graph displays all three mass flow controller's flow rates. MFC \#1, MFC \#2, and MFC \#3 controlled the flow rates of total diluted exhaust, the dilution air, and the exiting gas, respectively. To maintain a constant dilution ratio of 4 to 1 , the MFCs were set to $7.5 \mathrm{slpm}, 6.0 \mathrm{slpm}$, and $1.5 \mathrm{slpm}$ for MFC \#1, MFC \#2, and MFC\#3, respectively. The dilution ratio was calculated using Equation 4.1.

$$
D R=\frac{Q_{t o t}}{Q_{e x h}}=\frac{Q_{t o t}}{Q_{t o t}-Q_{\text {dil }}}
$$

where $\mathrm{Q}_{\text {tot }}=$ total mass flow rate in micro-dilution system $[\mathrm{lpm}]$

$\mathrm{Q}_{\mathrm{exh}}=$ exhaust mass flow rate in micro-dilution system [lpm]

$\mathrm{Q}_{\mathrm{exh}}=$ dilution air mass flow rate in micro-dilution system [lpm]

The next graph displays the comparison of the air flow rates entering and exiting the micro-dilution system. The air entering the system can be calculated from subtracting the sense values of MFC-1 from MFC-2. The air exiting the system is the sense value of MFC-3.

The next graph displays the differential pressures across the tunnel and PM filter. In the final design, the differential pressures gages were removed to reduce the length between the tunnel and PM filter. The reduced length helped decrease the temperature drop of the diluted exhaust between the tunnel and PM filter.

Also presented at the end of each section is a table that presents data on critical parameters of the micro-dilution tunnel, and compares the TPM (g/test) as measured by the micro-dilution tunnel system and the full-flow tunnel system. The mass flow rate into the micro-dilution system is integrated over the sampling period. The fuel flow rate and intake air flow rate are calculated from the EERL in-house data reduction programs. The total exhaust mass flow rate is calculated from the fuel flow rate, intake air flow rate, and 
sampling time, as shown in Equation 4.3. This mass flow rate is then converted to volumetric flow rate by using the density in the table, as shown in Equation 4.4. The mass on the 47-mm filter is obtained by weighing the filter before and after each test, and calculating the difference. The $\mathrm{P}_{\text {test }}$ (micro-tunnel) is calculated from the mass flow rate of the total exhaust that entered into micro-dilution system, as shown in Equation 4.2. The $\mathrm{P}_{\text {test }}$ (test cell) is calculated using the EERL in-house reduction program that follows the specifications outlined in the CFR-40. The percent difference, as shown in Equation 4.5 , between these two values is calculated and evaluated.

$$
P_{\text {test }}(\text { micro }- \text { tunnel })=\frac{m_{P M} * V_{e x h}}{V_{\text {in }} * 1000}
$$

where $V_{\text {exh }}=$ volume of exhaust [liters]

$$
\begin{aligned}
& \mathrm{m}_{\mathrm{PM}}=\text { mass collected on } 47-\mathrm{mm} \text { filter }[\mathrm{mg}] \\
& \mathrm{V}_{\mathrm{in}}=\text { volume into micro-dilution system [liters] }
\end{aligned}
$$

$$
m_{\text {exh }}=m_{\text {fuel }}+m_{\text {air }} * t
$$

where $\mathrm{m}_{\text {fuel }}=$ mass of fuel $[\mathrm{kg}]$

$$
\mathrm{m}_{\text {air }}=\text { intake air mass flow }[\mathrm{kg} / \mathrm{min}]
$$

$$
V_{e x h}=\frac{m_{e x h} * 1000}{\rho}
$$

where $\mathrm{m}_{\mathrm{exh}}=$ mass of exhaust $[\mathrm{kg}]$

$$
\begin{aligned}
& \rho=\text { density }\left[\mathrm{kg} / \mathrm{m}^{3}\right] \\
& \text { Percent Error }=\frac{P_{\text {test }}(\text { testcell })-P_{\text {test }}(\text { micro }- \text { tunnel })}{P_{\text {test }}(\text { testcell })}
\end{aligned}
$$




\subsection{Steady State Tests}

The first eight tests with the Navistar T444E engine coupled to the GE DC dynamometer are presented in this section. The first six tests were all ran on the same day and the last two repeated the previous tests. Each steady state test correlated well between the micro-dilution system and the full flow tunnel system, as shown in Figure 4.1. The $\mathrm{CO}_{2}$ and $\mathrm{NO}_{\mathrm{x}}$ emissions data for the full flow tunnel system are shown in Figure 4.2 and Figure 4.3, respectively. In general, all the tests produced the same $\mathrm{CO}_{2}$ emissions, except for test \#7. Test \#7 produced $50 \mathrm{~g} / \mathrm{bhp}$-hr less than the remaining seven steady state tests. However, the first six tests produced similar amounts of $\mathrm{NO}_{\mathrm{x}}$ emissions, but the $\mathrm{NO}_{\mathrm{x}}$ emissions produced increased by $3 \mathrm{~g} / \mathrm{bhp}$-hr for test \#7 and test \#8.

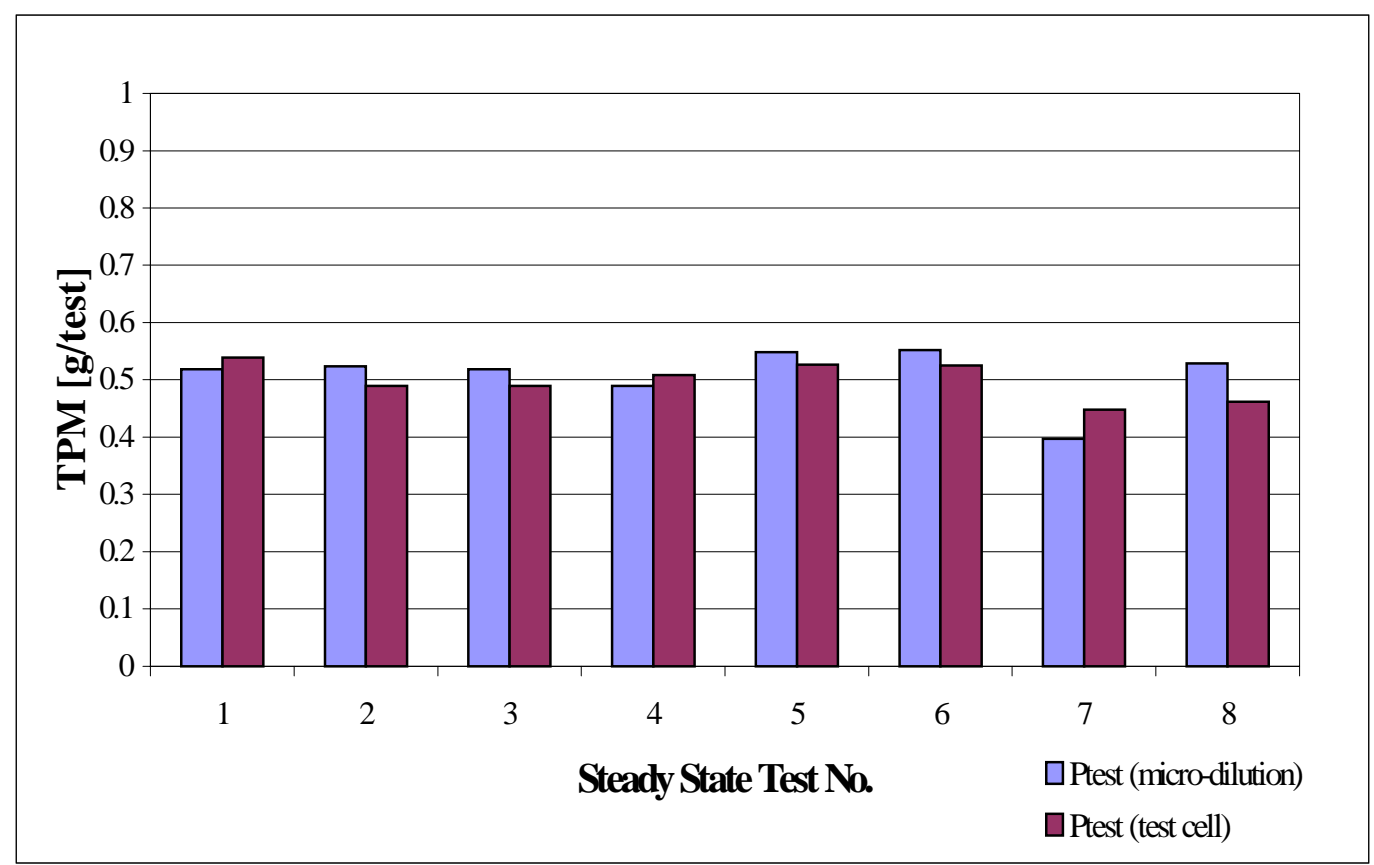

Figure 4.1 Comparison of Total Particulate Matter for Steady State Tests 


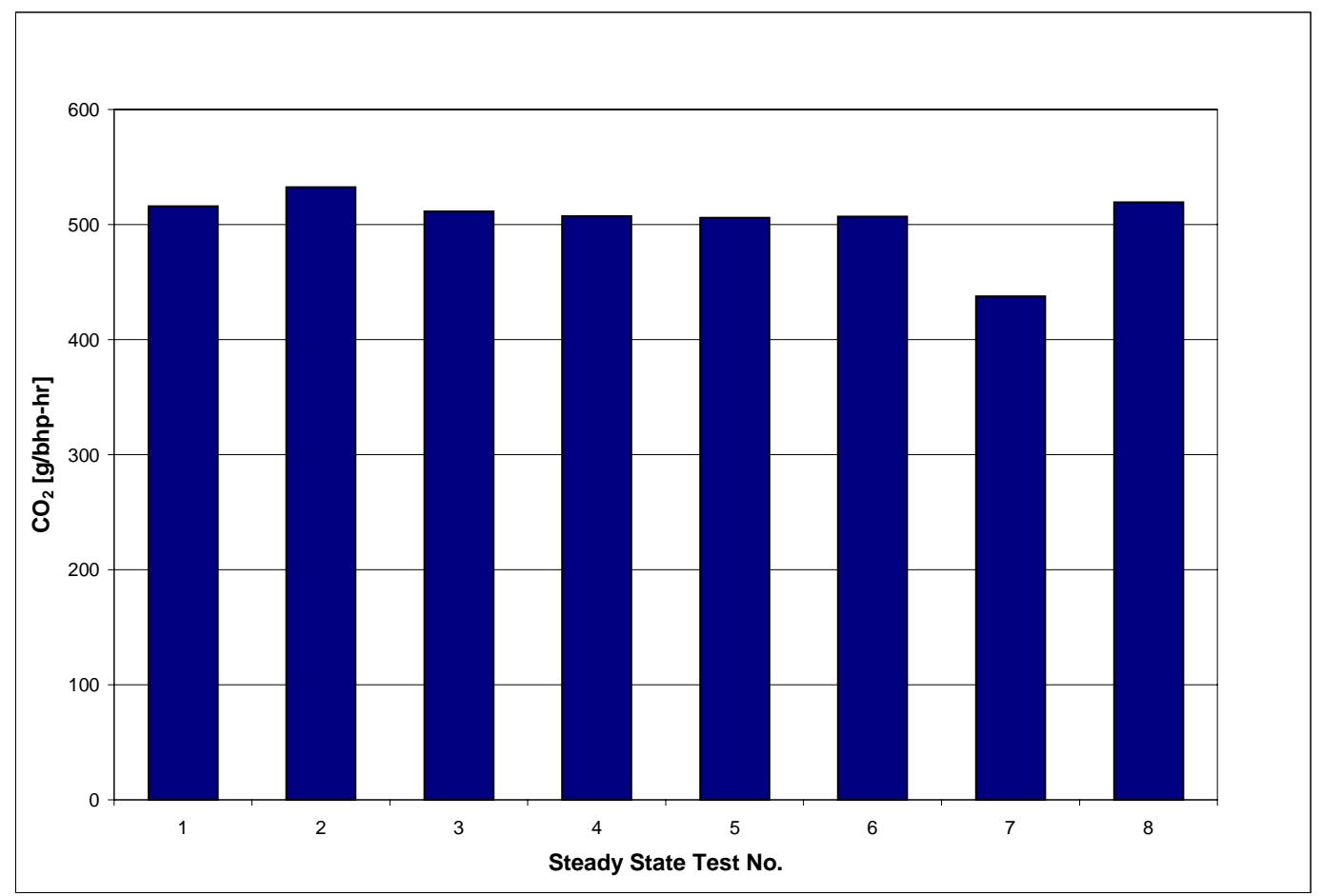

Figure 4.2 Comparison of $\mathrm{CO}_{2}$ Emissions Data for Steady State Tests

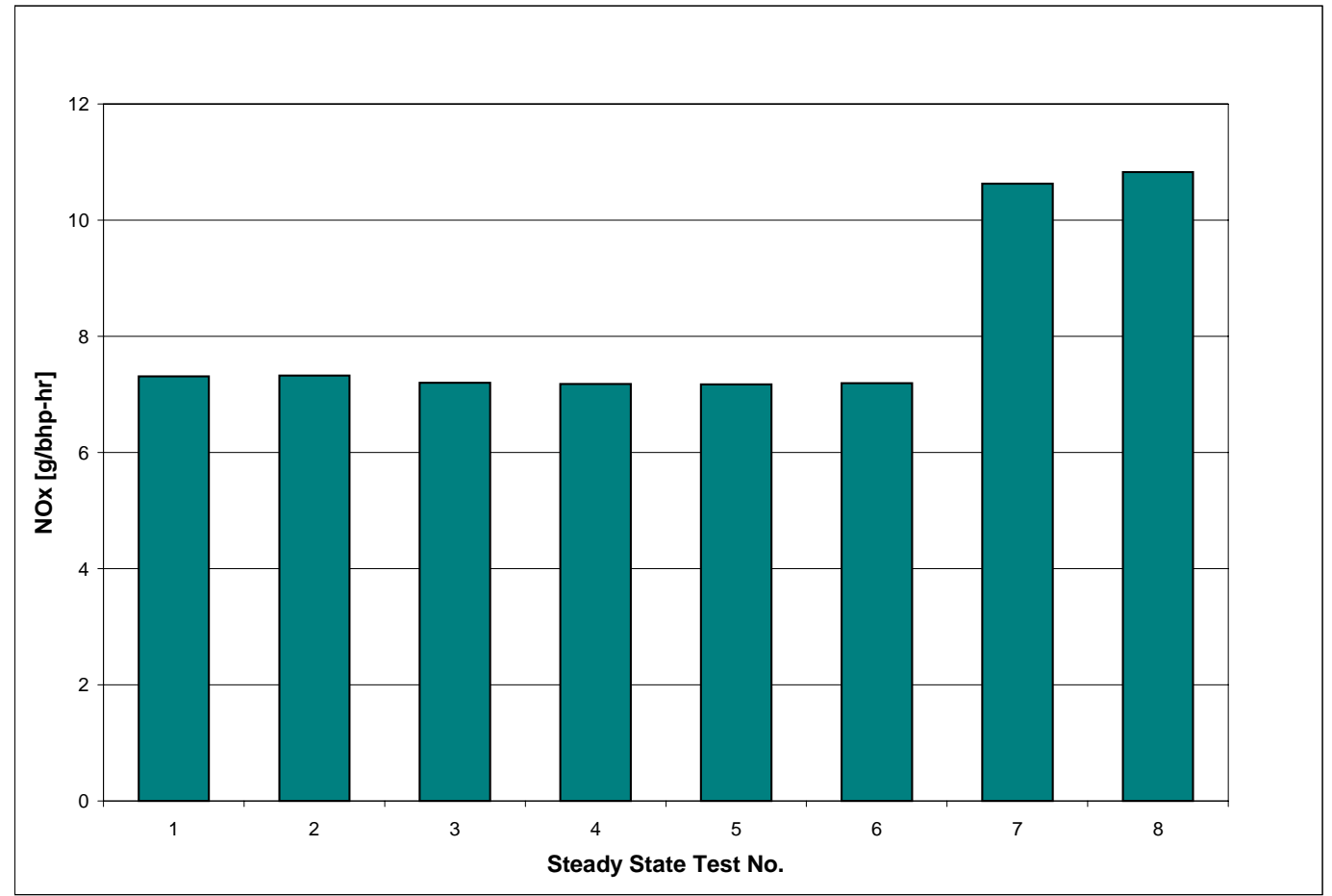

Figure 4.3 Comparison of NOx Emissions Data for Steady State Tests 


\subsubsection{Test \#1 (1900 rpm, 330 ft-lb)}

The first steady state test with the Navistar T444E engine was run at approximately $75 \%$ rated speed $(1900 \mathrm{rpm})$ and $75 \%$ rated load $(330 \mathrm{ft}-\mathrm{lb}(447 \mathrm{~N}-\mathrm{m}))$. The engine was allowed to stabilize for 3 minutes before sampling for 10 minutes. This section discusses the results of this test, and the comparison between the micro-dilution and the full flow dilution tunnels.

Figure 4.4 shows the temperatures of the raw exhaust, PM filter face, dilution air mass flow controller \#1, chiller and mass flow controller \#3. The temperature of the raw exhaust varied sinusoidally because the four-inch section between the heated line and dilution tunnel was not insulated. The temperatures at the PM filter face, MFC-1, chiller, and MFC-3 all linearly increased, but different rates. The PM filter face temperature approached its maximum temperature allowable at the end of the test run.

Figure 4.5 and Figure 4.6 show the flow rates of each of the mass flow controllers into the micro-dilution system. In Figure 4.5, the first thirty seconds show the mass flow controllers being set and stabilizing to their appropriate setpoints. Mass flow rates were stable for the remainder of the test. The dilution air MFC took longer to reach its setpoint than the other two MFCs. In Figure 4.6, the difference of the total and the dilution air is compared against the amount that is exiting from the micro-dilution system. By the end of the test cycle, the difference between the two flow rates was negligible.

Figure 4.7 shows the differential pressure across the micro-dilution tunnel and the PM filter as it was loaded with particulate matter. As expected, the differential pressure of the tunnel and the PM filter increased initially, and then stabilized. 
Table 4.1 shows the values of various critical parameters of the micro-dilution during Test \#1, and also compares the TPM (g/test) from the micro- and full-flow tunnels. The volume into the micro-dilution system was integrated over the sampling time was calculated to be 14.7 liters during a 10 minute test. The fuel consumption and intake air mass flow rates were $3.2 \mathrm{~kg}$ and $10.32 \mathrm{~kg} / \mathrm{min}$, respectively. The total exhaust volume was calculated to be 88715 liters. This test yielded only a $4 \%$ difference between the $\mathrm{P}_{\text {test }}$ (test cell) and $\mathrm{P}_{\text {test }}$ (micro-tunnel).

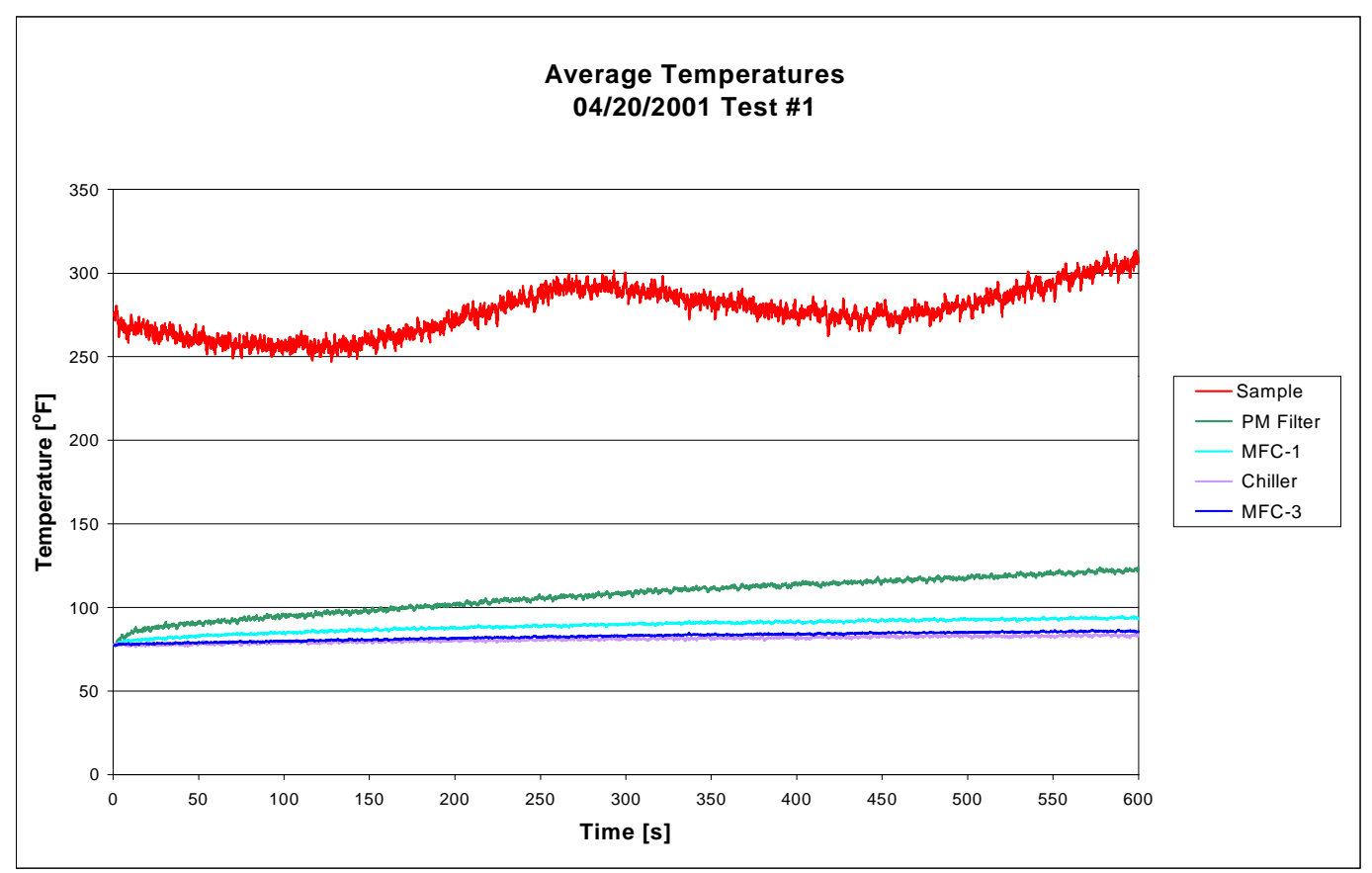

Figure 4.4 Temperatures During Steady State Test \#1 


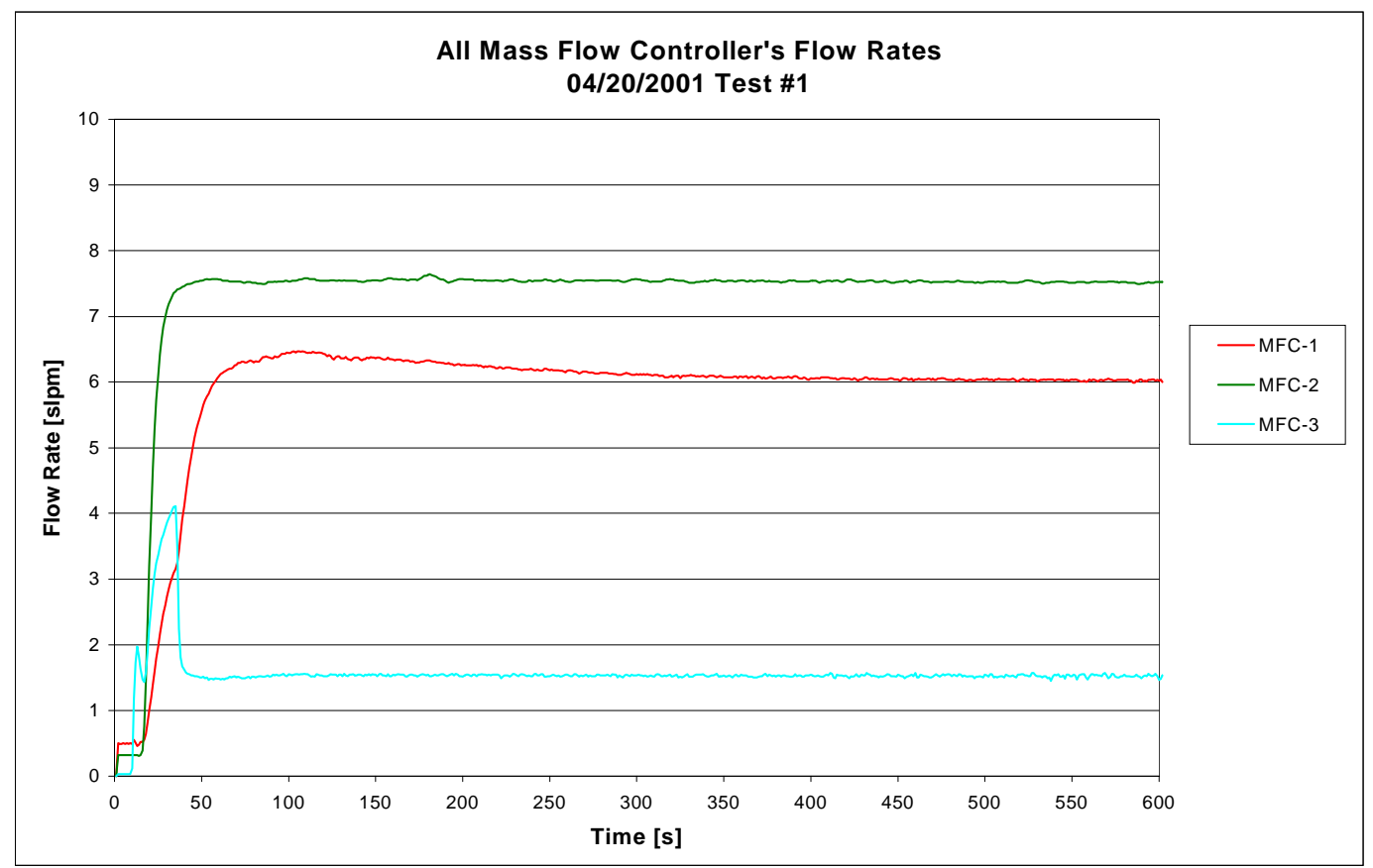

Figure 4.5 Mass Flow Rates During Steady State Test \#1

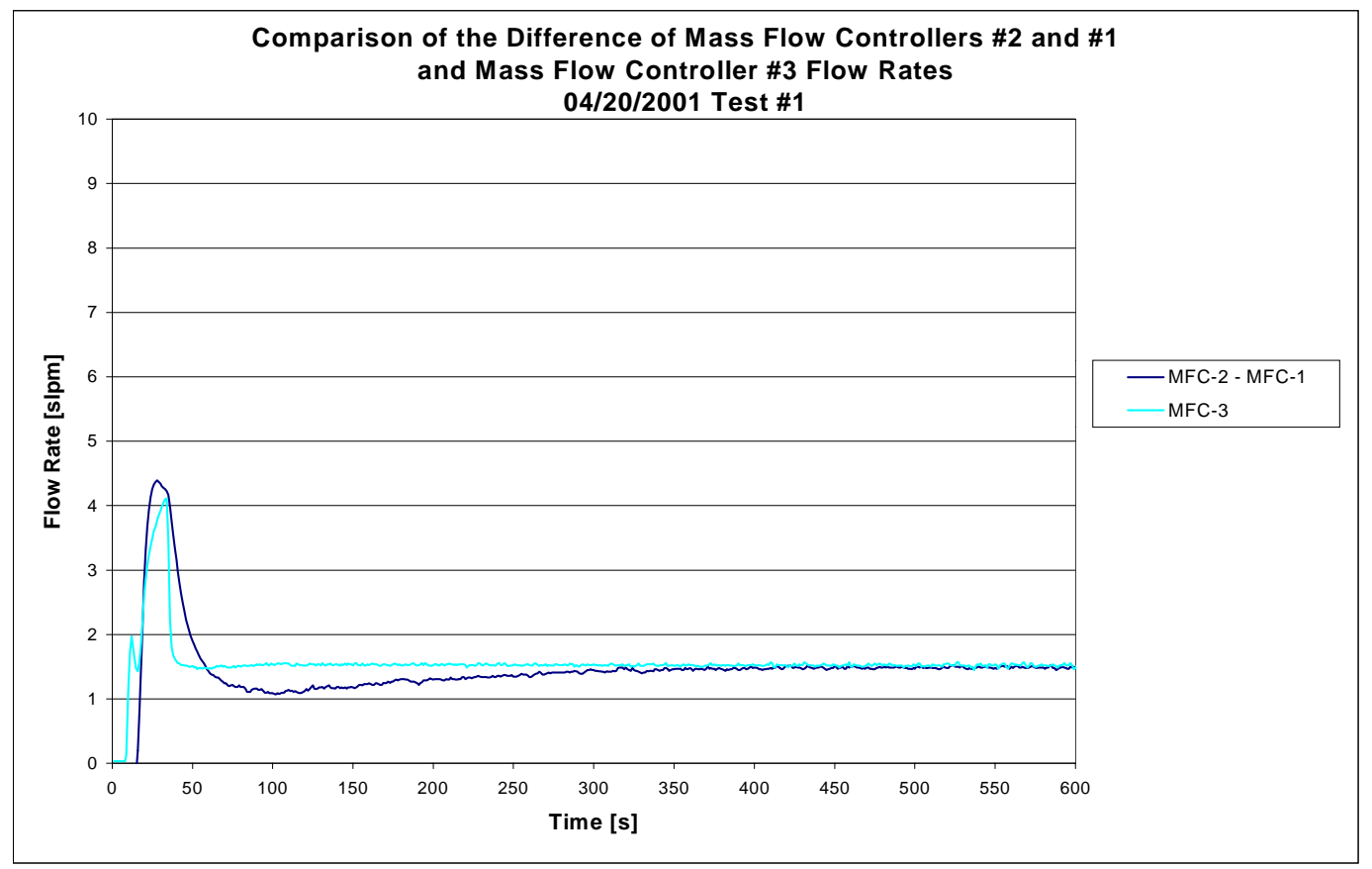

Figure 4.6 Comparison of Raw Exhaust and Bleed Flow Rates During Steady State Test \#1 


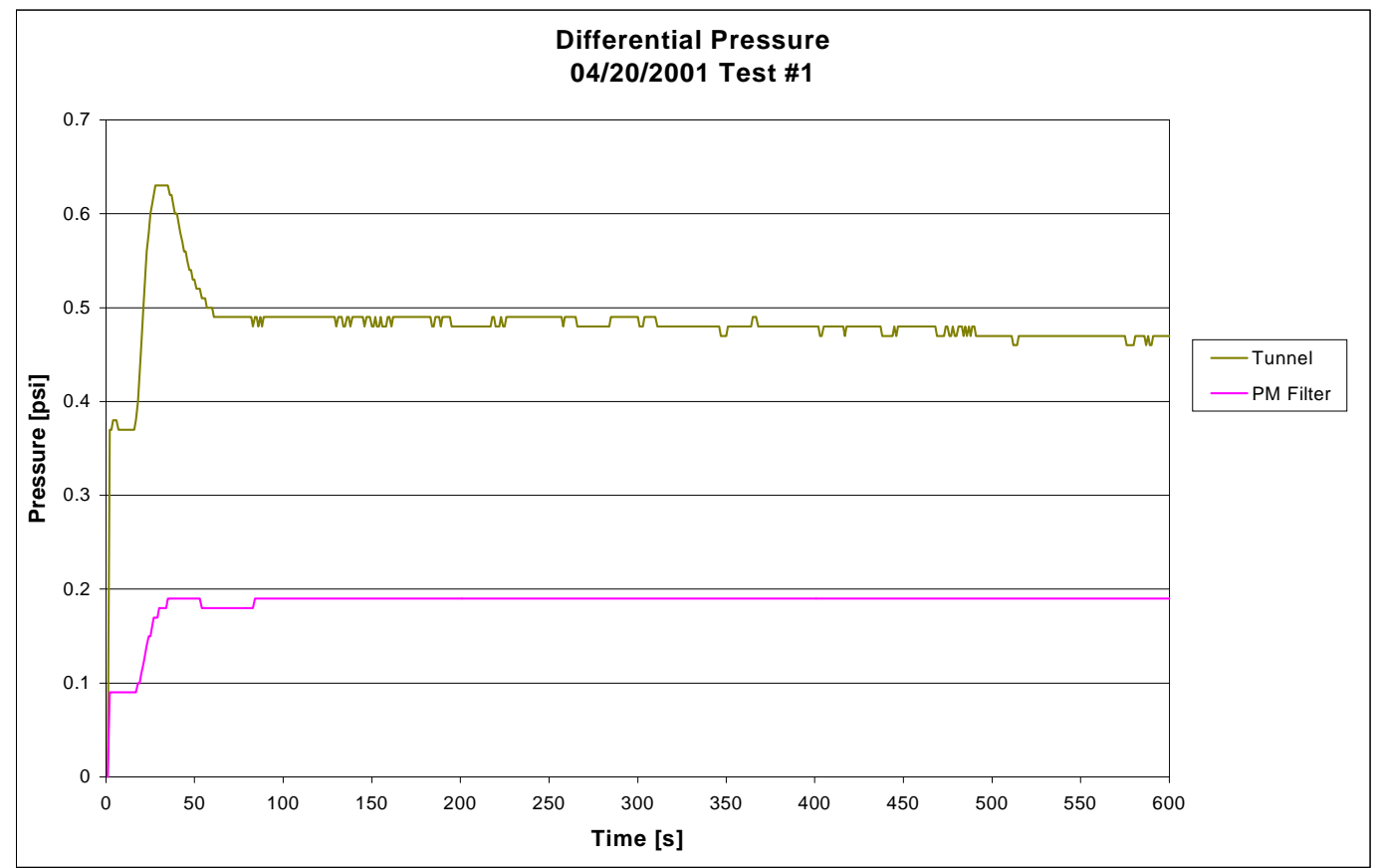

Figure 4.7 Differential Pressures During Steady State Test \#1

Table 4.1 Comparison of Full-Flow Dilution and Micro-Dilution Tunnels for Steady State Test \#1

\begin{tabular}{|l|r|l|}
\hline Volume into micro-dilution system $=$ & 14.71 & {$[\mathrm{liters}]$} \\
\hline Fuel Consumption from Counter $=$ & 3.26 & {$[\mathrm{~kg}]$} \\
\hline Intake Air Mass Flow $=$ & 10.32 & {$[\mathrm{~kg} / \mathrm{min}]$} \\
\hline Length of Sampling Time $=$ & 10 & {$[\mathrm{~min}]$} \\
\hline Total Exhaust Mass $=$ & 106.46 & {$[\mathrm{~kg}]$} \\
\hline Density $=$ & 1.2 & {$\left[\mathrm{~kg} / \mathrm{m}^{3}\right]$} \\
\hline Volume Total Exhaust $=$ & 88715 & {$[\mathrm{liters}]$} \\
\hline Mass on 47-mm filter $=$ & 0.086 & {$[\mathrm{mg}]$} \\
\hline Mass on 70-mm filter $=$ & 1.962 & {$[\mathrm{mg}]$} \\
\hline $\mathrm{P}_{\text {test }}($ micro-tunnel $)=$ & 0.52 & {$[\mathrm{~g} / \mathrm{test}]$} \\
\hline $\mathrm{P}_{\text {test }}($ test cell $)=$ & 0.54 & {$[\mathrm{~g} / \mathrm{test}]$} \\
\hline Percent Error $=$ & $\mathbf{4 \%}$ & \\
\hline
\end{tabular}

\subsubsection{Test \#2 (1900 rpm, $330 \mathrm{ft}-\mathrm{lb})$}

The second steady state test with the Navistar T444E ran under the same loading conditions as the previous test. The total sample time for this test was also ten minutes. 
This section discusses the repeatability, results of this test, and the micro-dilution and full-flow dilution tunnels.

Figure 4.8 shows target temperature profiles throughout the micro-dilution system. All of the temperatures behaved similarly to the previous test. The temperature at the PM filter face approached its limit as well. Figure 4.9 and Figure 4.10 show that the mass flow rates stabilized. The differential pressures across the tunnel and PM filter also remained the same, as shown in Figure 4.11. Table 4.2 shows a $7 \%$ difference between the particulate collected per test using the full flow tunnel dilution system and the micro-dilution tunnel system.

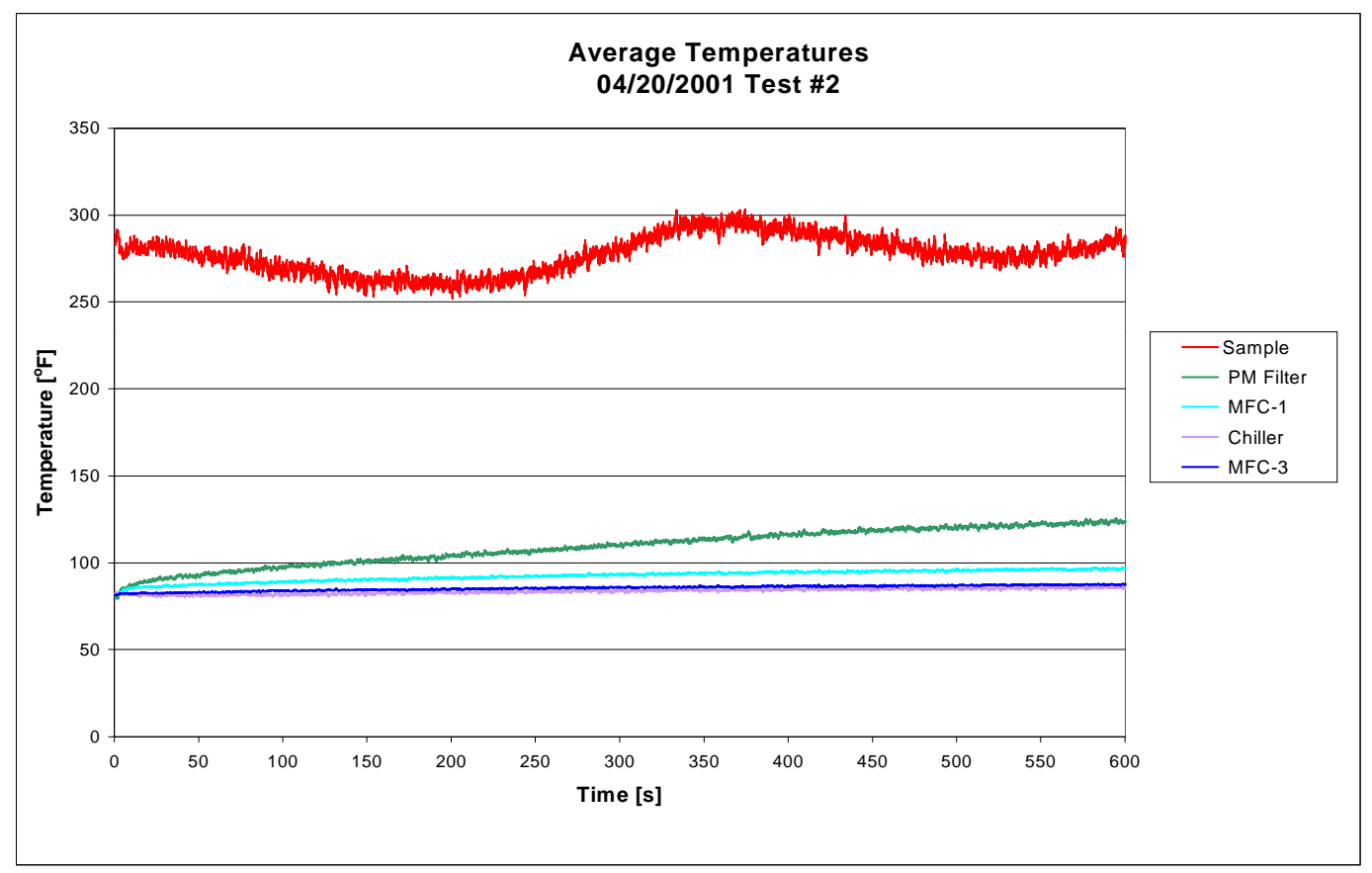

Figure 4.8 Temperatures During Steady State Test \#2 


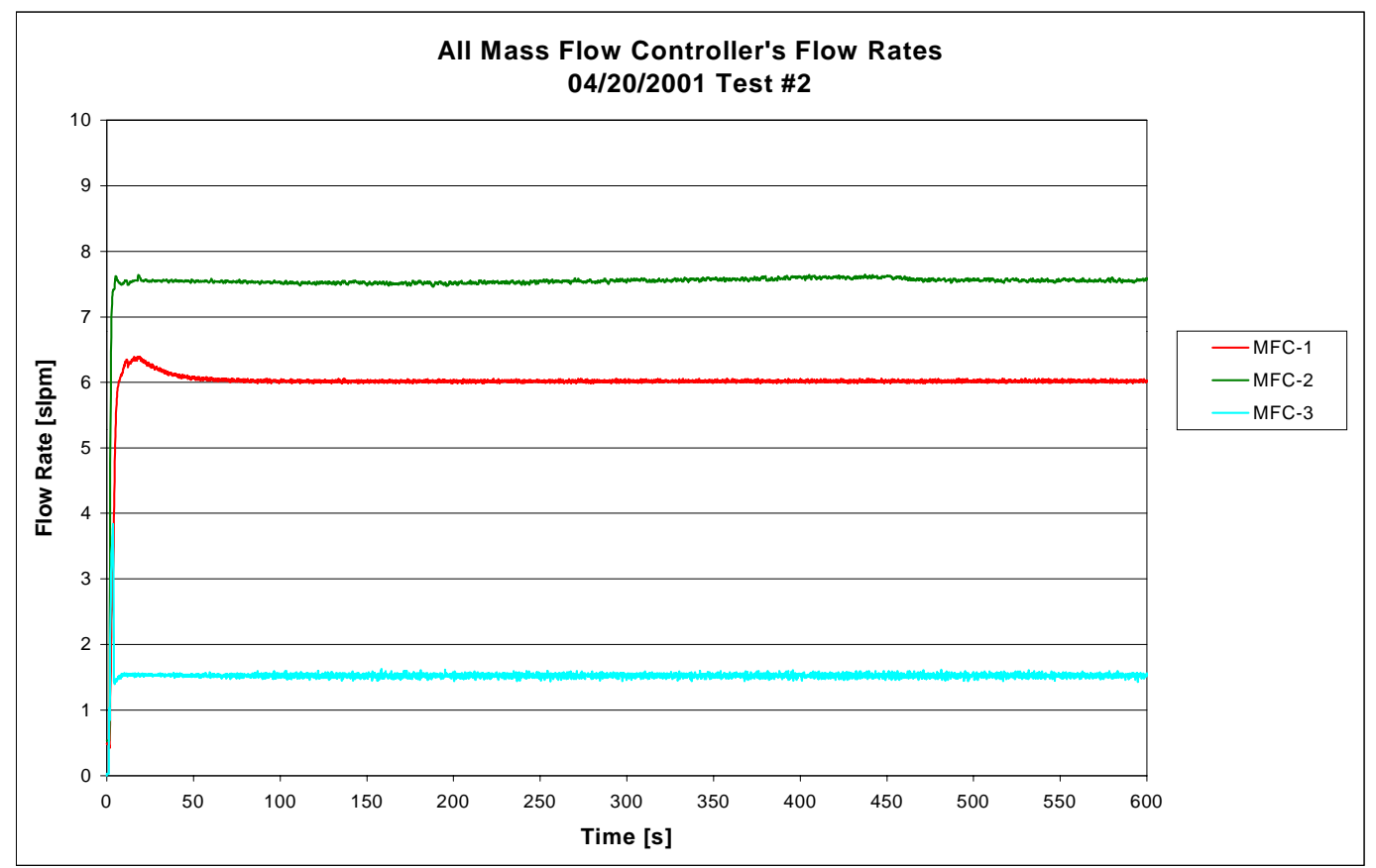

Figure 4.9 Mass Flow Rates During Steady State Test \#2

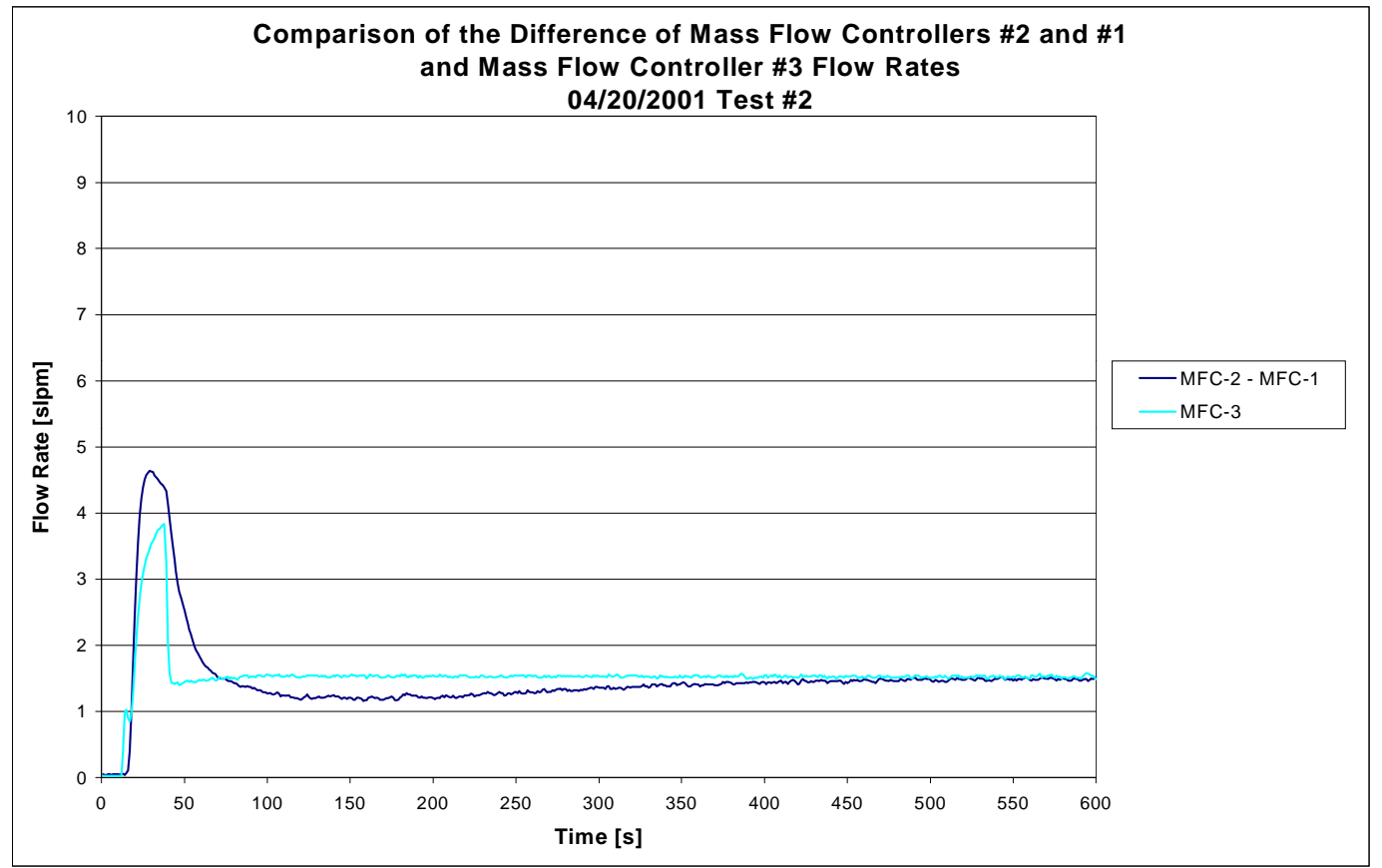

Figure 4.10 Comparison of Raw Exhaust and Bleed Flow Rates During Steady State Test \#2 


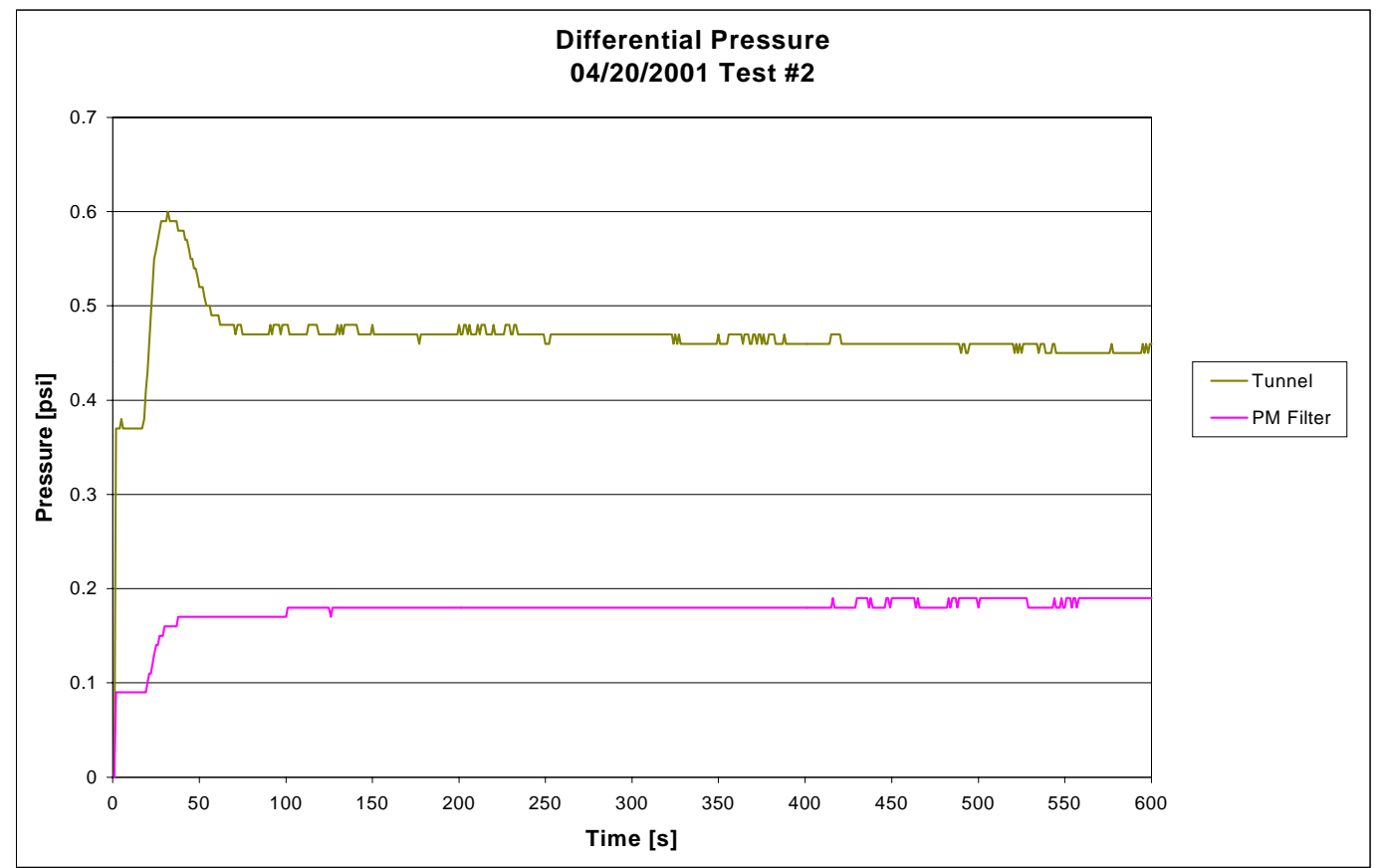

Figure 4.11 Differential Pressures During Steady State Test \#2

Table 4.2 Comparison of Full-Flow Dilution and Micro-Dilution Tunnels for Steady State Test \#2

\begin{tabular}{|l|r|l|}
\hline Volume into micro-dilution system $=$ & 15.29 & {$[\mathrm{liters}]$} \\
\hline Fuel Consumption from Counter $=$ & 3.22 & {$[\mathrm{~kg}]$} \\
\hline Intake Air Mass Flow $=$ & 10.47 & {$[\mathrm{~kg} / \mathrm{min}]$} \\
\hline Length of Sampling Time $=$ & 10 & {$[\mathrm{~min}]$} \\
\hline Total Exhaust Mass $=$ & 107.92 & {$[\mathrm{~kg}]$} \\
\hline Density $=$ & 1.2 & {$\left[\mathrm{~kg} / \mathrm{m}^{3}\right]$} \\
\hline Volume Total Exhaust $=$ & 89936 & {$[\mathrm{liters}]$} \\
\hline Mass on 47-mm filter $=$ & 0.089 & {$[\mathrm{mg}]$} \\
\hline Mass on 70-mm filter $=$ & 1.913 & {$[\mathrm{mg}]$} \\
\hline $\mathrm{P}_{\text {test }}($ micro-tunnel $)=$ & 0.52 & {$[\mathrm{~g} / \mathrm{test}]$} \\
\hline $\mathrm{P}_{\text {test }}$ (test cell $)=$ & 0.49 & {$[\mathrm{~g} / \mathrm{test}]$} \\
\hline Percent Error $=$ & $\mathbf{- 7 \%}$ & \\
\hline
\end{tabular}

\subsubsection{Test \#3 (1900 rpm, $330 \mathrm{ft}-\mathrm{lb})$}

The third steady state test used the same conditions and same engine as the first two steady states. Figure 4.12 shows the temperatures were similar to these in the 
previous two tests, and the temperature at the PM filter face temperature reached the maximum temperature limit of $125^{\circ} \mathrm{F}$ at the end of the test.

Mass flow rates throughout the system were similar to those in previous two tests as shown in Figure 4.13. In Figure 4.14, the difference between the diluted exhaust total and dilution air flow rate is compared against the flow rate that is exiting from the microdilution system, that is the bleed flow rate. At the beginning of the test, the mass flow controllers were stabilizing and by the end of the test, the flow rates converged toward each other. Figure 4.15 shows that the differential pressure across the tunnel and PM filter remained the same as well.

The $6 \%$ difference between the full-flow tunnel and the micro-dilution tunnel results is shown in Table 4.3. The first three tests were comparable to one another, and also with the full-flow tunnel system as seen from the small differences between these two systems.

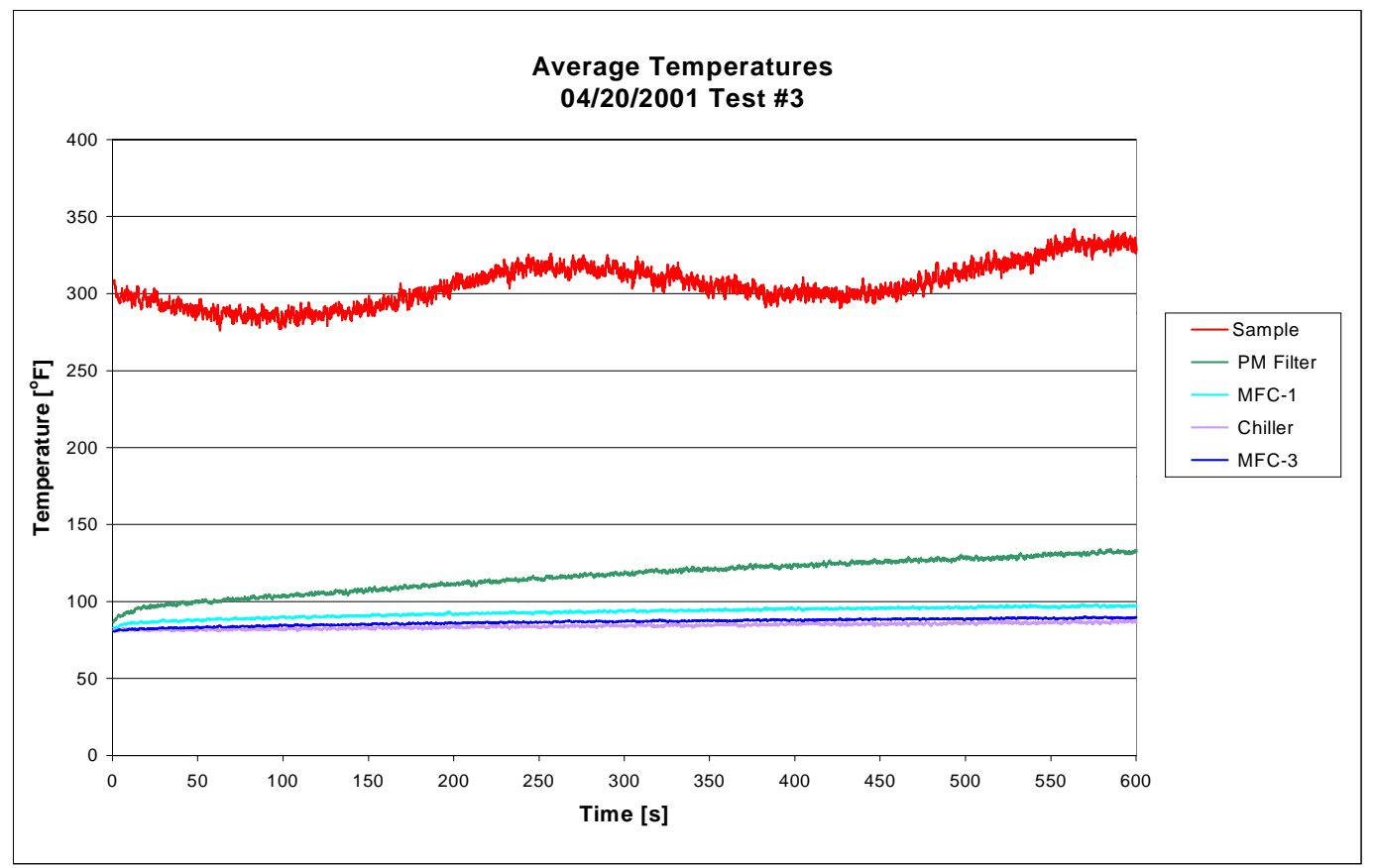

Figure 4.12 Temperatures During Steady State Test \#3 


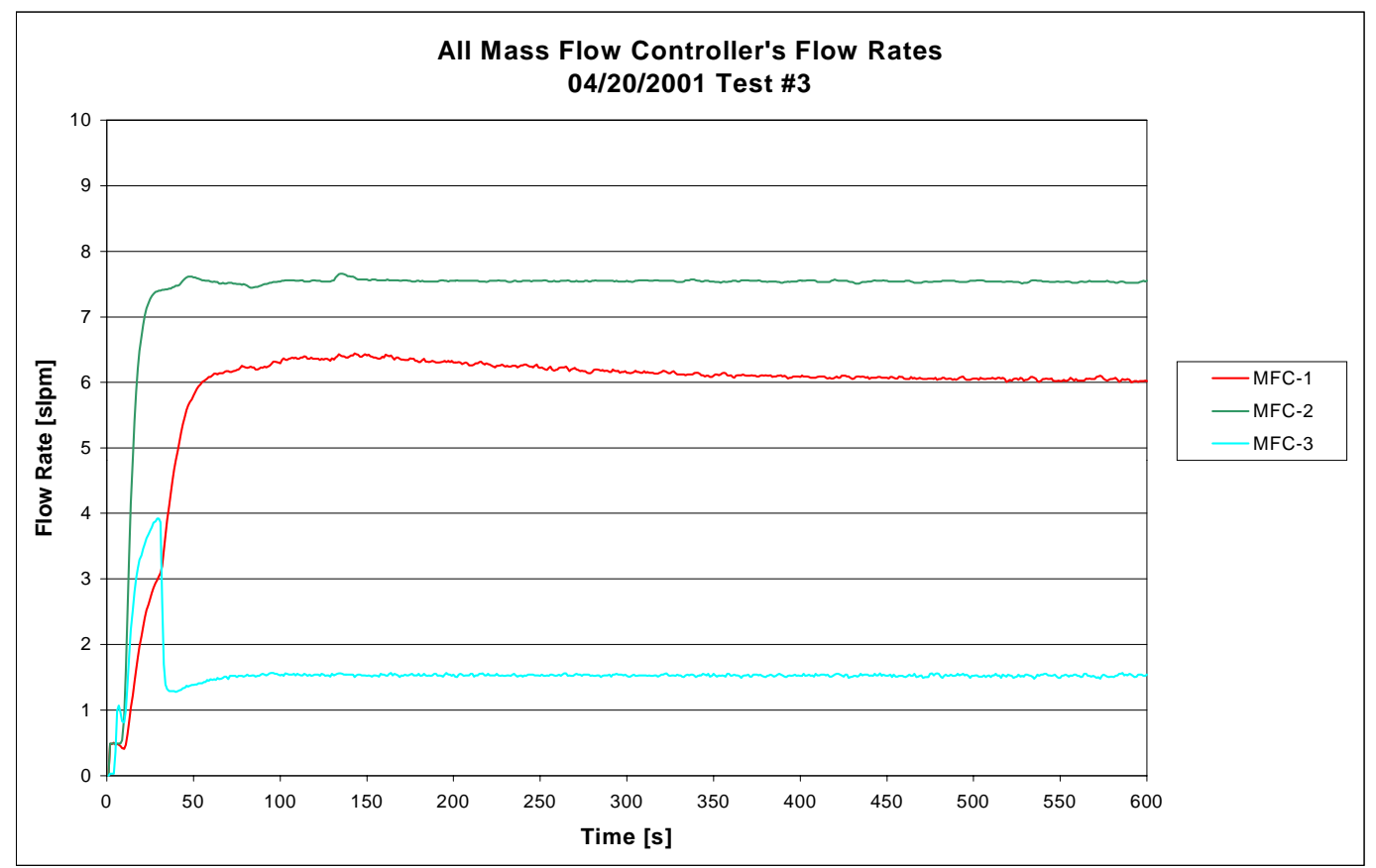

Figure 4.13 Mass Flow Rates During Steady State Test \#3

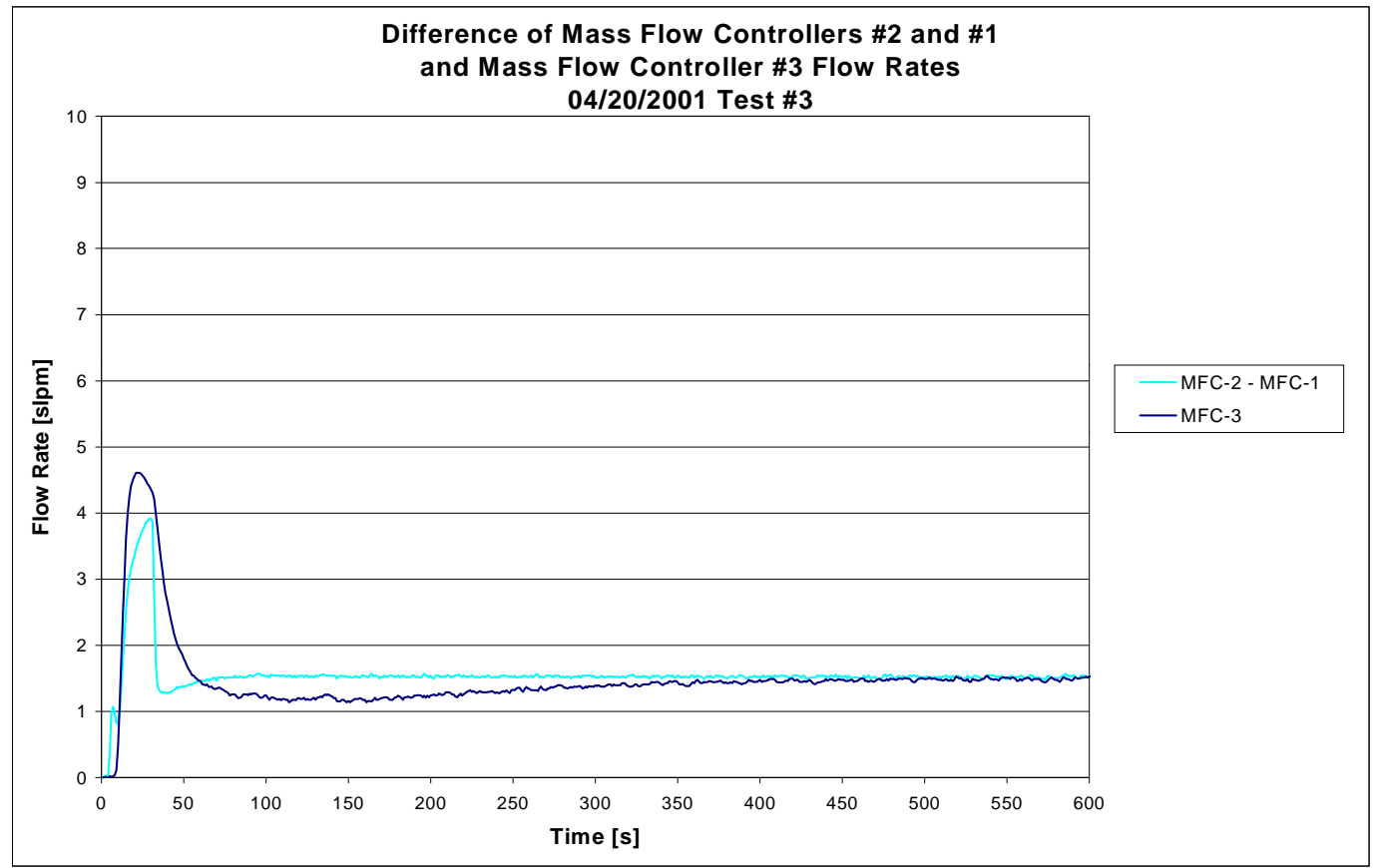

Figure 4.14 Comparison of Raw Exhaust and Bleed Flow Rates During Steady State Test \#3 


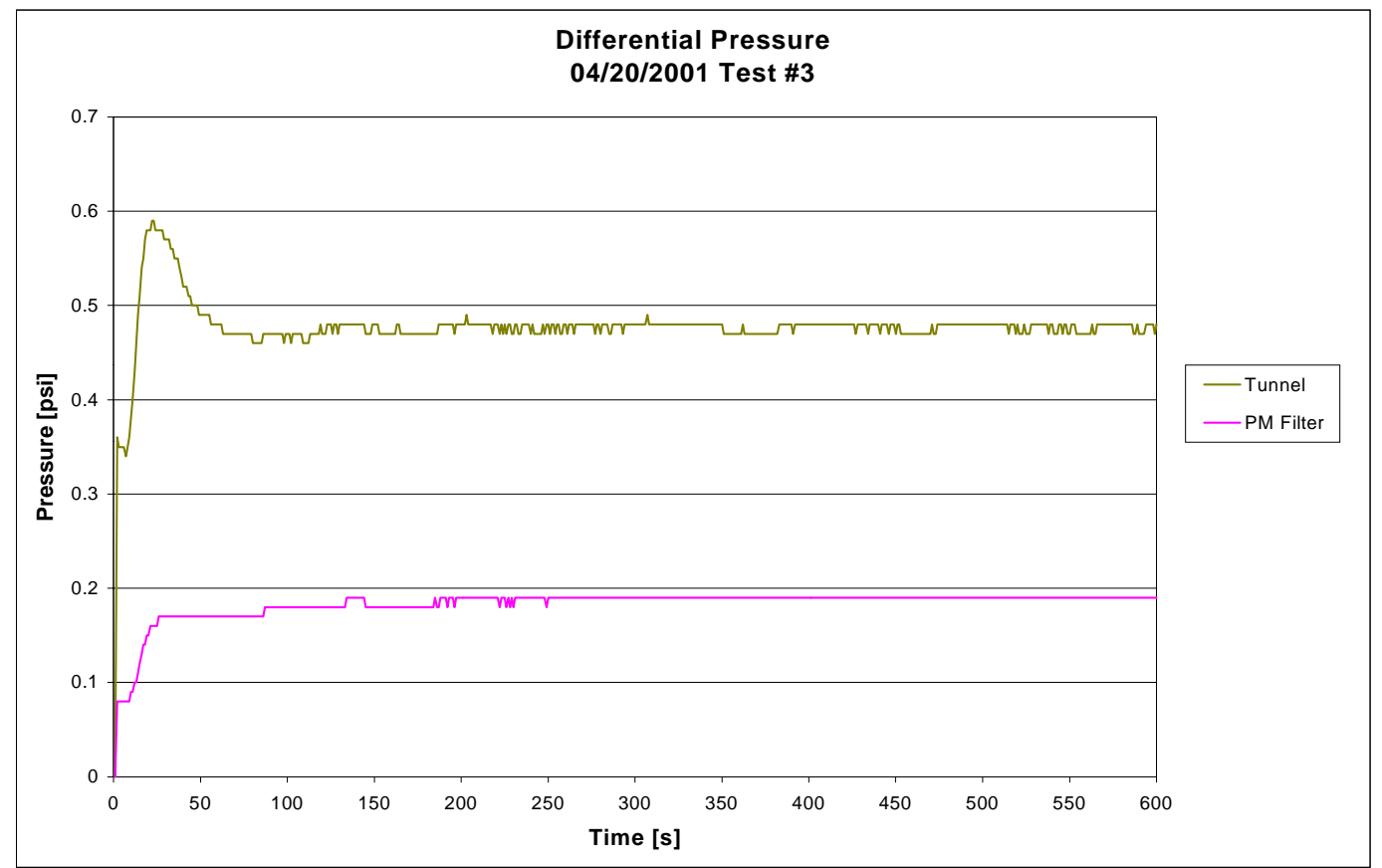

Figure 4.15 Differential Pressures During Steady State Test \#3

Table 4.3 Comparison of Full-Flow Dilution and Micro-Dilution Tunnels for Steady State Test \#3

\begin{tabular}{|l|r|l|}
\hline Volume into micro-dilution system $=$ & 15.24 & {$[\mathrm{liters}]$} \\
\hline Fuel Consumption from Counter $=$ & 3.25 & {$[\mathrm{~kg}]$} \\
\hline Intake Air Mass Flow $=$ & 10.32 & {$[\mathrm{~kg} / \mathrm{min}]$} \\
\hline Length of Sampling Time $=$ & 10 & {$[\mathrm{~min}]$} \\
\hline Total Exhaust Mass $=$ & 106.45 & {$[\mathrm{~kg}]$} \\
\hline Density $=$ & 1.2 & {$\left[\mathrm{~kg} / \mathrm{m}^{3}\right]$} \\
\hline Volume Total Exhaust $=$ & 88712 & {$[\mathrm{liters}]$} \\
\hline Mass on 47-mm filter $=$ & 0.089 & {$[\mathrm{mg}]$} \\
\hline Mass on 70-mm filter $=$ & 1.787 & {$[\mathrm{mg}]$} \\
\hline $\mathrm{P}_{\text {test }}(\mathrm{micro}-$ tunnel $)=$ & 0.52 & {$[\mathrm{~g} / \mathrm{test}]$} \\
\hline $\mathrm{P}_{\text {test }}($ test cell $)=$ & 0.49 & {$[\mathrm{~g} / \mathrm{test}]$} \\
\hline Percent Error $=$ & $\mathbf{- 6 \%}$ & \\
\hline
\end{tabular}

\subsubsection{Test \#4 (1900 rpm, $330 \mathrm{ft}-\mathrm{lb})$}

Figure 4.16 and Figure 4.19 both exhibit similar behavior as the first three steady state tests. As expected, these results were similar to the previous tests, since none of the test conditions changed. However, Figure 4.17 and Figure 4.18 differed slightly in the 
beginning of the test run. Mass flow controller \#3 was "hunting" prior to reaching its setpoint of $1.5 \mathrm{slpm}$. This slight excursion did not affect the test results. The percent error for this test run was again only $4 \%$.

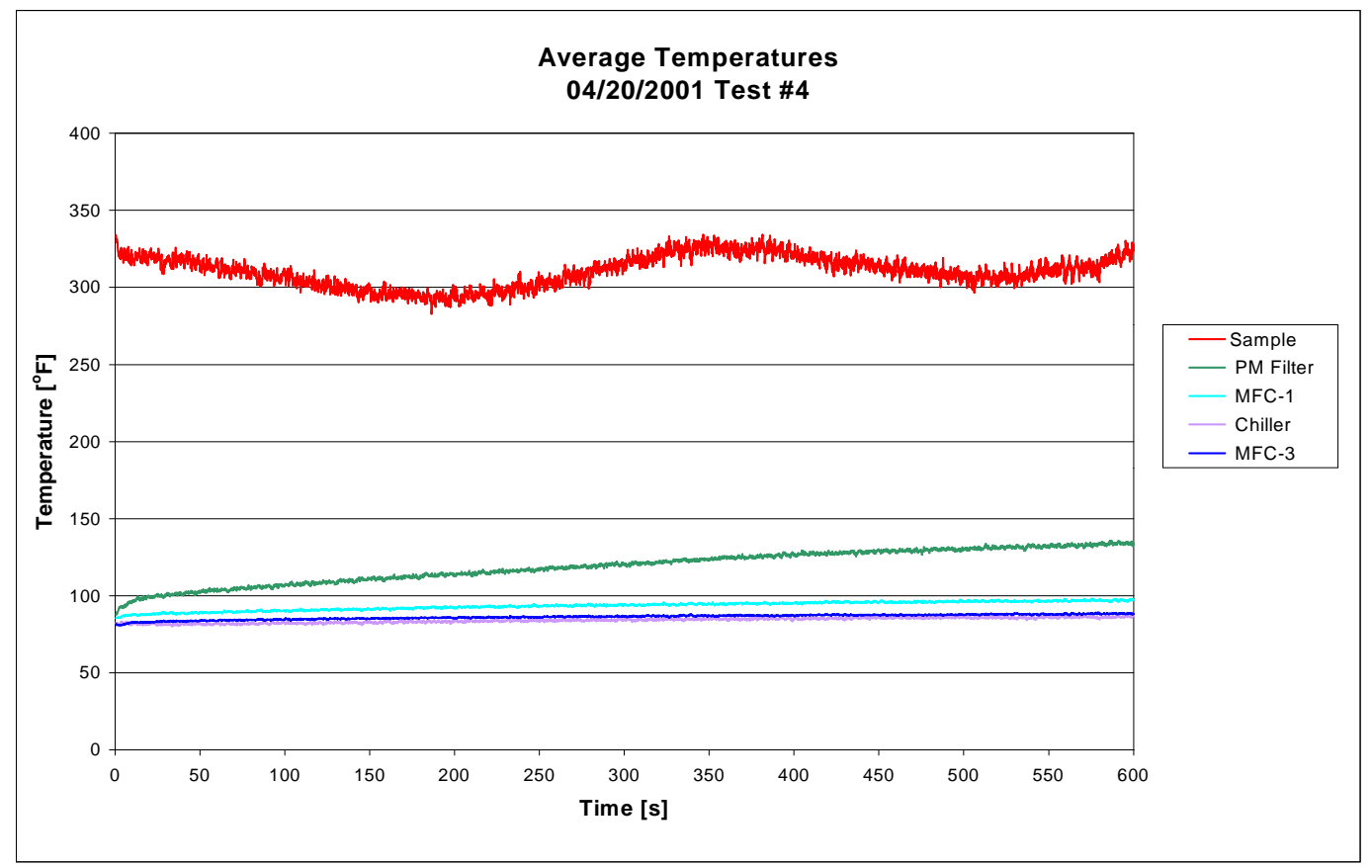

Figure 4.16 Temperatures During Steady State Test \#4 


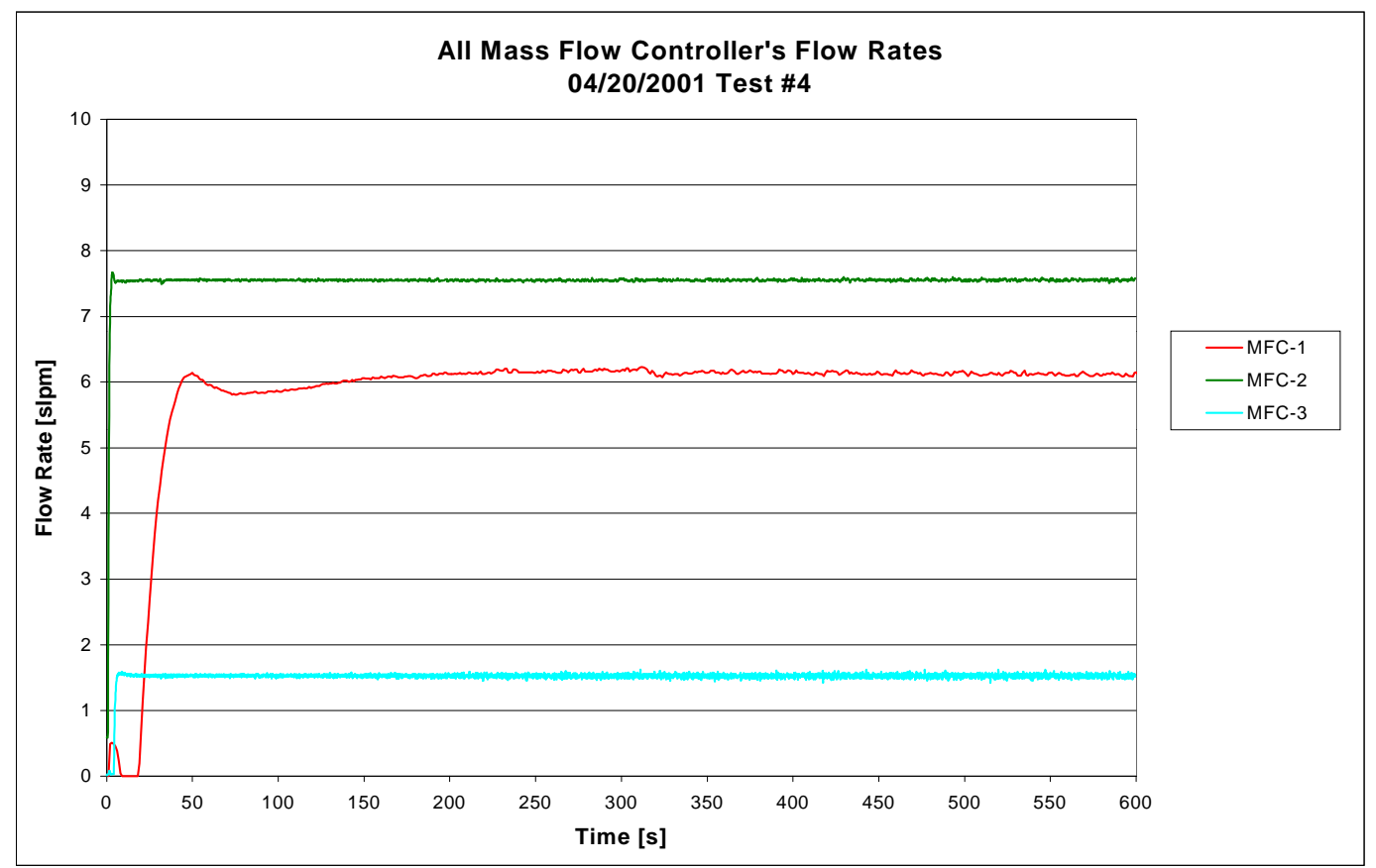

Figure 4.17 Mass Flow Rates During Steady State Test \#4

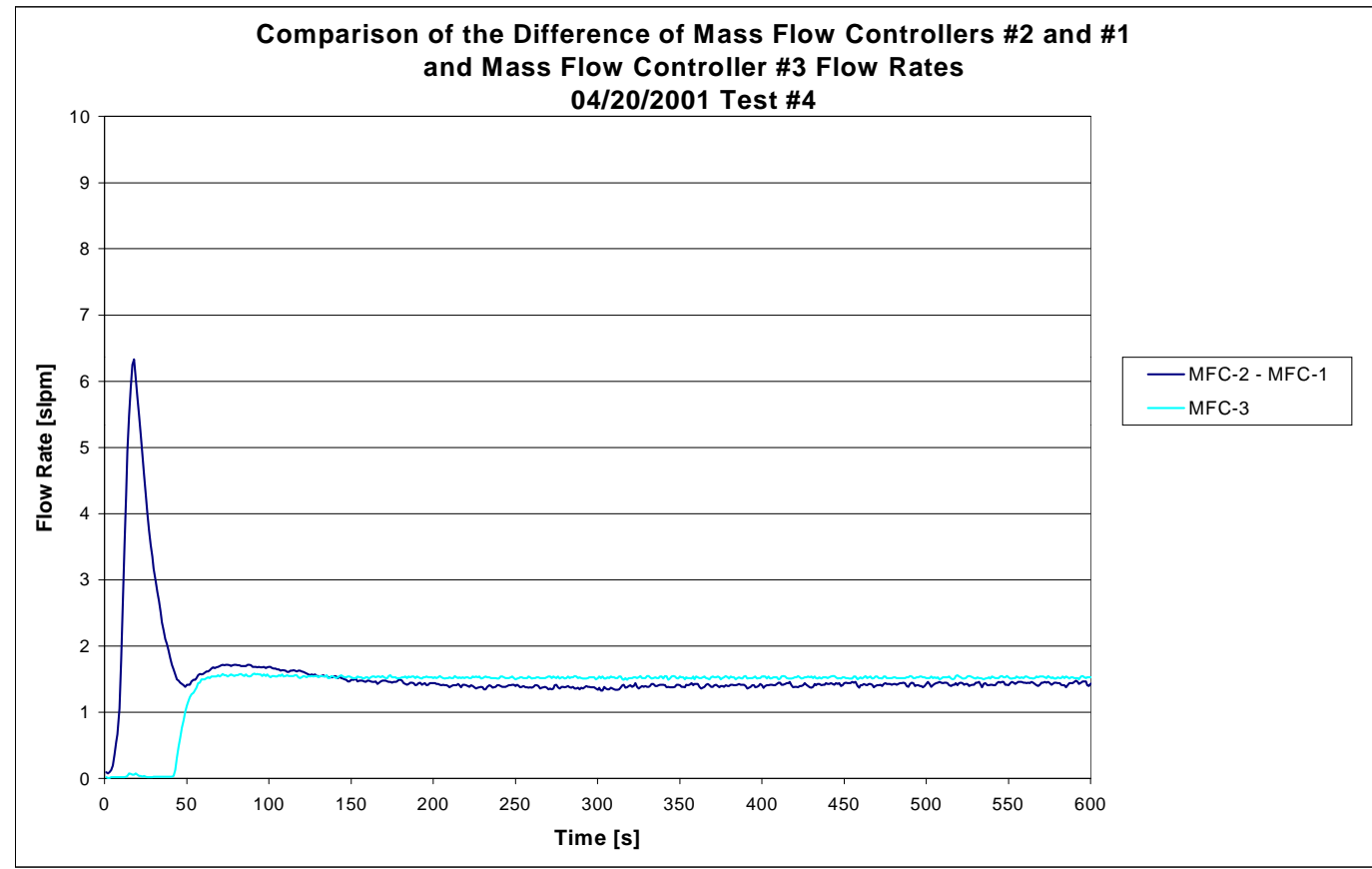

Figure 4.18 Comparison of Raw Exhaust and Bleed Flow Rates During Steady State Test \#4 


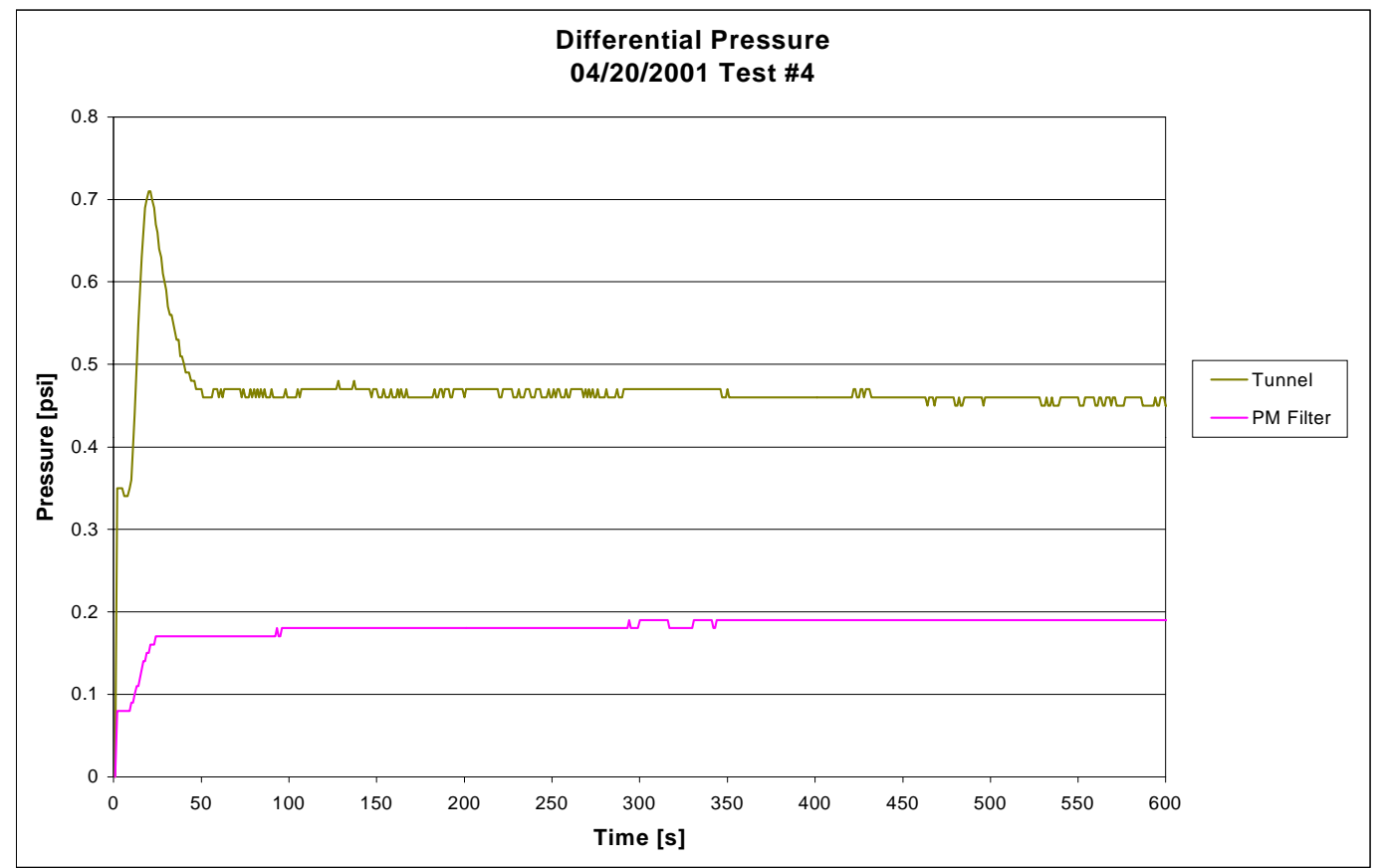

Figure 4.19 Differential Pressure During Steady State Test \#4

Table 4.4 Comparison of Full-Flow Dilution and Micro-Dilution Tunnels for Steady State Test \#4

\begin{tabular}{|l|r|l|}
\hline Volume into micro-dilution system $=$ & 15.27 & {$[\mathrm{liters}]$} \\
\hline Fuel Consumption from Counter $=$ & 3.23 & {$[\mathrm{~kg}]$} \\
\hline Intake Air Mass Flow $=$ & 10.48 & {$[\mathrm{~kg} / \mathrm{min}]$} \\
\hline Length of Sampling Time $=$ & 10 & {$[\mathrm{~min}]$} \\
\hline Total Exhaust Mass $=$ & 108.03 & {$[\mathrm{~kg}]$} \\
\hline Density $=$ & 1.2 & {$\left[\mathrm{~kg} / \mathrm{m}^{3}\right]$} \\
\hline Volume Total Exhaust $=$ & 90021 & {$[\mathrm{liters}]$} \\
\hline Mass on 47-mm filter $=$ & 0.083 & {$[\mathrm{mg}]$} \\
\hline Mass on 70-mm filter $=$ & 1.855 & {$[\mathrm{mg}]$} \\
\hline $\mathrm{P}_{\text {test }}(\mathrm{micro}-$-tunnel $)=$ & 0.49 & {$[\mathrm{~g} / \mathrm{test}]$} \\
\hline $\mathrm{P}_{\text {test }}($ test cell $)=$ & 0.51 & {$[\mathrm{~g} / \mathrm{test}]$} \\
\hline Percent Error $=$ & $\mathbf{4 \%}$ & \\
\hline
\end{tabular}

\subsubsection{Test \#5 (1900 rpm, $330 \mathrm{ft}-\mathrm{lb})$}

This test also resembled the previous four tests as expected. Unlike the previous test, the last mass flow controller behaved, as it should have in the initial part of the test. It initially overshot the setpoint and then stabilized at its setpoint. The percent difference 
was also only $4 \%$, similar to the previous test; however, the TPM collected in this test collected $0.018 \mathrm{~g} /$ test and $0.058 \mathrm{~g} /$ test less than the previous test for the full-flow and micro-dilution tunnel systems, respectively. The engine's performance for this test resulted in less TPM.

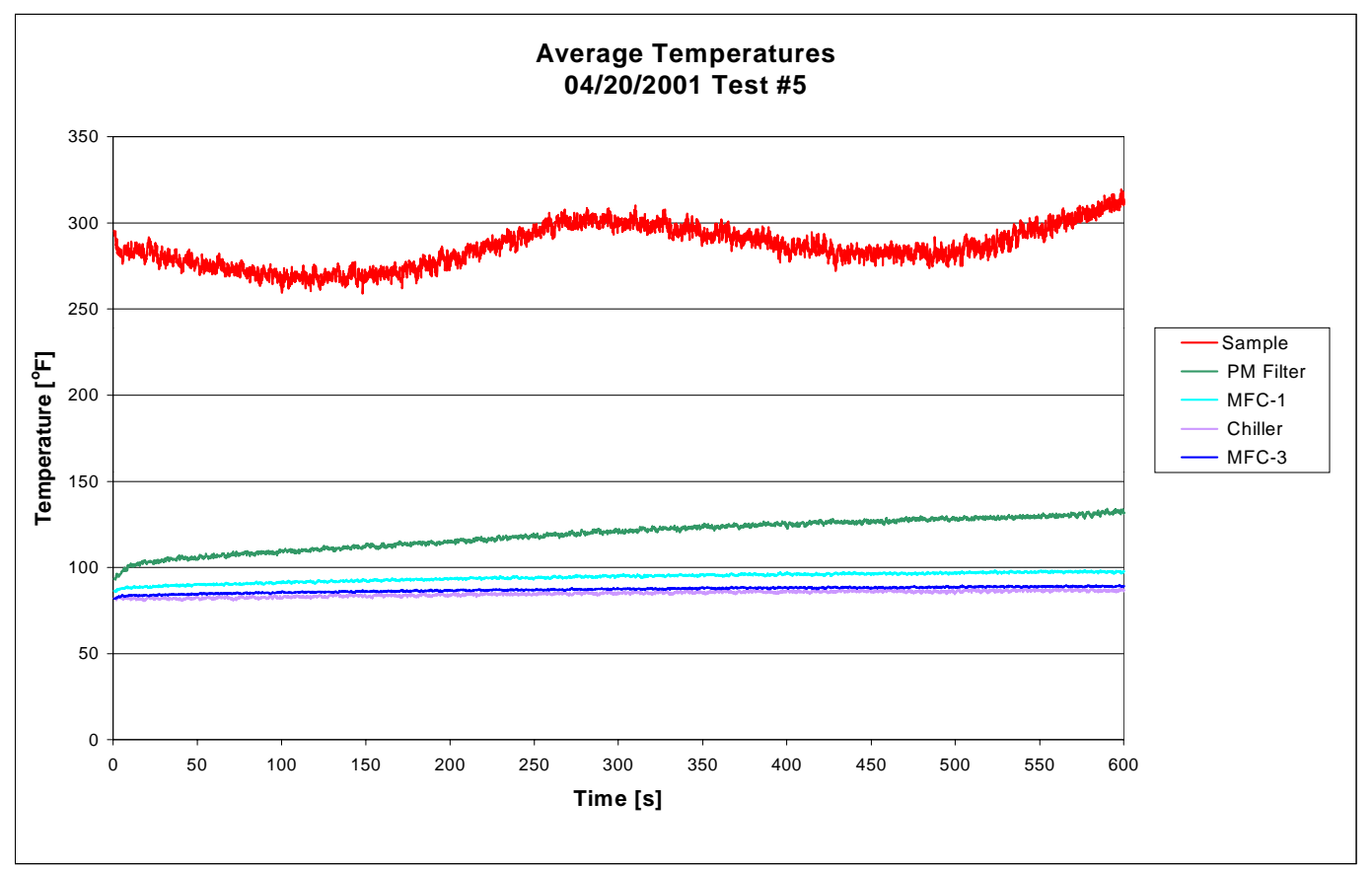

Figure 4.20 Temperatures During Steady State Test \#5 


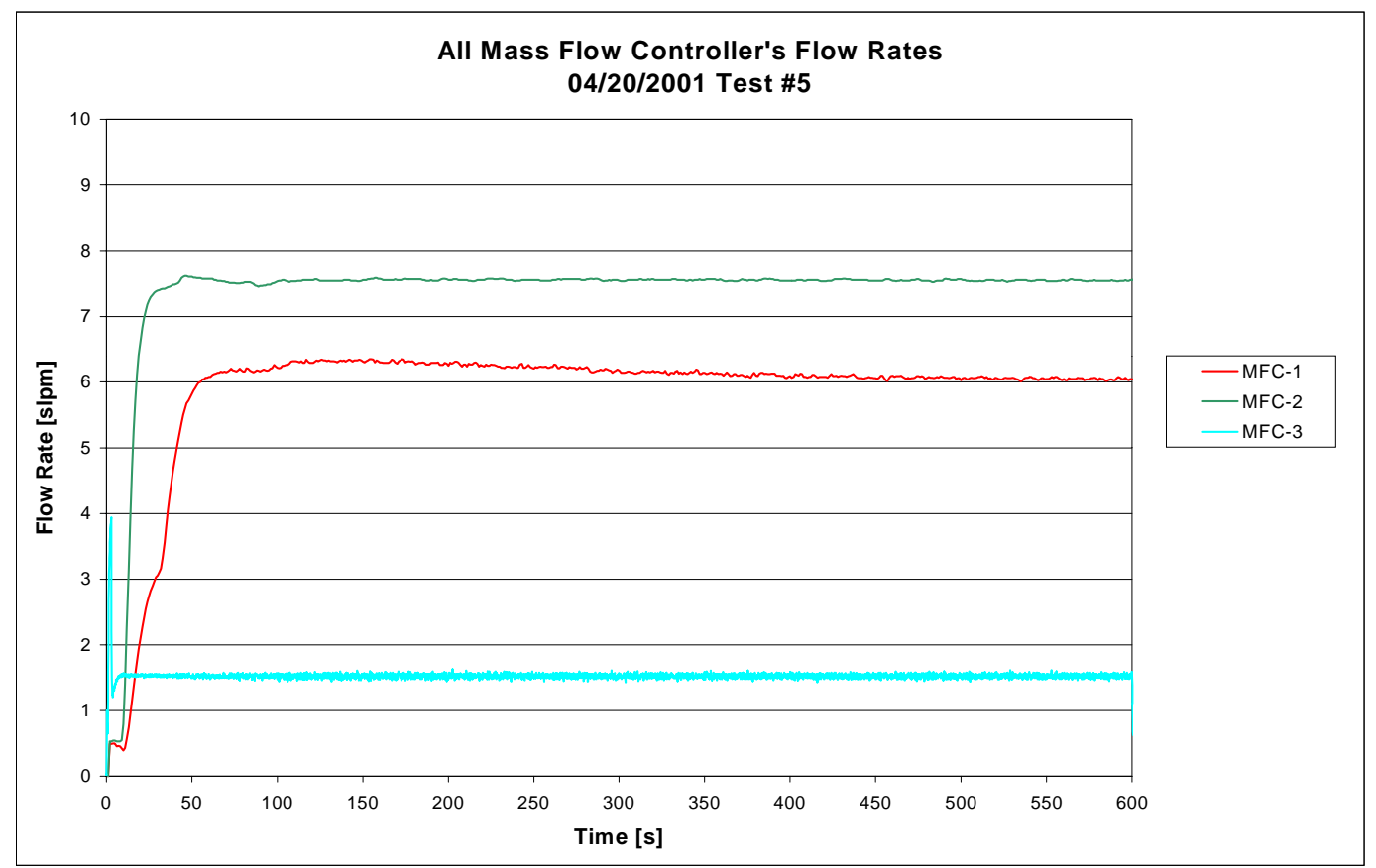

Figure 4.21 Mass Flow Rates During Steady State Test \#5

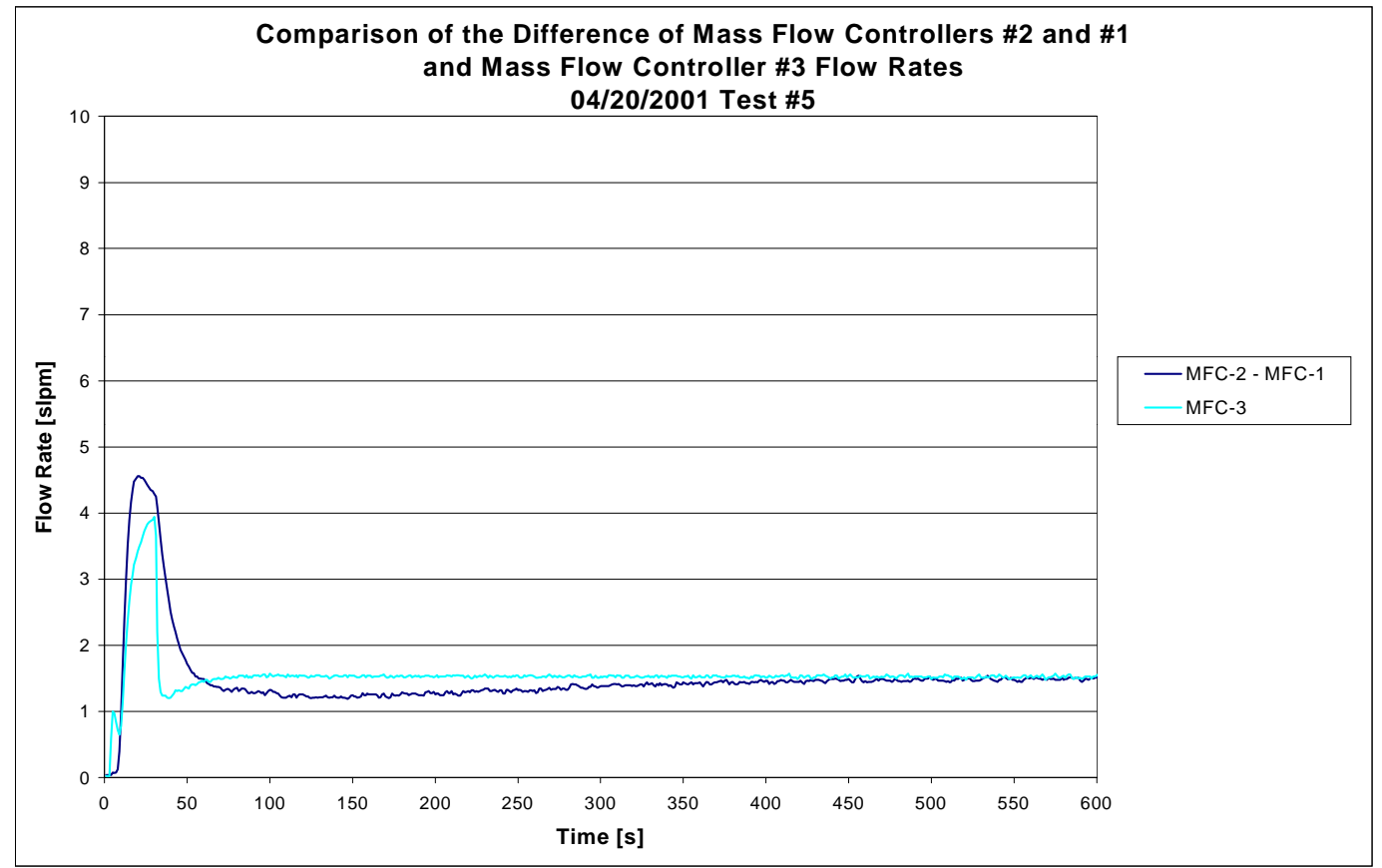

Figure 4.22 Comparison of Raw Exhaust and Bleed Flow Rates During Steady State Test \#5 


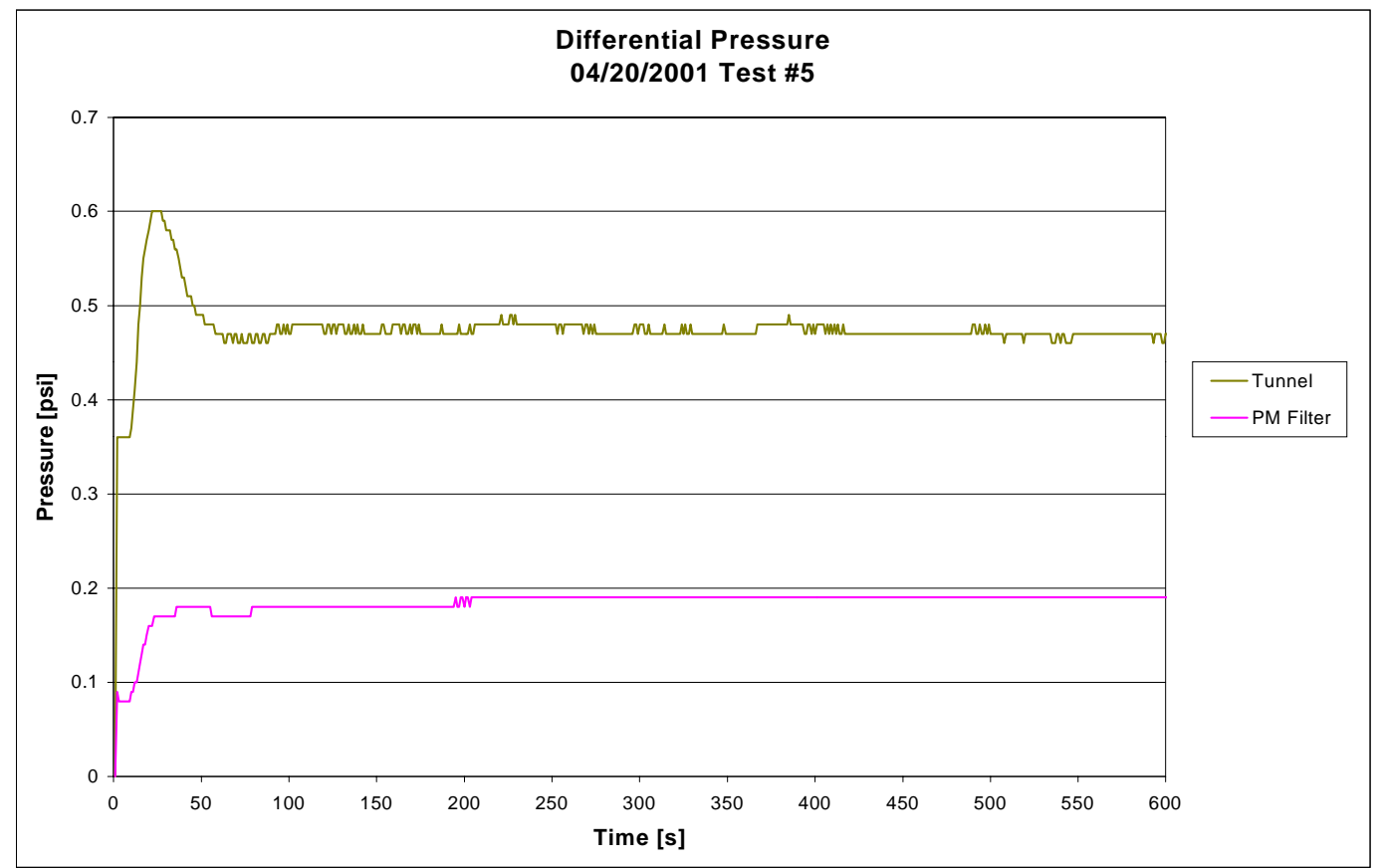

Figure 4.23 Differential Pressure During Steady State Test \#5

Table 4.5 Comparison of Full-Flow Dilution and Micro-Dilution Tunnels for Steady State Test \#5

\begin{tabular}{|l|r|l|}
\hline Volume into micro-dilution system $=$ & 15.27 & {$[\mathrm{liters}]$} \\
\hline Fuel Consumption from Counter $=$ & 3.22 & {$[\mathrm{~kg}]$} \\
\hline Intake Air Mass Flow $=$ & 10.47 & {$[\mathrm{~kg} / \mathrm{min}]$} \\
\hline Length of Sampling Time $=$ & 10 & {$[\mathrm{~min}]$} \\
\hline Total Exhaust Mass $=$ & 107.92 & {$[\mathrm{~kg}]$} \\
\hline Density $=$ & 1.2 & {$\left[\mathrm{~kg} / \mathrm{m}^{3}\right]$} \\
\hline Volume Total Exhaust $=$ & 89937 & {$[\mathrm{liters}]$} \\
\hline Mass on 47-mm filter $=$ & 0.093 & {$[\mathrm{mg}]$} \\
\hline Mass on 70-mm filter $=$ & 1.919 & {$[\mathrm{mg}]$} \\
\hline $\mathrm{P}_{\text {test }}($ micro-tunnel) $=$ & 0.55 & {$[\mathrm{~g} / \mathrm{test}]$} \\
\hline $\mathrm{P}_{\text {test }}$ (test cell $)=$ & 0.53 & {$[\mathrm{~g} / \mathrm{test}]$} \\
\hline Percent Error $=$ & $\mathbf{- 4 \%}$ & \\
\hline
\end{tabular}

\subsubsection{Test \#6 (1900 rpm, $330 \mathrm{ft}-\mathrm{lb}$ )}

The experimental set-up for the sixth steady state test was differently from the first five steady state tests. Similar to the first five steady states, the Navistar T444E engine was operated at $75 \%$ load and $75 \%$ speed, but this setup included two pumps 
instead of one. One pump was used to draw the total diluted exhaust, and the other was used to draw fresh dilution air from the surroundings. The subtraction of two large numbers resulted in errors when calculating the quantity of raw exhaust entering the micro-dilution system. This test was performed to check if the micro-dilution recirculation system was yielding accurate results. A schematic of this setup is shown in Appendix B.

Even though the setup for this test was a little different than the previous five tests, the results overall were all similar. This showed that the recirculated air could be used as the dilution air instead of adding an additional pump to the system. The only difference in this test is shown in Figure 4.25 and Figure 4.26. In these figures, the dilution air MFC remained unstable about its setpoint of $6.0 \mathrm{slpm}$ for the entire test. The other mass flow controllers stabilized to their setpoints instantly. In turn, MFC-2's behavior affected their resulting entering flow rate. Even with the mass flow controller not completely stabilizing at the set value, the percent difference between the two systems was only $5 \%$. 


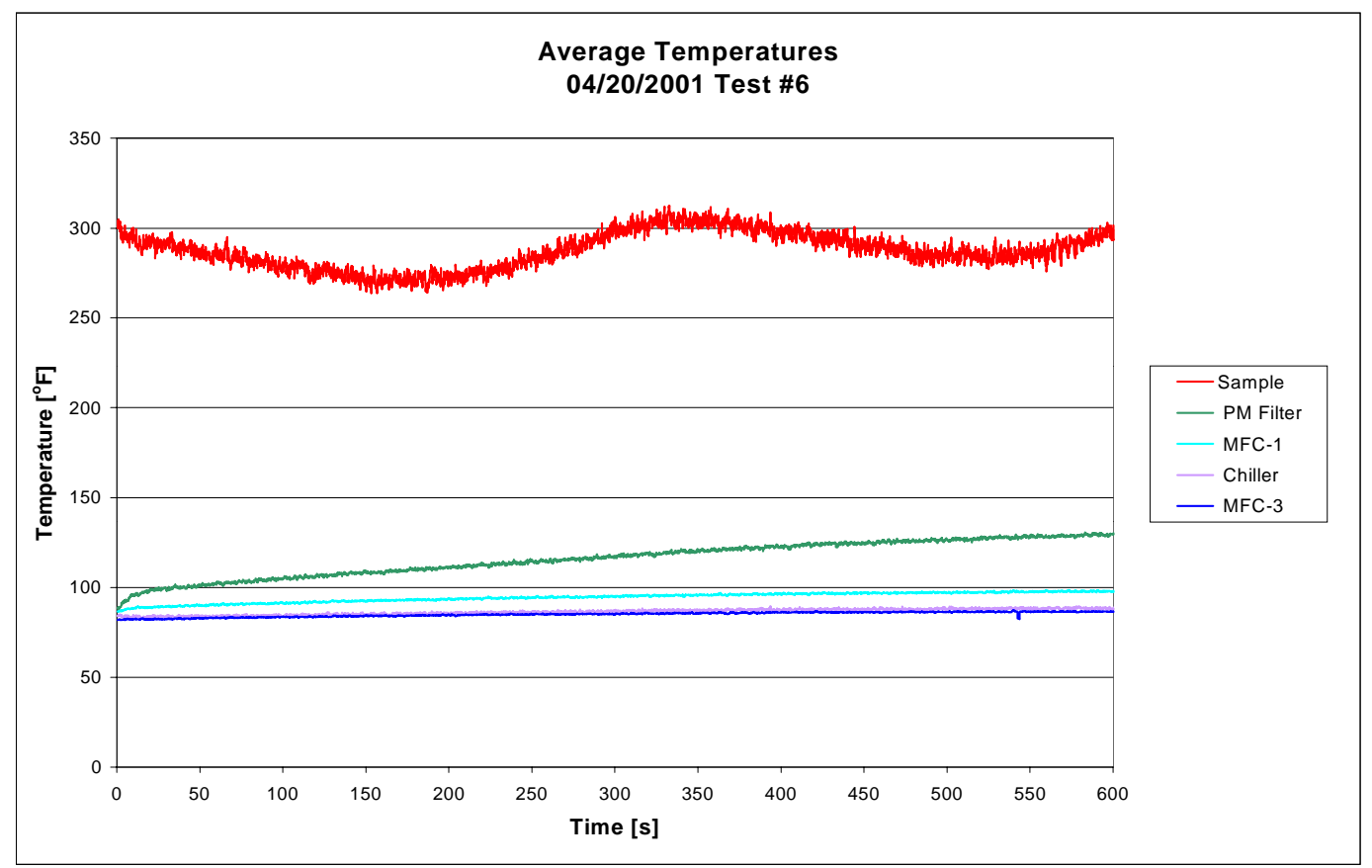

Figure 4.24 Temperatures During Steady State Test \#6

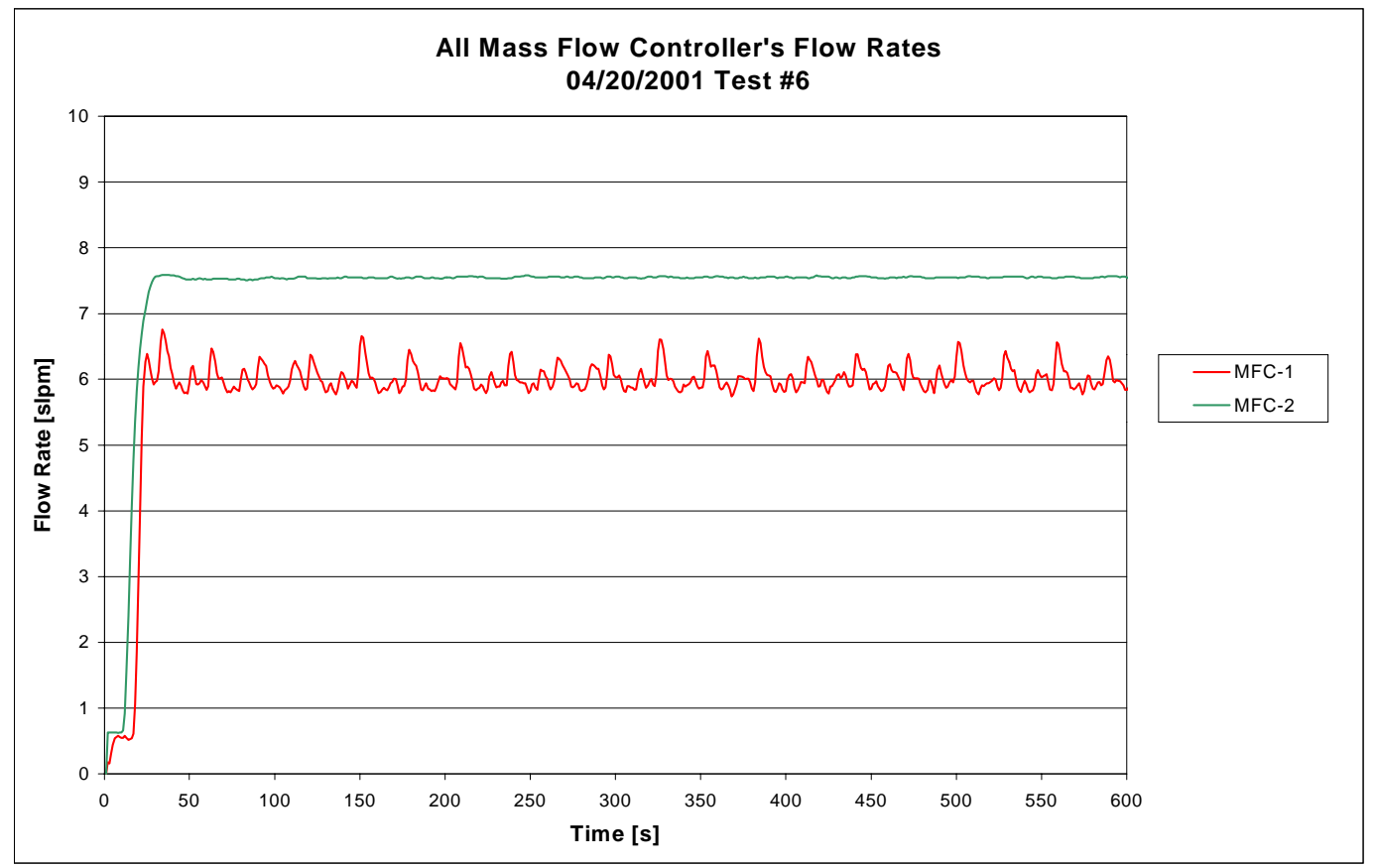

Figure 4.25 Mass Flow Rates During Steady State Test \#6 


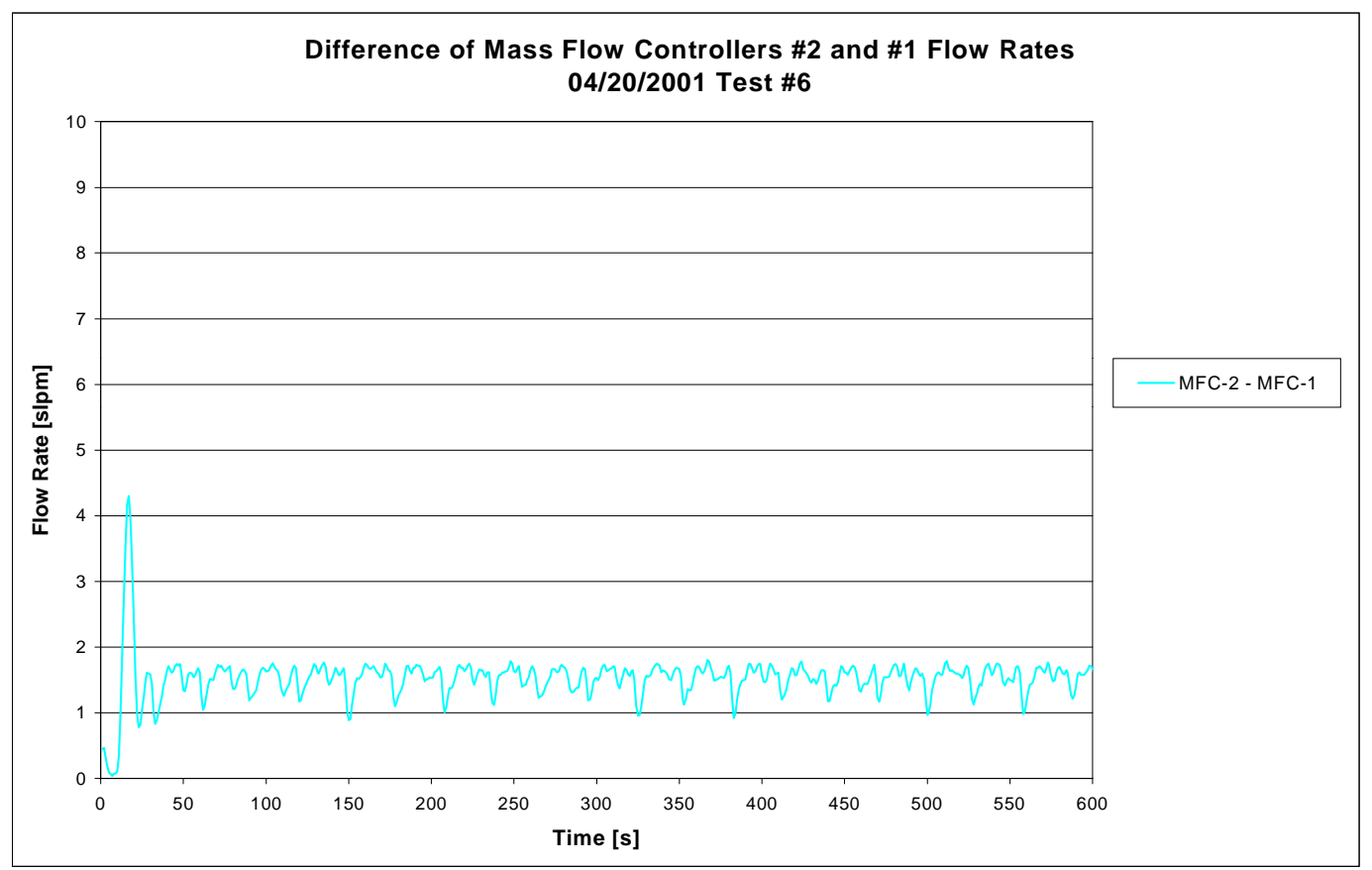

Figure 4.26 Entering Flow Rate During Steady State Test \#6

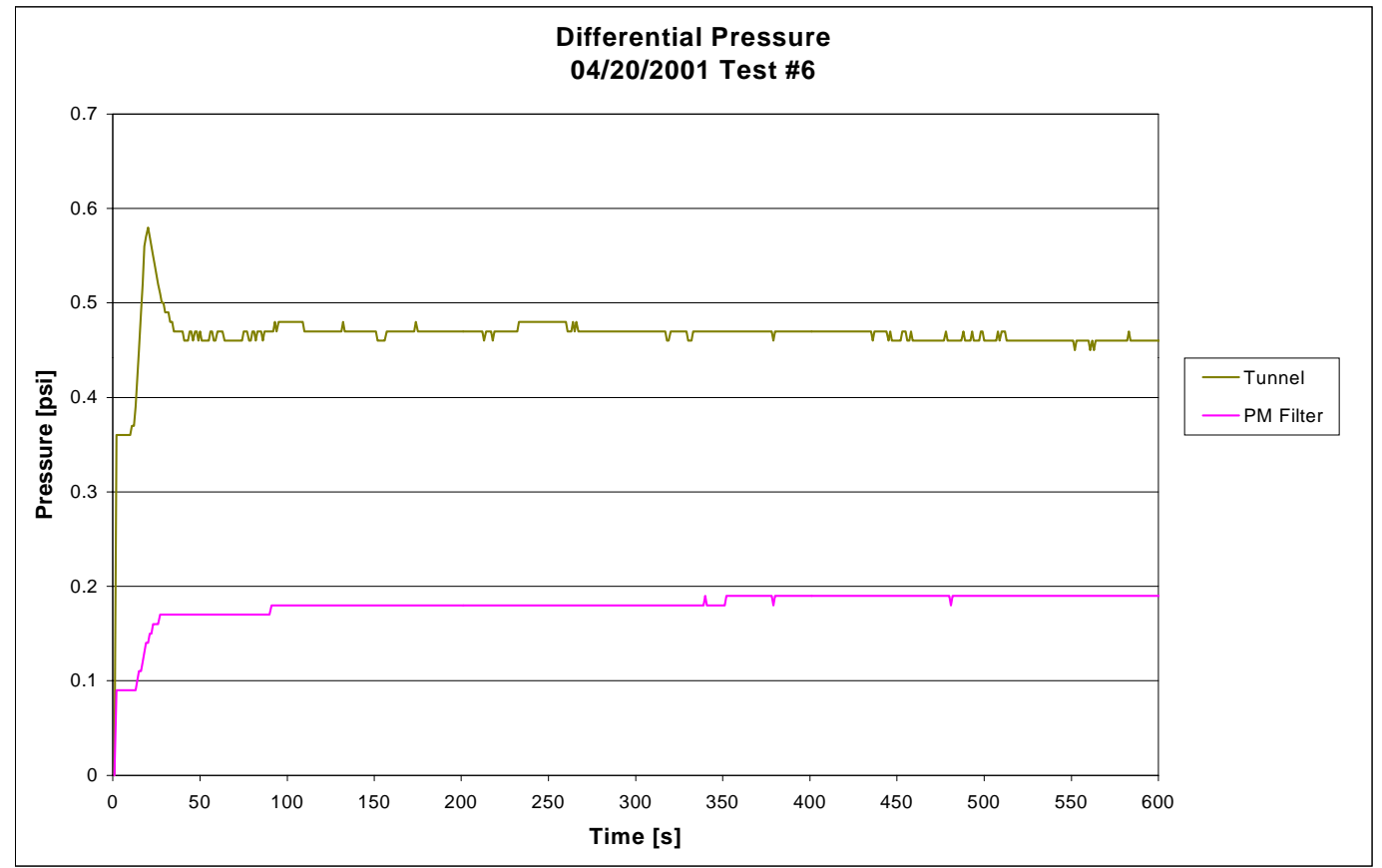

Figure 4.27 Differential Pressure During Steady State Test \#6 


\section{Table 4.6 Comparison of Full-Flow Dilution and Micro-Dilution Tunnels for Steady State Test \#6}

\begin{tabular}{|l|r|l|}
\hline Volume into micro-dilution system $=$ & 15.31 & {$[\mathrm{liters}]$} \\
\hline Fuel Consumption from Counter $=$ & 3.23 & {$[\mathrm{~kg}]$} \\
\hline Intake Air Mass Flow $=$ & 10.45 & {$[\mathrm{~kg} / \mathrm{min}]$} \\
\hline Length of Sampling Time $=$ & 10 & {$[\mathrm{~min}]$} \\
\hline Total Exhaust Mass $=$ & 107.73 & {$[\mathrm{~kg}]$} \\
\hline Density $=$ & 1.2 & {$\left[\mathrm{~kg} / \mathrm{m}^{3}\right]$} \\
\hline Volume Total Exhaust $=$ & 89773 & {$[\mathrm{liters}]$} \\
\hline Mass on 47-mm filter $=$ & 0.094 & {$[\mathrm{mg}]$} \\
\hline Mass on 70-mm filter $=$ & 1.912 & {$[\mathrm{mg}]$} \\
\hline $\mathrm{P}_{\text {test }}(\mathrm{micro}-$ tunnel $)=$ & 0.55 & {$[\mathrm{~g} / \mathrm{test}]$} \\
\hline $\mathrm{P}_{\text {test }}($ test cell $)=$ & 0.52 & {$[\mathrm{~g} / \mathrm{test}]$} \\
\hline Percent Error $=$ & $\mathbf{- 5 \%}$ & \\
\hline
\end{tabular}

\subsubsection{Test \#7 (1900 rpm, 330 ft -lb)}

To verify the six tests as previously discussed, the experiment was repeated on a different day. Figure 4.28 shows noise in the temperature lines as shown by the high amplitudes of the curve, especially with the raw exhaust temperature curve. This was due to the vibrations coming from the Navistar T444E engine. On the other hand, the mass flow controllers stabilized more quickly than the previous six tests, as shown in Figure 4.29 and Figure 4.30. At this point in the testing, the pressure sensors were disconnected to reduce the length of sample line throughout the system. For this test, when the microdilution system was compared with the full flow tunnel system, and the difference was now $11 \%$. It was suspected that the Navistar engine may have had some turbocharger related problems. 


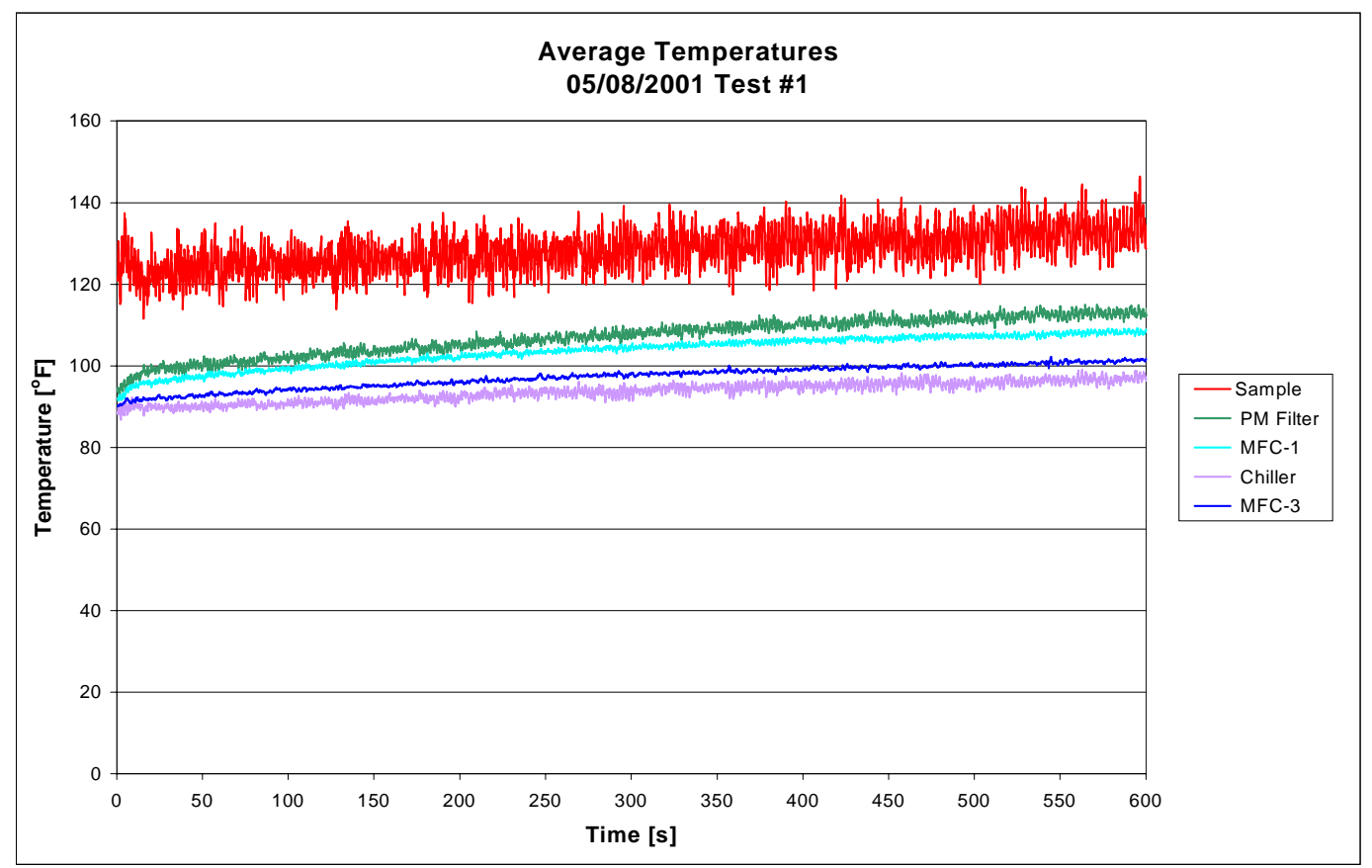

Figure 4.28 Temperatures During Steady State Test \#7

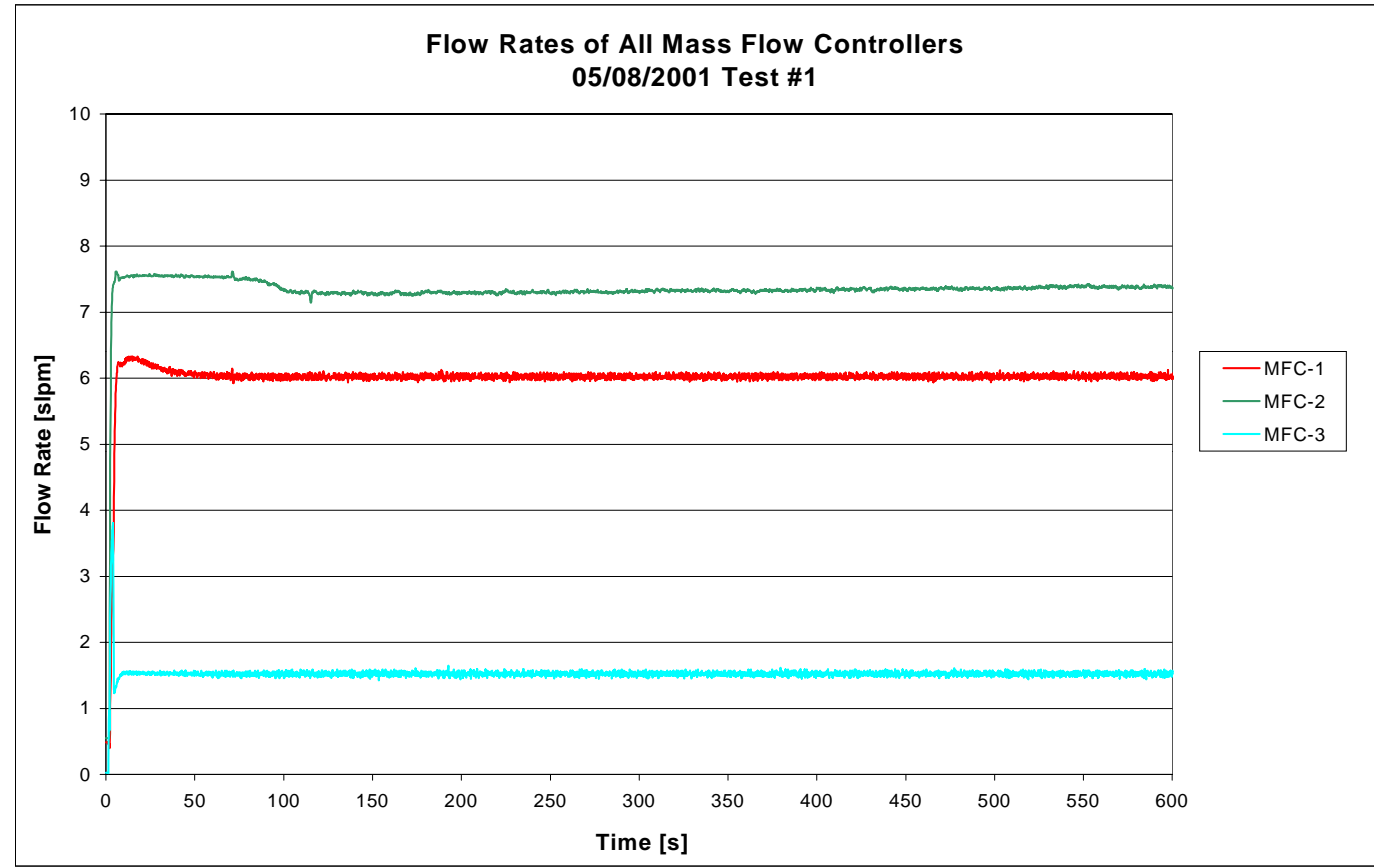

Figure 4.29 Mass Flow Rates During Steady State Test \#7 


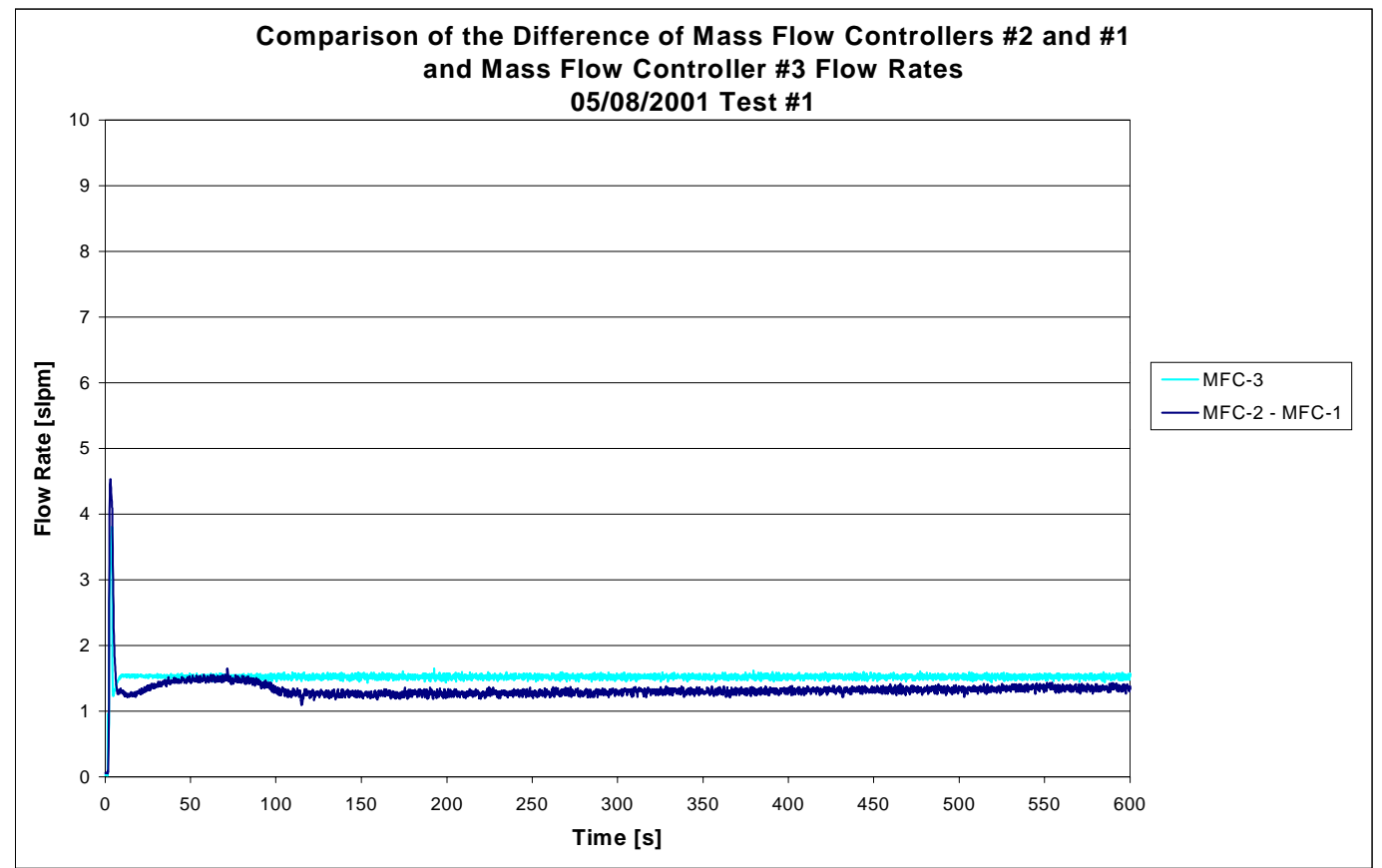

Figure 4.30 Comparison of Raw Exhaust and Bleed Flow Rates During Steady State Test \#7

Table 4.7 Comparison of Full-Flow Dilution and Micro-Dilution Tunnels for Steady State Test \#7

\begin{tabular}{|l|r|l|}
\hline Volume into micro-dilution system $=$ & 13.35 & {$[\mathrm{liters}]$} \\
\hline Fuel Consumption from Counter $=$ & 3.35 & {$[\mathrm{~kg}]$} \\
\hline Intake Air Mass Flow $=$ & 10.25 & {$[\mathrm{~kg} / \mathrm{min}]$} \\
\hline Length of Sampling Time $=$ & 10 & {$[\mathrm{~min}]$} \\
\hline Total Exhaust Mass $=$ & 105.85 & {$[\mathrm{~kg}]$} \\
\hline Density $=$ & 1.2 & {$\left[\mathrm{~kg} / \mathrm{m}^{3}\right]$} \\
\hline Volume Total Exhaust $=$ & 88210 & {$[\mathrm{liters}]$} \\
\hline Mass on 47-mm filter $=$ & 0.06 & {$[\mathrm{mg}]$} \\
\hline Mass on 70-mm filter $=$ & 1.673 & {$[\mathrm{mg}]$} \\
\hline $\mathrm{P}_{\text {test }}($ micro-tunnel $)=$ & 0.40 & {$[\mathrm{~g} / \mathrm{test}]$} \\
\hline $\mathrm{P}_{\text {test }}($ test cell $)=$ & 0.45 & {$[\mathrm{~g} / \mathrm{test}]$} \\
\hline Percent Error $=$ & $\mathbf{1 1 \%}$ & \\
\hline
\end{tabular}

\subsubsection{Test \#8 (1900 rpm, $330 \mathrm{ft}-\mathrm{lb})$}

The second test to verify the first six tests is presented in this section. Figure 4.31 shows the same noise in the temperature lines as the previous test. The mass flow controllers remained steady throughout the majority of the test cycle as shown in Figure 
4.32 and Figure 4.33. The percent difference between the micro-dilution system and the full flow tunnel system increased by 3 more percent to $14 \%$.

The percent difference increase was due to the Navistar T444E engine not performing consistently. The first six steady state tests with the Navistar T444E all performed the same. However, the last two tests show that the engine was not consistently performing; hence, the results were not the same. Further inspection of the engine did reveal that the turbocharger seal had to be replaced. Full-flow dilution also showed that the test to test variabilities were high and inconsistent.

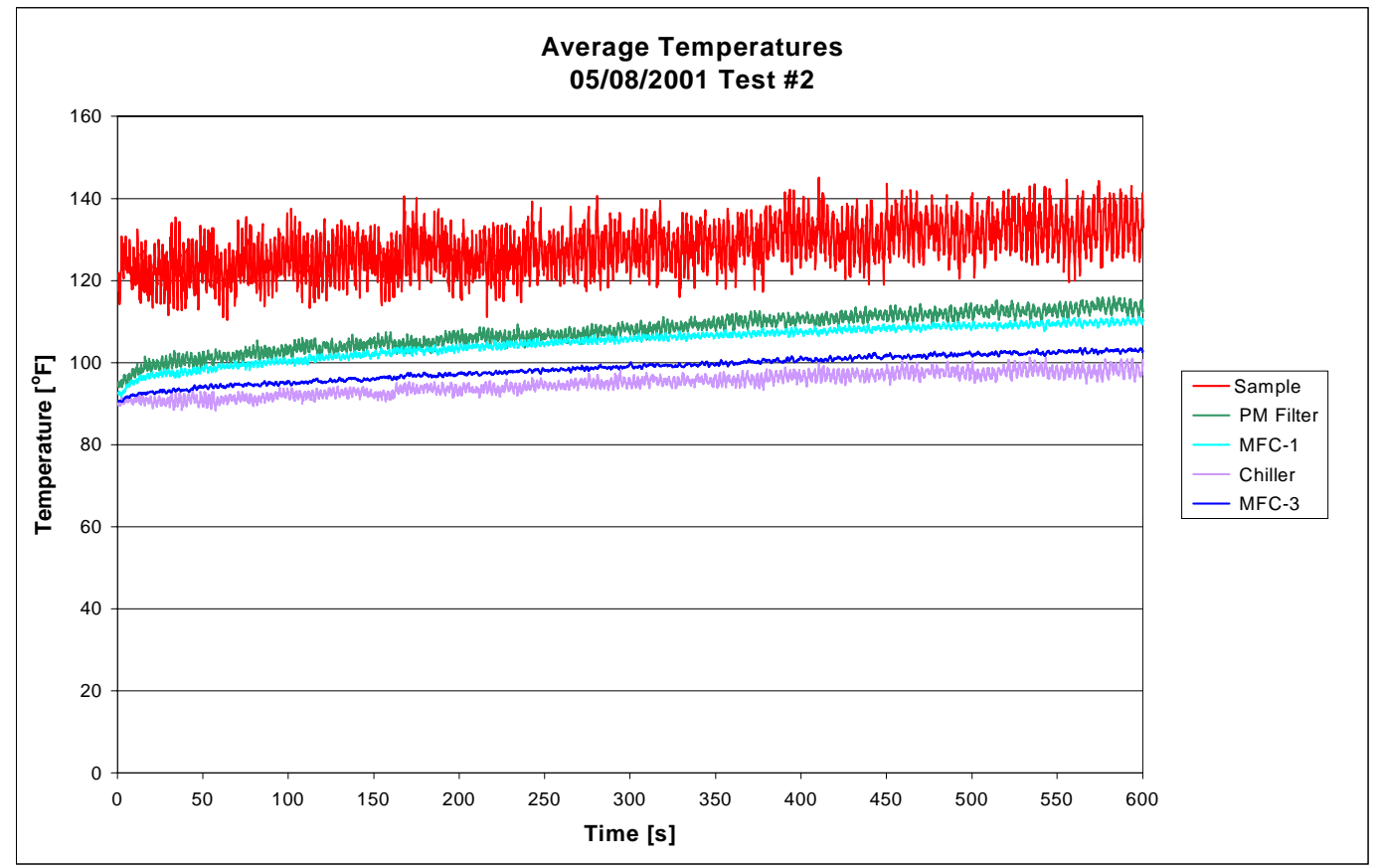

Figure 4.31 Temperatures During Steady State Test \#8 


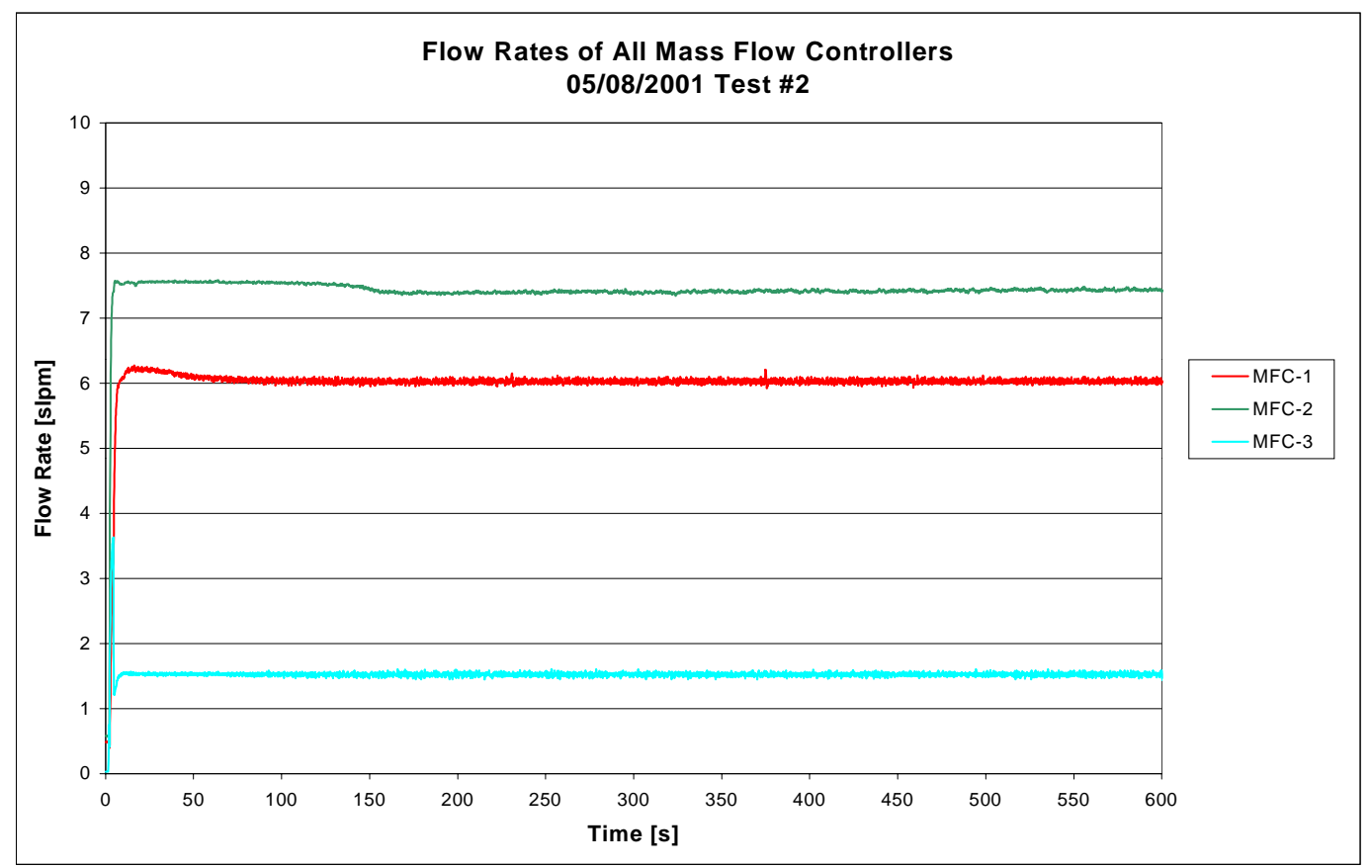

Figure 4.32 Mass Flow Rates During Steady State Test \#8

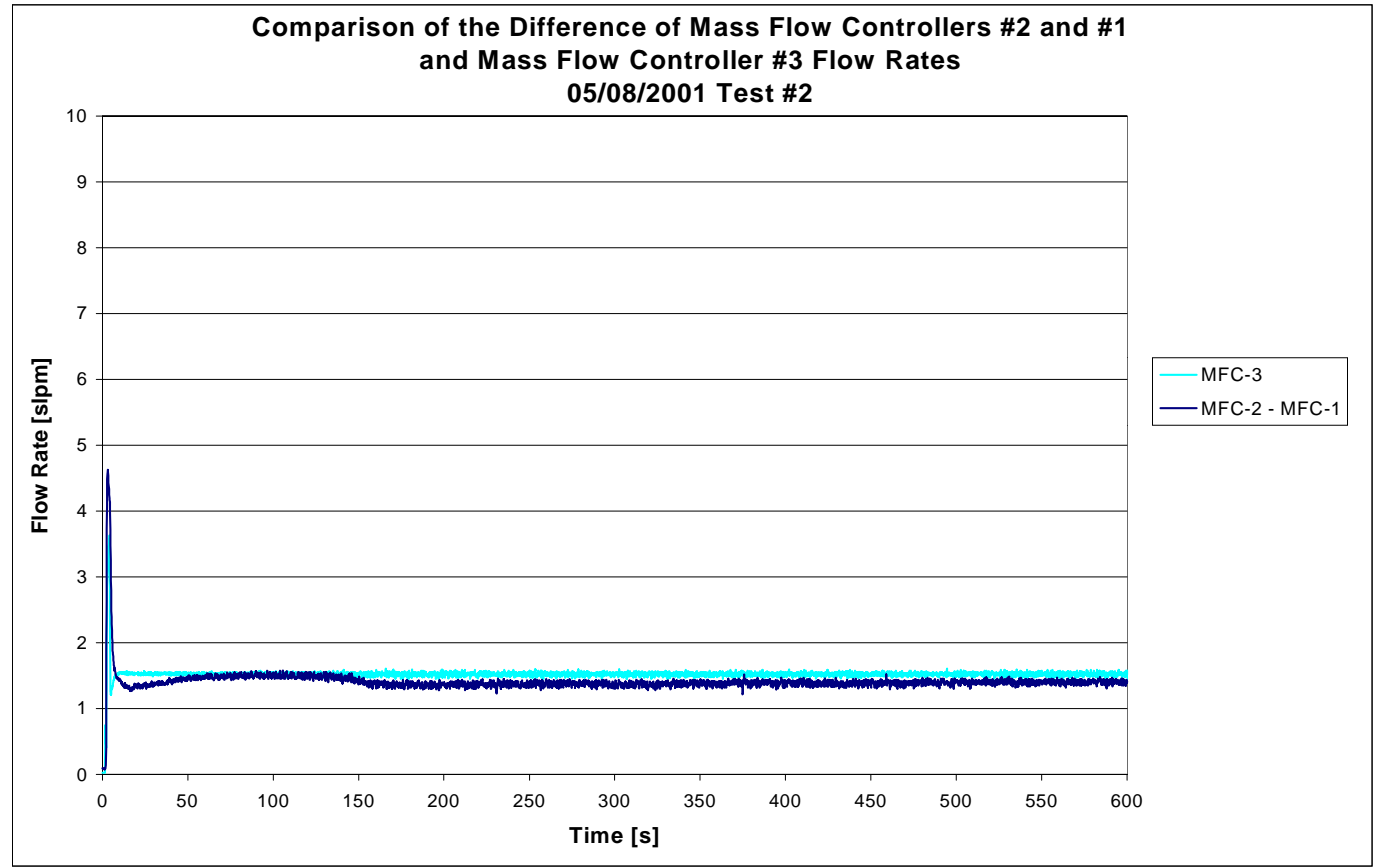

Figure 4.33 Comparison of Raw Exhaust and Bleed Flow Rates During Steady State Test \#8 
Table 4.8 Comparison of Full-Flow Dilution and Micro-Dilution Tunnels for Steady State Test \#8

\begin{tabular}{|l|r|l|}
\hline Volume into micro-dilution system $=$ & 14.15 & {$[\mathrm{liters}]$} \\
\hline Fuel Consumption from Counter $=$ & 3.25 & {$[\mathrm{~kg}]$} \\
\hline Intake Air Mass Flow $=$ & 10.23 & {$[\mathrm{~kg} / \mathrm{min}]$} \\
\hline Length of Sampling Time $=$ & 10 & {$[\mathrm{~min}]$} \\
\hline Total Exhaust Mass $=$ & 105.55 & {$[\mathrm{~kg}]$} \\
\hline Density $=$ & 1.2 & {$\left[\mathrm{~kg} / \mathrm{m}^{3}\right]$} \\
\hline Volume Total Exhaust $=$ & 87958 & {$[\mathrm{liters}]$} \\
\hline Mass on 47-mm filter $=$ & 0.085 & {$[\mathrm{mg}]$} \\
\hline Mass on 70-mm filter $=$ & 1.724 & {$[\mathrm{mg}]$} \\
\hline $\mathrm{P}_{\text {test }}($ micro-tunnel $)=$ & 0.53 & {$[\mathrm{~g} / \mathrm{test}]$} \\
\hline $\mathrm{P}_{\text {test }}($ test cell $)=$ & 0.46 & {$[\mathrm{~g} / \mathrm{test}]$} \\
\hline Percent Error $=$ & $\mathbf{- 1 4 \%}$ & \\
\hline
\end{tabular}

\subsection{Transient Tests}

The first six transient tests were oscillation tests with the Navistar T444E engine coupled to the GE DC dynamometer. These oscillating transient tests were conducted for another study conducted by a graduate student (Bane, 2001).

The test procedure was divided into four main steps and included the following:

1. Three minutes the torque was set to the low end of the range

2. Three minutes the torque was set to the high end of the range

3. Three minutes the torque was set back to the low end of the range

4. Six minutes of oscillating between the low and high range of the torque

This section will describe each transient test performed and how well it compared with the full flow dilution tunnel. Figure 4.34 compares the total particulate (TPM) of the micro-dilution tunnel system and the full-flow tunnel system for each oscillating transient test that was performed.

Each section includes the temperatures and mass flow controller rates recorded in the micro-dilution tunnel system. The temperatures recorded were the raw exhaust 
entering the system, at the PM filter face, before MFC-1, after the chiller, and after MFC3. Each of the three mass flow controller's sense and set values were also recorded. Also shown in a comparison between each of the micro-dilution system test results and the full-flow dilution tunnel results. A comparison of all the test results are shown in Figure 4.34. The amount of particulate matter collected during the test is calculated using the fuel consumption rate from the fuel flow meter and intake air flow rate over the sample length time.

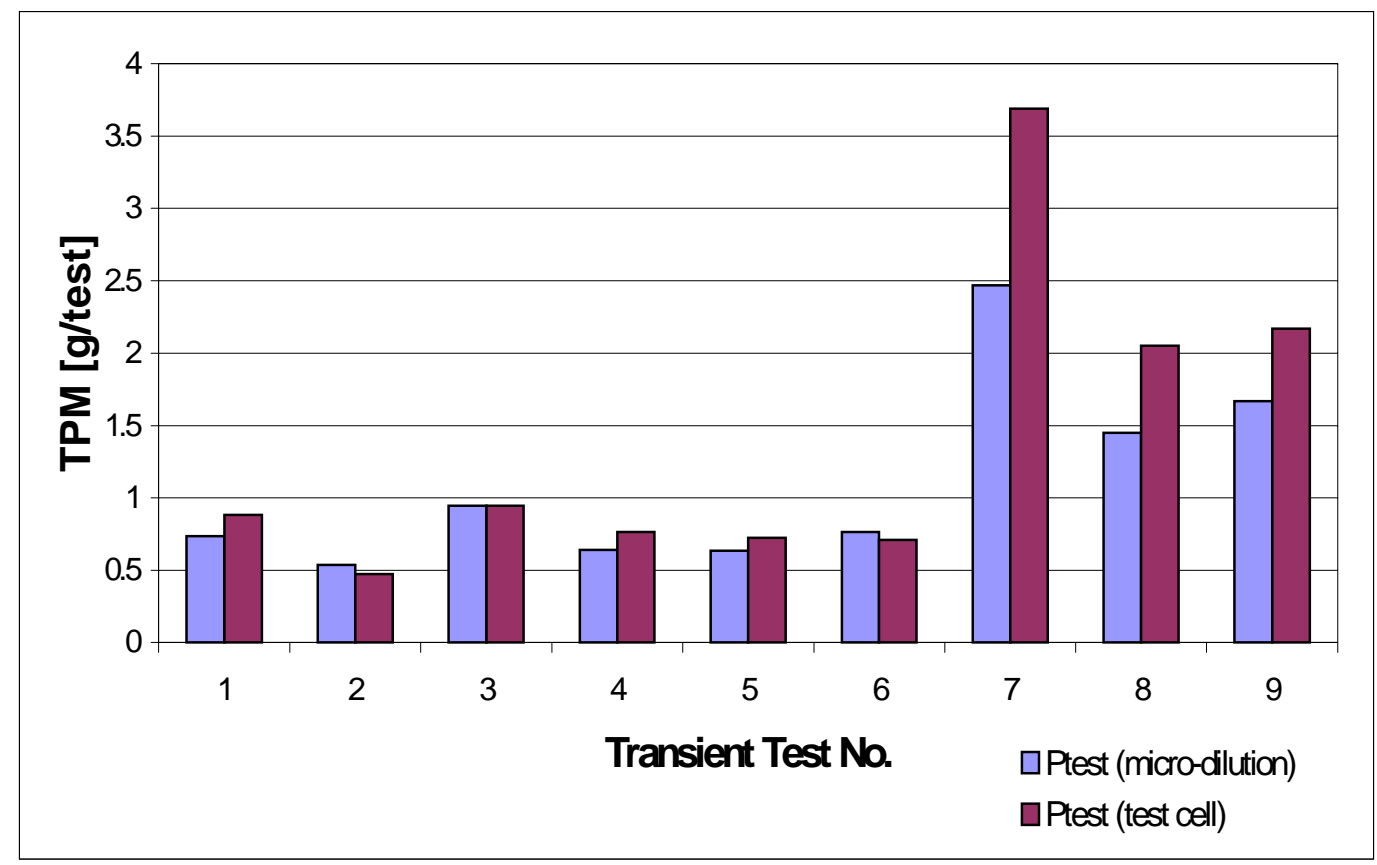

Figure 4.34 Comparison of Oscillating Transient Tests with the Navistar T444E Engine

Figure 4.35 and Figure 4.36 show the $\mathrm{CO}_{2}$ and $\mathrm{NO}_{\mathrm{x}}$ emissions data for the full flow tunnel system for the nine transient tests performed. In general, the six oscillating transient tests produced 100 to $150 \mathrm{~g} / \mathrm{bhp}-\mathrm{hr}$ less $\mathrm{CO}_{2}$ emissions and 3 to $5 \mathrm{~g} / \mathrm{bhp}$-hr more $\mathrm{NO}_{\mathrm{x}}$ than the three FTP transient tests. 


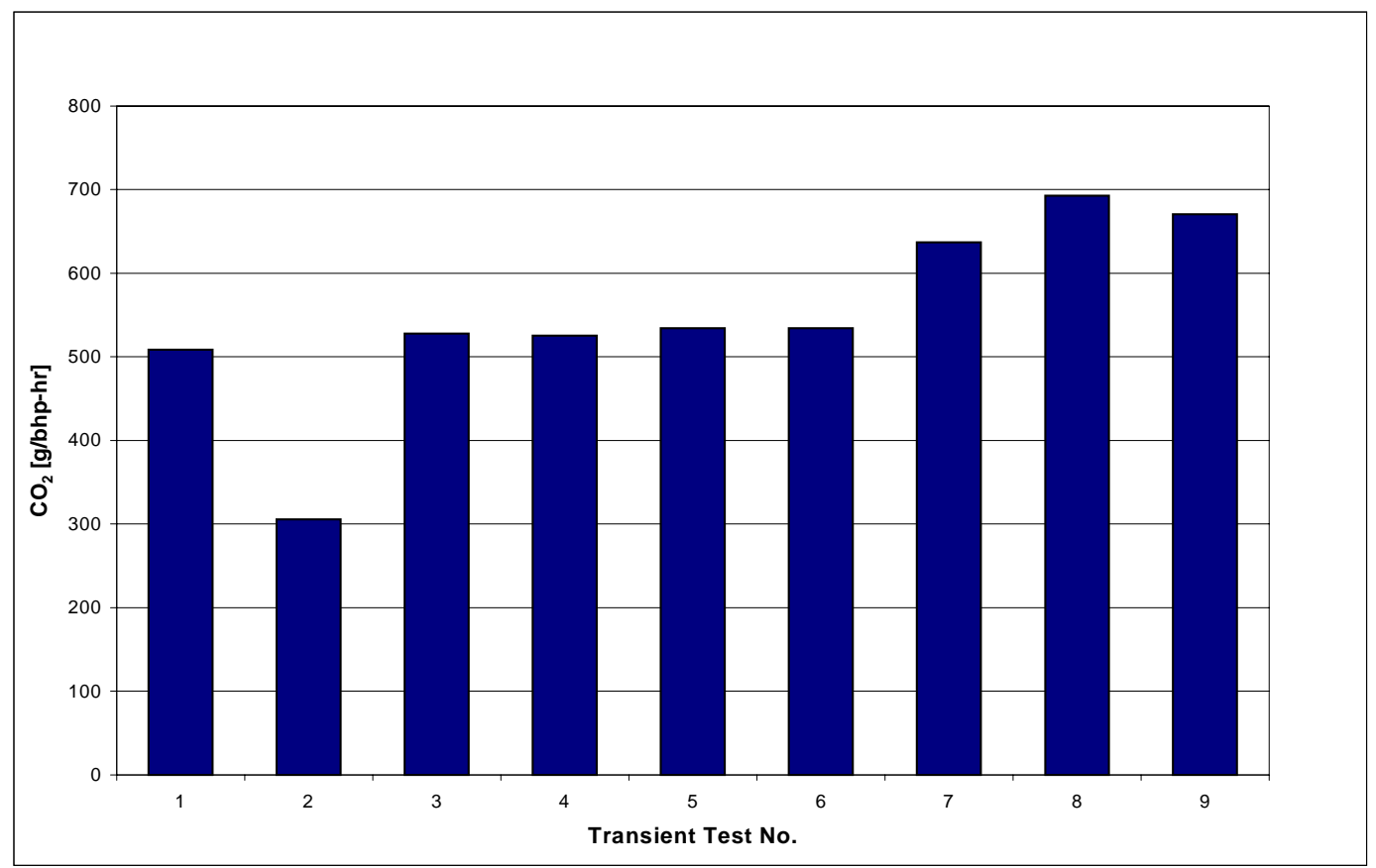

Figure 4.35 Comparison of $\mathrm{CO}_{2}$ Emissions Data for Transient Tests

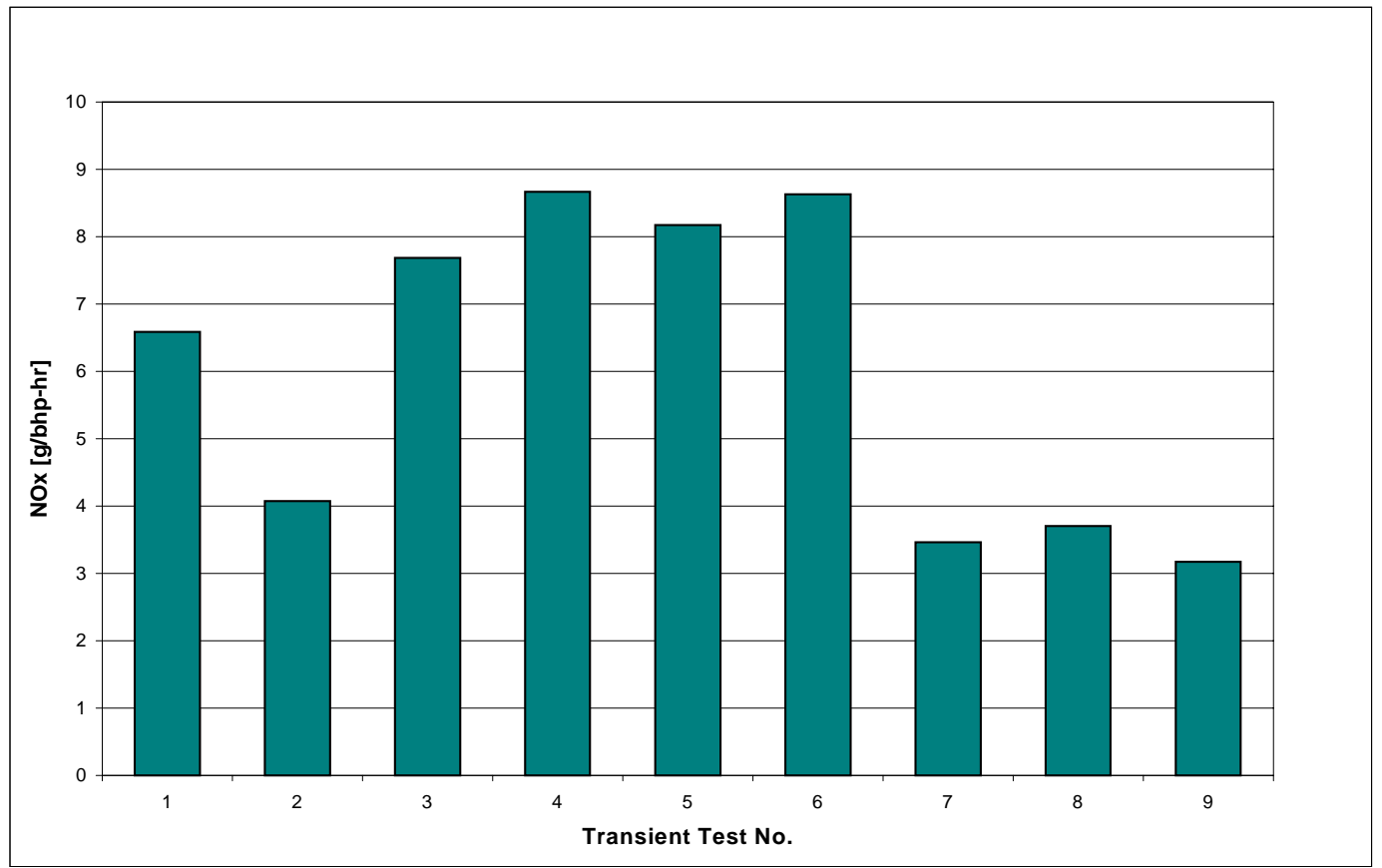

Figure 4.36 Comparison of $\mathrm{NO}_{x}$ Emissions Data for Transient Tests 


\subsubsection{Test \#1 (OSC \#7)}

The OSC \#7 was a sequence number assigned to this test. This test had oscillation periods of 20 seconds and oscillated between 300 and $400 \mathrm{ft}-\mathrm{lb}$ (406.7 to 542.3 $\mathrm{N}-\mathrm{m}$ ), as shown in Figure 4.37. This torque range was selected so that the turbo charger would be spooling the entire time. The calculated manifold pressure using the specified torque would range from 4.5 to 7 psi.

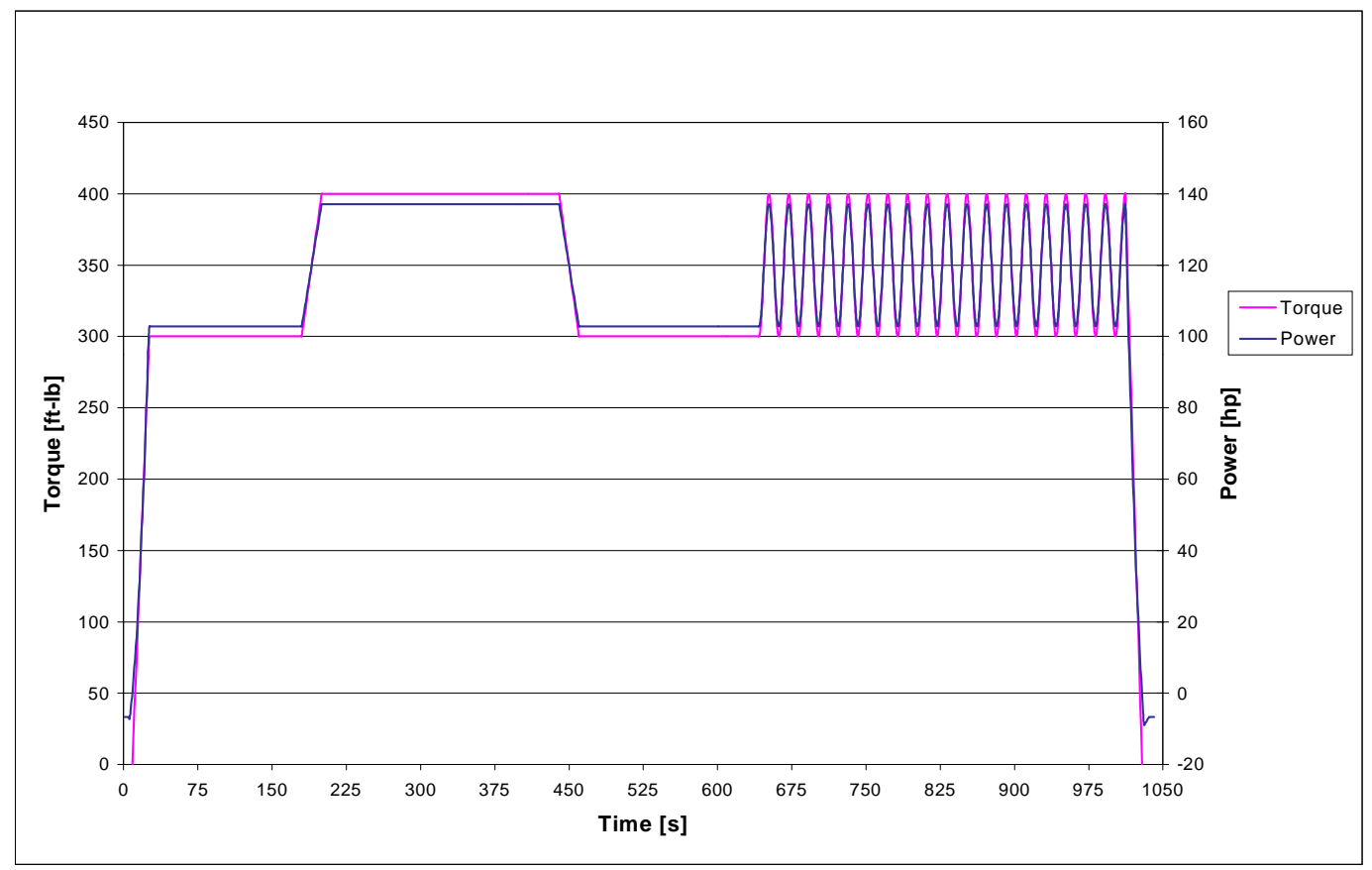

Figure 4.37 Oscillating Transient Test \#7 Cycle

Figure 4.38 displays all five temperatures recorded in the micro-dilution system.

The temperature of the raw exhaust entering the system increased from $120^{\circ} \mathrm{F}$ to $140{ }^{\circ} \mathrm{F}$ and vibrated continuously throughout the 17.35 minute test due to noise in the data acquisition system. The temperature at the filter face almost reached $120^{\circ} \mathrm{F}$ by the end of the test, which is below the upper limit of the filter face temperature of $125^{\circ} \mathrm{F}$. The MFC-1, chiller, and MFC-3 all started at $85^{\circ} \mathrm{F}$ and reached $110^{\circ} \mathrm{F}, 102^{\circ} \mathrm{F}$, and $94^{\circ} \mathrm{F}$ by the end of the test run, respectively. 
Figure 4.39 displays the flow rates of each of the mass flow controllers. MFC-1 and MFC-2 both maintained their set values throughout the test. However, MFC-2, followed the oscillating path of the engine. Figure 4.40 compares the flow rate entering and exiting the system. In the beginning of the test run, MFC-2 was not achieving its setpoint so the air entering the system did not equal the air exiting the system. However, halfway through the test, MFC-2 reached its setpoint and the air entering was approximately equal to the air exiting the micro-dilution system.

The first transient test of this type was $17 \%$ off from the full-flow dilution tunnel. This percentage difference may seem high, but the subsequent tests show a better correlation between the micro-dilution system and the full-flow dilution tunnel system using different oscillating tests. It should be noted that the most currently available minidilution tunnels (BG-1, Horiba Inc., AVL) show similar and/or worse correlation over transient tests.

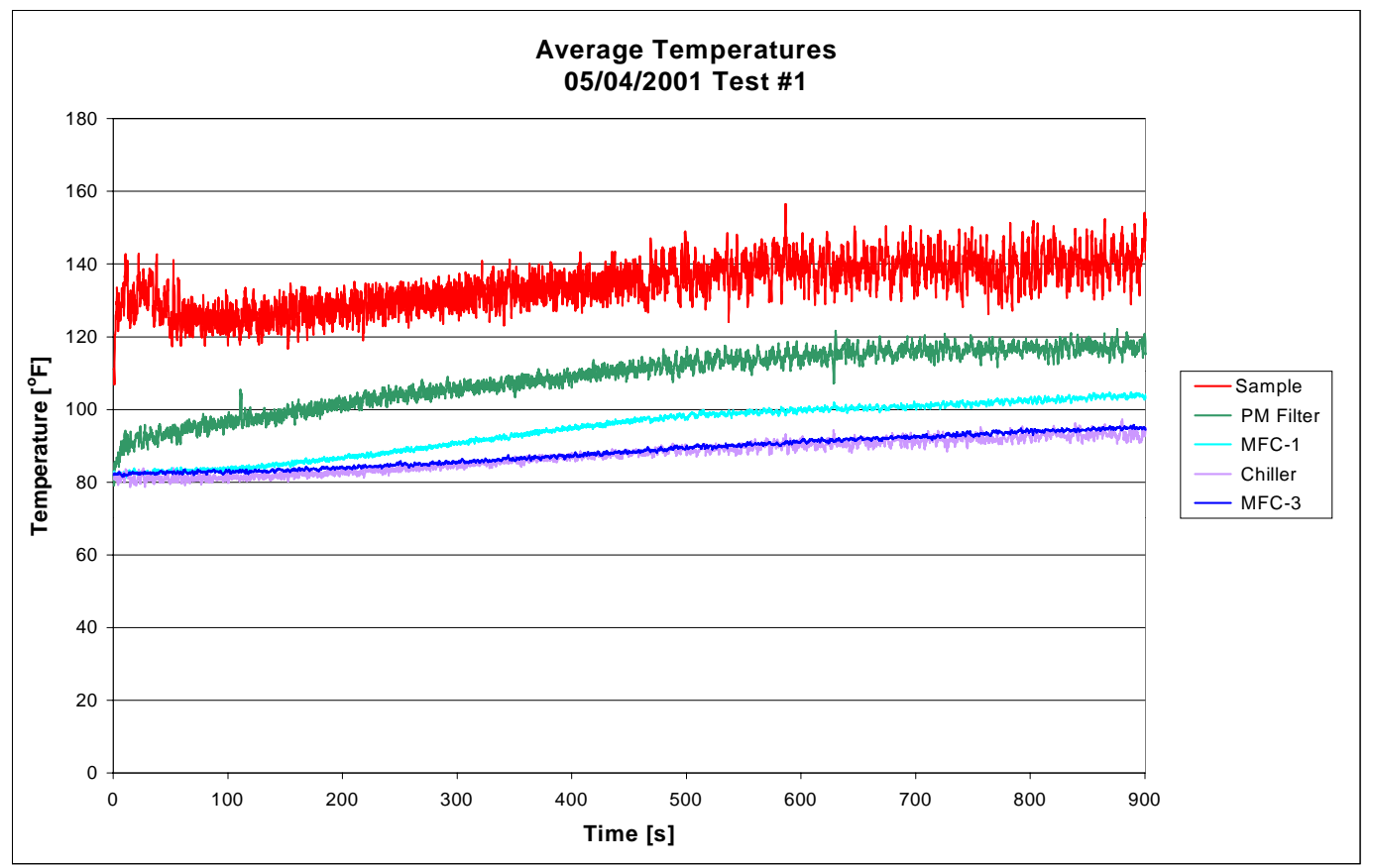

Figure 4.38 Temperatures During Transient Test \#1 


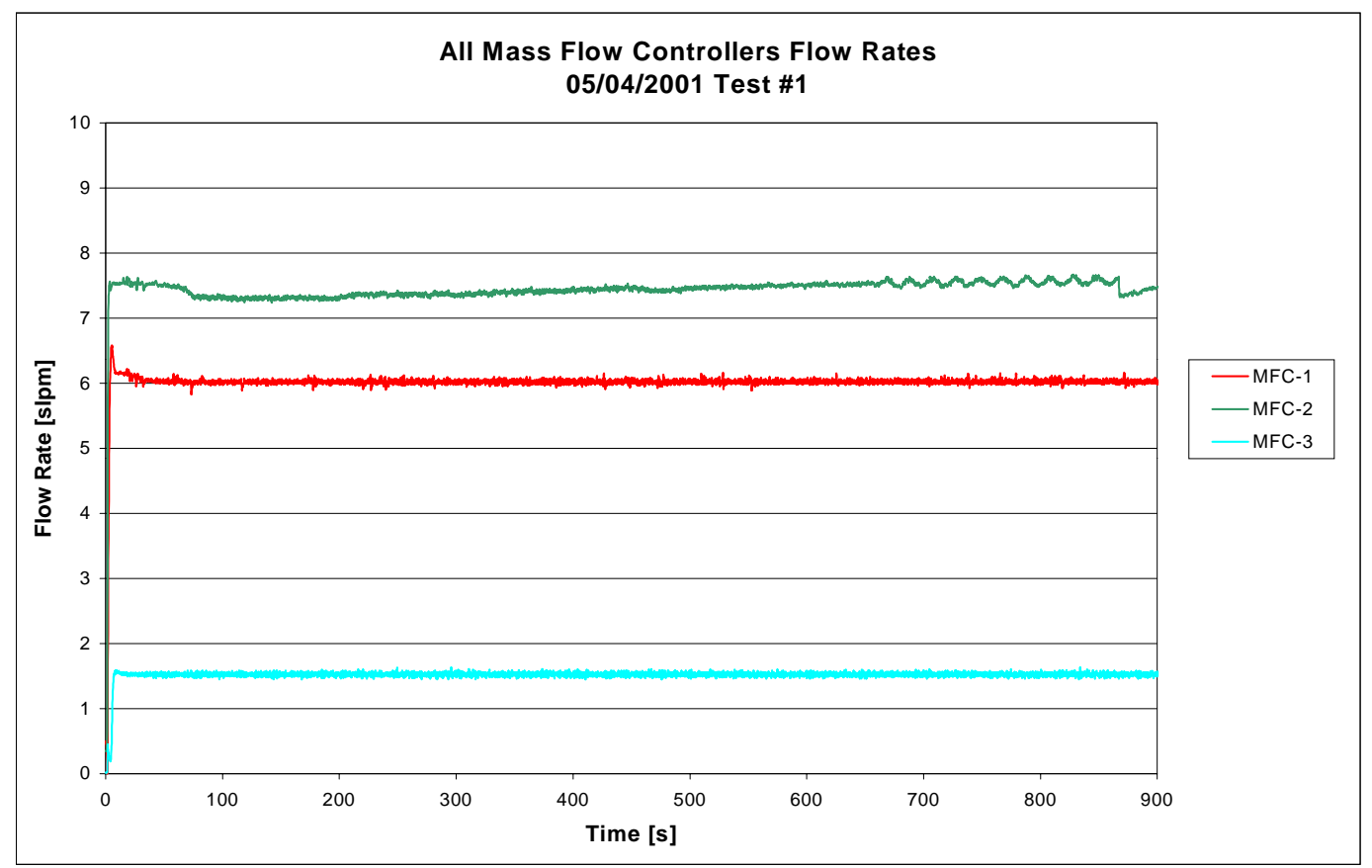

Figure 4.39 Mass Flow Rates During Transient Test \#1

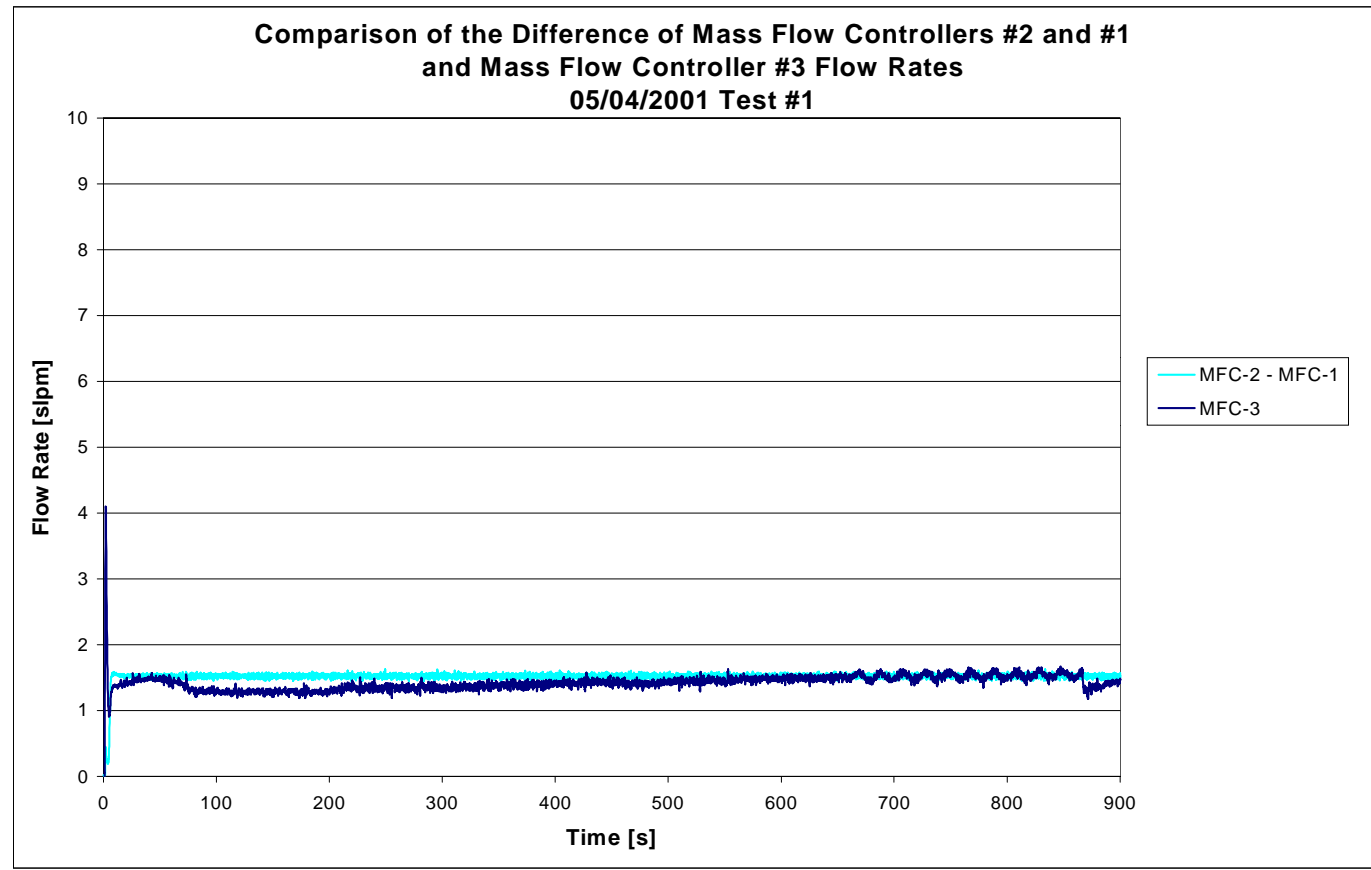

Figure 4.40 Comparison of Raw Exhaust and Bleed Flow Rates During Transient Test \#1 


\section{Table 4.9 Comparison of Full-Flow Dilution and Micro-Dilution Tunnels for Transient Test \#1}

\begin{tabular}{|l|r|l|}
\hline Volume into micro-dilution system $=$ & 21.78 & {$[\mathrm{liters}]$} \\
\hline Fuel Consumption from Counter $=$ & 4.47 & {$[\mathrm{~kg}]$} \\
\hline Intake Air Mass Flow $=$ & 135.82 & {$[\mathrm{~kg}]$} \\
\hline Length of Sampling Time $=$ & 15 & {$[\mathrm{~min}]$} \\
\hline Total Exhaust Mass $=$ & 140.29 & {$[\mathrm{~kg}]$} \\
\hline Density = & 1.2 & {$\left[\mathrm{~kg} / \mathrm{m}^{3}\right]$} \\
\hline Volume Total Exhaust $=$ & 116909 & {$[\mathrm{liters}]$} \\
\hline Mass on 47-mm filter $=$ & 0.137 & {$[\mathrm{mg}]$} \\
\hline Mass on 70-mm filter $=$ & 3.143 & {$[\mathrm{mg}]$} \\
\hline P $_{\text {test }}($ micro-tunnel) $=$ & 0.74 & {$[\mathrm{~g} / \mathrm{test}]$} \\
\hline Pest $_{\text {test }}$ (tell) $=$ & 0.88 & {$[\mathrm{~g} /$ test $]$} \\
\hline Percent Error $=$ & $\mathbf{1 7 \%}$ & \\
\hline
\end{tabular}

\subsubsection{Test \#2 (OSC \#8)}

The second transient test, OSC \#8, used the same range of torque as the OSC \#7 to oscillate between, but decreased the period time from 20 seconds to 10 seconds. This test cycle is shown in Figure 4.41. Figure 4.42, Figure 4.43, Figure 4.44 and Table 4.10 show the results from this test. All of the temperatures were similar to those in previous test, but the mass flow controllers differed slightly. The dilution air mass flow controller was found to be vibrating on its base, which explains the erratic spikes on the curve. 


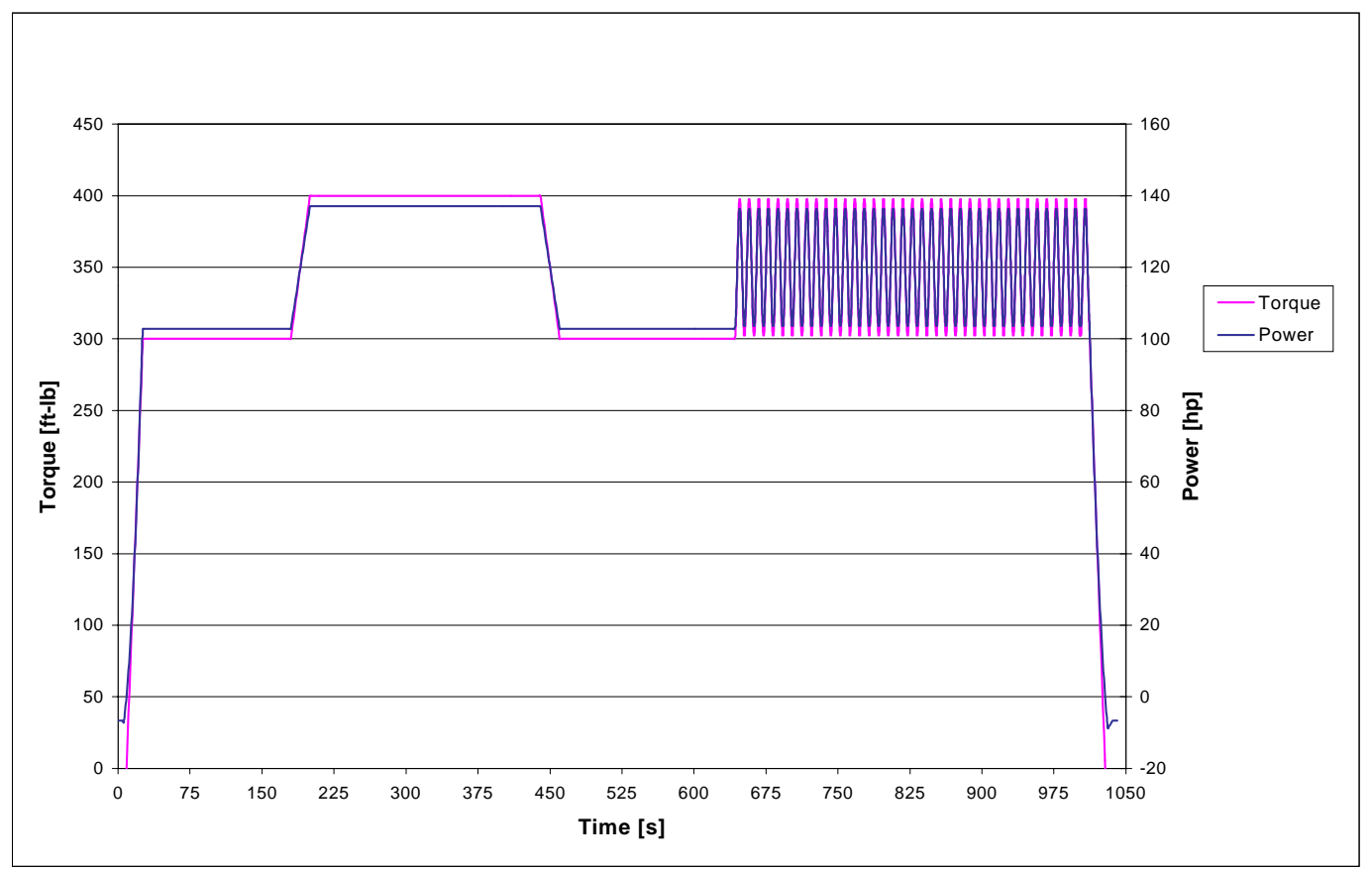

Figure 4.41 Oscillating Transient Test \#8 Cycle

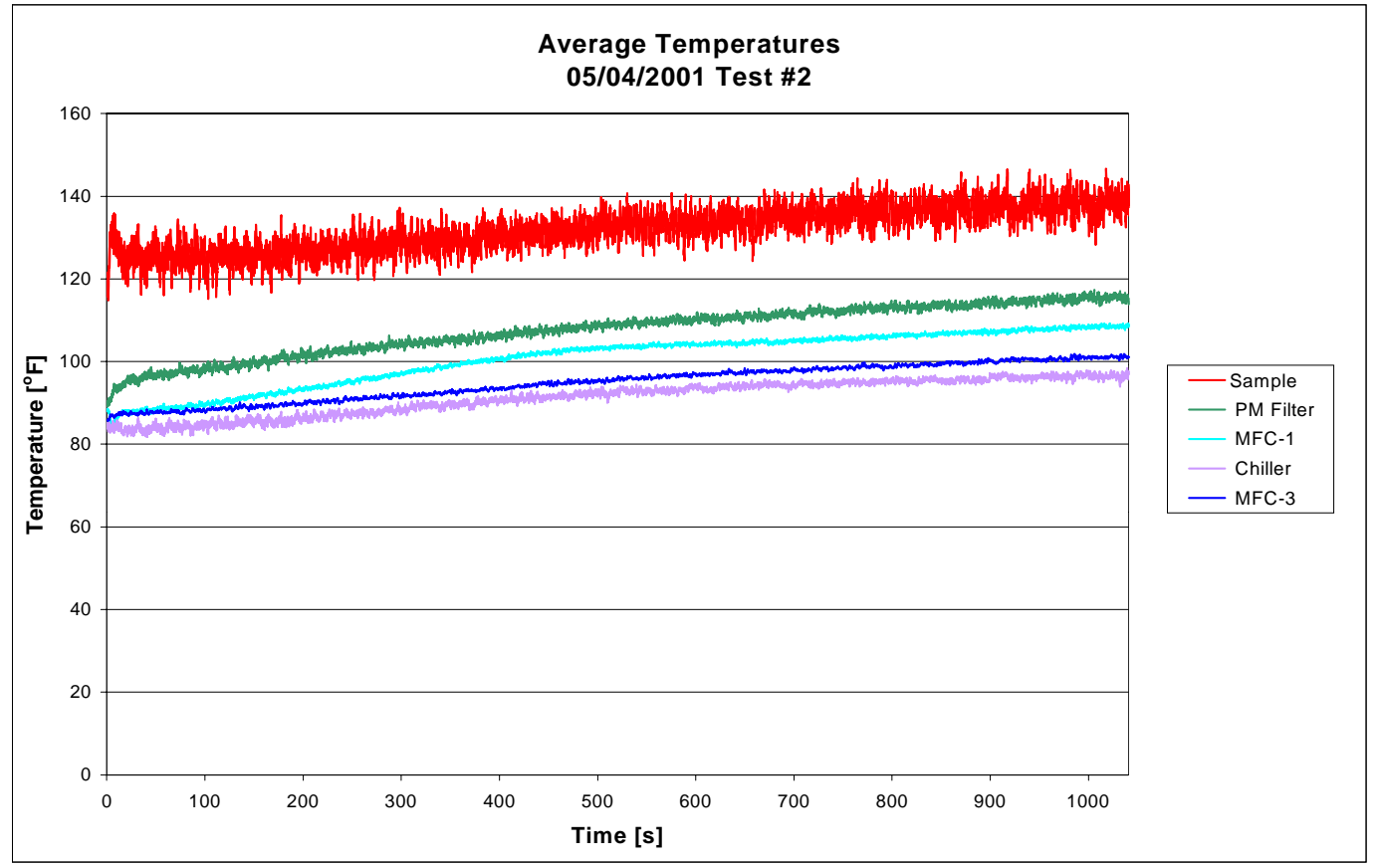

Figure 4.42 Temperatures During Transient Test \#2 


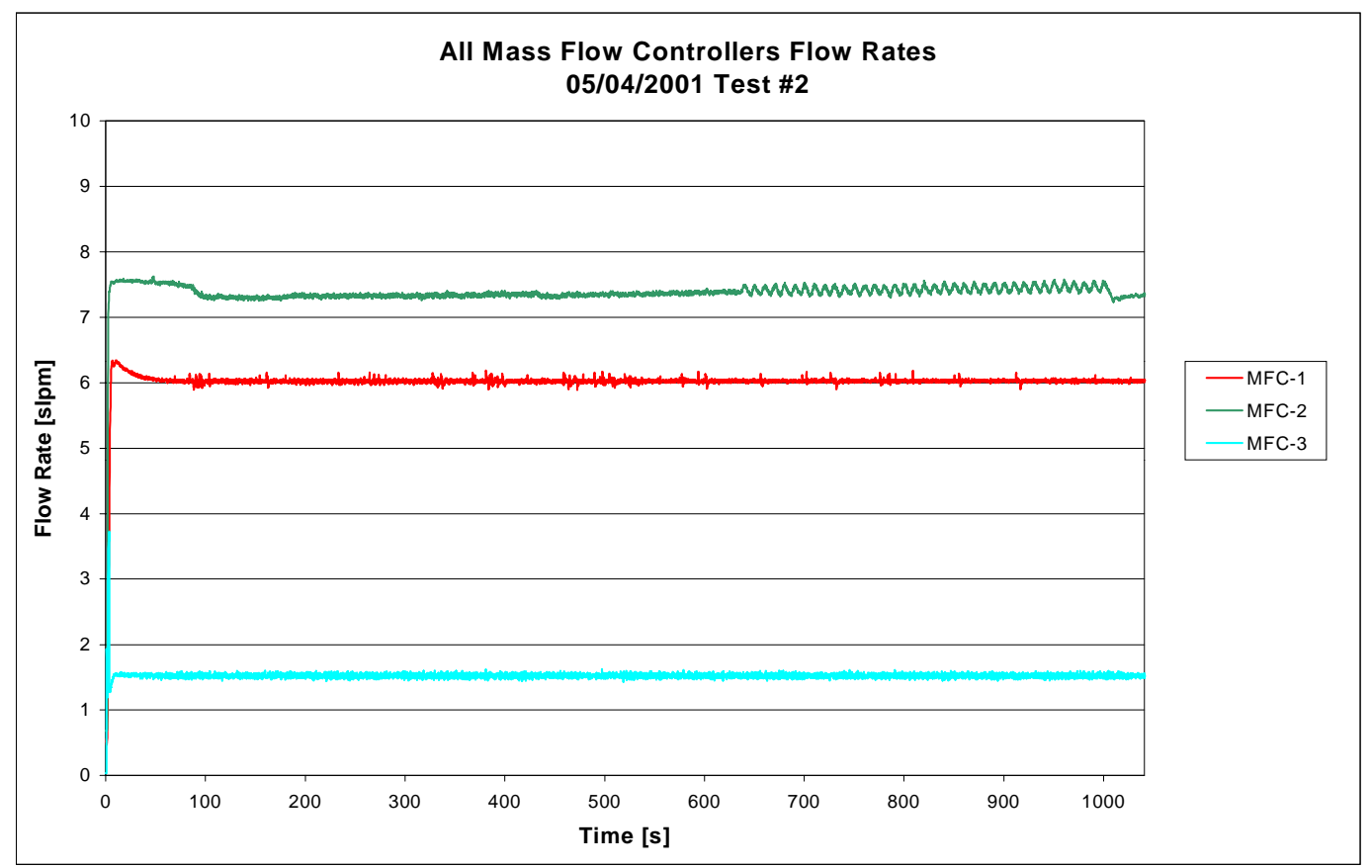

Figure 4.43 Mass Flow Rates During Transient Test \#2

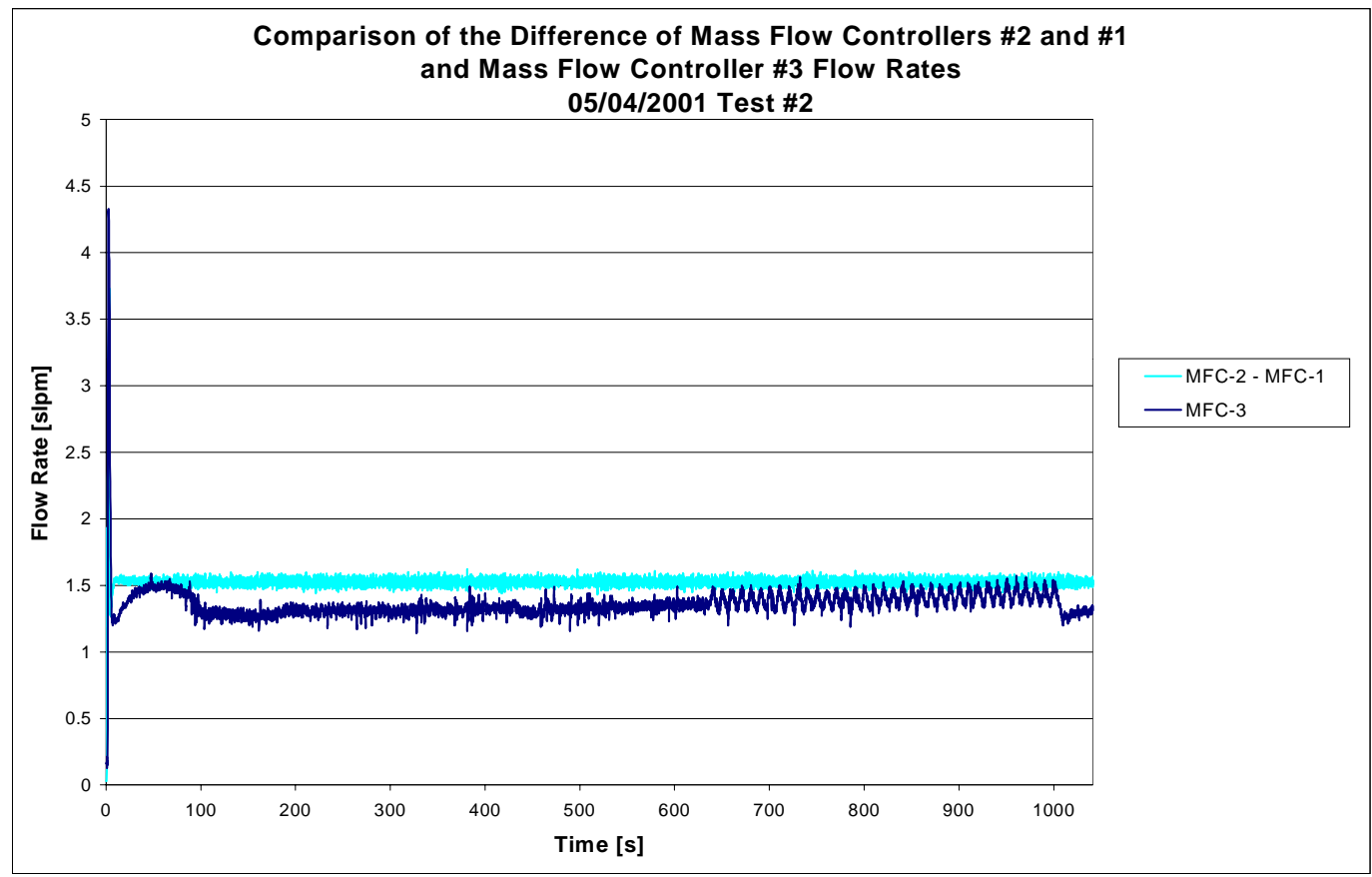

Figure 4.44 Comparison of Raw Exhaust and Bleed Flow Rates During Transient Test \#2 
Table 4.10 Comparison of Full-Flow Dilution and Micro-Dilution Tunnels for Transient Test \#2

\begin{tabular}{|l|r|l|}
\hline Volume into micro-dilution system $=$ & 26.03 & {$[\mathrm{liters}]$} \\
\hline Fuel Consumption from Counter $=$ & 5.45 & {$[\mathrm{~kg}]$} \\
\hline Intake Air Mass Flow $=$ & 163.77 & {$[\mathrm{~kg}]$} \\
\hline Length of Sampling Time $=$ & 17.35 & {$[\mathrm{~min}]$} \\
\hline Total Exhaust Mass $=$ & 169.22 & {$[\mathrm{~kg}]$} \\
\hline Density $=$ & 1.2 & {$\left[\mathrm{~kg} / \mathrm{m}^{3}\right]$} \\
\hline Volume Total Exhaust $=$ & 141015 & {$[\mathrm{liters}]$} \\
\hline Mass on 47-mm filter $=$ & 0.099 & {$[\mathrm{mg}]$} \\
\hline Mass on 70-mm filter $=$ & 1.683 & {$[\mathrm{mg}]$} \\
\hline $\mathrm{P}_{\text {test }}($ micro-tunnel) $=$ & 0.54 & {$[\mathrm{~g} / \mathrm{test}]$} \\
\hline $\mathrm{P}_{\text {test }}$ (test cell $)=$ & 0.47 & {$[\mathrm{~g} / \mathrm{test}]$} \\
\hline Percent Error $=$ & $\mathbf{- 1 3 \%}$ & \\
\hline
\end{tabular}

\subsubsection{Test \#3 (OSC \#7)}

The third test was a repeat of the first transient test on a different day using test OSC \#7. The temperatures for this test run compared to test \#1, prove to be better. The amount of particulate per test in the micro-dilution system almost equaled the amount of particulate per test in the full-flow dilution system. The temperatures increased, but not linearly. The MFCs reached their setpoints faster and in turn the exiting and entering flow rates almost equaled. 


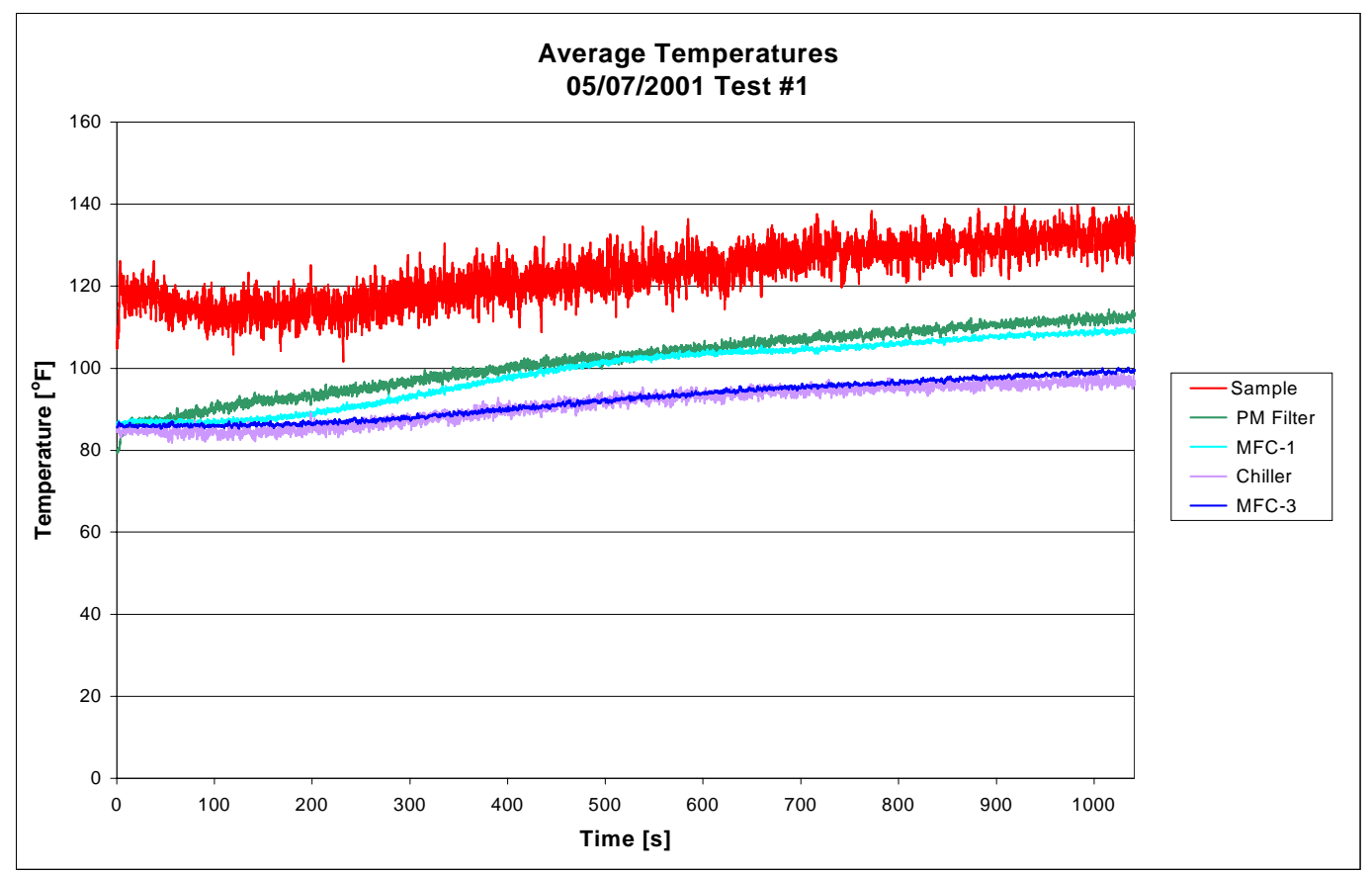

Figure 4.45 Temperatures During Transient Test \#3

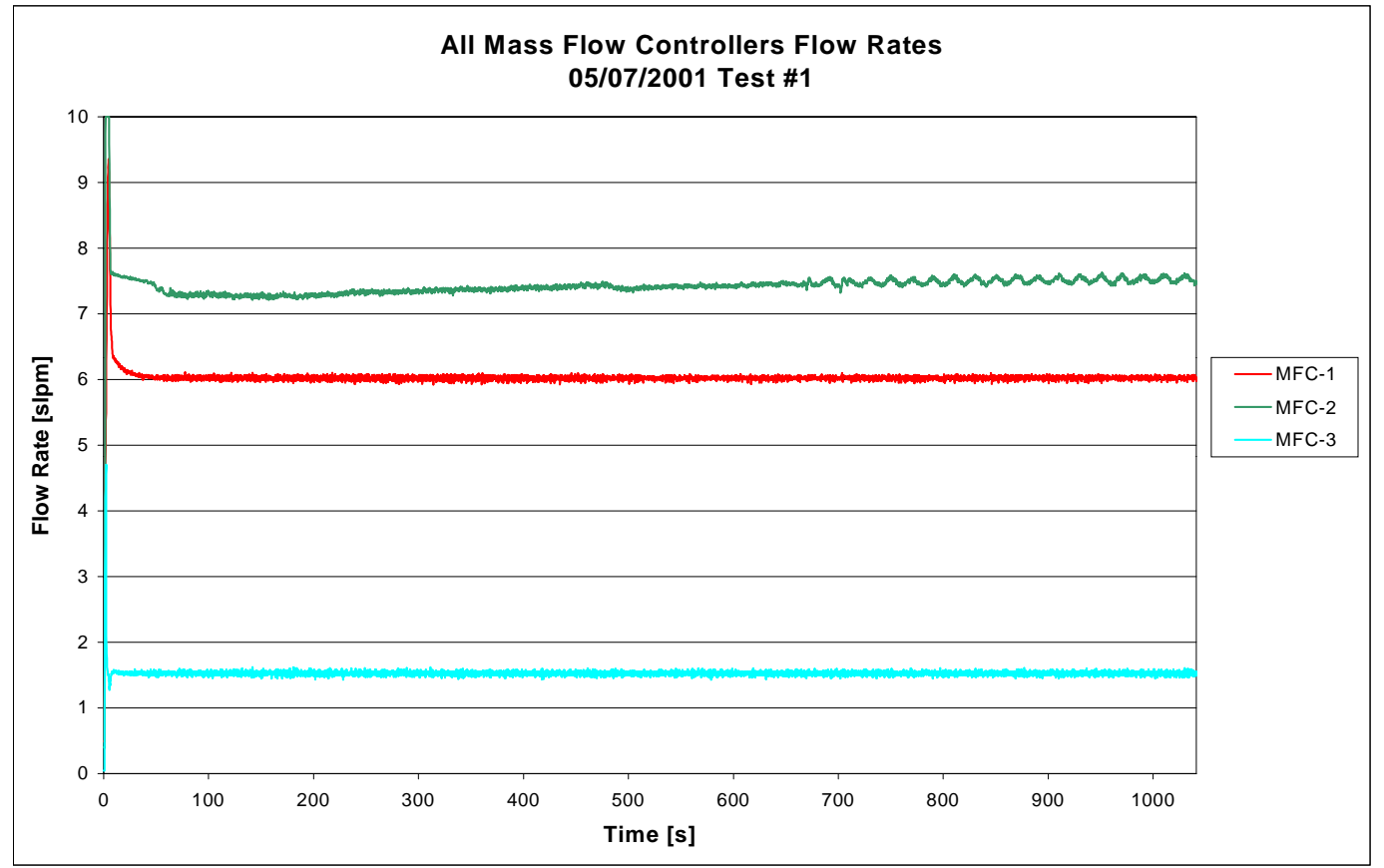

Figure 4.46 Mass Flow Rates During Transient Test \#3 


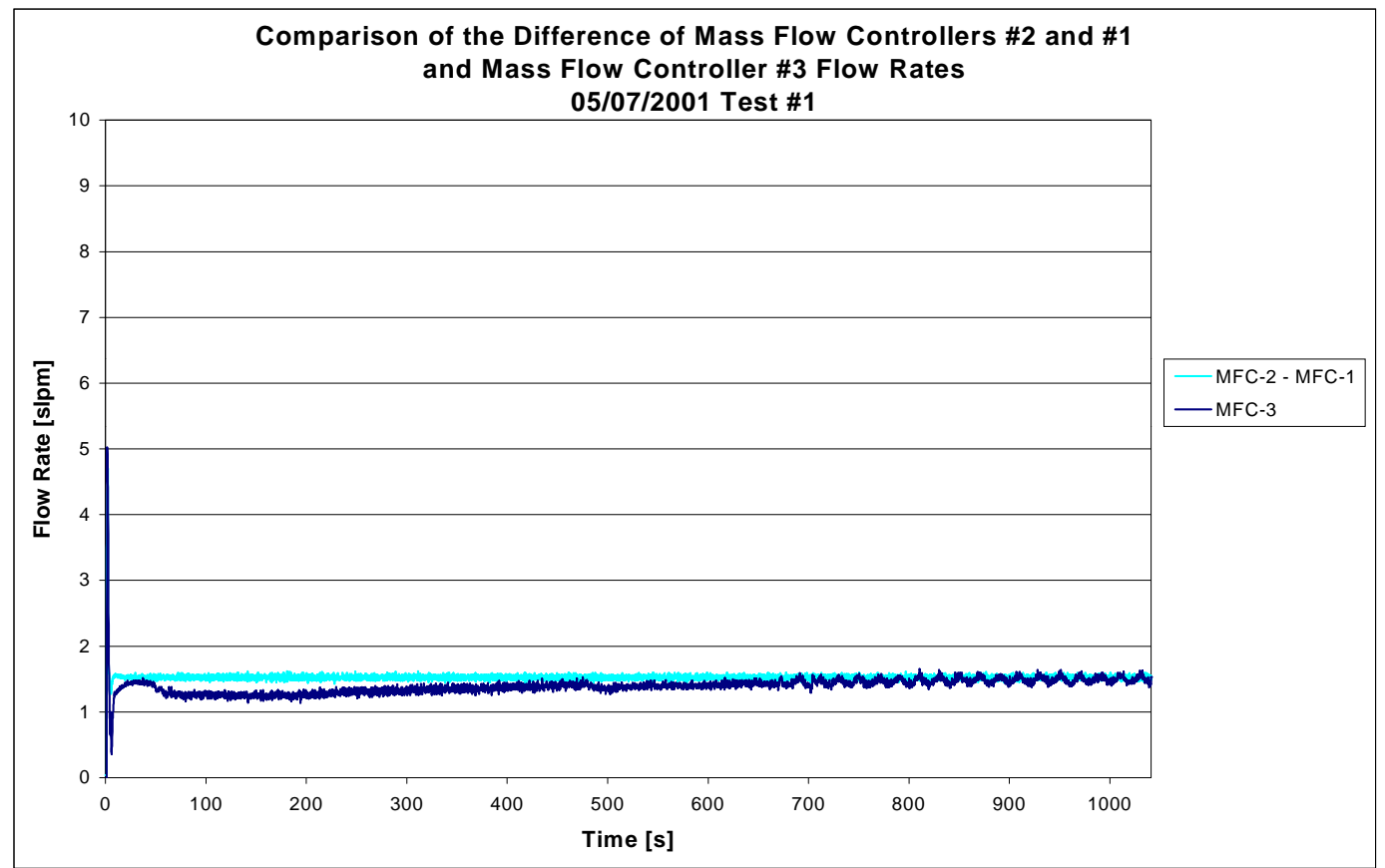

Figure 4.47 Comparison of Raw Exhaust and Bleed Flow Rates During Transient Test \#3

Table 4.11 Comparison of Full-Flow Dilution and Micro-Dilution Tunnels for Transient Test \#3

\begin{tabular}{|l|r|l|}
\hline Volume into micro-dilution system $=$ & 25.81 & {$[\mathrm{liters}]$} \\
\hline Fuel Consumption from Counter $=$ & 5.22 & {$[\mathrm{~kg}]$} \\
\hline Intake Air Mass Flow $=$ & 162.05 & {$[\mathrm{~kg}]$} \\
\hline Length of Sampling Time $=$ & 17.35 & {$[\mathrm{~min}]$} \\
\hline Total Exhaust Mass $=$ & 167.27 & {$[\mathrm{~kg}]$} \\
\hline Density $=$ & 1.2 & {$\left[\mathrm{~kg} / \mathrm{m}^{3}\right]$} \\
\hline Volume Total Exhaust $=$ & 139390 & {$[\mathrm{liters}]$} \\
\hline Mass on 47-mm filter $=$ & 0.175 & {$[\mathrm{mg}]$} \\
\hline Mass on 70-mm filter $=$ & 3.505 & {$[\mathrm{mg}]$} \\
\hline $\mathrm{P}_{\text {test }}($ micro-tunnel $)=$ & 0.95 & {$[\mathrm{~g} / \mathrm{test}]$} \\
\hline $\mathrm{P}_{\text {test }}($ test cell $)=$ & 0.94 & {$[\mathrm{~g} / \mathrm{test}]$} \\
\hline Percent Error $=$ & $\mathbf{0 \%}$ & \\
\hline
\end{tabular}

\subsubsection{Test \#4 (OSC \#8)}

The fourth test was a repeat of the second transient test on a different day using test OSC \#8. The temperatures and flow rates of this test were similar to those from test 
\#2. When compared to the full-flow dilution tunnel the micro-dilution tunnel system was $16 \%$ less than the full-flow tunnel results. The results from this test follow.

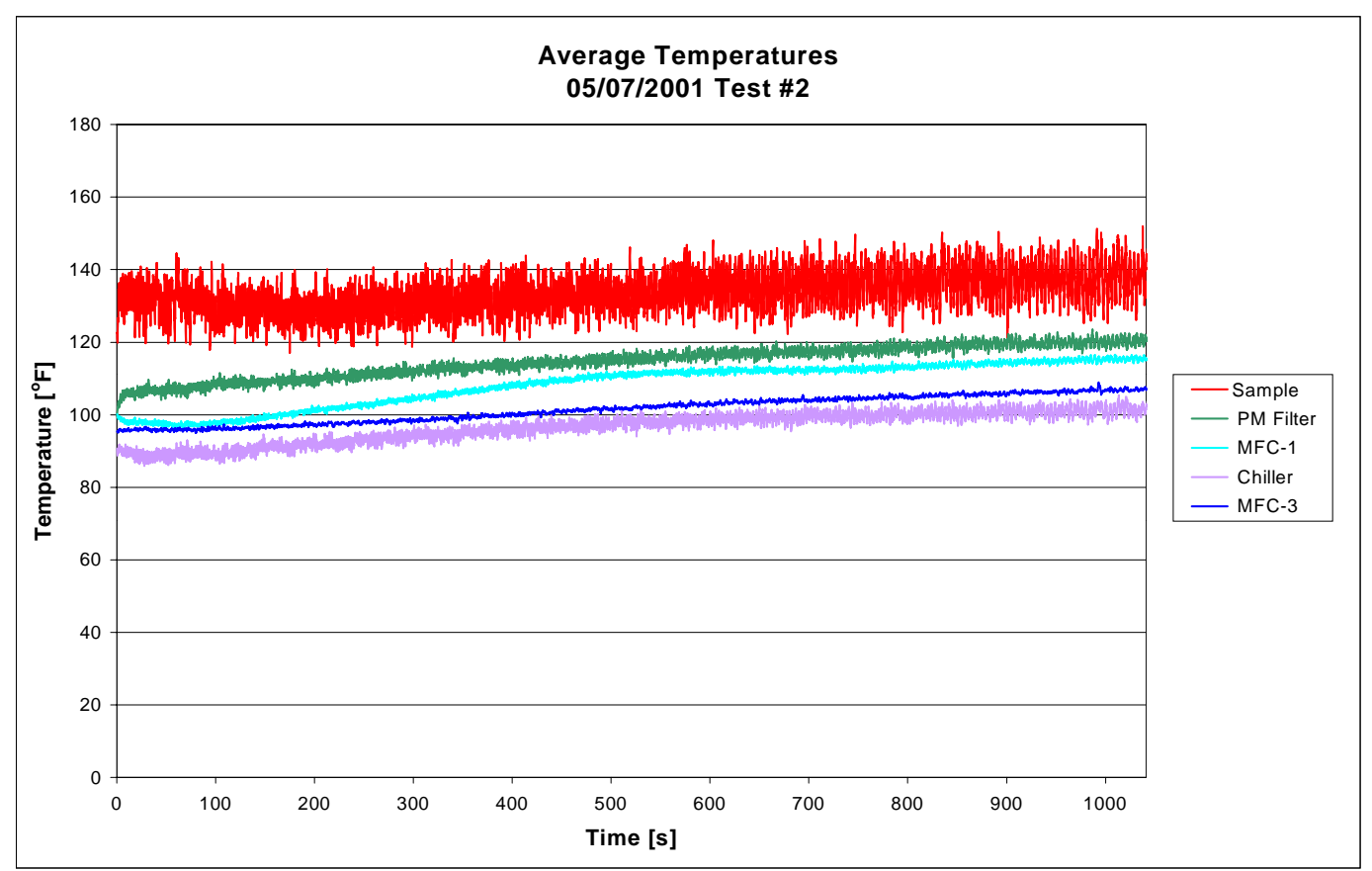

Figure 4.48 Temperatures During Transient Test \#4 


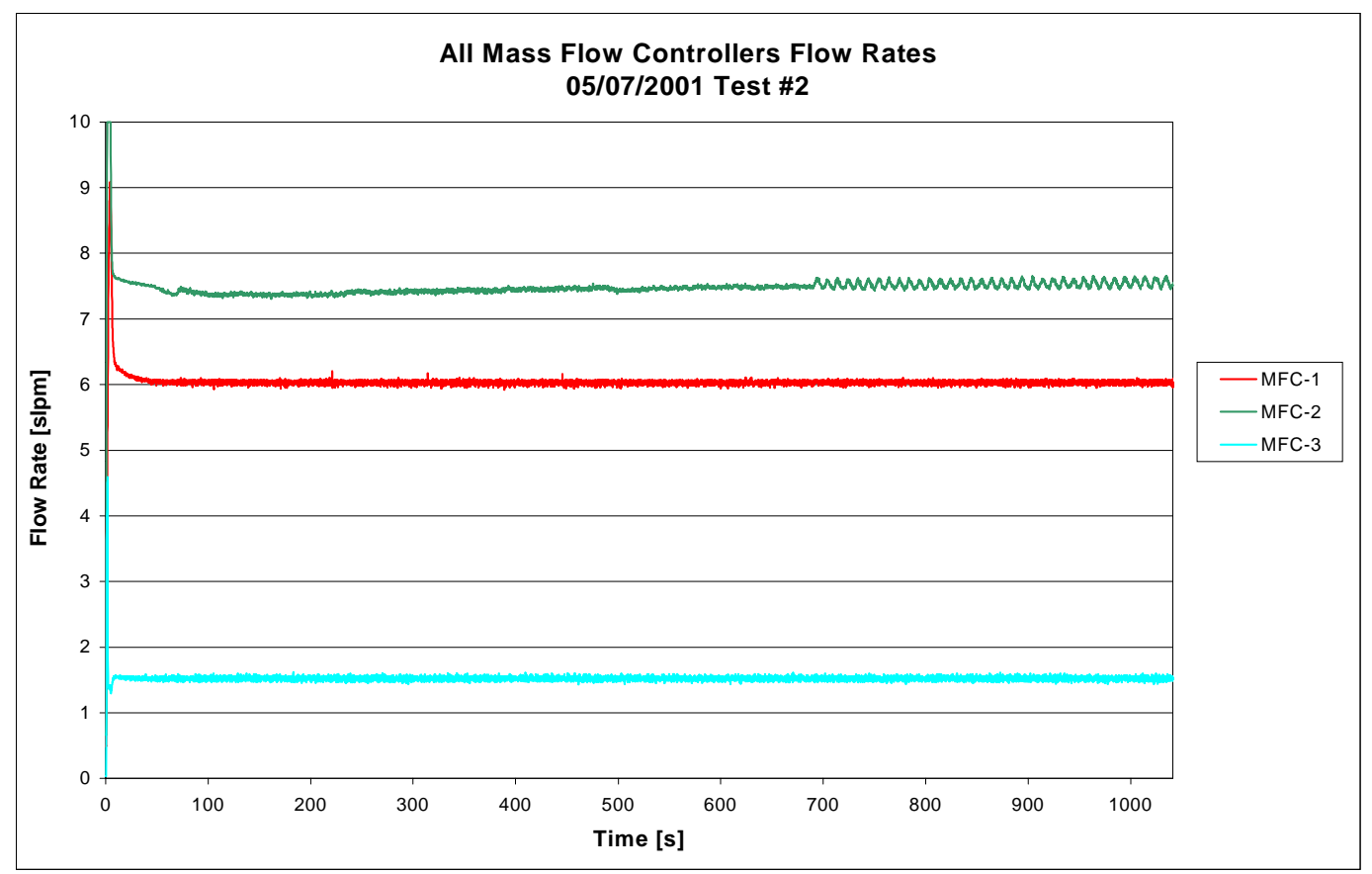

Figure 4.49 Mass Flow Rates During Transient Test \#4

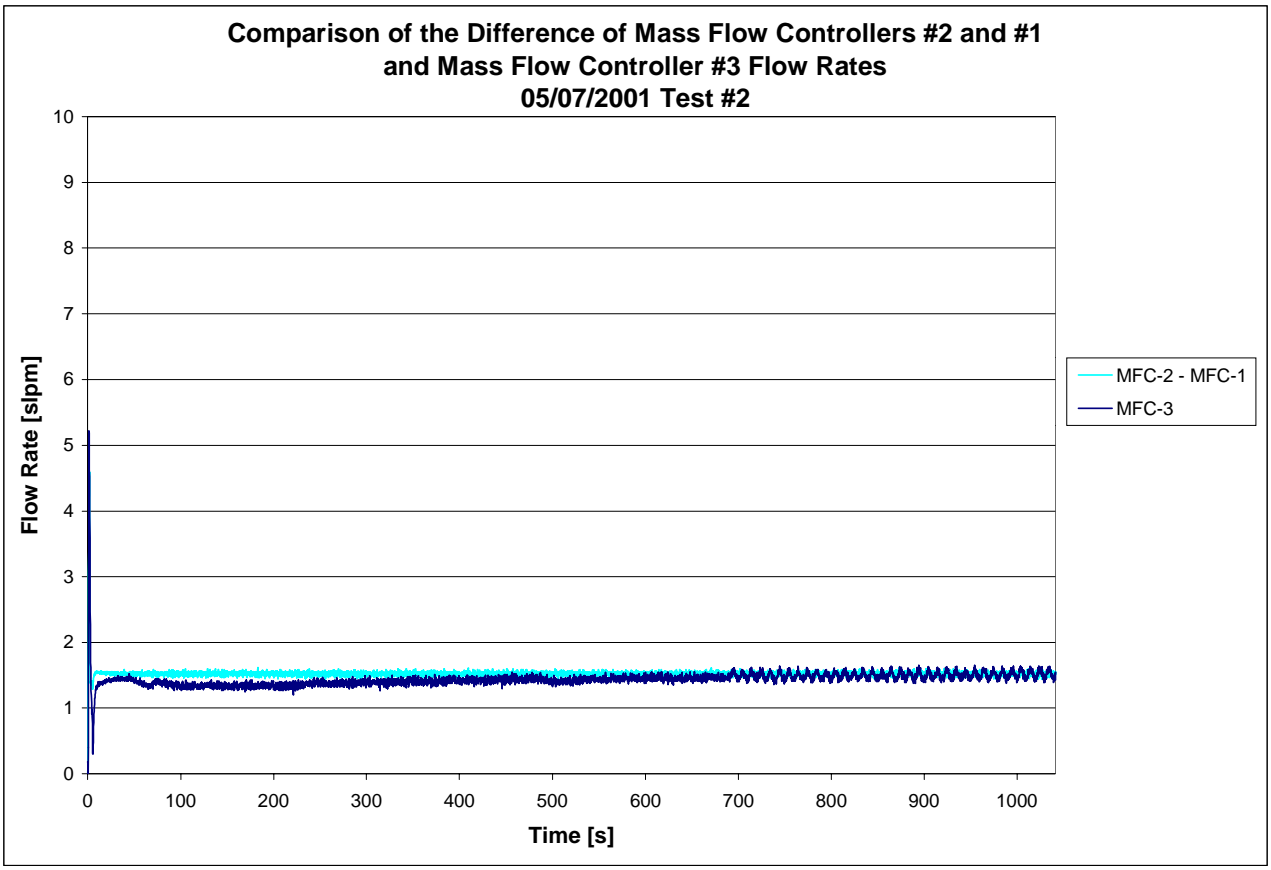

Figure 4.50 Comparison of Raw Exhaust and Bleed Flow Rates During Transient Test \#4 
Table 4.12 Comparison of Full-Flow Dilution and Micro-Dilution Tunnels for Transient Test \#4

\begin{tabular}{|l|r|l|}
\hline Volume into micro-dilution system $=$ & 26.77 & {$[\mathrm{liters}]$} \\
\hline Fuel Consumption from Counter $=$ & 5.20 & {$[\mathrm{~kg}]$} \\
\hline Intake Air Mass Flow $=$ & 160.59 & {$[\mathrm{~kg}]$} \\
\hline Length of Sampling Time $=$ & 17.35 & {$[\mathrm{~min}]$} \\
\hline Total Exhaust Mass $=$ & 165.79 & {$[\mathrm{~kg}]$} \\
\hline Density $=$ & 1.2 & {$\left[\mathrm{~kg} / \mathrm{m}^{3}\right]$} \\
\hline Volume Total Exhaust $=$ & 138155 & {$[\mathrm{liters}]$} \\
\hline Mass on 47-mm filter $=$ & 0.124 & {$[\mathrm{mg}]$} \\
\hline Mass on 70-mm filter $=$ & 2.86 & {$[\mathrm{mg}]$} \\
\hline $\mathrm{P}_{\text {test }}($ micro-tunnel) $=$ & 0.64 & {$[\mathrm{~g} / \mathrm{test}]$} \\
\hline $\mathrm{P}_{\text {test }}($ test cell $)=$ & 0.76 & {$[\mathrm{~g} / \mathrm{test}]$} \\
\hline Percent Error $=$ & $\mathbf{1 6 \%}$ & \\
\hline
\end{tabular}

\subsubsection{Test \#5 (OSC \#9)}

In the fifth oscillating transient test, the torque range was increased by $100 \mathrm{ft}-\mathrm{lb}$ (135.6 N-m). The torque range was 200 to $400 \mathrm{ft}-\mathrm{lb}(271.1 \mathrm{~N}-\mathrm{m}$ to $542.3 \mathrm{~N}-\mathrm{m})$ and the period was 20 seconds, as shown in Figure 4.51. This torque range would spool the turbo charger in and out of its operation. The calculated manifold pressure for this torque range would approximately equal 3 to 7 psi. 


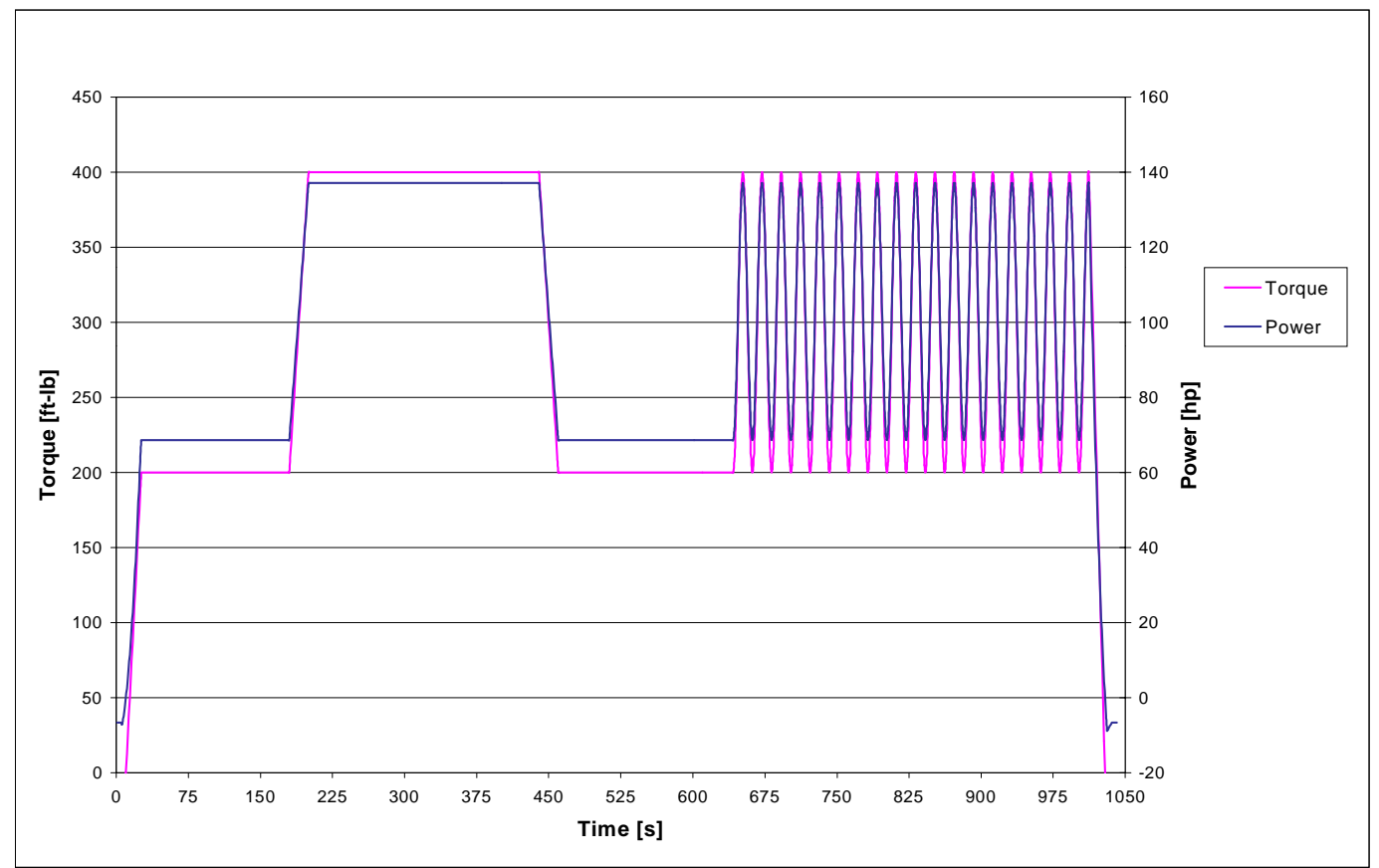

Figure 4.51 Oscillating Transient Test \#9 Cycle

The results of this test are discussed in this section. The temperatures behaved similarly as the previous four oscillating transient tests. The mass flow controllers responded better for this test run. The air entering and exiting were closer during this test run than the previous tests. However, the percent difference between the two systems was $12 \%$. 


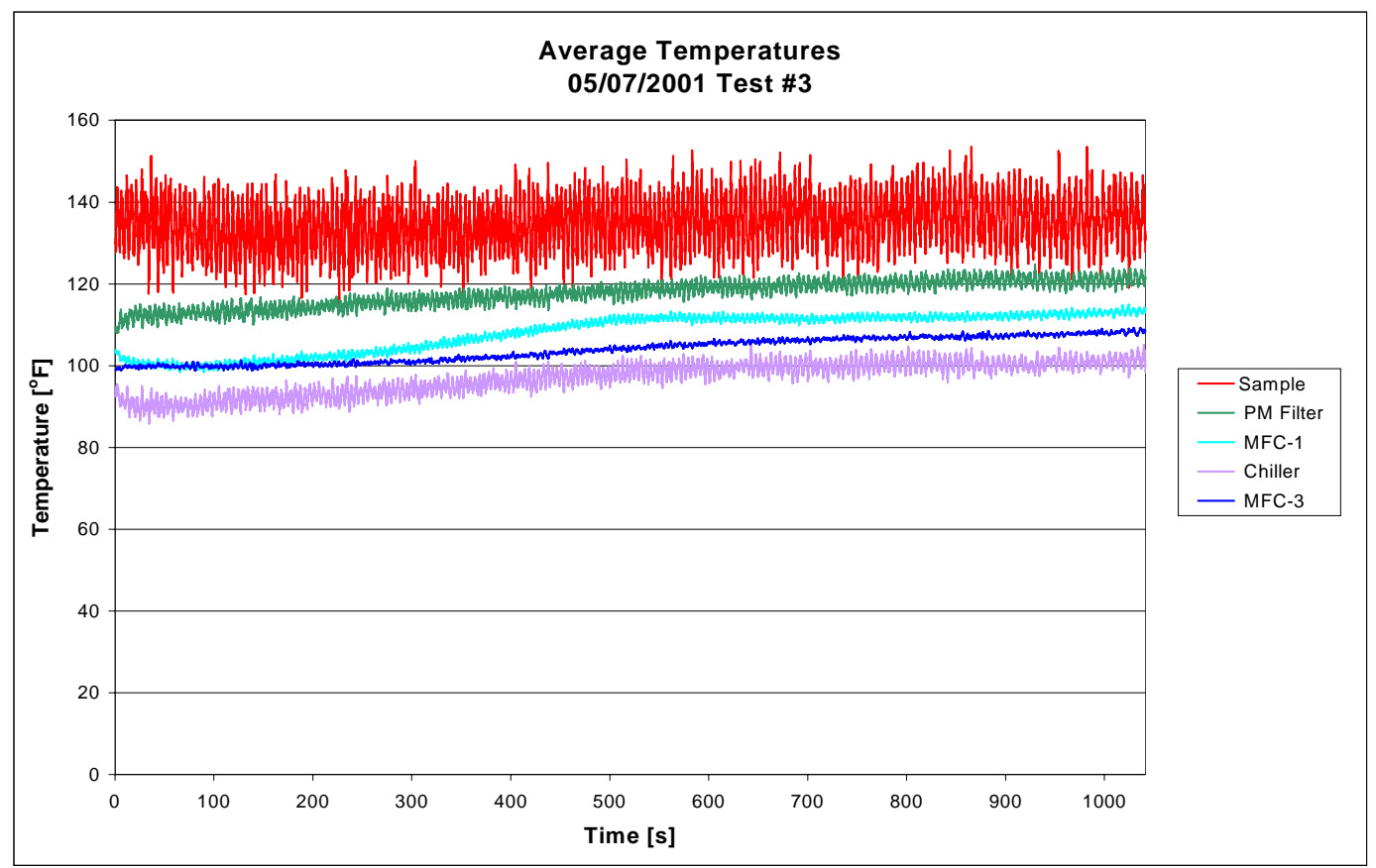

Figure 4.52 Temperatures During Transient Test \#5

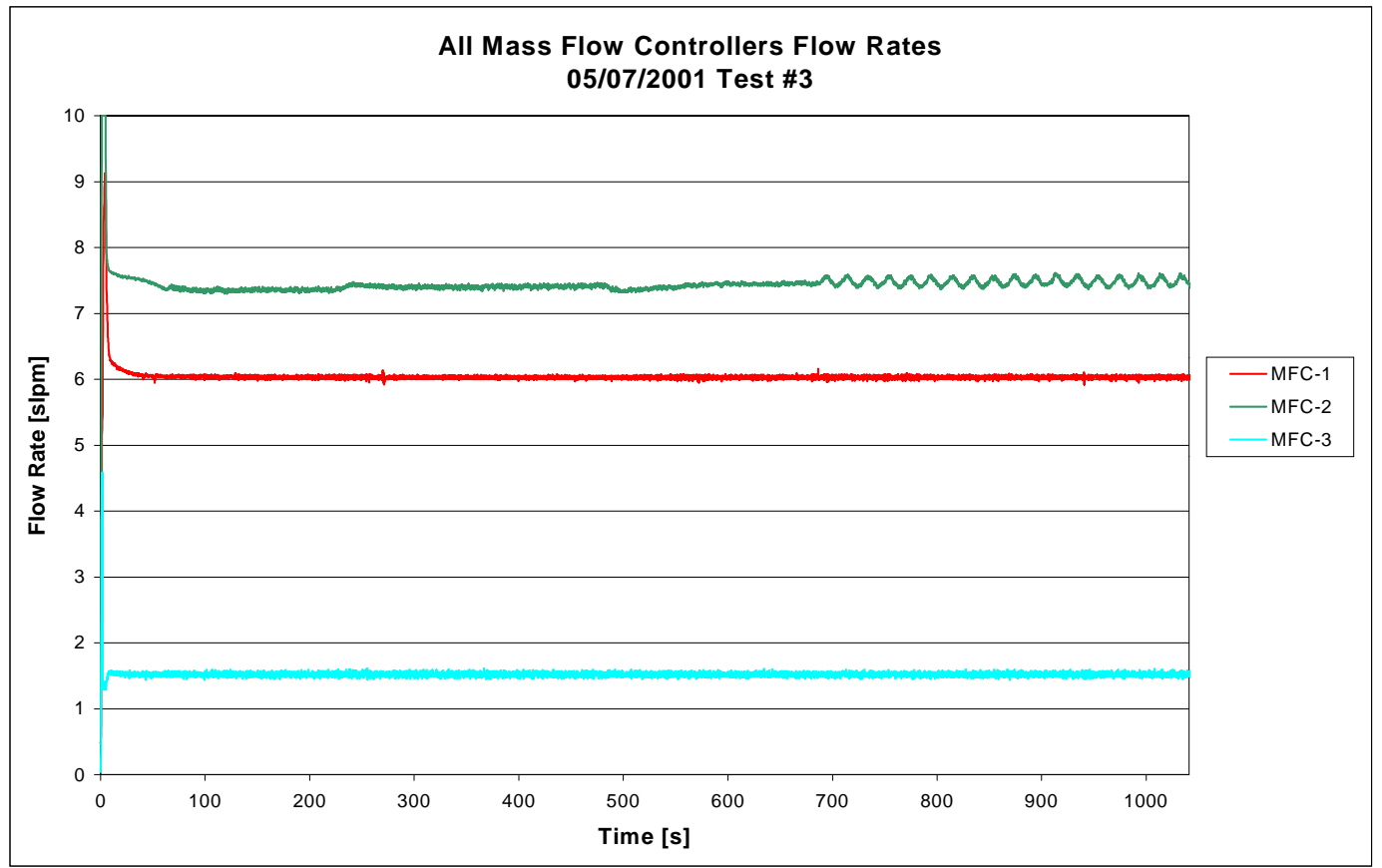

Figure 4.53 Mass Flow Rates During Transient Test \#5 


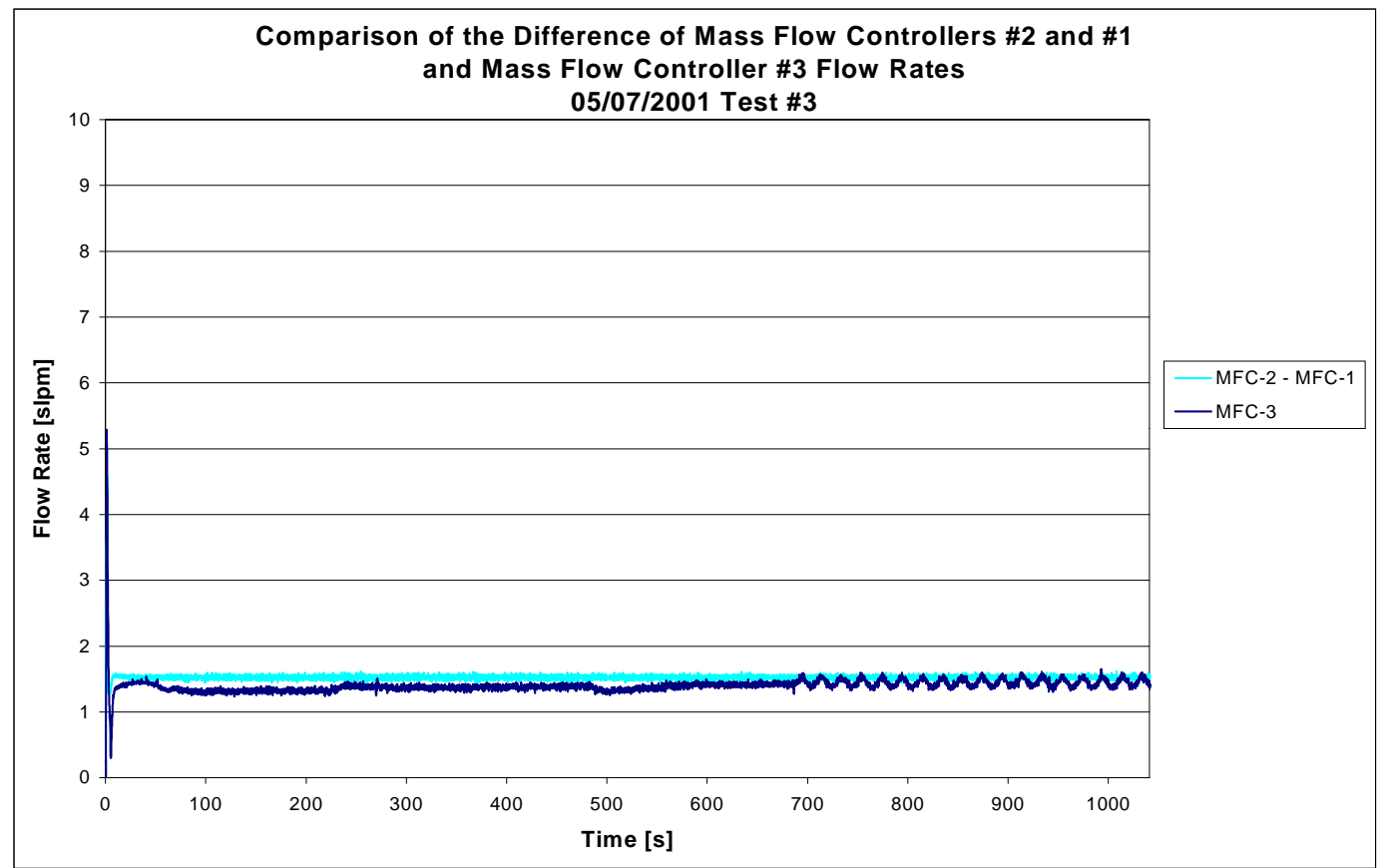

Figure 4.54 Comparison of Raw Exhaust and Bleed Flow Rates During Transient Test $\# 5$

Table 4.13 Comparison of Full Flow and Micro-Dilution Tunnels for Transient Test \#5

\begin{tabular}{|l|r|l|}
\hline Volume into micro-dilution system $=$ & 25.78 & {$[\mathrm{liters}]$} \\
\hline Fuel Consumption from Counter $=$ & 4.44 & {$[\mathrm{~kg}]$} \\
\hline Intake Air Mass Flow $=$ & 153.09 & {$[\mathrm{~kg}]$} \\
\hline Length of Sampling Time $=$ & 17.35 & {$[\mathrm{~min}]$} \\
\hline Total Exhaust Mass $=$ & 157.53 & {$[\mathrm{~kg}]$} \\
\hline Density $=$ & 1.2 & {$\left[\mathrm{~kg} / \mathrm{m}^{3}\right]$} \\
\hline Volume Total Exhaust $=$ & 131273 & {$[\mathrm{liters}]$} \\
\hline Mass on 47-mm filter $=$ & 0.125 & {$[\mathrm{mg}]$} \\
\hline Mass on 70-mm filter $=$ & 2.725 & {$[\mathrm{mg}]$} \\
\hline $\mathrm{P}_{\text {test }}(\mathrm{micro}-$ tunnel $)=$ & 0.64 & {$[\mathrm{~g} / \mathrm{test}]$} \\
\hline $\mathrm{P}_{\text {test }}($ test cell $)=$ & 0.72 & {$[\mathrm{~g} / \mathrm{test}]$} \\
\hline Percent Error $=$ & $\mathbf{1 2 \%}$ & \\
\hline
\end{tabular}

\subsubsection{Test \#6 (OSC \#10)}

The sixth test decreased the time period of oscillations back to 10 seconds and used the same torque range of 200 to $400 \mathrm{ft}-\mathrm{lb}(271.1$ to $543.3 \mathrm{~N}-\mathrm{m})$ as the previous test. The test results for OSC \#10 differed more so than any other test. The temperature of the 
raw exhaust toggled around $140^{\circ} \mathrm{F}$ for the entire test, unlike any of the previous tests. The other temperatures increased in a fashion similar to the previous five tests. Also, the mass flow controller that measured the total flow never fully reached its setpoint of 7.5 slpm. In turn, the flow rates entering and exiting the micro-dilution tunnel also never overlapped like they did in the previous tests. Despite these two differences, this test resulted in a percent difference between the two systems of $8 \%$. The results from this test follow.

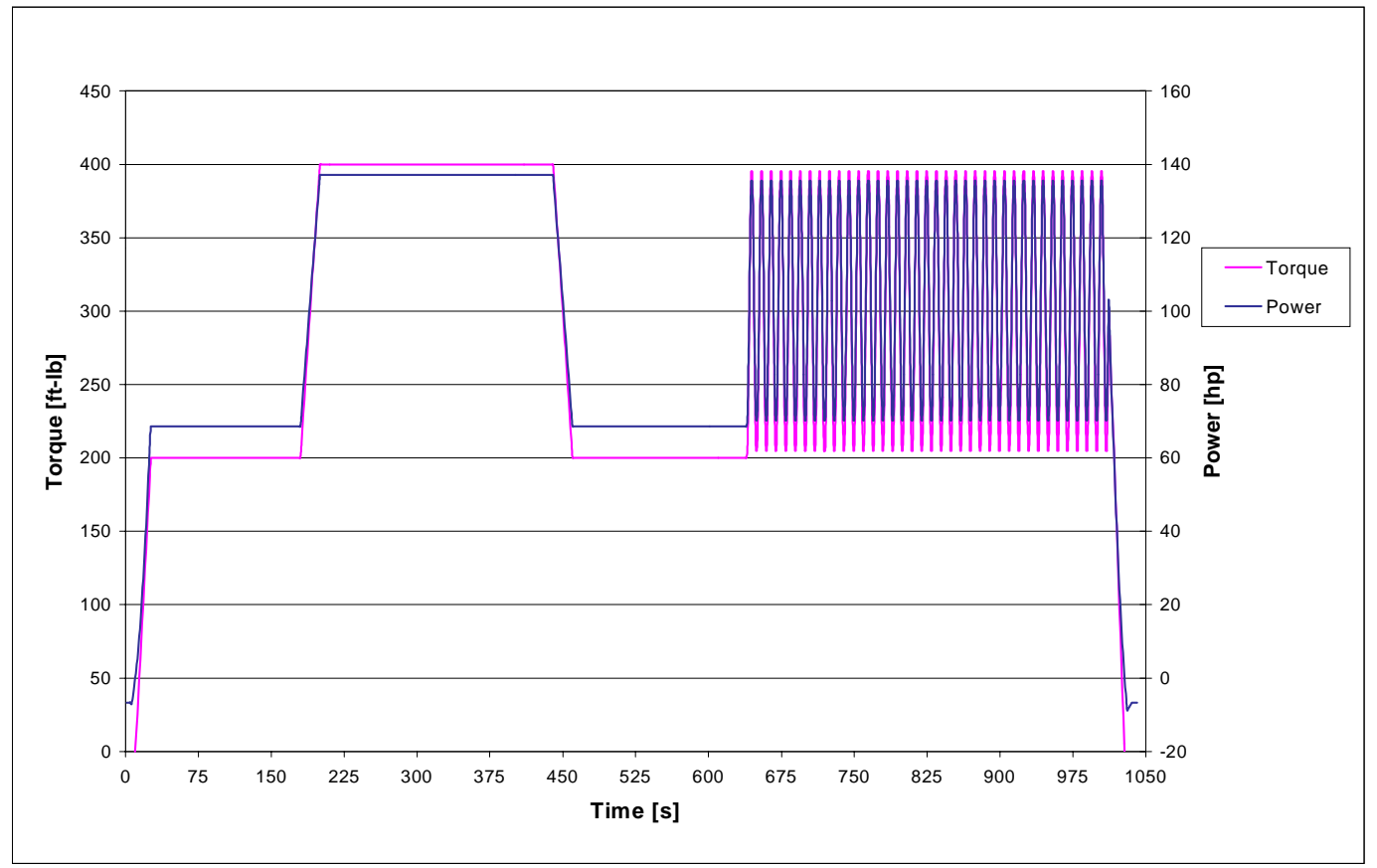

Figure 4.55 Oscillating Transient Test \#10 Cycle 


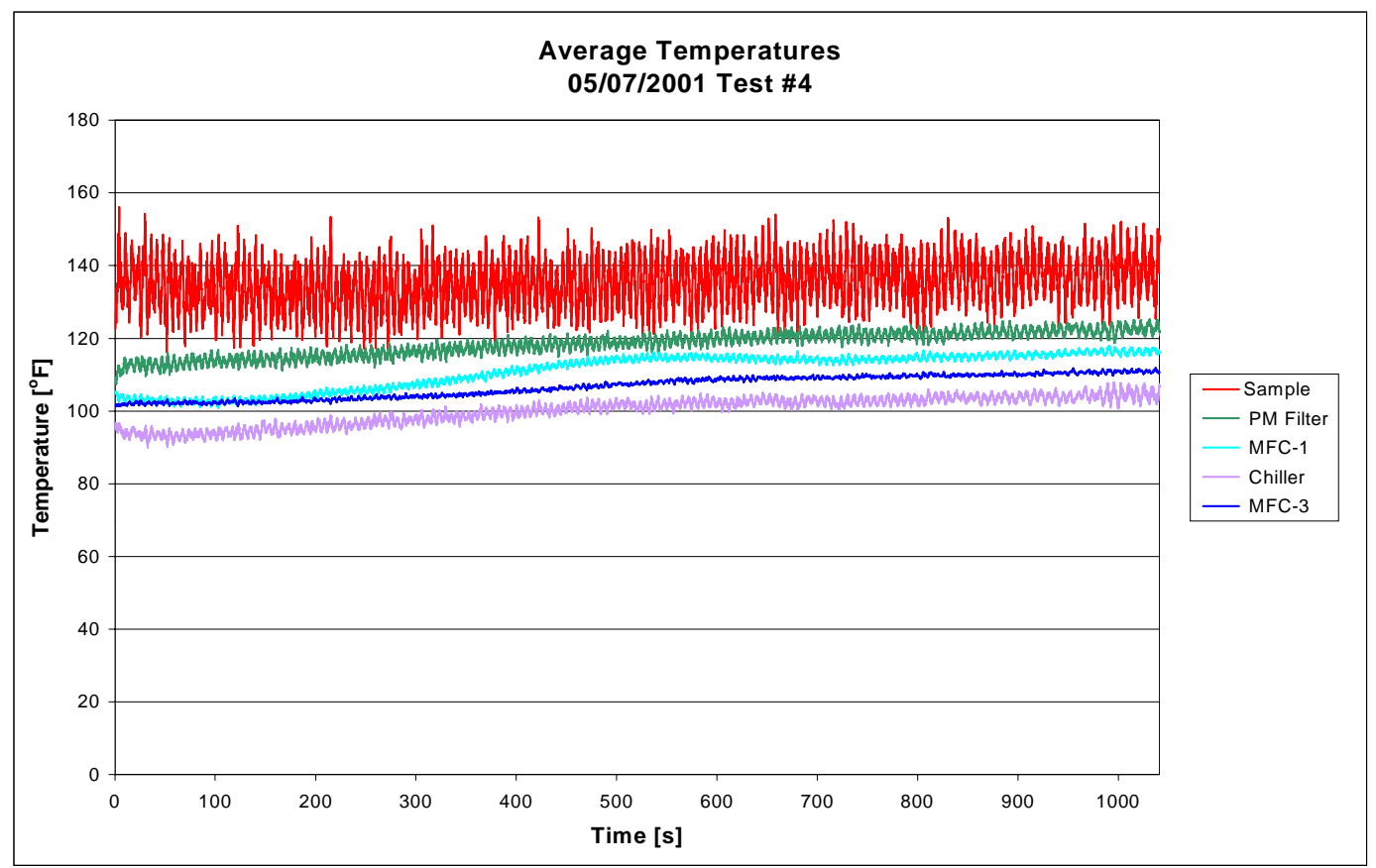

Figure 4.56 Temperatures During Transient Test \#6

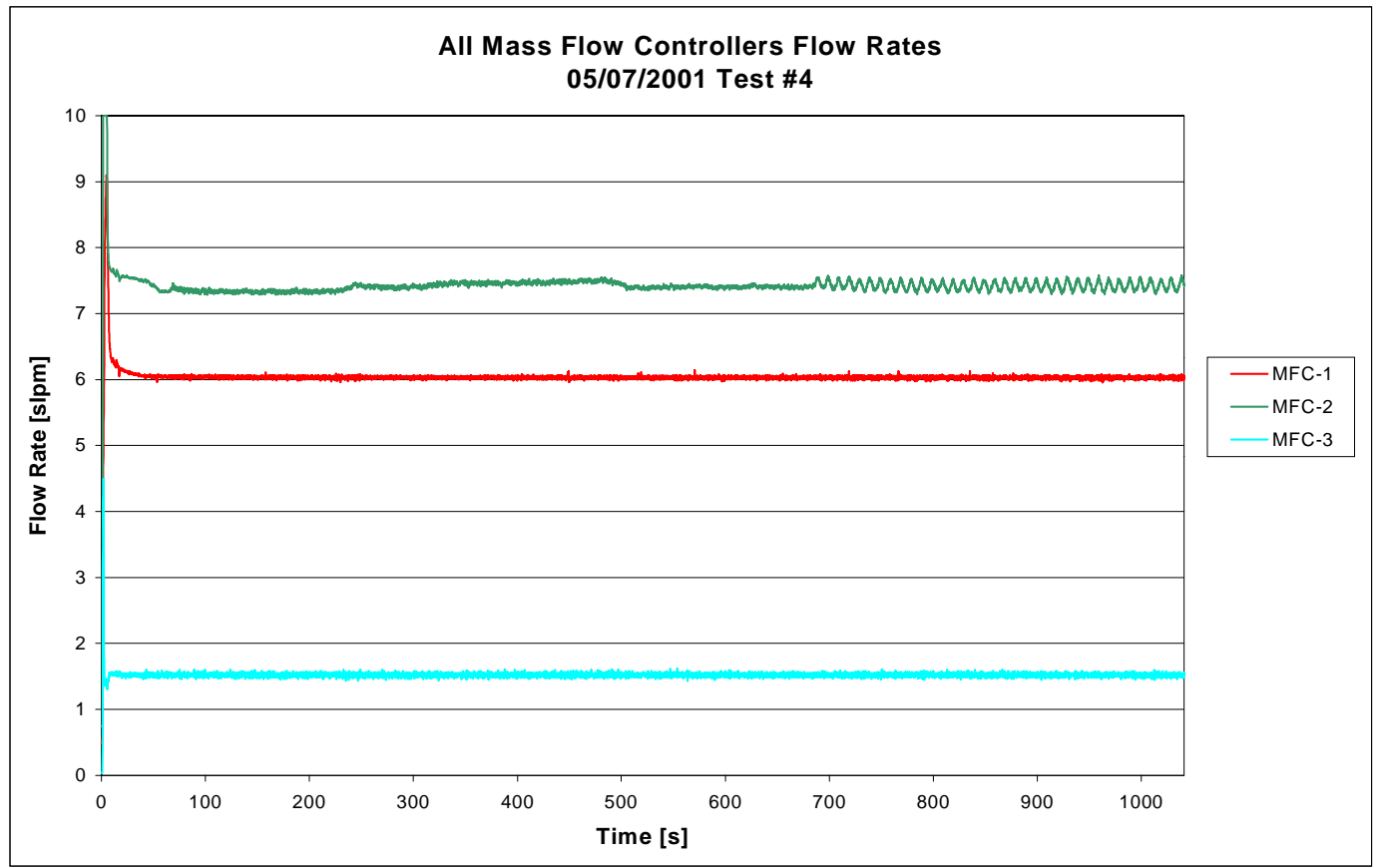

Figure 4.57 Mass Flow Rates for Transient Test \#6 


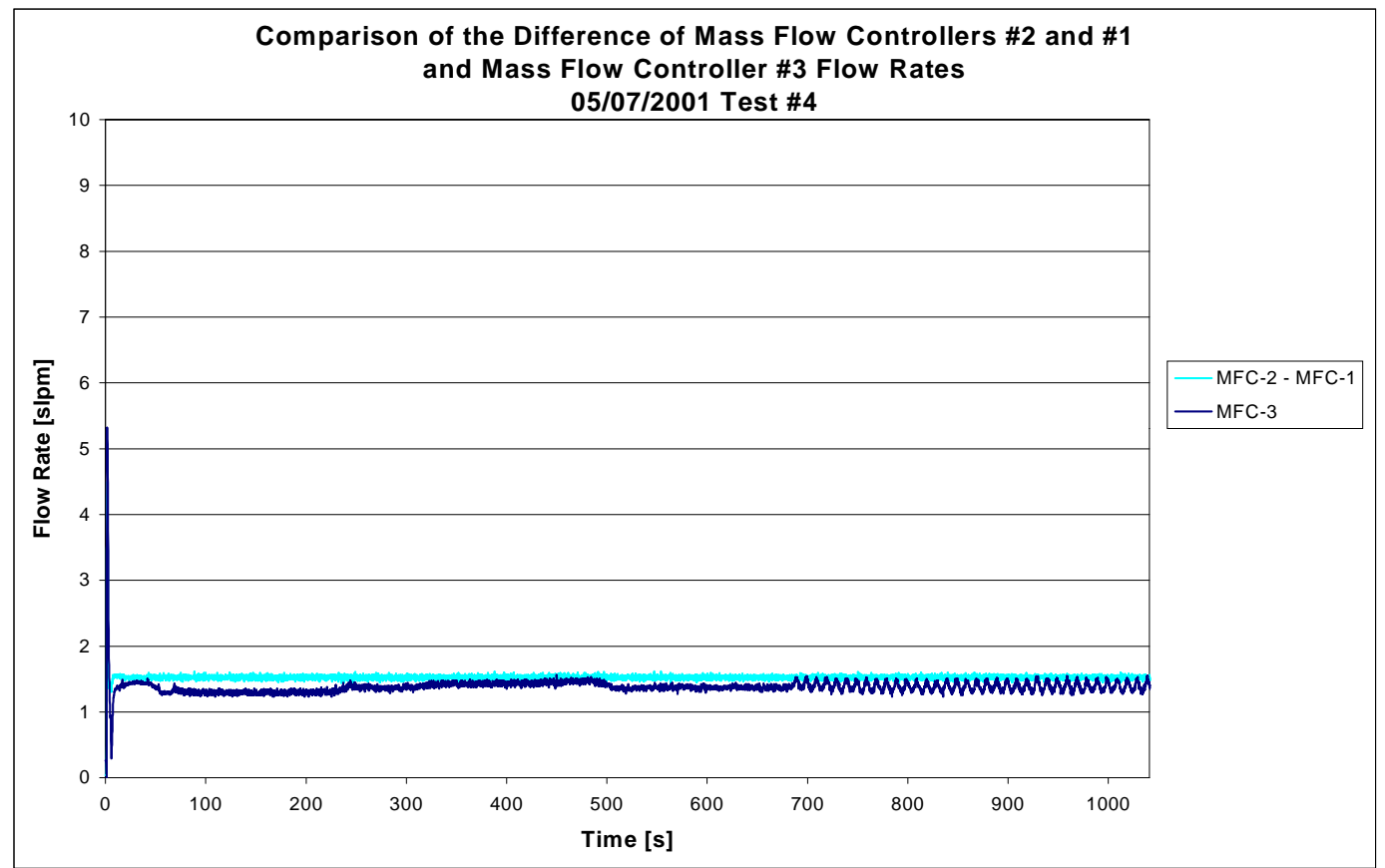

Figure 4.58 Comparison of Raw Exhaust and Bleed Flow Rates for Transient Test \#6

Table 4.14 Comparison of Full-Flow Dilution and Micro-Dilution Tunnels for Transient Test \#6

\begin{tabular}{|l|r|l|}
\hline Volume into micro-dilution system $=$ & 25.49 & {$[\mathrm{liters}]$} \\
\hline Fuel Consumption from Counter $=$ & 4.44 & {$[\mathrm{~kg}]$} \\
\hline Intake Air Mass Flow $=$ & 152.82 & {$[\mathrm{~kg}]$} \\
\hline Length of Sampling Time $=$ & 17.35 & {$[\mathrm{~min}]$} \\
\hline Total Exhaust Mass $=$ & 157.26 & {$[\mathrm{~kg}]$} \\
\hline Density $=$ & 1.2 & {$\left[\mathrm{~kg} / \mathrm{m}^{3}\right]$} \\
\hline Volume Total Exhaust $=$ & 131049 & {$[\mathrm{liters}]$} \\
\hline Mass on 47-mm filter $=$ & 0.149 & {$[\mathrm{mg}]$} \\
\hline Mass on 70-mm filter $=$ & 2.679 & {$[\mathrm{mg}]$} \\
\hline $\mathrm{P}_{\text {test }}($ micro-tunnel $)=$ & 0.77 & {$[\mathrm{~g} / \mathrm{test}]$} \\
\hline $\mathrm{P}_{\text {test }}($ test cell $)=$ & 0.71 & {$[\mathrm{~g} / \mathrm{test}]$} \\
\hline Percent Error $=$ & $\mathbf{- 8 \%}$ & \\
\hline
\end{tabular}

Each steady state and transient test results showed that the more particulate matter collected on a filter, the more accurate the test was. The full-flow tunnel results varied from test-to-test, even when the test setup was exactly the same. This means that the results cannot be compared from test-to-test, but only for the given test. 


\subsubsection{Test \#7 (FTP \#1)}

The previous six tests were representative of the Navistar T444E engine. The next three transient tests were performed with the Detroit Diesel Series 60 using the Federal Test Procedure (FTP). The sampling time during the test was 20 minutes. Figure 4.59 displays five temperatures in the micro-dilution tunnel system that were recorded during this transient test. The temperatures for this test remained relatively cooler than previous transient tests. The temperature exiting the micro-dilution system was significantly lower by $40{ }^{\circ} \mathrm{F}$ than previous transient tests. Also, the thermocouples did not have nearly as much noise in the lines as with the Navistar T444E transient results.

Figure 4.60 displays the behavior of each MFC. MFC-1 and MFC-3 behaved as expected, however, MFC-2 never reached its setpoint of $7.5 \mathrm{slpm}$. This misbehavior caused the entering flow rate not to equal the exiting flow rate, as shown in Figure 4.61. Table 4.15 shows that the integrated volume entering the micro-dilution tunnel was significantly lower than expected. This value was approximately 9 liters less. This explains the high percent difference of $33 \%$ between the micro-dilution tunnel system and the full flow tunnel system. 


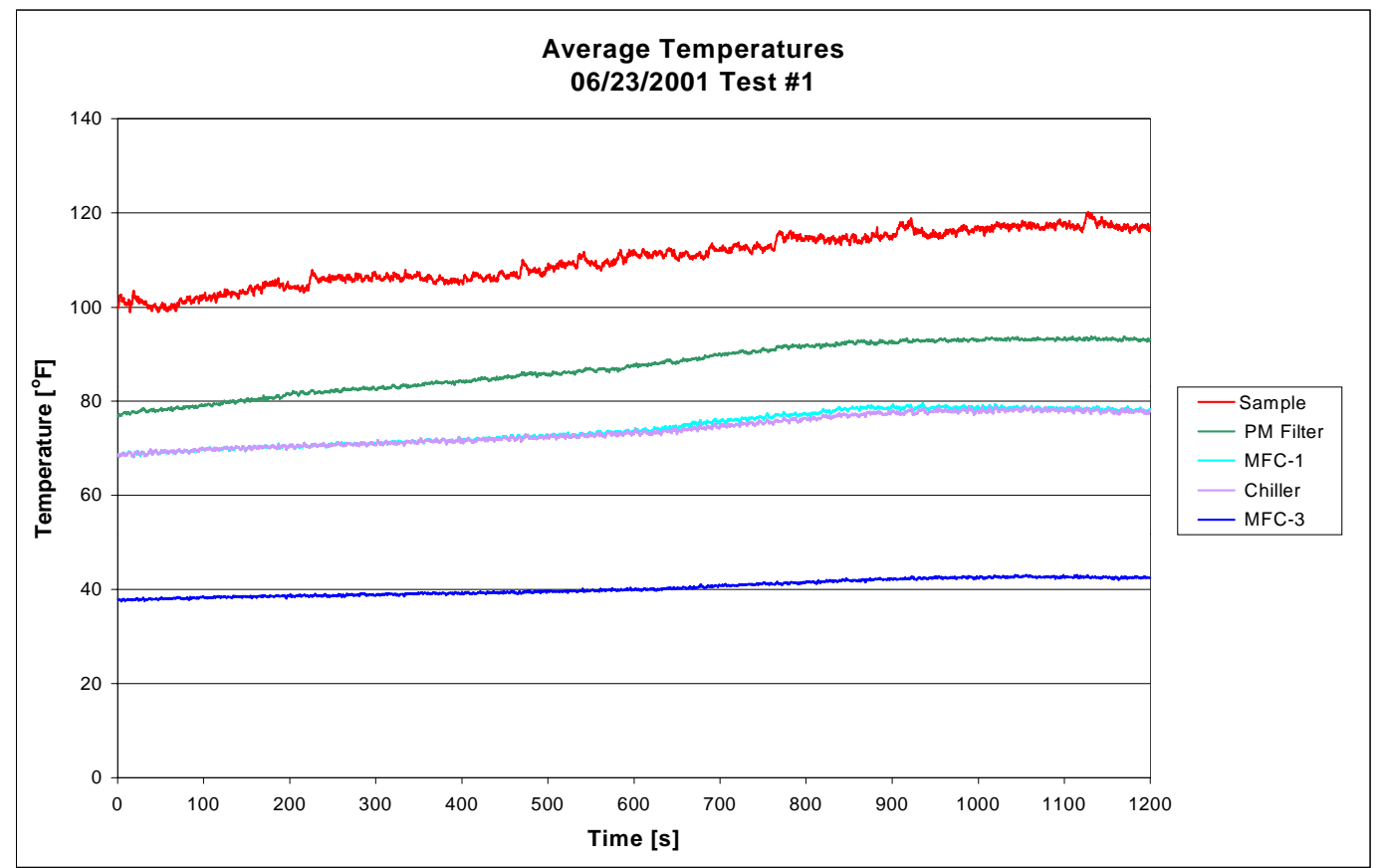

Figure 4.59 Temperatures During Transient Test \#7

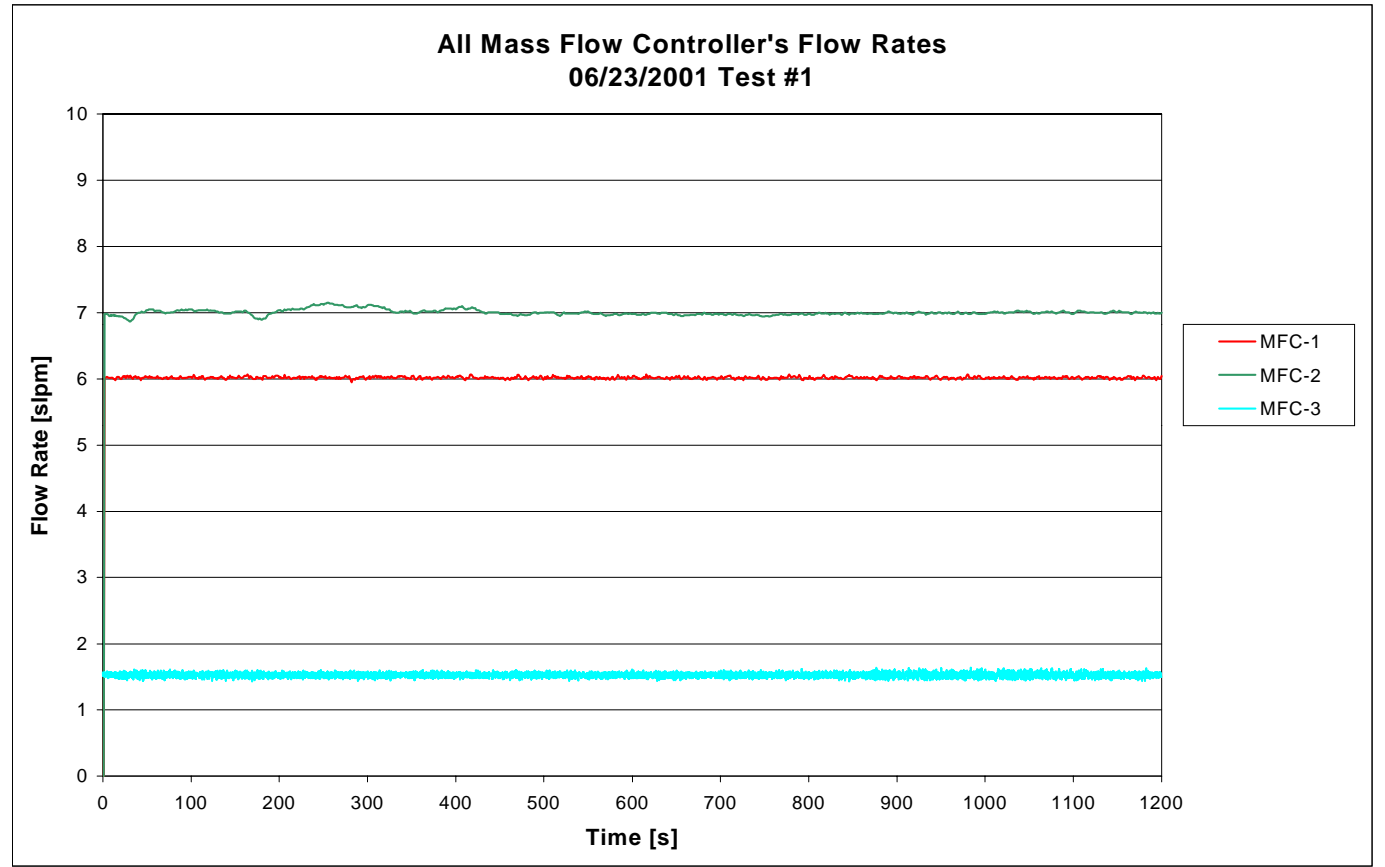

Figure 4.60 Mass Flow Rates During Transient Test \#7 


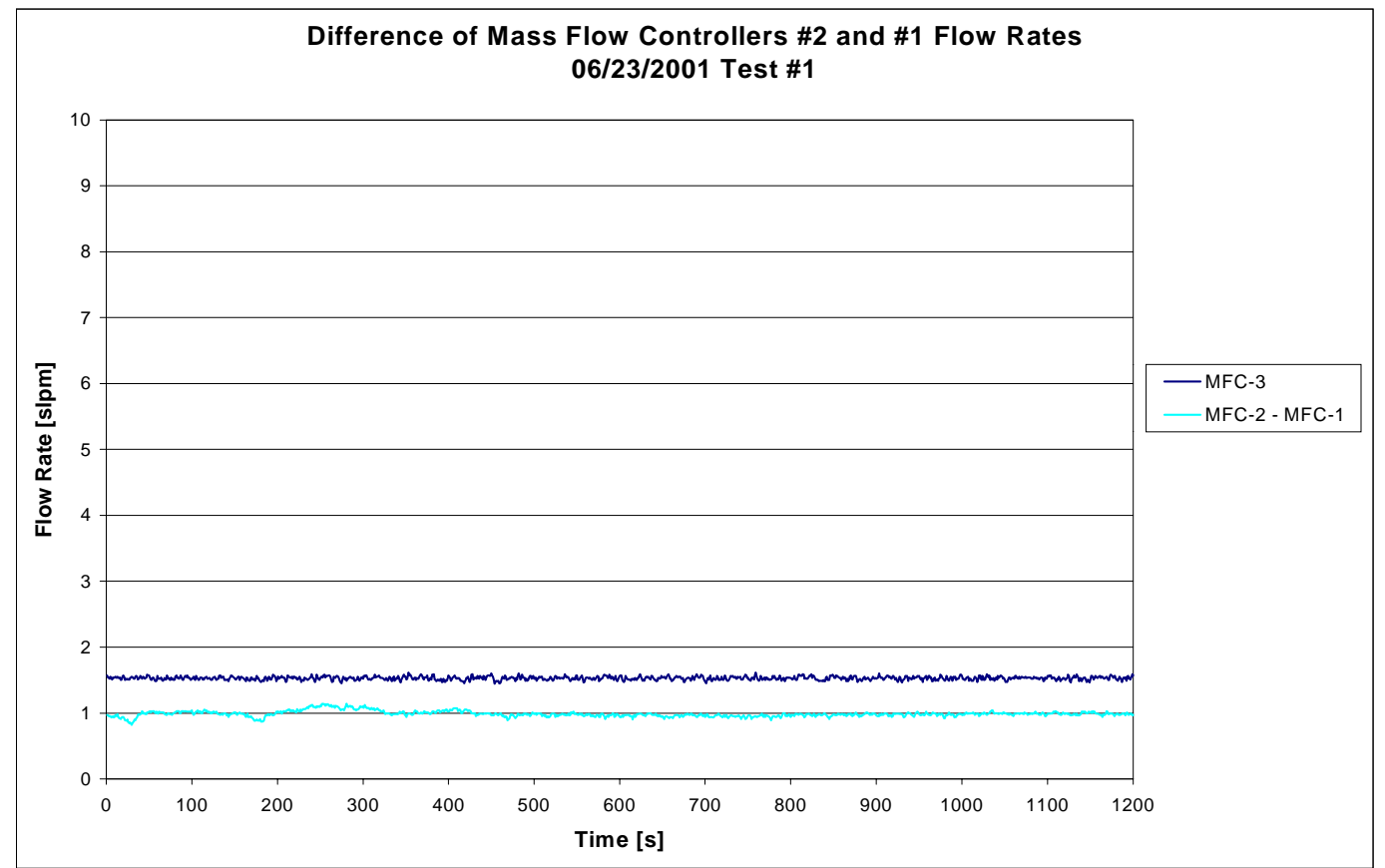

Figure 4.61 Comparison of Raw Exhaust and Bleed Flow Rates During Transient Test \#7

Table 4.15 Comparison of Full-Flow Dilution Dilution and Micro-Dilution Tunnels for Transient Test \#7

\begin{tabular}{|l|r|l|}
\hline Volume into micro-dilution system $=$ & 20.74 & {$[\mathrm{liters}]$} \\
\hline Fuel Consumption from Counter $=$ & 6.26 & {$[\mathrm{~kg}]$} \\
\hline Intake Air Mass Flow $=$ & 309.45 & {$[\mathrm{~kg}]$} \\
\hline Total Exhaust Mass $=$ & 315.72 & {$[\mathrm{~kg}]$} \\
\hline Density $=$ & 1.2 & {$\left[\mathrm{~kg} / \mathrm{m}^{3}\right]$} \\
\hline Volume Total Exhaust $=$ & 263098 & {$[\mathrm{liters}]$} \\
\hline Mass on 47-mm filter $=$ & 0.195 & {$[\mathrm{mg}]$} \\
\hline Mass on 70-mm filter $=$ & & {$[\mathrm{mg}]$} \\
\hline $\mathrm{P}_{\text {test }}($ micro-tunnel $)=$ & 2.47 & {$[\mathrm{~g} / \mathrm{test}]$} \\
\hline $\mathrm{P}_{\text {test }}($ test cell $)=$ & 3.69 & {$[\mathrm{~g} / \mathrm{test}]$} \\
\hline Percent Error $=$ & $\mathbf{3 3 \%}$ & \\
\hline
\end{tabular}

\subsubsection{Test \#8 (FTP \#2)}

The filter face temperature of the full-flow tunnel reached its maximum allowable temperature of $125^{\circ} \mathrm{F}$ during the previous test due to the blower limitations at the EERL. The secondary dilution tunnel could have used to supply additional air; however, the 
mass flow controller for the secondary dilution tunnel was not in working order at the time of this test. For this test, it was decided to use $50 \%$ of the rated torque to maintain a temperature lower than $125^{\circ} \mathrm{F}$ at the filter face.

The five temperatures recorded are shown in Figure 4.62. The temperatures for this test were a slightly higher than previous transient test due to the temperature of the surroundings. The temperatures were $20^{\circ} \mathrm{F}$ higher for the raw exhaust sample, MFC-1 and chiller. The temperature at the filter face and MFC-3 were $25^{\circ} \mathrm{F}$ and $45^{\circ} \mathrm{F}$ higher than the previous test, respectively.

Each MFC initially overshot its setpoint and then stabilized after 15 seconds for MFC-3 and 90 seconds for MFC-1 and MFC-2, as shown in Figure 4.63. After the 90 seconds, MFC-1 and MFC-3 maintained their setpoints of 6.0 slpm and 1.5 slpm, respectively. However, MFC-2 did reach its setpoint for 500 seconds and then decreased to $7.25 \mathrm{slpm}$ at the end of the test. Figure 4.64 shows the effect of MFC-2 not maintaining its setpoint in comparison to MFC-3. In turn, the TPM difference between the micro-dilution and full-flow tunnel systems resulted in a $29 \%$ difference, as shown in Table 4.16. 


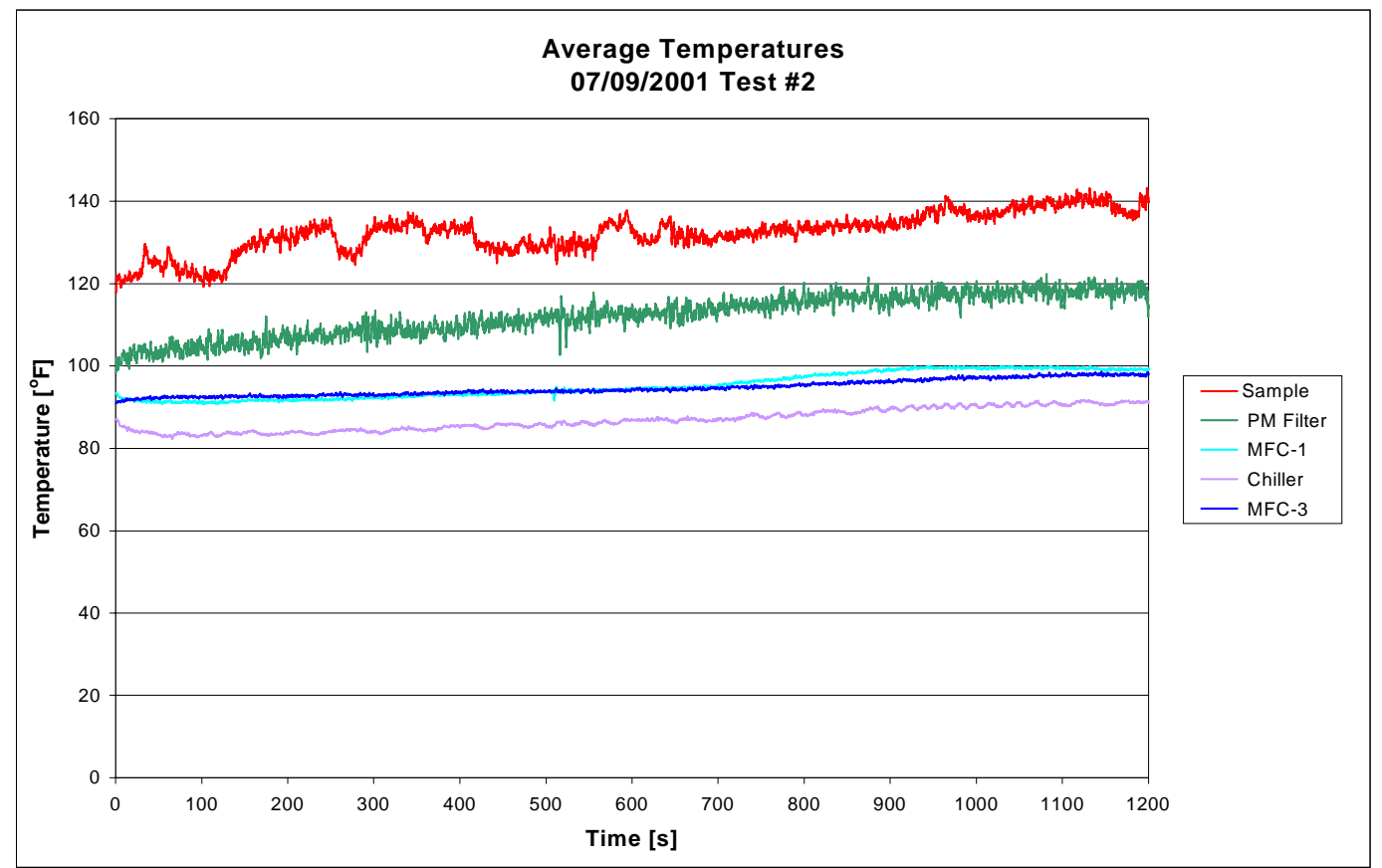

Figure 4.62 Temperatures During Transient Test \#8

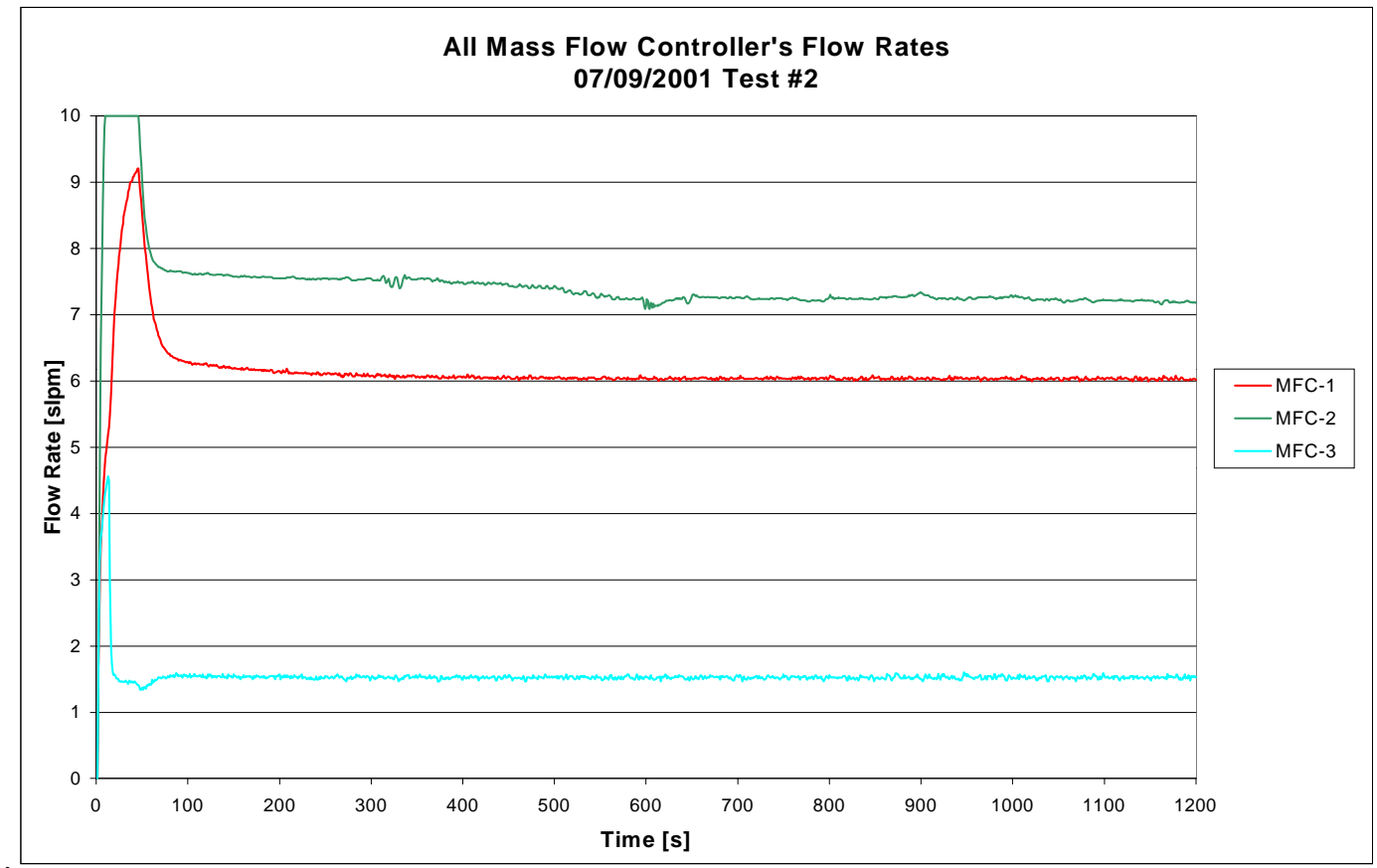

Figure 4.63 Mass Flow Rates During Transient Test \#8 


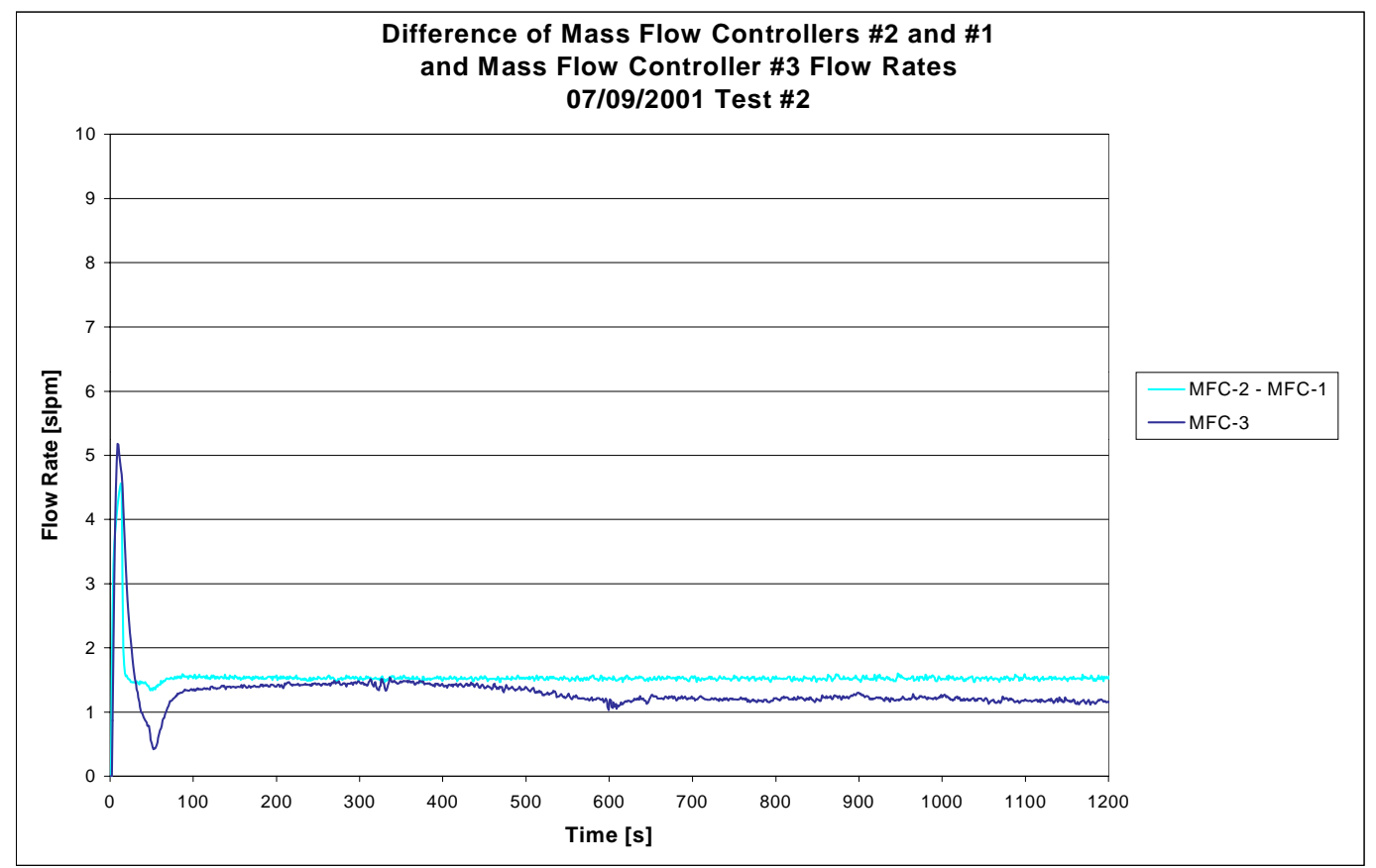

Figure 4.64 Comparison of Raw Exhaust and Bleed Flow Rates During Transient Test $\# 8$

Table 4.16 Comparison of Full-Flow Dilution Dilution and Micro-Dilution Tunnels for Transient Test \#8

\begin{tabular}{|l|r|l|}
\hline Volume into micro-dilution system $=$ & 25.03 & {$[\mathrm{liters}]$} \\
\hline Fuel Consumption from Counter $=$ & 3.52 & {$[\mathrm{~kg}]$} \\
\hline Intake Air Mass Flow $=$ & 238 & {$[\mathrm{~kg}]$} \\
\hline Total Exhaust Mass $=$ & 241.52 & {$[\mathrm{~kg}]$} \\
\hline Density $=$ & 1.2 & {$\left[\mathrm{~kg} / \mathrm{m}^{3}\right]$} \\
\hline Volume Total Exhaust $=$ & 201267 & {$[\mathrm{liters}]$} \\
\hline Mass on 47-mm filter $=$ & 0.18 & {$[\mathrm{mg}]$} \\
\hline Mass on 70-mm filter $=$ & 3.72 & {$[\mathrm{mg}]$} \\
\hline $\mathrm{P}_{\text {test }}($ micro-tunnel) $=$ & 1.45 & {$[\mathrm{~g} /$ test $]$} \\
\hline $\mathrm{P}_{\text {test }}($ test cell $)=$ & 2.05 & {$[\mathrm{~g} /$ test $]$} \\
\hline Percent Error $=$ & $\mathbf{2 9 \%}$ & \\
\hline
\end{tabular}

\subsubsection{Test \#9 (FTP \#3)}

This test used $75 \%$ of the rated torque to give results in between transient test \#7 and test \#8 in Section 4.2.7 and Section 4.2.8, respectively. The temperatures of raw exhaust sample, PM filter face, entrance to MFC-1, chiller exit, and entrance to MFC-3 
are shown in Figure 4.65. The temperatures recorded for this test were similar to the previous transient test as discussed in Section 4.2.8. Figure 4.66 shows that each MFC initially overshot its setpoint and then stabilized after 10 seconds for each MFC, except for MFC-2. MFC-2 fluctuated around its setpoint due to pressure variations in the sample line. Figure 4.67 compares the raw exhaust sample entering and bleed off flow rates in the micro-dilution system. Since MFC-2 did not maintain its setpoint of 7.5 slpm, the TPM between the two systems was $23 \%$, as shown in Table 4.17 .

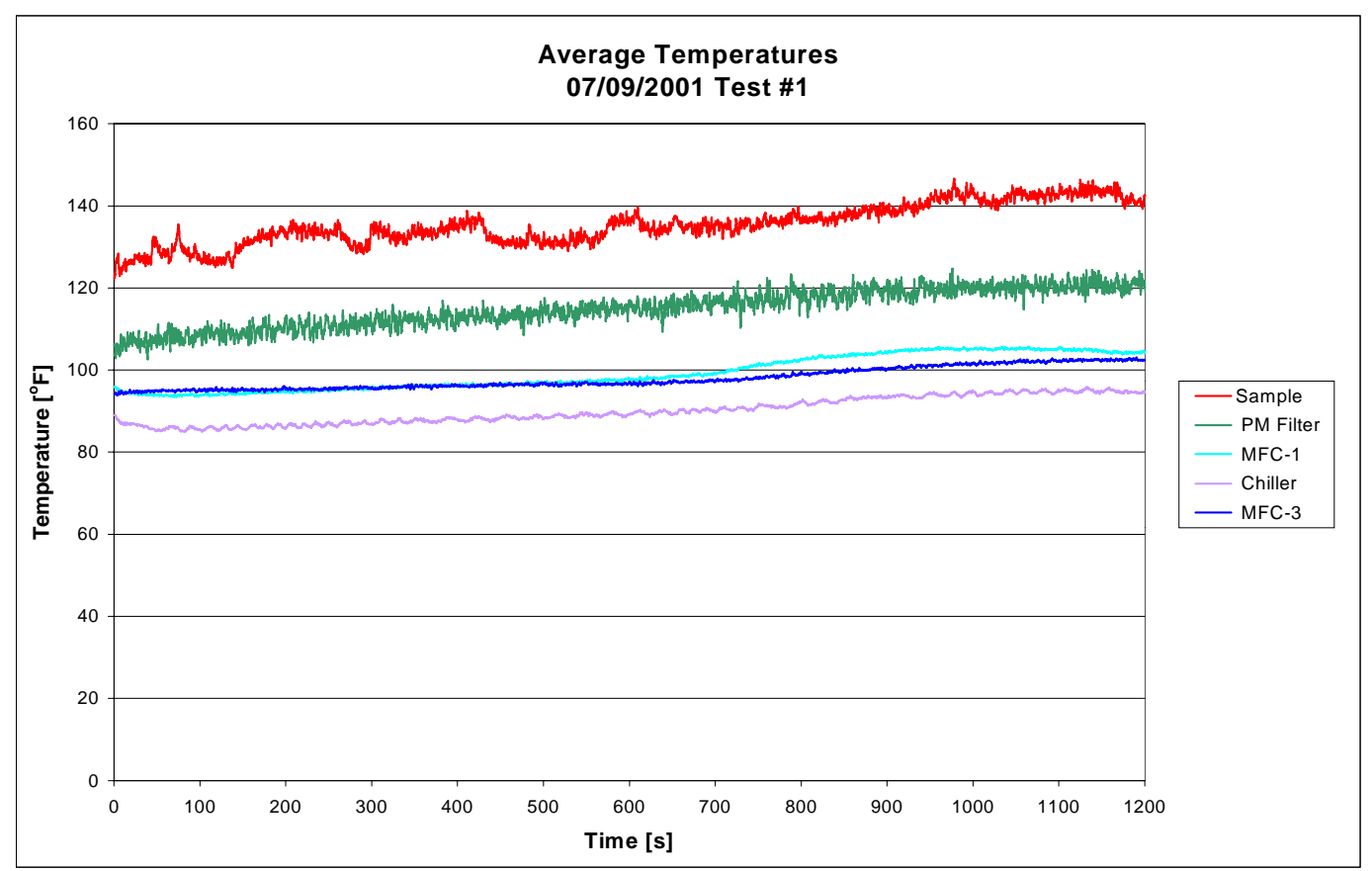

Figure 4.65 Temperatures During Transient Test \#9 


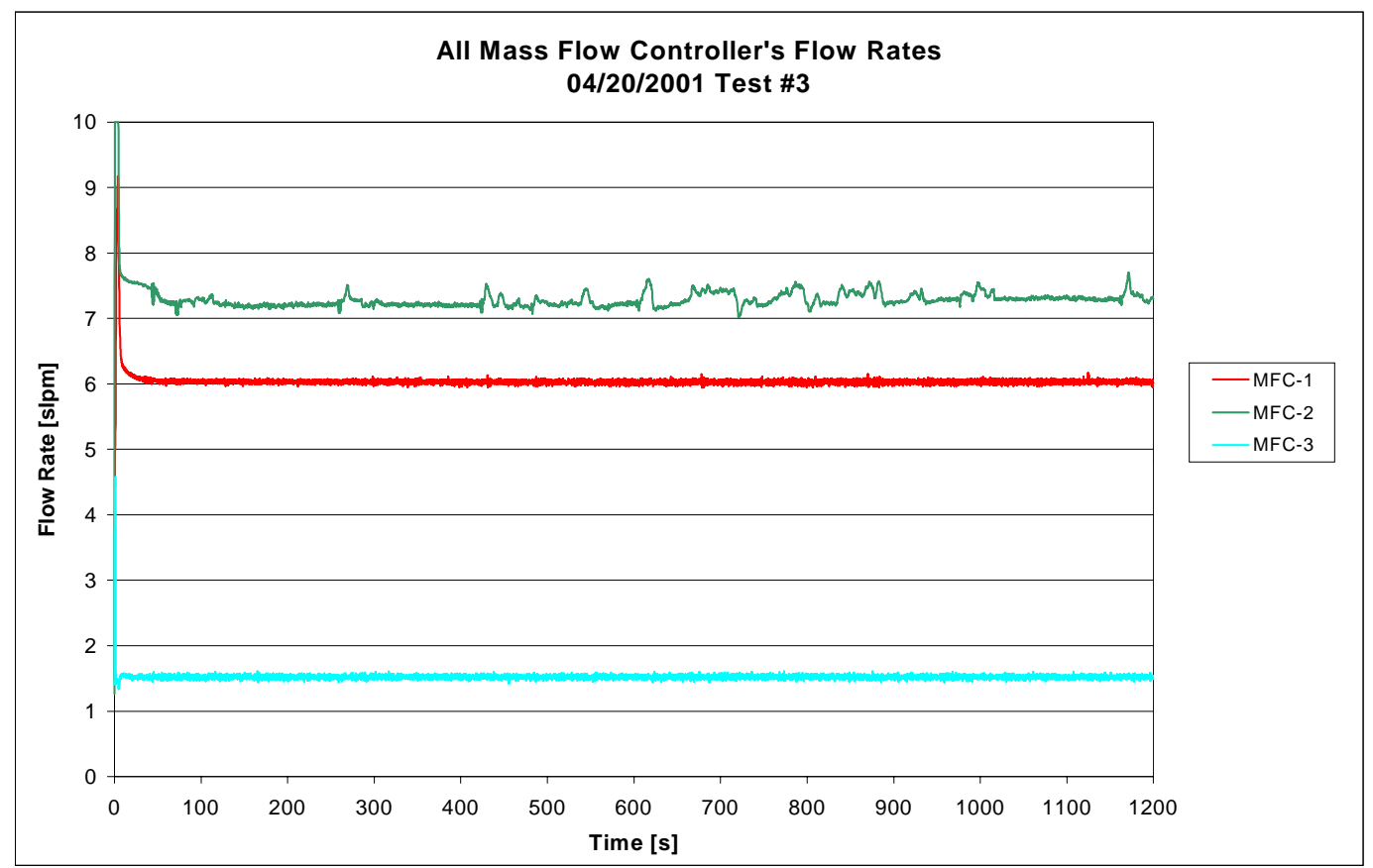

Figure 4.66 Mass Flow Rates During Transient Test \#9

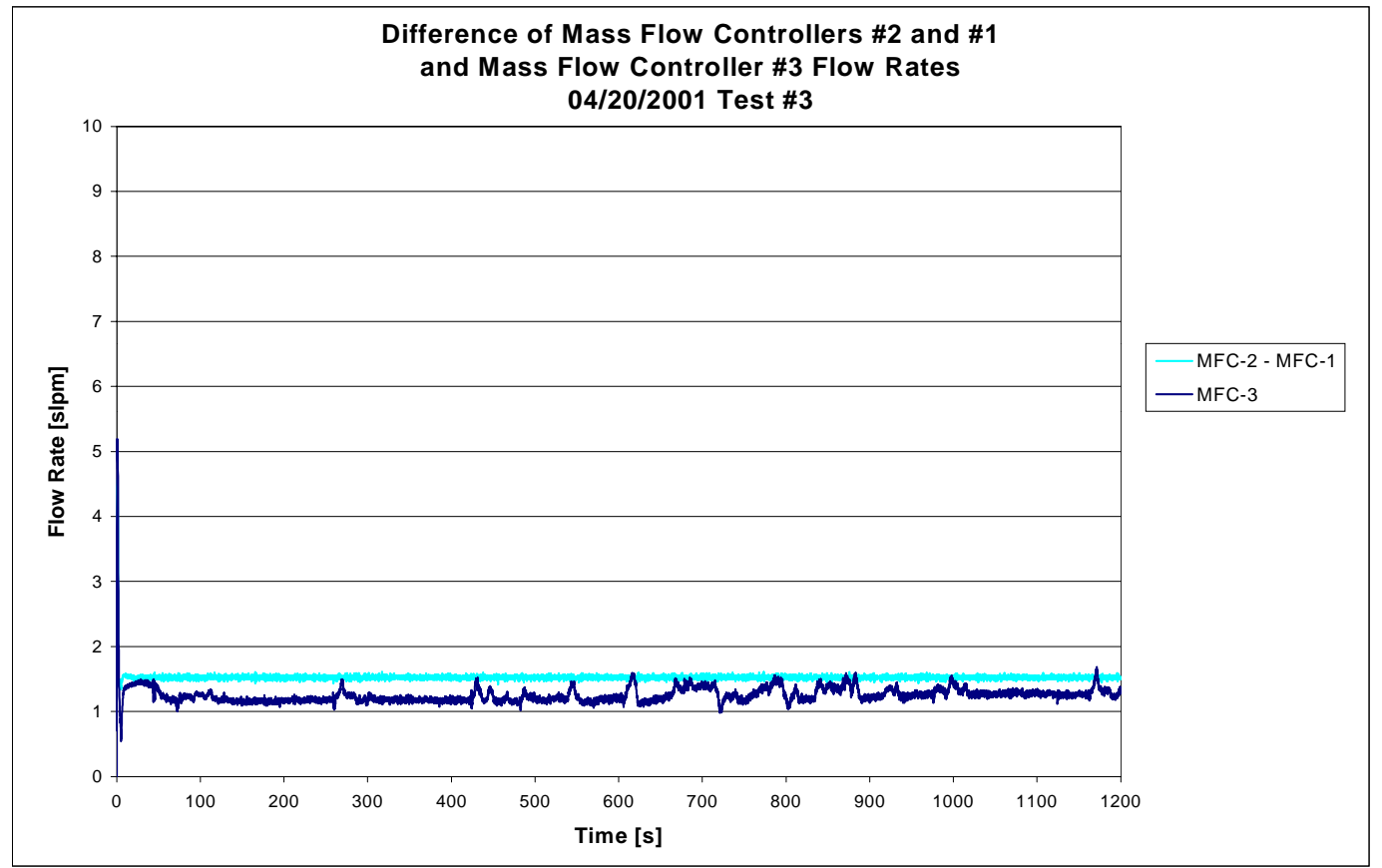

Figure 4.67 Comparison of Raw Exhaust and Bleed Flow Rates During Transient Test \#9 
Table 4.17 Comparison of Full-Flow Dilution Dilution and Micro-Dilution Tunnels for Transient Test \#9

\begin{tabular}{|l|r|l|}
\hline Volume into micro-dilution system $=$ & 25.05 & {$[\mathrm{liters}]$} \\
\hline Fuel Consumption from Counter $=$ & 5.06 & {$[\mathrm{~kg}]$} \\
\hline Intake Air Mass Flow $=$ & 273.9 & {$[\mathrm{~kg}]$} \\
\hline Total Exhaust Mass $=$ & 278.96 & {$[\mathrm{~kg}]$} \\
\hline Density $=$ & 1.2 & {$\left[\mathrm{~kg} / \mathrm{m}^{3}\right]$} \\
\hline Volume Total Exhaust $=$ & 232467 & {$[\mathrm{liters}]$} \\
\hline Mass on 47-mm filter $=$ & 0.18 & {$[\mathrm{mg}]$} \\
\hline Mass on 70-mm filter $=$ & 3.528 & {$[\mathrm{mg}]$} \\
\hline $\mathrm{P}_{\text {test }}($ micro-tunnel) $=$ & 1.67 & {$[\mathrm{~g} / \mathrm{test}]$} \\
\hline $\mathrm{P}_{\text {test }}$ (test cell) $=$ & 2.17 & {$[\mathrm{~g} / \mathrm{test}]$} \\
\hline Percent Error $=$ & $\mathbf{2 3 \%}$ & \\
\hline
\end{tabular}




\subsection{Conclusions and Recommendations}

\subsection{Conclusions}

In order to achieve the main objective of this research, a portable micro-dilution tunnel system was designed, developed and qualified. A full-flow tunnel is required to measure particulate emissions from diesel fueled engines according to the Code of Federal Regulations (CFR 40, 1997). The emission measurements equipment in the EERL follows the specifications of the CFR 40, Part 86, Subpart N. The developed micro-dilution tunnel operates on the same principle as the full-flow dilution tunnel, but uses mass flow controllers to accurately control the dilution ratio, and operates with only one pump. Tests performed with the EERL showed consistent results over several steady state and transient cycles between the full-flow and the micro-dilution tunnels using a 7.3-liter Navistar T444E and a 12.7-liter Detroit Diesel Series 60 engines.

A dilution ratio of four to one was successfully achieved with the micro-dilution system during both steady state and transient test operations. Eight steady state and eleven transient test cycles were performed to compare the micro-dilution tunnel's ability to measure PM mass emissions with that of the full-flow dilution tunnel system. As expected, the particulate matter data from the steady state tests correlated better than the transient tests with the total exhaust dilution data. The particulate matter mass emission rates for the steady state tests were within $14 \%$ of the full-flow laboratory's PM mass emissions data. The PM emission rates for the micro-dilution tunnel were within $17 \%$ of the full flow tunnel in majority of the transient tests, except for the FTP transient tests. The results from the FTP transient tests results varied between $23 \%$ and $33 \%$ difference due to the dilute exhaust mass flow controller not stabilizing at its setpoint. 
The test results indicate that modifications are necessary to the micro-dilution system before it is to be used for on-road PM emission measurements. These recommendations are presented in the next section.

\subsection{Recommendations}

This research undertook a major shift from the established techniques for PM mass emission measurements. Not only was there a major modification to the measurement system, but the potential application of the system was also very novel. The micro-dilution tunnel was designed to be used for on-board, in-use PM emission measurements. The research effort involved a very delicate balance between theoretically calculated design parameters, and practical application and interaction of various components. Four recommendations for this research project, before it goes onboard for testing, would include a smaller filter holder, bypass filter, smaller sized chiller, and higher flow rates. These recommendations would not only help in increasing the filter loading but also in the optimization of the performance of the micro-dilution tunnel system. The next four sections will discuss each recommendation briefly.

\subsubsection{Filter Size}

The current filter size for the PM filter is 47-mm with 3/8 in fittings on either end. A smaller filter holder would increase the filter face velocity and decrease the fitting size. Decreasing the fitting size would shorten the length between the PM filter and the dilution tunnel. Gelman Sciences offers two other stainless steel filter holders that would suffice for the micro-dilution system. A $25-\mathrm{mm}$ or $13-\mathrm{mm}$ filter could replace the current 47-mm without any problems. The filter face velocities for the $25-\mathrm{mm}$ and $13-\mathrm{mm}$ filter holders are presented in Table 5.1 and Table 5.2, respectively. 
Table 5.1 Filter Face Velocities (25-mm)

\begin{tabular}{|c|c|c|}
\hline $\begin{array}{c}\text { Flow Rate } \\
{[\mathrm{scfm}]}\end{array}$ & $\begin{array}{c}\text { Flow Rate } \\
{\left[\mathrm{m}^{3} / \mathrm{min}\right]}\end{array}$ & $\begin{array}{c}\text { Filter Face Velocity } \\
{[\mathrm{cm} / \mathrm{s}]}\end{array}$ \\
\hline \hline 0.1 & 0.0028 & 12.76 \\
\hline 0.15 & 0.0042 & 19.13 \\
\hline 0.2 & 0.0057 & 25.51 \\
\hline 0.25 & 0.0071 & 31.89 \\
\hline 0.3 & 0.0085 & 38.27 \\
\hline 0.35 & 0.0099 & 44.64 \\
\hline 0.4 & 0.0113 & 51.02 \\
\hline 0.45 & 0.0127 & 57.40 \\
\hline
\end{tabular}

Table 5.2 Filter Face Velocities (13-mm)

\begin{tabular}{|c|c|c|}
\hline $\begin{array}{c}\text { Flow Rate } \\
{[\mathrm{scfm}]}\end{array}$ & $\begin{array}{c}\text { Flow Rate } \\
{\left[\mathrm{m}^{3} / \mathrm{min}\right]}\end{array}$ & $\begin{array}{c}\text { Filter Face Velocity } \\
{[\mathrm{cm} / \mathrm{s}]}\end{array}$ \\
\hline \hline 0.1 & 0.0028 & 52.44 \\
\hline 0.15 & 0.0042 & 78.66 \\
\hline 0.2 & 0.0057 & 104.88 \\
\hline 0.25 & 0.0071 & 131.10 \\
\hline 0.3 & 0.0085 & 157.32 \\
\hline 0.35 & 0.0099 & 183.54 \\
\hline 0.4 & 0.0113 & 209.76 \\
\hline 0.45 & 0.0127 & 235.98 \\
\hline
\end{tabular}

\subsubsection{Bypass}

The second recommendation is to add a bypass around the PM filter holder. A bypass would enable the instruments to stabilize before testing begins, particularly the mass flow controllers. The bypass would require a three-way valve between the dilution tunnel and PM filter, and also an additional filter in the bypass path. The three-way valve would direct the flow through the bypass or the PM filter. The bypass filter would collect particulate to protect the instruments that follow.

\subsubsection{Chiller}

The current chiller used for this research is useable only in a laboratory setting because of its size compared to the micro-dilution system as a whole. A smaller sized chiller would be recommended to maintain a small system overall. Another suggestion would be to use a different water-removing device, such as a heatless air dryer or a 
desiccant system. However, if the flow rates were increased, then a smaller sized chiller would not be adequate because it would not be able to handle the higher flow rates.

\subsubsection{Flow rates}

If the flow rates were increased to at least double the value used in this research, that would reduce the amount of error that occurs with the amount of particulate collected on filters. The flow rate should be around 16 slpm for the total flow, 12 slpm for the dilution air and $4 \mathrm{slpm}$ for the raw exhaust entering the micro-dilution system. These mass flow rates would maintain a dilution ratio of 4 to 1 as implemented in this research. If the flow rate of the raw exhaust is increased, the need for a heated line to the sampling point may not be needed.

Also, if the total flow rate was increased, then the dilution ratio could be modified. This would also enable the system to decrease the transfer tube temperature of the micro-dilution system, if the temperature at the filter face was too high. In turn, a heated line may not be needed as the transfer tube. If the mass flow rates were increased, then some of the mass flow controllers would need to be recalibrated. The maximum flow rate that the mass flow controller can handle should be slightly above the desired maximum flow rate. This would be to minimize any errors that would occur from the mass flow controllers. 


\subsection{References}

Abdul-Khalek, I.S., Kittelson, D.B., Graskow, B.R., and Wei, Q. "Diesel Exhaust Particle Size: Measurement Issues and Trends." SAE Technical Paper No. 980525, 1998.

Asaumi, Y. and S. Ueki. "Measurement of Diesel Particulate Emission Using a MiniDilution Tunnel.” Nissan Diesel Technical Report, 1989.

Austin, T.C. and Caretto, L.S. "Improving the Calculation of Exhaust Gas Dilution During Constant Volume Sampling." SAE Technical Paper No. 980678, 1998.

Bane, B. Personal Communications, Department of Mechanical and Aerospace Engineering, West Virginia University, Morgantown, WV, 2001.

Baumgard, K.J. "Estimation of Diesel Particulate Matter Reductions in Underground Mines Resulting From the Use of a Ceramic Particulate Trap." Ann Am. Conf. GOV. Ind. Hyg., Vol. 14, 1986.

Black, F. and L. Doberstein. "Filter Media for Collecting Diesel Particulate Matter." Environmental Sciences Research Laboratory Report, US EPA, Research Triangle Park, NC., 1980.

Black, F. and L. High. "Methodology for Determining Particulate and Gaseous Diesel Hydrocarbon Emissions." SAE Technical Paper No. 790422, 1979.

Beltzer, M., Campoin, R.J., and Petersen, W.L. "Measurement of Vehicle Particulate Emissions.” SAE Technical Paper No. 740286, 1974.

Çengal, Y.A. and M.A. Boles. Thermodynamics: An Engineering Approach. Hightstown, NJ: McGraw-Hill, Inc., 1994.

Code of Federal Regulations, Title 40, Part 86, Subpart N - Emissions Regulations for New Otto-Cycle and Diesel Heavy Duty Engines; Gaseous and Particulate Exhaust Tests Procedures, 1997.

Dementhon, J.B. and B. Martin. "Influence of Various Diesel Traps on Particulate Size Distribution.” SAE Technical Paper No. 972999, 1997.

Duleep, K.G., "Analysis of Automotive Particulate Sampling Techniques.” SAE Technical Paper No. 800184, 1980.

Epstein, M., Hauser, G.M., and Henry, R.E. "Thermophorectic Deposition of Particles in Natural Convection Flow From a Vertical Plate.” Journal of Heat Transfer, 107, $272,1985$. 
Gautam, M., Clark, N. N., Thompson, G. J., Lyons, D. W., “Assessment of Mobile Monitoring Technologies for Heavy-Duty Vehicle Emissions." Department of Mechanical and Aerospace Engineering, West Virginia University, Morgantown, WV, 1999.

Gautam, M., Kelly, B., Gupta, D., Clark, N., Atkinson, R., El-Gazzar, L., Lyons, D.W. "Sampling Strategies of Characterization of the Reactive Components of Heavy Duty Diesel Exhaust Emissions.” SAE Technical Paper No. 942262, 1994.

Gautam, M., Gupta, D., El-Gazzar, L., Lyons, D.W., Popuri, S. "Specification of HeavyDuty Diesel Exhaust Emissions under Steady State Operating Conditions." SAE Technical Paper No. 962159, 1996.

Gautam, M., Miller, E.S., Ferguson, D.H. and Lyons, D.W. "Uncertainty in Real-World Particulate Matter Emission Measurements from a Transportable Heavy-Duty Vehicle Emissions Testing Laboratory." Heavy Vehicle Systems, Int. J. of Vehicle Design, Vol. 5, No. 3/4 1998.

Gautam, M., Nussear, D.L., Hong-Guang, G., Clark, N.N., and Wallace, W.E., "Mutagenicity of Diesel Exhaust Particulate Matter in Mining Operations." Journal of Environmental Science and Health, 28(3), 505-523, 1993.

Genova, F.D., Heirigs, P., and Reineman, M. “Alternative Techniques for Detecting Excessive Evaporative Emissions During I/M Tests.” SAE Technical Paper No. 962093, 1996.

González-Oropeza, R. and A.F. Romero-López. "Particulate matter Emissions, Analysis by Means of a Sampling Sonde Technique." SAE Technical Paper No.: 940741, 1994.

Goren, S.L. "Thermophoresis of Aerosol Particles in the Laminar Boundary Layer on a Flat Plate.”, J. Colloid Interface Sci., 61, 77, 1977.

Graze, R.R., Jr. "Development of a Miniaturized, Dilution-Based Diesel engine Particulate Sampling System for Gravimetric Measurement of Particulates." SAE Technical Paper No. 931190, 1993.

Hall, D.E., Goodfellow, C.L., Heinze, P., Rickeard, D.J., Nancekievill, G., Martini, G. Hevesi, J., Rantanen, L, Merino, P.M. Morgan, T.D.B., Zemroch, P.J. . “A Study of the Size, Number and Mass Distribution of the Automotive Particulate Emissions from European Light Duty Vehicles." SAE Technical Paper No. 982600, 1998.

Hall, D.E., King, D.J., Morgan, T.B.D., Baverstock, S.J., Heinze, P., Simpson, B.J. “A Review of Recent Literature Investigating the Measurement of Automotive 
Particulate; The Relationship with Environmental Aerosol, Air Quality and Health Effects." SAE Technical Paper No. 982602, 1998.

Harrington, J.A., and Y.A. Yetter. "Application of a Mini-Dilution Tube in the Study of Fuel Effects on Stratified Charge Engine Emissions and Combustion." SAE Technical Paper No. 811198, 1981.

Hirakouchi, N., Fukano, I. and Nagano, H. "Measurement of Unregulated Exhaust Emissions from Heavy Duty Diesel Engines with Mini-Dilution Tunnel." SAE Technical Paper No. 900643, 1990.

International Agency for Research on Cancer, "Diesel and Gasoline Engine Exhaust and some Nitroarenes." IARC Monographs on the Evaluation of Carcinogenic Risks to Humans, Vol. 46, Lyon, France, 1989.

Johnson, T.V. "Diesel Emission Control - Last 12 Months in Review." SAE Technical Paper No. 2000-01-2817, 2000.

Khatri, N.J., Johnson, J.H. and Leddy, D.G. "The Characterization of the Hydrocarbon and Sulfate Fractions of Diesel Particulate Matter." SAE Technical Paper No. $780111,1978$.

Kittelson, D.B. and J.H. Johnson. "Variability in Particulate Emission Measurements in the Heavy Duty Transient Test.” SAE Technical Paper No. 910738, 1991.

Laymac, T.D., Johnson, J.H., Bagley, S.T. “The Measurement and Sampling of Controlled Regeneration Emissions from a Diesel Wall-Flow Particulate Trap." SAE Technical Paper No. 910606, 1991.

Lies, K.H., Postulka, A., and Gring, H. "Particulate Emissions from Diesel Engines Evaluation of Measurement and Results.” SAE Technical Paper No. 830455, 1983.

Lipkea, W.H., Johnson, J.H., and Vuk, C.T. "The Physical and Chemical Character of Diesel Particulate Emissions - Measurement Techniques and Fundamental Considerations.” SAE Technical Paper No. 780108, 1978.

MacDonald, J.S., Barsic, N.J., Gross, G.P. Shahed, S.P. and Johnson, J.H., "Status of Diesel Particulate Measurement Methods.” SAE Technical Paper No. 840345, 1984.

MacDonald, J.S., Plee, S.L., D’Arcy, J.B. and Schreck, R.M. "Experimental Measurements of the Independent Effects of Dilution Ratio and Filter Temperature on Diesel Exhaust Particulate Samples." SAE Technical Paper No. $800185,1980$. 
Miller, E.S. "Measurement of Diesel Particulate Matter Emissions with a Modified Multi-tube Type Mini-Dilution Tunnel.” Morgantown, WV: West Virginia University, 1997.

Nussear, D.L. "An Experimental Study of the Genotoxic Potential of Diesel Particulate Matter." Morgantown, WV: West Virginia University, 1992.

O'Neal, G.B., Dietzman, H.E., Ryan III, T.W. and Waytulonis, R.W. "Control of Diesel Exhaust Emissions in Underground Coal Mines - Steady-State and Transient Engine Tests with a Five Percent Water-in-Fuel Microemulsion." SAE Technical Paper No. 830555, 1983.

Ower, E. and R.C. Pankhurst. The Measurement of Airflow. Pergamon Press, 1966.

Potter, C.J., Bailey, J.C., Savage, C.A., Schmidl, B., Simmonds, A.C., and Williams, M.L. "The Measurement of Gaseous and Particulate Emissions from Light-Duty and Heavy-Duty Motor Vehicles Under Road Driving Conditions." SAE Technical Paper No. 880313, 1988.

Rickeard, D.J., Bateman, J.R., Kwon, Y.K., McAughey, J.J., and Dickens, C.J. "Exhaust Particulate Size Distribution: Vehicle and Fuel Influences in Light Duty Vehicles.” SAE Technical Paper No. 961980, 1996.

Rosemount Analytical Model 402 Hydrocarbon Analyzer Instruction Manual 015082132-H, Rosemount Analytical Inc., La Habra, California, 1991.

Rosemount Analytical Model 868 NDIR Analyzer Instruction Manual 015-748003-H, Rosemount Analytical Inc., La Habra, California, 1991.

Rosemount Analytical Model 955 NO/NOx Analyzer Instruction Manual 015-555479-F, Rosemount Analytical Inc., La Habra, California, 1992.

Sierra Instruments, Model BG-1 Micro-Dilution Test Stand, Diesel Emissions Division, 1995.

Silvis, W.M. and Chase, R.E. "Proportional Ambient Sampling: A CVS Improvement for ULEV and Lean Engine Operation." SAE Technical Paper No. 1999-010154, 1999.

Silvis, W.M., Harvey, R.N, and Dageforde, A.F. "A CFV Type Mini-Dilution Sampling System for Vehicle Exhaust Emissions Measurement." SAE Technical Paper No. 1999-01-0151, 1991.

Smith, R.C. II. "Comparison of Heavy Duty Diesel Engine Transient Emissions Measurement using a Mini- and Full-Flow Dilution Tunnel." Morgantown, WV: West Virginia University, 1993. 
Stotler, R. and D. Human. "An ISO 8178 Correlation Study Between Raw and Dilute Exhaust Emission Sampling Systems.” SAE Technical Paper No. 952060, 1995.

Suzuki, J., Yamazaki, H., Yoshida, Y. and Hori, M. "Development of Dilution MiniTunnel and Its Availability for Measuring Diesel Exhaust Particulate Matter." SAE Technical Paper No. 851547, 1985.

Takeda, Y., Fukano, I., Yamasaki, A., and Suzuki, T. "Measurement of Diesel Particulate Using Multi-tube Type Mini-Dilution Tunnel.” JSAE Review 12.4, Oct. 1991.

Universal Analyzers Sample Cooler Model 1080 Instruction Manual, Universal Analyzers, Inc., Carson City, NV, 1999.

Vuk, C.T., Jones, M.A., and Johnson, J.H., "The Measurement and Analysis of the Physical Character of Diesel Particulate Emissions." SAE Technical Paper No. 760131, 1976.

Waldenmaier, D.A., Gratz, L.D. Bagley, S.T., Johnson, J.H. and Leddy, D.G., "The Influence of Sampling Conditions on the Repeatability of Diesel Particulate and Vapor Phase Hydrocarbon and PAH Measurements.", SAE Technical Paper No. 900642, 1990.

Walker, K.L., Homsy, G.M., and Geyling, F.T. "Thermophoretic Deposition of Small Particles in Laminar Tube Flow.” J. Colloid Interface Sci., 69, 138, 1979.

Yamane, K., Chikahisa, T., Murayama, T., and Miyamoto, N. "Measurement of Particulate and Unburnt Hydrocarbon Emissions from Diesel Engines." SAE Technical Paper No. 880343, 1988.

Young, D.F., Munson, B.R., and Okiishi, T.H.. Fluid Mechanics. Canada: John Wiley \& Sons, Inc., 1997. 
APPENDIX A. Filter Weights

Table A.1 Filter Weights for Steady State Tests No. 1 to 6

Date: $4 / 20 / 01$

Test Series:

Navistar T444E

\begin{tabular}{|l|c|c|}
\hline & Chamber & Room \\
\hline Initial Humidity [\%]: & 48 & 42 \\
\hline Initial Temperature [deg F]: & 71 & 70 \\
\hline Final Humidity [\%]: & 49 & 50 \\
\hline Final Temperature [deg F]: & 71 & 70 \\
\hline
\end{tabular}

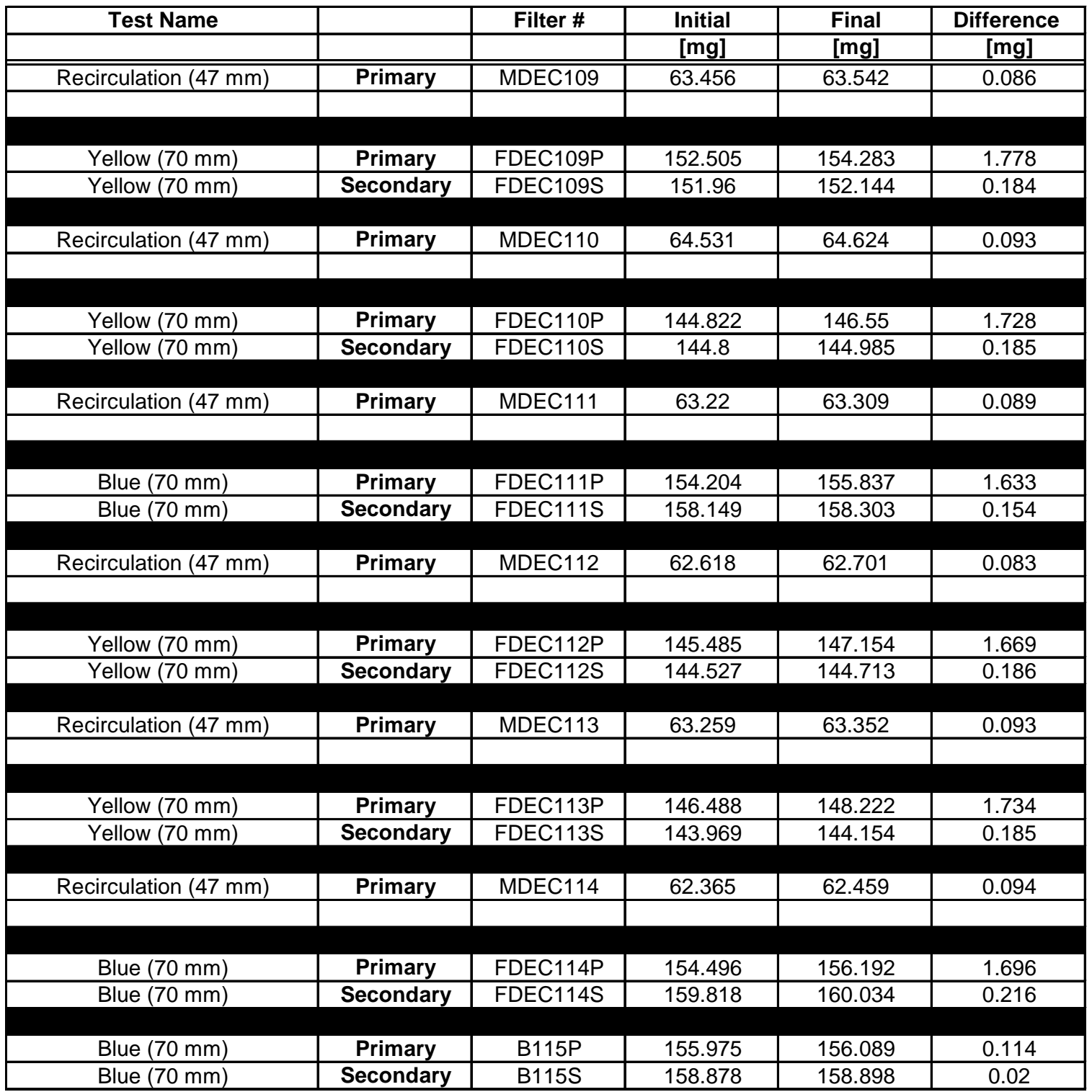




\section{Table A.2 Filter Weights for Steady State Tests No. 7 and 8}

Date:

$5 / 8 / 01$

Test Series: Navistar T444E

\begin{tabular}{|l|c|c|}
\hline & Chamber & Room \\
\hline Initial Humidity [\%]: & 49 & 54 \\
\hline Initial Temperature [deg F]: & 71 & 72 \\
\hline Final Humidity [\%]: & 48 & 52 \\
\hline Final Temperature [deg F]: & 71 & 72 \\
\hline
\end{tabular}

\begin{tabular}{|c|c|c|c|c|c|}
\hline Test Name & & Filter \# & Initial & Final & Difference \\
\hline & & & [mg] & [mg] & [mg] \\
\hline Recirculation (47 mm) & Primary & MDEC167 & 63.27 & 63.33 & 0.06 \\
\hline & & & & & \\
\hline Yellow $(70 \mathrm{~mm})$ & Primary & FDEC167P & 141.912 & 143.332 & 1.42 \\
\hline Yellow $(70 \mathrm{~mm})$ & Secondary & FDEC167S & 159.91 & 160.163 & 0.253 \\
\hline Recirculation $(47 \mathrm{~mm})$ & Primary & MDEC168 & 67.324 & 67.409 & 0.085 \\
\hline & & & & & \\
\hline Yellow $(70 \mathrm{~mm})$ & Primary & FDEC168P & 144.493 & 145.983 & 1.49 \\
\hline Yellow $(70 \mathrm{~mm})$ & Secondary & FDEC168S & 158.509 & 158.743 & 0.234 \\
\hline Blue $(70 \mathrm{~mm})$ & Primary & B170P & 155.975 & 156.089 & 0.114 \\
\hline Blue $(70 \mathrm{~mm})$ & Secondary & B170S & 158.878 & 158.898 & 0.02 \\
\hline
\end{tabular}

Table A.3 Filter Weights for Transient Tests No. 1 and 2

Date: $5 / 4 / 01$

Test Series:

Navistar T444E Transient

\begin{tabular}{|l|c|c|}
\hline & Chamber & Room \\
\hline Initial Humidity [\%]: & 49 & 53 \\
\hline Initial Temperature [deg F]: & 71 & 73 \\
\hline Final Humidity [\%]: & 49 & 48 \\
\hline Final Temperature [deg F]: & 71 & 72 \\
\hline
\end{tabular}

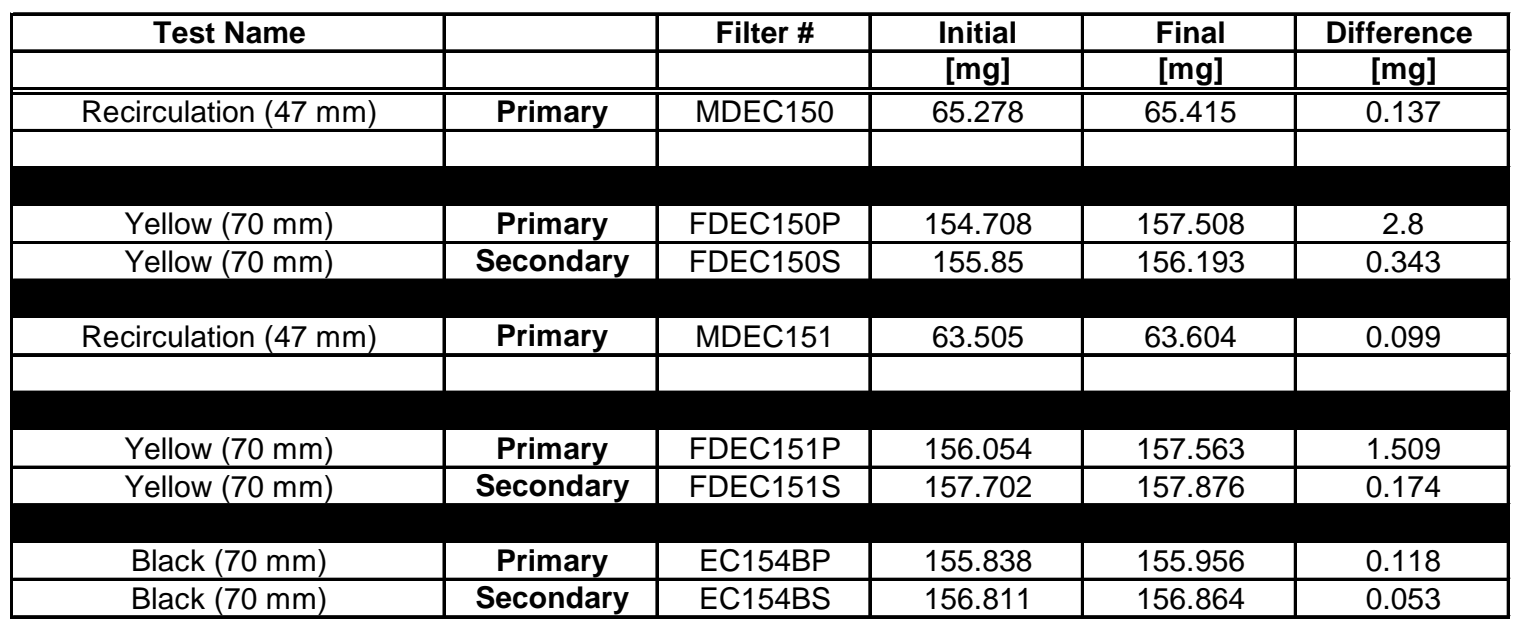


Table A.4 Filter Weights for Transient Tests No. 3 to 6

Date: $5 / 7 / 01$

Test Series: Navistar T444E

\begin{tabular}{|l|c|c|}
\hline & Chamber & Room \\
\hline Initial Humidity [\%]: & 51 & 52 \\
\hline Initial Temperature [deg F]: & 72 & 72 \\
\hline Final Humidity [\%]: & 49 & 50 \\
\hline Final Temperature [deg F]: & 71 & 70 \\
\hline
\end{tabular}

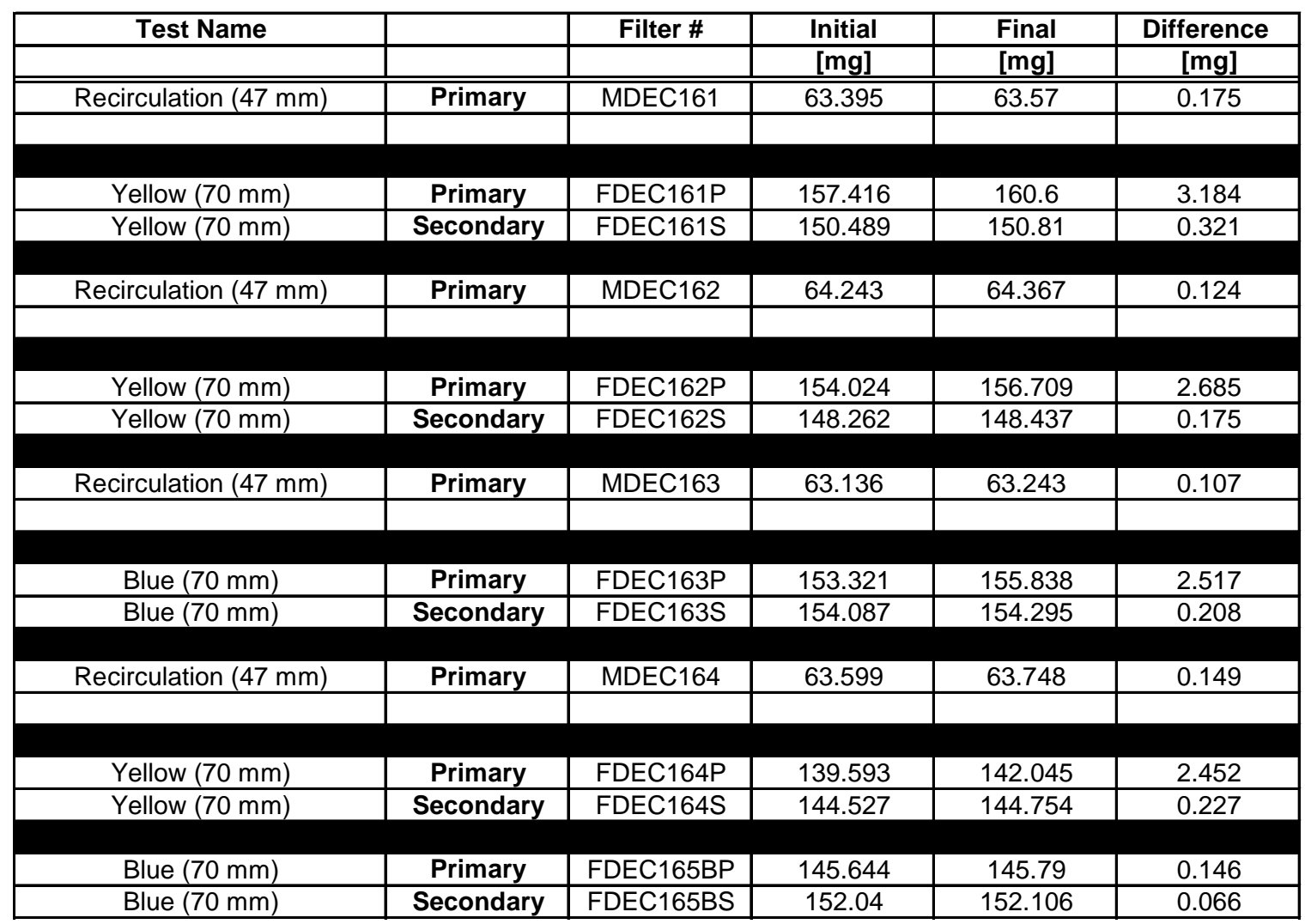


Table A.5 Filter Weights for Transient Tests No. 7

Date:

$6 / 23 / 01$

Test Series:

Detroit Diesel Series 60

\begin{tabular}{|l|c|c|}
\hline & Chamber & Room \\
\hline Initial Humidity [\%]: & 49 & 54 \\
\hline Initial Temperature [deg F]: & 71 & 72 \\
\hline Final Humidity [\%]: & 48 & 52 \\
\hline Final Temperature [deg F]: & 71 & 72 \\
\hline
\end{tabular}

\begin{tabular}{|c|c|c|c|c|c|}
\hline Test Name & & Filter \# & Initial & Final & Difference \\
\hline & & & {$[\mathrm{mg}]$} & {$[\mathrm{mg}]$} & {$[\mathrm{mg}]$} \\
\hline \hline Recirculation (47 mm) & Primary & MDEC205 & 64.064 & 64.259 & 0.195 \\
\hline \multicolumn{7}{|l|}{} & & & & \\
\hline Yellow (70 mm) & Primary & FDEC205P & 141.912 & 143.332 & 1.42 \\
\hline Yellow (70 mm) & Secondary & FDEC205S & 159.91 & 160.163 & 0.253 \\
\hline
\end{tabular}

Table A.6 Filter Weights for Transient Tests No. 8 and 9

Date: $7 / 9 / 01$

Test Series: Detroit Diesel Series 60

\begin{tabular}{|l|c|c|}
\hline & Chamber & Room \\
\hline Initial Humidity [\%]: & 49 & 54 \\
\hline Initial Temperature [deg F]: & 71 & 72 \\
\hline Final Humidity [\%]: & 48 & 52 \\
\hline Final Temperature [deg F]: & 71 & 72 \\
\hline
\end{tabular}

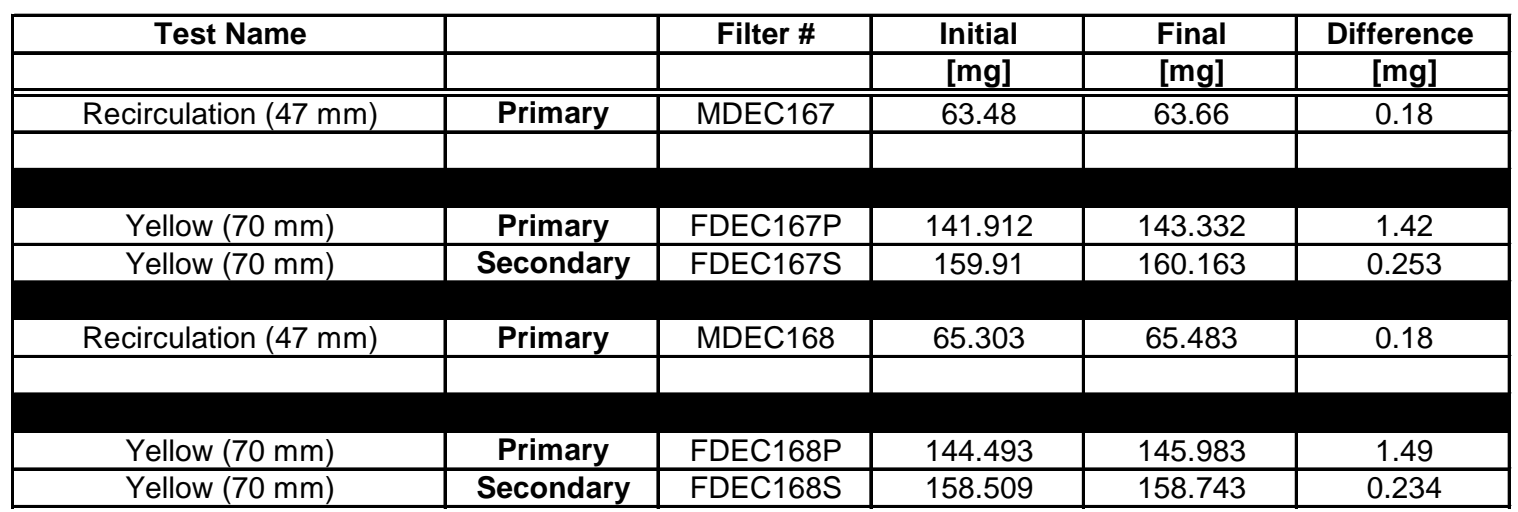




\section{APPENDIX B. Original Design}

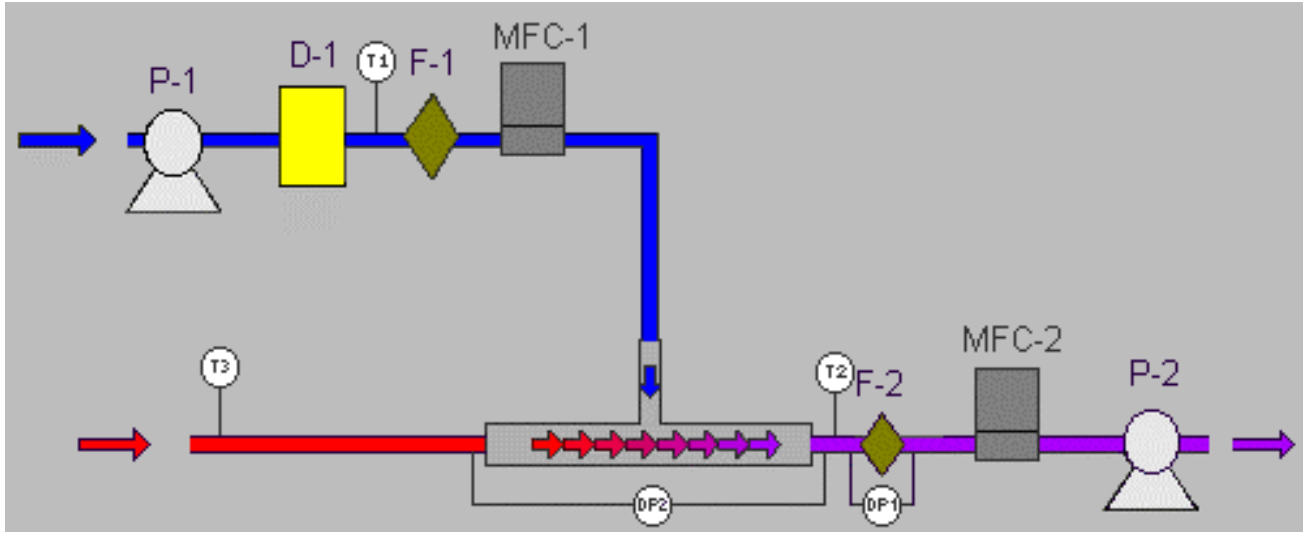

Figure B.1 Micro-Dilution System with Two Pumps 


\section{APPENDIX C. Uncertainty Analysis}

The procedure outlined by Kline and McClintok (1953) has been used to determine the uncertainty in the flow measurements. In this procedure, the uncertainty of a measured quantity is expressed as:

$$
\mathrm{R} \pm \mathrm{u}_{\mathrm{R}}
$$

where $\mathrm{R}$ is the mean value of the variable and $\mathrm{u}_{\mathrm{R}}$ the uncertainty interval.

Consider a variable $\mathrm{Y}$ which is a function of $\mathrm{n}$ independent variables:

$$
Y=f\left(x_{1}, x_{2}, \ldots x_{n}\right)
$$

then the uncertainty in $\mathrm{Y}$ is given by:

$$
u(y)=\sqrt{\left(\frac{\partial y}{\partial x_{1}} u\left(x_{1}\right)\right)^{2}+\left(\frac{\partial y}{\partial x_{2}} u\left(x_{2}\right)\right)^{2}+\ldots+\left(\frac{\partial y}{\partial x_{n}} u\left(x_{n}\right)\right)^{2}}
$$

The dilution ratio is calculated using the mass flow rates as expressed in Equation 4.1 below.

$$
D R=\frac{Q_{t o t}}{Q_{e x h}}=\frac{Q_{t o t}}{Q_{t o t}-Q_{\text {dil }}}
$$

Then the uncertainty in DR is related by:

$$
u(D R)=(D R-1) \sqrt{\left(u\left(Q_{D}\right)\right)^{2}+\left(u\left(Q_{A}\right)\right)^{2}}
$$

Using Equation C.4 with dilution ratios of 4, 10, 15 and 30 yield an uncertainty of $7 \%, 16 \%, 24 \%$, and $50 \%$, respectively. 


\title{
APPENDIX D. Visual Basic Program
}

\author{
Option Explicit
}

' Project Name: MiniDilution.vbp

' Form Name: frmMain.frm

" Description: This program operates a mini-dilution system to test

' emissions by collecting particulate matter on a filter

" Authors: Emily D. Cirillo \& F. Andreas J. Pertl

' Date: 5/2000

" Notes: Measurement \& Annotation (Channel Wizard) cannot be

' be open while running Visual Basic program

' Abbreviations:

' MFC - Mass Flow Controller

' M\&A - Measurement and Annotation

' CW - Component Works

' AI - Analog Input

' AO - Analog Output

' DIO - Digital Input Output

' Revision History:

' Date

Author

Description

' $05 / 15 / 2000$

F. Andreas Pertl

Setup initial program

, $05 / 22 / 2000$

Emily D. Cirillo

Add pressure sensors

, $05 / 24 / 2000$

Emily D. Cirillo

Add thermocouples

' $06 / 01 / 2000$

Emily D. Cirillo

Test system w/ ambient air

' $06 / 08 / 2000$

Emily D. Cirillo

Test system w/ hot air

, $07 / 31 / 2000$

Emily D. Cirillo

Change colors of temp. controls

' $08 / 07 / 2000$

Emily D. Cirillo

Shut down everything upon exiting

, 09/06/2000

F. Andreas Pertl

Add timer delay and sample time

' $09 / 07 / 2000$

Emily D. Cirillo

Get signal using DI to sample at the test cell does

$11 / 02 / 2000$

Emily D. Cirillo

Adding steady state and transient

' $11 / 08 / 2000$

Emily D. Cirillo

Fixing startup control

' $01 / 22 / 2001$

Emily D. Cirillo

Add in DAC for MFC-3

$02 / 23 / 2001$

Emily D. Cirillo

Add Sampling Type Method

$03 / 05 / 2001$

Emily D. Cirillo

Add two thermocouples (chiller outlet and MFC-3)

' Operating Instructions:

' First start running program then click start data from data menu to' start recording data.

' The button will turn yellow if the system is' turned on and red if the system is turned off.

' This does not mean that' it is taking data. The signal comes from a byte in the OICA ' program. 
' Measurement \& Annotation Setup:

\begin{tabular}{lccc}
\multicolumn{1}{c}{ Channel } & \multicolumn{3}{c}{ Device } \\
' Name & Type & Channel(s) Name \\
' DP1_Sense & AI & 2 & DAQ-Card 1200 \\
' DP2_Sense & AI & 3 & DAQ-Card 1200 \\
' MFC1_Sense & AI & 0 & DAQ-Card 1200 \\
' MFC2_Sense & AI & 1 & DAQ-Card 1200 \\
' MFC3_Sense & AI & 4 & DAQ-Card 1200 \\
' MFC3_Sense2 & AI & 5 & DAQ-Card 1200 \\
' MFC1_Set & AO & 0 & DAQ-Card 1200 \\
' MFC2_Set & AO & 1 & DAQ-Card 1200
\end{tabular}

' RawExhaust_Temp AI 1(+)9(-) DAQ-Card A1-16E-4

' MFC1_Temp AI 2(+)10(-) DAQ-Card A1-16E-4

'PMFilter_Temp AI 3(+)11(-) DAQ-Card A1-16E-4

' Chiller_Temp AI 4(+)12(-) DAQ-Card A1-16E-4

'MFC3_Temp AI 5(+)13(-) DAQ-Card A1-16E-4

Enum ControlType

cConstVol $=0$

cPropVol = 1

End Enum

' Global Variables

Const debugging $=$ False

'Const debugging = True

Private MFC1_Sense As Integer

Private MFC2_Sense As Integer

Private MFC3_Sense As Integer

'Private MFC3_Sense2 As Integer

Private DP1_Sense As Integer

Private DP2_Sense As Integer

Private controlling As Boolean

Private ControlStrategy As ControlType

Private AutoTimingEnabled As Boolean

Private SecToAutoStart As Long

Private Sub Command1_Click()

Call WriteSDAC(0\#)

'CWDIO1.Channels("SDAC_ChipSelect").SingleWrite (1)

End Sub

Private Sub cwSetMFC3_ValueChanged(Value As Variant, PreviousValue As Variant, ByVal OutOfRange As Boolean)

Call SetMFC3(CSng(Value))

End Sub

Private Sub cwSlideChillerTemperature_PointerValueChanged(ByVal Pointer As Long, Value As Variant) 
' Display temperature value of chiller exit

cwNumEditT3. Value $=$ Value

' Thermometer colors: Green $=$ Okay; Red $=$ Above limit

If cwNumEditT3.Value > 100\# Then

cwSlideChillerTemperature.Pointers(1).FillColor $=$ vbRed

Else

cwSlideChillerTemperature.Pointers(1).FillColor $=$ vbGreen

End If

End Sub

Private Sub cwSlideMFC3Temperature_PointerValueChanged(ByVal Pointer As Long, Value As Variant)

' Display temperature value of MFC-3 outlet

cwNumEditT4. Value $=$ Value

' Thermometer colors: Green $=$ Okay; Red $=$ Above limit

If cwNumEditT4.Value > 100\# Then

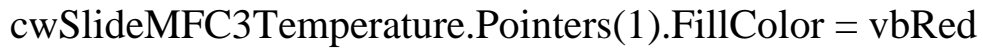

Else

cwSlideMFC3Temperature.Pointers(1).FillColor $=$ vbGreen

End If

End Sub

Private Sub Form_Load()

'Warn user if debugging is set to true

If debugging Then

Call MsgBox("Warning! Debugging Enabled", vbInformation + vbOKOnly, "Hey Emily!")

End If

'Manual control at startup

controlling $=$ False

'Default to Control Volume Sampling

mnuControlVolume. Checked $=$ True

ControlStrategy $=\mathrm{cConstVol}$

'No autotiming

AutoTimingEnabled $=$ False

' Assign Channel Strings defined in M\&A

CWAOPoint1.ChannelString = "MFC1_Set"

CWAOPoint2.ChannelString = "MFC2_Set"

' Set voltages to zero

If Not debugging Then

Call CWAOPoint 1.SingleWrite(0)

Call CWAOPoint2.SingleWrite(0) 
End If

' Set to aquire 1 scans before calling acquired function

CWAI1.NScans $=10$

' Set to $100 \mathrm{scans} / \mathrm{sec}$ (actual sampling frequency)

CWAI1.ScanClock.Frequency $=100$

' Set Data Capture Buffer

CWAI1.NScansPerBuffer $=$ 1000: CWAI1.UseDefaultBufferSize $=$ False

CWAI1.StopCondition. Type $=$ cwaiContinuous

' Add Analog Input Channels for DAQCard-1200

Call CWAI1.Channels.Add("MFC1_Sense"): MFC1_Sense $=0$

Call CWAI1.Channels.Add("MFC2_Sense"): MFC2_Sense $=1$

Call CWAI1.Channels.Add("MFC3_Sense"): MFC3_Sense $=2$

'Call CWAI1.Channels.Add("MFC3_Sense2"): MFC3_Sense2 = 3

Call CWAI1.Channels.Add("DP1_Sense"): DP1_Sense = 3

Call CWAI1.Channels.Add("DP2_Sense"): DP2_Sense $=4$

If Not debugging Then

Call CWAI1.Configure

End If

CWAI2.NScans $=10$

'Set Data Capture Buffer

CWAI2.NScansPerBuffer = 1000: CWAI2.UseDefaultBufferSize $=$ False

CWAI2.ScanClock.Frequency $=100$

CWAI2.StopCondition. Type $=$ cwaiContinuous

' Add Analog Input Channel Strings for DAQCard-A1-16E-4

Call CWAI2.Channels.Add("CJC")

Call CWAI2.Channels.Add("RawExhaust_Temp")

Call CWAI2.Channels.Add("MFC1_Temp")

Call CWAI2.Channels.Add("PMFilter_Temp")

Call CWAI2.Channels.Add("Chiller_Temp")

Call CWAI2.Channels.Add("MFC3_Temp")

' Call CWAI2.Channels.Add("MFC2_Temp")

If Not debugging Then

Call CWAI2.Configure

End If

'Add Digital Output Channel Strings for DAQCard-1200

Call CWDIO1.Channels.Add("Pump_Switch")

' Call CWDIO1.Channels.Add("HAD_Switch")

Call CWDIO1.Channels.Add("SDAC_ChipSelect")

Call CWDIO1.Channels.Add("SDAC_Clock")

Call CWDIO1.Channels.Add("SDAC_Data") 


\section{Call CWDIO2.Channels.Add("SampleTrigger")}

' Start acquiring data

If Not debugging Then

CWAI1.Start

CWAI2.Start

End If

End Sub

Private Sub CWAI1_DAQError(ByVal StatusCode As Long, ByVal ContextID As Long, ByVal ContextDescription As String)

Call MsgBox(CWDAQTools1.GetErrorText(StatusCode), vbCritical + vbApplicationModal + vbOKOnly, "Error CWAI1")

End Sub

Private Sub CWAI2_DAQError(ByVal StatusCode As Long, ByVal ContextID As Long, ByVal ContextDescription As String)

Call MsgBox(CWDAQTools1.GetErrorText(StatusCode), vbCritical + vbApplicationModal + vbOKOnly, "Error CWAI2")

End Sub

Private Sub cwButtonSamplingEnabled_ValueChanged(ByVal Value As Boolean)

If Value Then

' Turn on pump and HAD

cwButtonPump. Value $=$ True

' CWButtonHAD.Value $=$ True

If mnuComputer.Checked Then

controlling $=$ True

Else

controlling $=$ False

End If

Else

' Turn off pump and HAD

cwButtonPump. Value $=$ False

controlling $=$ False

Call SetMFC3(0)

Call CWAOPoint1.SingleWrite(0)

Call CWAOPoint2.SingleWrite(0)

' $\mathrm{CWButtonHAD.Value}=$ False

End If

End Sub

Private Sub cwButtonPump_ValueChanged(ByVal Value As Boolean)

' Switch pump on and off

With CWDIO1.Channels("Pump_Switch") 


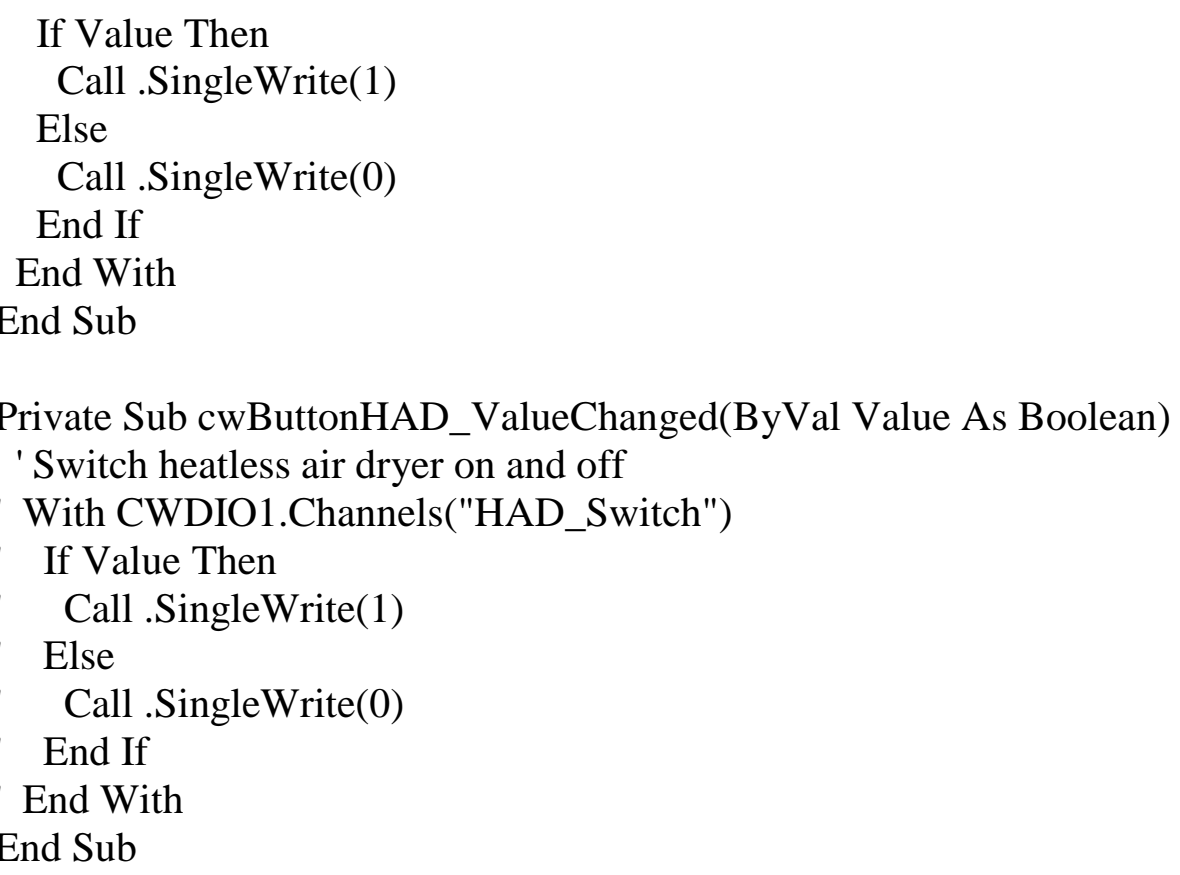

Private Sub CWAI1_AcquiredData(ScaledData As Variant, BinaryCodes As Variant) Static ControlCount As Long Static MFC1Set As Single Static MFC2Set As Single ' Display MFC values on dials in slpm cwKnobMFC1. Value $=$ CWStat1.Mean(CWArray1.IndexArray (ScaledData, Array(MFC1_Sense, Null))) cwKnobMFC2. Value $=$ CWStat1.Mean $($ CWArray1. IndexArray $($ ScaledData, Array(MFC2_Sense, Null))) cwKnobMFC3. Value $=$ CWStat 1.Mean(CWArray1. IndexArray $($ ScaledData, Array(MFC3_Sense, Null))) 'cwKnobMFC3Sense2. Value = CWStat1.Mean $($ CWArray1.IndexArray $($ ScaledData, Array(MFC3_Sense2, Null))) cwKnobTunnelPressure. Value $=$ CWStat1.Mean $($ CWArray1.IndexArray $($ ScaledData, Array(DP1_Sense, Null))) cwKnobPMFilterPressure. Value $=$ CWStat1.Mean(CWArray1.Index Array $($ ScaledData, Array(DP2_Sense, Null))) 'Debug.Print ScaledData(MFC2_Sense, 1)

'Control

'Debug.Print controlling

If controlling $=$ True Then

Select Case ControlStrategy

Case cConstVol

If Me.cwButtonSamplingEnabled Then cwSetMFC3. Value $=1.5$

Else 
cwSetMFC3. Value $=0 \#$

End If

Case cPropVol

' $\mathrm{cwSetMFC3}$. Value $=$ Tunnel $/$ 1000\#

End Select

' Set for dilution ratio of 1:4

MFC1Set $=4 \# *$ cwSetMFC3.Value

MFC2Set $=5 \# *$ cwSetMFC3.Value

Call CWAOPoint1.SingleWrite(MFC1Set)

Call CWAOPoint2.SingleWrite(MFC2Set)

$\mathrm{cwSetMFC1}$.Value $=$ MFC1Set

$\mathrm{cwSetMFC2}$. Value $=$ MFC2Set

'If cwKnobMFC3.Value > 0.3 And ControlCount > 30 Then

' Set value of MFC1

' $\mathrm{cwSetMFC1.Value}=4 \# *$ cwKnobMFC3. Value

' $\mathrm{cwSetMFC2}$.Value $=5 \# *$ cwKnobMFC3. Value

'Else

' ' was cwSetMFC1.Value $=4 \# *$ cwKnobMFC3Sense2. Value

' cwSetMFC1. Value $=4 \# *$ cwKnobMFC3.Value

' $\mathrm{cwSetMFC2}$. Value $=5 \# *$ cwKnobMFC3. Value

'End If

ControlCount $=$ ControlCount +1

Else

ControlCount $=0$

MFC1Set $=$ cwSetMFC1. Value

MFC2Set $=\mathrm{cwSetMFC2}$. Value

Call CWAOPoint1.SingleWrite(MFC1Set)

Call CWAOPoint2.SingleWrite(MFC2Set)

End If

Dim BitValue As Variant

If mnuBit.Checked $=$ True Then

With CWDIO2.Channels("SampleTrigger")

Call .SingleRead(BitValue)

If BitValue $=$ False Then

cwButtonSamplingEnabled. Value $=$ True

Call mnuComputer_Click

Else

cwButtonSamplingEnabled. Value $=$ False

Call mnuManual_Click

End If

End With

End If 
If mnuStartData.Checked Then

Call WritetoFile

End If

'If controlling $=$ False Then

' Call mnuManual_Click

'End If

End Sub

Private Sub CWAI2_AcquiredData(ScaledData As Variant, BinaryCodes As Variant)

' Display temperatures on slide bars in deg F

cwSlideRawExhaustTemperature. Value =

CWStat1.Mean(CWArray1.IndexArray(ScaledData, Array(1, Null)))

cwSlideMFC1Temperature. Value =

CWStat1.Mean(CWArray1.IndexArray(ScaledData, Array(2, Null)))

cwSlidePMFilterTemperature. Value $=$

CWStat1.Mean(CWArray1.IndexArray(ScaledData, Array(3, Null)))

cwSlideChillerTemperature. Value $=$

CWStat1.Mean(CWArray1.IndexArray(ScaledData, Array(4, Null)))

cwSlideMFC3Temperature. Value =

CWStat1.Mean(CWArray1.IndexArray(ScaledData, Array(5, Null)))

' cwSlideMFC2Temperature. Value =

CWStat1.Mean(CWArray1.IndexArray(ScaledData, Array(4, Null)))

End Sub

Private Sub cwSlideRawExhaustTemperature_PointerValueChanged(ByVal Pointer As Long, Value As Variant)

' Display temperature value of raw exhaust

cwNumEditT0. Value $=$ Value

' Thermometer colors: Green = Okay; Red = Above limit

If cwNumEditT0.Value > 400\# Then

cwSlideRawExhaustTemperature.Pointers(1).FillColor $=$ vbRed

Else

cwSlideRawExhaustTemperature.Pointers(1).FillColor $=$ vbGreen

End If

End Sub

Private Sub cwSlideMFC1Temperature_PointerValueChanged(ByVal Pointer As Long, Value As Variant)

' Display temperature value of MFC1

cwNumEditT1. Value $=$ Value

' Thermometer colors: Green = Okay; Red = Above limit

If cwNumEditT1.Value > 100\# Then

cwSlideMFC1Temperature.Pointers(1).FillColor = vbRed

Else

cwSlideMFC1Temperature.Pointers(1).FillColor = vbGreen 
End If

End Sub

Private Sub cwSlidePMFilterTemperature_PointerValueChanged(ByVal Pointer As

Long, Value As Variant)

' Display temperature value of PM Filter

cwNumEditT2. Value $=$ Value

' Thermometer colors: Green = Okay; Red $=$ Above limit

If cwNumEditT2.Value > 125\# Then

cwSlidePMFilterTemperature.Pointers(1).FillColor $=$ vbRed

Else

cwSlidePMFilterTemperature.Pointers(1).FillColor $=$ vbGreen

End If

End Sub

Private Sub cwSlideMFC2Temperature_PointerValueChanged(ByVal Pointer As Long, Value As Variant)

' Display temperature value of MFC2

' $\mathrm{cwNumEditT3}$. Value $=$ Value

' Thermometer colors: Green = Okay; Red = Above limit

' If cwNumEditT3.Value > 100\# Then

' $\quad$ cwSlideMFC2Temperature.Pointers(1).FillColor $=$ vbRed

' Else

' cwSlideMFC2Temperature.Pointers(1).FillColor = vbGreen

' End If

End Sub

Private Sub cwKnobMFC1_PointerValueChanged(ByVal Pointer As Long, Value As Variant)

' Display flow rate value of MFC1

cwNumEditMFC1. Value $=$ Value

End Sub

Private Sub cwKnobMFC2_PointerValueChanged(ByVal Pointer As Long, Value As Variant)

' Display flow rate value of MFC2

cwNumEditMFC2. Value = Value

End Sub

Private Sub cwKnobMFC3_PointerValueChanged(ByVal Pointer As Long, Value As Variant)

' Display flow rate value of MFC3

cwNumEditMFC3. Value = Value

End Sub 
'Private Sub cwKnobMFC3Sense2_PointerValueChanged(ByVal Pointer As Long, Value As Variant)

' Display flow rate value of MFC3 Set

' $\mathrm{cwNumEditMFC3Sense2}$. Value $=$ Value

'End Sub

Private Sub cwKnobPMFilterPressure_PointerValueChanged(ByVal Pointer As Long, Value As Variant)

' Display differential pressure in psi across PM filter

cwNumEditDP2. Value $=$ Value

End Sub

Private Sub cwKnobTunnelPressure_PointerValueChanged(ByVal Pointer As Long,

Value As Variant)

' Display differential pressure in psi across tunnel

cwNumEditDP1. Value $=$ Value

End Sub

Private Sub cwSetMFC1_ValueChanged(Value As Variant, PreviousValue As Variant, ByVal OutOfRange As Boolean)

' Set value of MFC1

'Call CWAOPoint1.SingleWrite(Value)

End Sub

Private Sub cwSetMFC2_ValueChanged(Value As Variant, PreviousValue As Variant, ByVal OutOfRange As Boolean)

'Set value of MFC2

'Call CWAOPoint2.SingleWrite(Value)

End Sub

Private Sub mnuBit_Click()

txtDelayedStart.Enabled $=$ False

txtSampleTime.Enabled $=$ False

mnuBit.Checked $=$ True

mnuCountdown. Checked $=$ False

Call mnuComputer_Click

End Sub

Private Sub mnuComputer_Click()

' Computer controlled

controlling $=$ True

mnuComputer. Checked $=$ True

mnuManual. Checked $=$ False

End Sub

Private Sub mnuControlVolume_Click() 


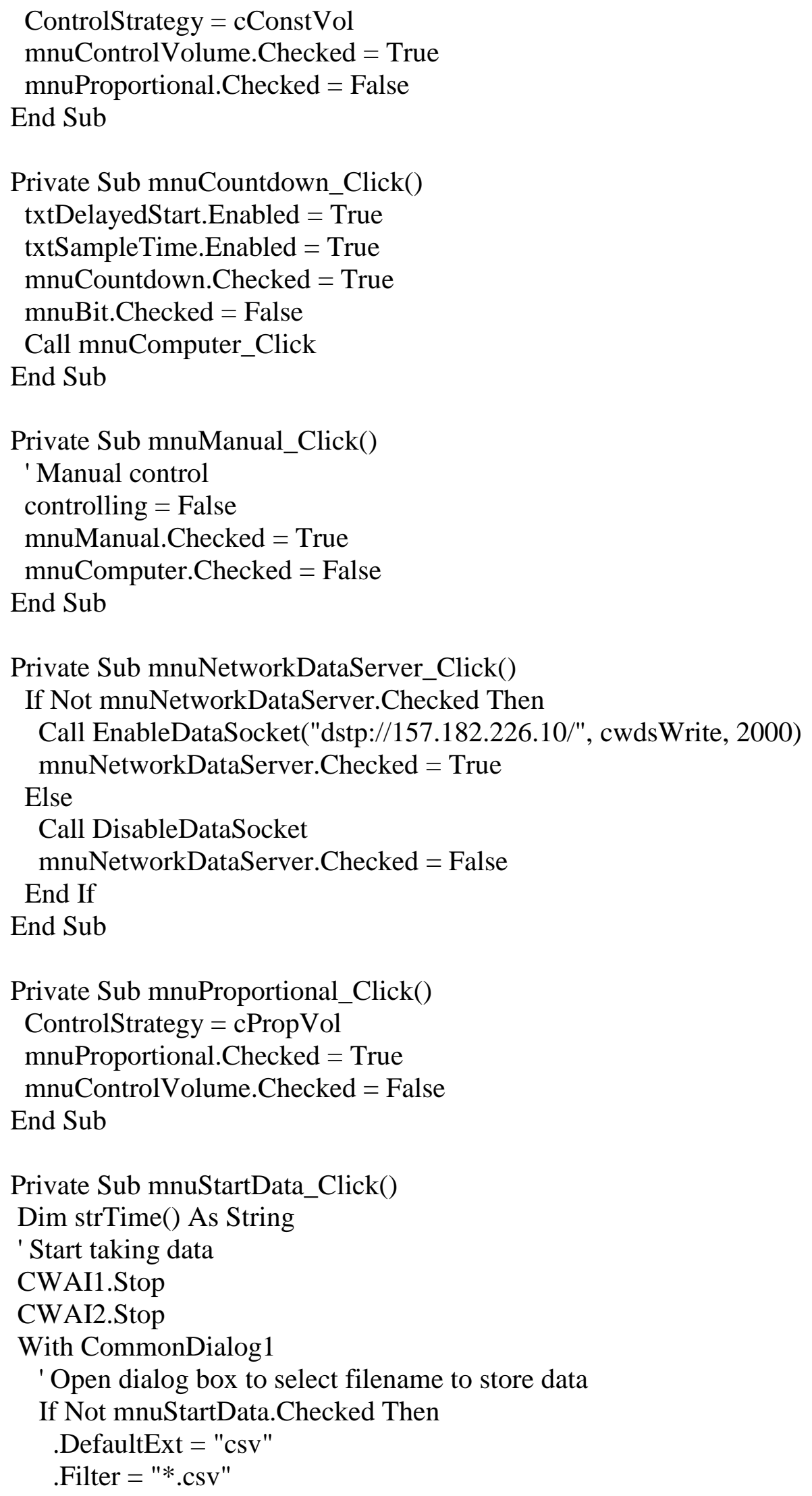




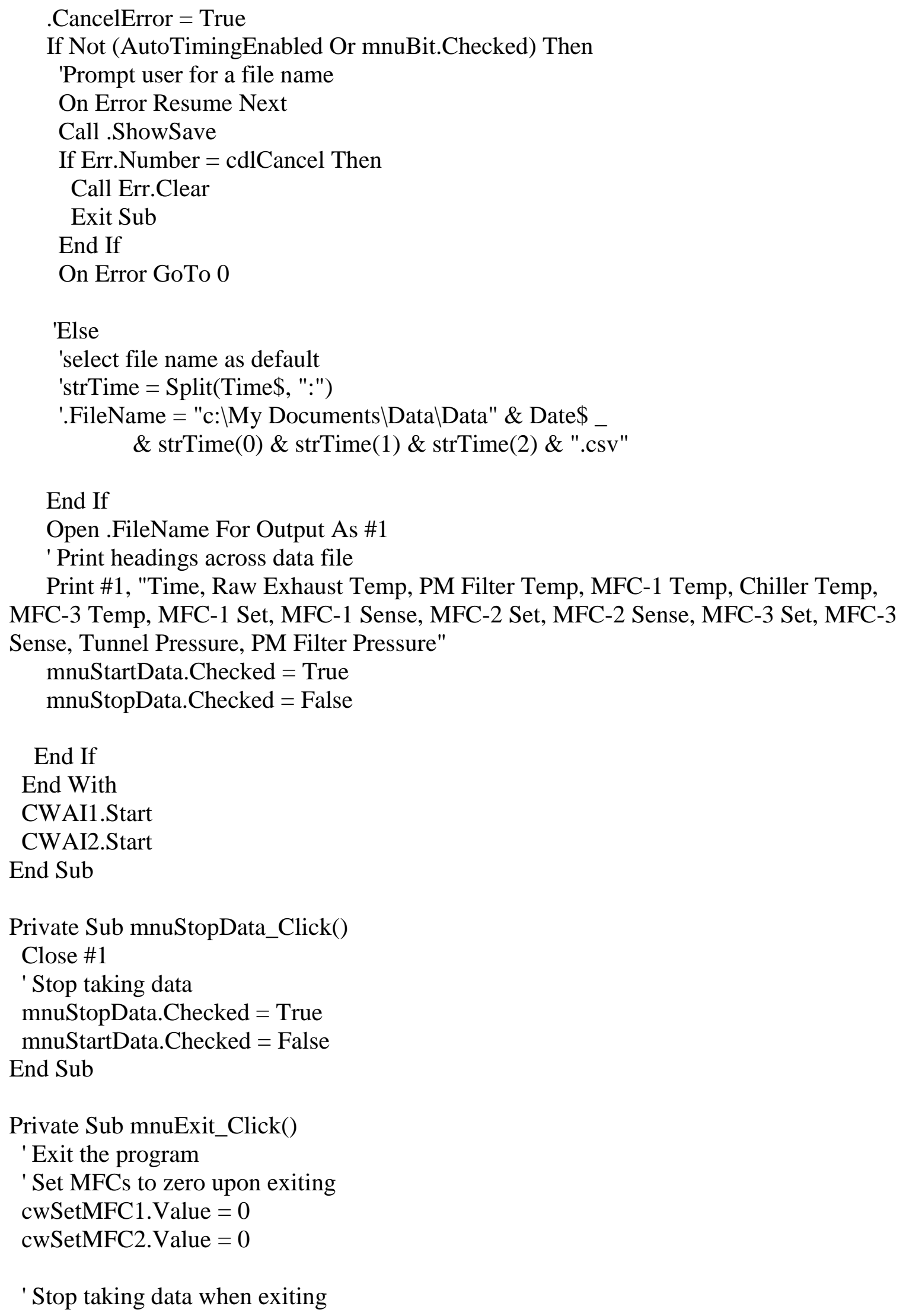


If mnuStartData.Checked $=$ True Then

Call mnuStopData_Click

End If

' Turn off pump and HAD upon exiting

If cwButtonPump. Value $=$ True Then

cwButtonPump. Value $=$ False

End If

' If CWButtonHAD. Value $=$ True Then

' CWButtonHAD.Value $=$ False

' End If

Unload Me

End Sub

Private Sub WritetoFile()

' Print values for time, raw exhaust, PM filter, MFC-1, MFC-2 temperatures,

' set and sense values for MFC-1, MFC-2, MFC-3, and differential pressure

' across the PM filter

Print \#1, Time\$ \& ",";

Print \#1, Format(cwSlideRawExhaustTemperature.Value, "\#\#0.00") \& ",";

Print \#1, Format(cwSlidePMFilterTemperature.Value, "\#\#\#0.00") \& ",";

Print \#1, Format(cwSlideMFC1Temperature.Value, "\#\#0.00") \& ",";

Print \#1, Format(cwSlideChillerTemperature.Value, "\#\#\#0.00") \& ",";

Print \#1, Format(cwSlideMFC3Temperature.Value, "\#\#\#0.00") \& ",";

'Print \#1, Format(cwSlideMFC2Temperature.Value, "\#\#\#0.00") \& ",";

Print \#1, Format(cwSetMFC1.Value, "\#\#0.00") \& ",";

Print \#1, Format(cwKnobMFC1.Value, "\#\#0.00") \& ",";

Print \#1, Format(cwSetMFC2.Value, "\#\#0.00") \& ",";

Print \#1, Format(cwKnobMFC2.Value, "\#\#0.00") \& ",";

'Print \#1, Format(cwKnobMFC3Sense2.Value, "\#\#0.00") \& ",";

Print \#1, Format(cwSetMFC3.Value, "\#\#0.00") \& ",";

Print \#1, Format(cwKnobMFC3.Value, "\#\#0.00") \& ",";

Print \#1, Format(cwKnobTunnelPressure.Value, "\#0.00") \& ",";

Print \#1, Format(cwKnobPMFilterPressure.Value, "\#0.00") \& ",";

Print \#1, ""

End Sub

Private Sub TimerDelayedStart_Timer()

Static state As Integer

Static Mins As Integer

Static Secs As Integer

Dim parse As Variant

SecToAutoStart $=$ SecToAutoStart -1

Mins $=$ Fix $($ SecToAutoStart $/ 60)$ 


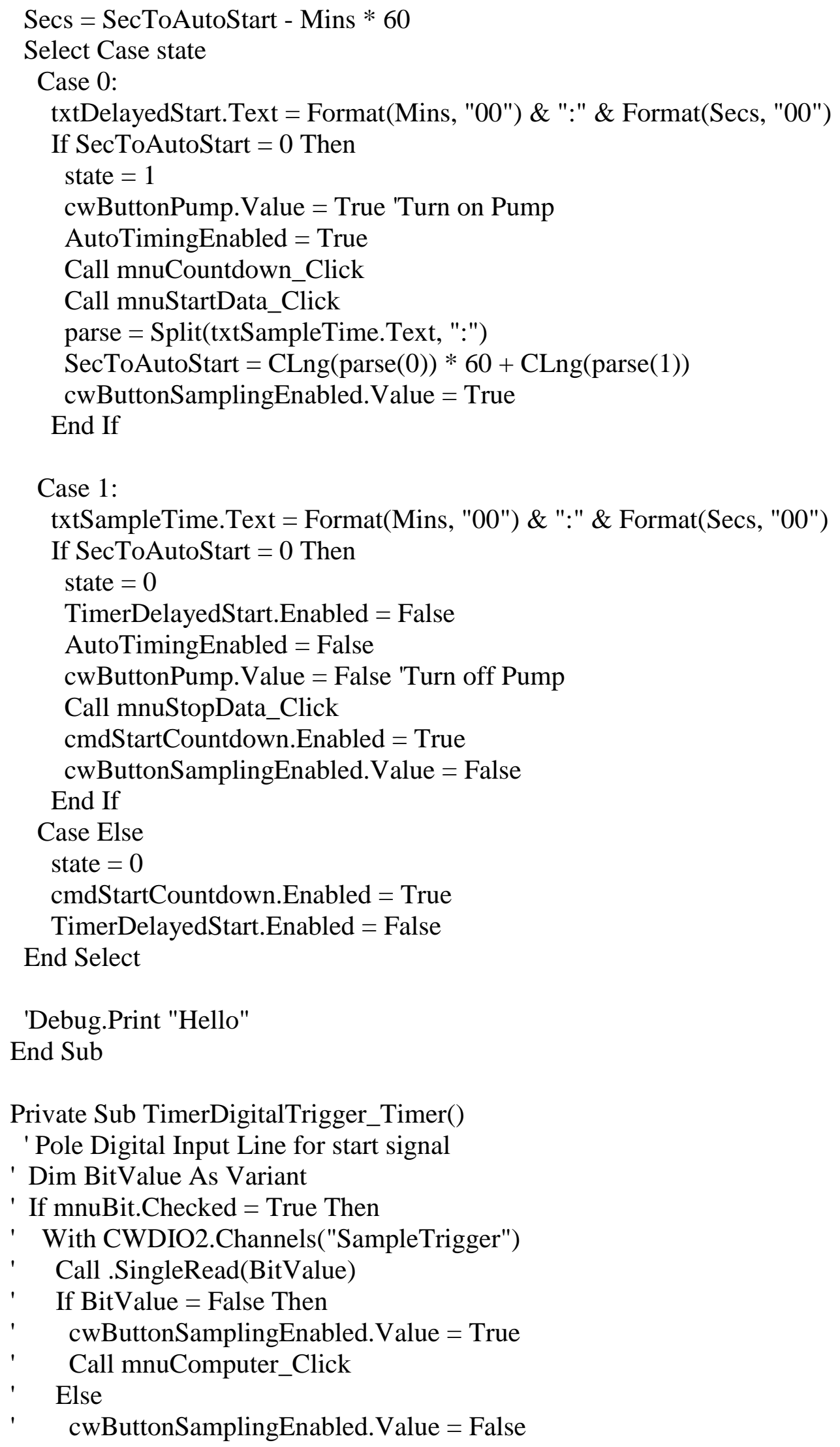


' Call mnuManual_Click

' End If

' End With

' End If

End Sub

Private Sub cmdStartCountdown_Click()

' Countdown after start countdown button is clicked

Dim parsed As Variant

cmdStartCountdown.Enabled $=$ False

parsed $=$ Split(txtDelayedStart.Text, ":")

SecToAutoStart $=60 *$ CLng $(\operatorname{parsed}(0))+$ CLng $(\operatorname{parsed}(1))$

TimerDelayedStart.Enabled $=$ True

End Sub

Private Sub WriteSDAC(Voltage As Single)

'Text1.Text $=$ Voltage

Const VRef $=2.5$

Dim DACCode As Integer

Dim bit As Integer

DACCode $=512 *$ Voltage $/$ VRef -1

If DACCode $<0$ Then DACCode $=0$

'DACCode $=682$

'Take Clock Low

Call CWDIO1.Channels("SDAC_Clock").SingleWrite(0)

'Take Chip Select Low

Call CWDIO1.Channels("SDAC_ChipSelect").SingleWrite(0)

'Loop through 10 bits

For bit $=9$ To 0 Step -1

'take clock low

Call CWDIO1.Channels("SDAC_Clock").SingleWrite(0)

'write data bit

If (DACCode And CInt $\left(2^{\wedge}\right.$ bit $\left.)\right)<>0$ Then

Call CWDIO1.Channels("SDAC_Data").SingleWrite(1)

Else

Call CWDIO1.Channels("SDAC_Data").SingleWrite(0)

End If

'take data bit high

Call CWDIO1.Channels("SDAC_Clock").SingleWrite(1)

Next bit

'Write out two zeros

Call CWDIO1.Channels("SDAC_Clock").SingleWrite(0)

Call CWDIO1.Channels("SDAC_Data").SingleWrite(0)

Call CWDIO1.Channels("SDAC_Clock").SingleWrite(1) 
Call CWDIO1.Channels("SDAC_Clock").SingleWrite(0)

Call CWDIO1.Channels("SDAC_Clock").SingleWrite(1)

Call CWDIO1.Channels("SDAC_Clock").SingleWrite(0)

'take chip select high (i.e deselect chip)

Call CWDIO1.Channels("SDAC_ChipSelect").SingleWrite(1)

End Sub

Private Sub SetMFC3(slpm As Single)

Dim Vset As Single

Vset $=$ slpm $/ 10 \# * 5 \#$

Call WriteSDAC(Vset)

End Sub

Private Sub EnableDataSocket(ServerURL As String, AccessMode As

CWDSLib.CWDSAccessModes, Optional MilliSeconds As Long)

Dim ctr As Control

Dim aCWBinding As CWBinding

For Each ctr In Controls

Select Case TypeName(ctr)

Case "CWSlide", "CWButton", "CWKnob", "CWNumEdit"

ctr.CWBindings.RemoveAll

Set aCWBinding = ctr.CWBindings.Add

With aCWBinding

Call .SetBindObject(ctr)

.AccessMode $=$ AccessMode

If Not IsMissing(MilliSeconds) Then

.TimerInterval $=$ MilliSeconds

End If

$. \mathrm{URL}=$ ServerURL \& ctr.Name

.BindProperty = "Value"

Call .Connect

End With

End Select

Next ctr

End Sub

Private Sub DisableDataSocket()

Dim ctr As Control

Dim aCWBinding As CWBinding

For Each ctr In Controls

Select Case TypeName(ctr)

Case "CWSlide", "CWButton", "CWKnob", "CWNumEdit"

Set aCWBinding = ctr.CWBindings $(1)$

With aCWBinding 
Call .Disconnect

End With

End Select

Next ctr

End Sub 